\title{
Integrated Advanced Reciprocating Internal Combustion Engine System for Increased Utilization of Gaseous Opportunity Fuels
}

\author{
Final Report \\ Reporting Period Start Date: 8/1/2009 \\ Reporting Period End Date: 8/31/2013 \\ Principal Author(s): John M. Pratapas, Serguei Zelepouga, Ph.D. and Vitaliy \\ Gnatenko, Gas Technology Institute (GTI) \\ Alexei V. Saveliev, Ph.D. and Vilas V Jangale, North Carolina State University \\ Hailin Li, Ph.D. and Timothy Getz, West Virginia University \\ Daniel Mather, Ph.D., Digital Engines,
}

Issued: December 2, 2013

DOE Award Number DE- EE0000556

Submitting Organization:

Gas Technology Institute

1700 So. Mount Prospect Road

Des Plaines, IL 60018 
DISCLAIMER - "This report was prepared as an account of work sponsored by an agency of the United States Government. Neither the United States Government nor any agency thereof, nor any of their employees, makes any warranty, express or implied, or assumes any legal liability or responsibility for the accuracy, completeness, or usefulness of any 


\section{Table of Contents}

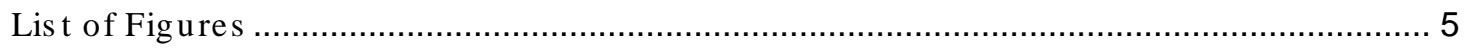

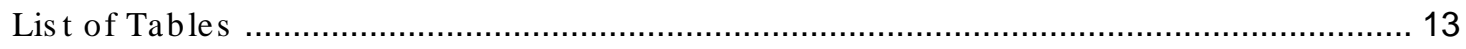

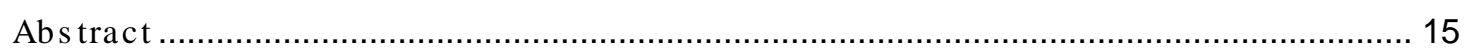

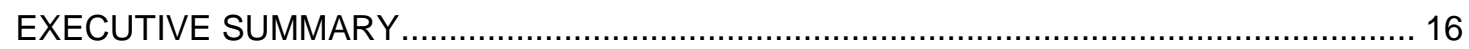

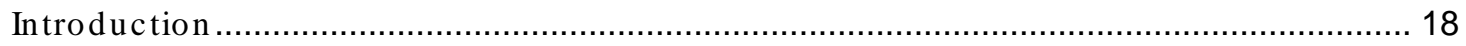

Task 2- DEVELOPMENT OF GAS QUALITY SENSOR FOR OPPORTUNITY FUELS ........ 23

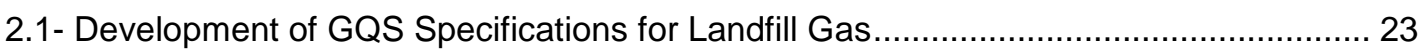

2.1.1 Carbon dioxide detection capability of gas quality sens or .............................. 23

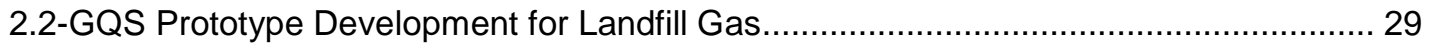

2.2.1-Improvement in and support of data acquisition for control software module ......... 29

2.2.2-Mathematical model for handling the temporal drift of spectral detector ................. 30

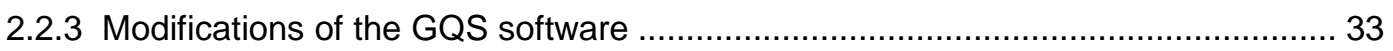

2.3-GQS Calibration and Bench Testing for Landfill Gas ................................................ 36

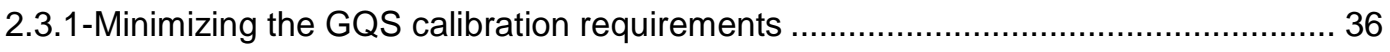

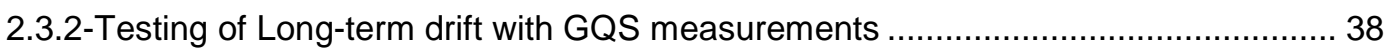

2.3.3 Experiments with blends of natural gas and landfill gas ..................................... 41

2.3.4 Experiments with landfill gas mixtures containing water vapor ........................... 44

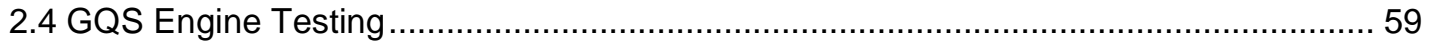

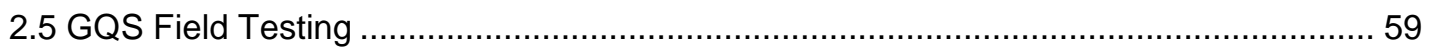

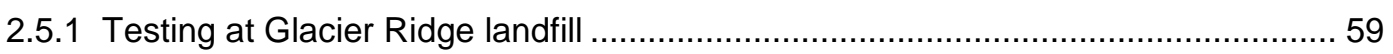

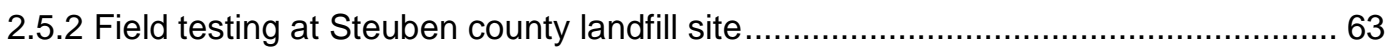

2.6 Development of Gas Quality Sensor Specifications for Producer Gas ......................... 67

2.6.1 Specifications of commercially available hydrogen sensors ................................. 67

2.6.2 Response time and cross-sensitivity of hydrogen gas sensor ...............................69

2.6.3. Response time and cross-sensitivity of carbon monoxide sensor ........................ 73

2.7 GQS Prototype Development for Producer Gas...................................................... 74

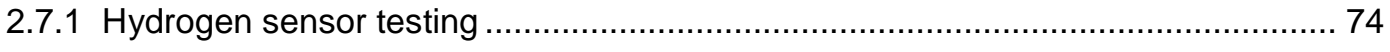

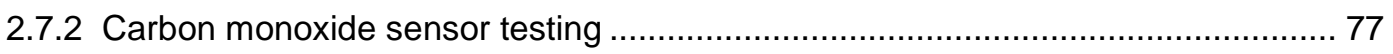

2.7.3 Integration of hydrogen and carbon monoxide sensors with GQS ........................ 79

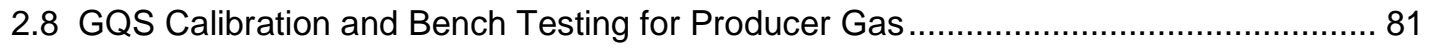

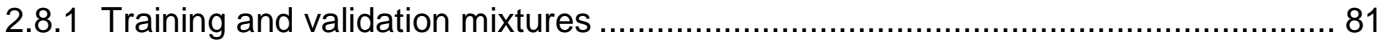

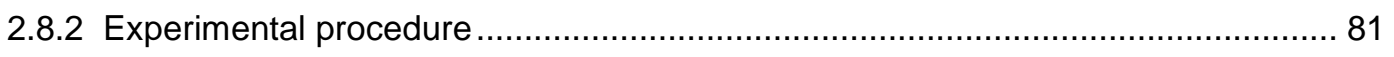

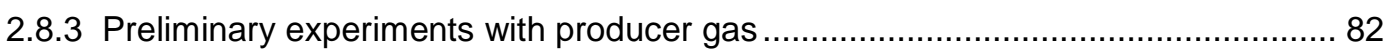

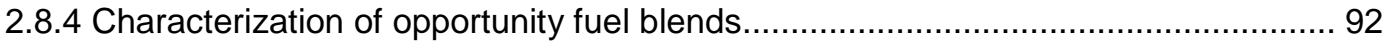

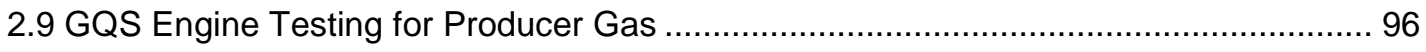

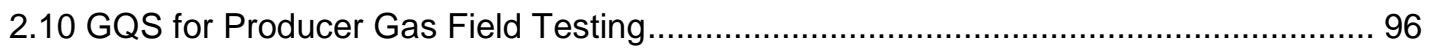




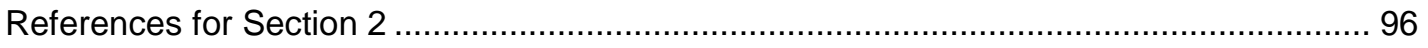

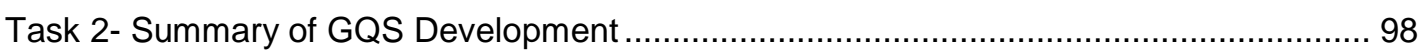

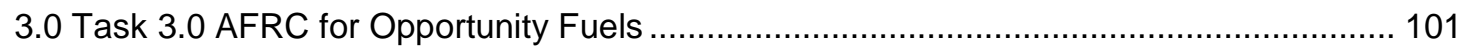

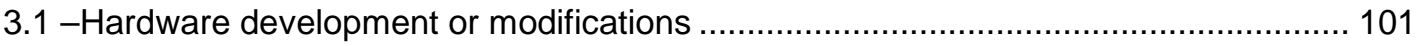

3.2 -Software development and implementation ........................................................ 101

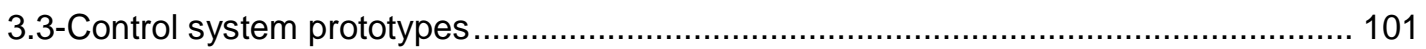

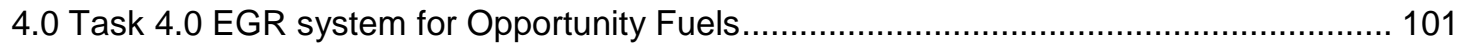

4.1 - Literature review of low BTU gaseous fuel composition and their application in

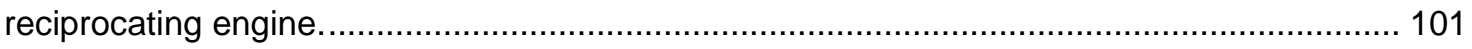

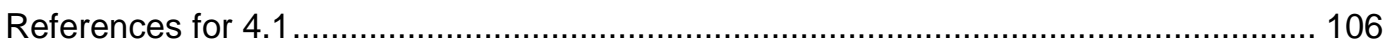

4.2 - Investigation of Impact of Diluents and Intake Pressure on Combustion Process of SI NG Engine Operated with Stoichiometric Mixture (Subtasks 4.2- 4.6) ............................... 107

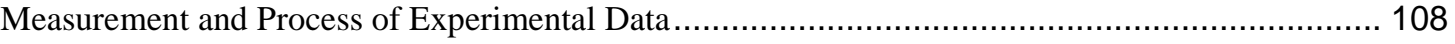

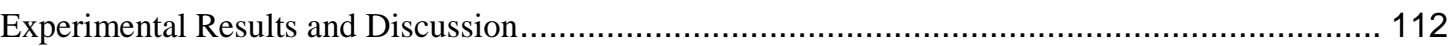

Effect of the addition of $\mathrm{CO}_{2}$ and $\mathrm{N}_{2}$ on knock limited spark timing ..................................... 112

Effect of the Presence of Diluents on Combustion and Emissions .............................................. 114

Effect of the Intake Pressure on the Engine Performance, Combustion and Exhaust Emissions .... 121

Effect of Engine Speed on Engine Performance, Combustion and Emissions ............................ 137

Effect of Spark Timing on Combustion and Emissions ......................................................... 152

5.0 Prototype Commercial Gas Quality Sensor for Opportunity Fueled Engines ................. 169

6.0 Field Evaluation of Integrated fuel gas cleanup with heat recovery on $\sim 1 \mathrm{MWe}$ engine with cooled EGR and Advanced Engine Monitoring and Control System for Opportunity Fuel ......... 169

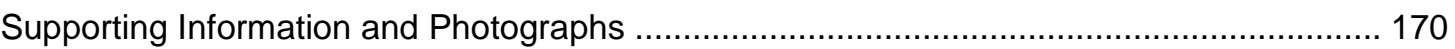




\section{Lis t of Figures}

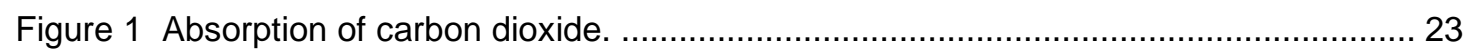

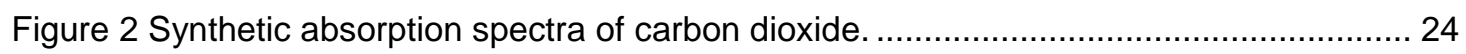

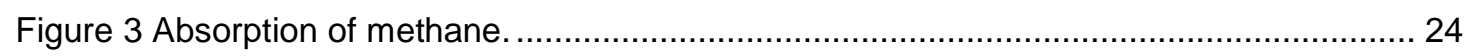

Figure 4 Synthetic absorption spectra of methane

Figure 5 Synthetic absorption spectra of methane, ethane, carbon dioxide and carbon monoxide

Figure 6. Absorbance of natural gas components (1 ppm-meter, $296 \mathrm{~K})$ in IR from PNNL database.

Figure 7. Absorbance of natural gas components (1 ppm-meter, $296 \mathrm{~K})$ on logarithmic scale in IR from PNNL database.

Figure 8. Absorbance of $\mathrm{CO}_{2}$ increases due to spectrometer drift during a set of tests conducted during 4 days ( 5 tests per day). 28

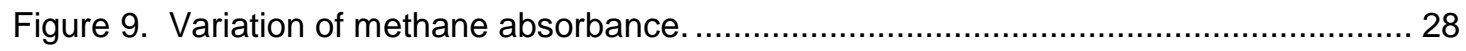

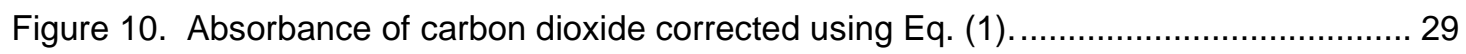

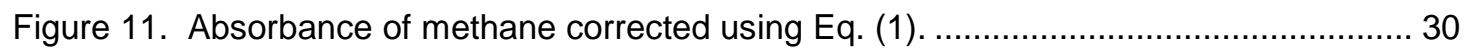

Figure 12. Measured absorption spestrum of carbon dioxide.......................................... 30

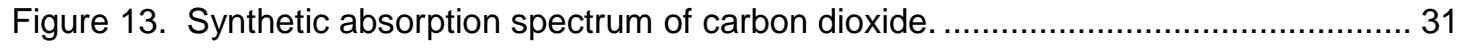

Figure 14. A polynomial curve fitted to the absorbances measured at non-absorbing wavelengths. 32

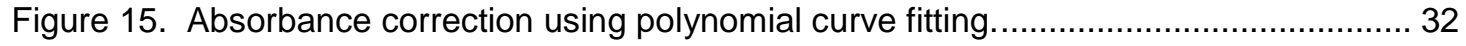

Figure 16. Comparison of absorption spectra corrected using polynomial function and linear

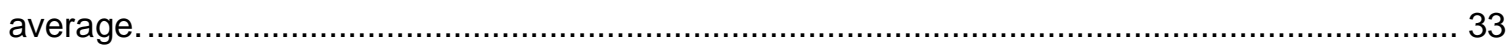

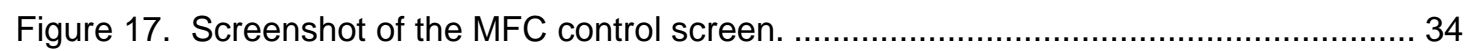

Figure 18. Absorption spectra of methane and carbon dioxide. ......................................... 34

Figure 19. Absorption spectrum of carbon dioxide corrected using Eq. (3)........................... 35

Figure 20. Comparison of measured and calculated NIR absorption spectra of binary mixtures of (a) $75 \%$ (b) $50 \%$ (c) $25 \%$ carbon dioxide and balance nitrogen............................................. 37

Figure 21. Comparison of GQS and GC measurements over a period of one hour: (a)

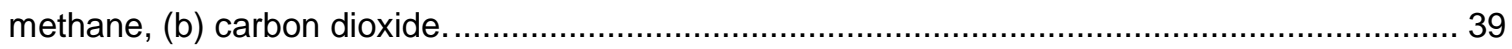

Figure 22.- Comparison of GQS and GC measurements over a period of one day: (a) methane, (b) carbon dioxide.

Figure 23. Near infrared absorption spectra of calibration mixtures 1, 2, 4 and 5 shown in Table 13

Figure 24. Near infrared absorption spectra of validation mixture (mixture 3) shown in Table 13.

Figure 25. Equilibrium water vapor pressure as a function of temperature. 45 
Figure 26. NIR spectra of water at $100 \%$ relative humidity for various temperatures. 45

Figure 27. Experimental setup for preparation and characterization of hydrocarbon fuel mixtures containing water vapor....... 46

Figure 28. Photo of the experimental setup for preparation and characterization of hydrocarbon fuel mixtures containing water vapor. The main parts include flow control system, gas heating system and data acquisition system.

Figure 29. Electrical connections of Omega humidity sensor HX93AC to analog input module NI9203. The humidity sensor provides the temperature and relative humidity measurements on a scale of 4 to $20 \mathrm{~mA}$ current.

Figure 30. The near absorption spectra of pure methane and water vapor. Methane is at 1 bar and $25{ }^{\circ} \mathrm{C}$. Water vapor is present in nitrogen at $50 \%$ relative humidity and $45{ }^{\circ} \mathrm{C}$. 48

Figure 31. The near infrared absorption spectra of water vapor. Water vapor is present in nitrogen at $34 \%$ relative humidity and $55^{\circ} \mathrm{C}$. The comparison of experimental and simulated spectra suggests that the humidity sensor has a significant error in $\mathrm{RH}$ measurement. .............. 50

Figure 32. Near infrared absorption spectra of synthetic landfill gas mixtures. 54

Figure 33. Residual absorbances computed by subtracting the absorption spectra of experimentally measured validation mixtures from the spectra of mixtures shown in Table 28... 56

Figure 34. Residual absorbances obtained by subtracting the spectra of mixtures shown in Table 29 from the experimentally measured validation spectra. 57

Figure 35. Residual absorbances computed by subtracting the absorption spectra of experimentally measured validation mixtures from the spectra of mixtures shown in Table 16

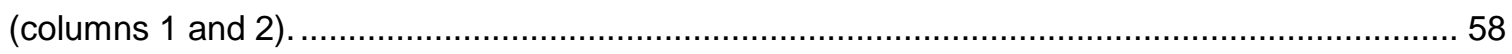

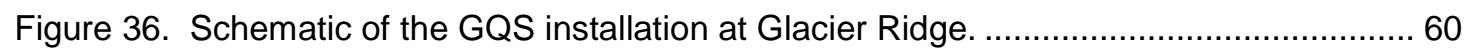

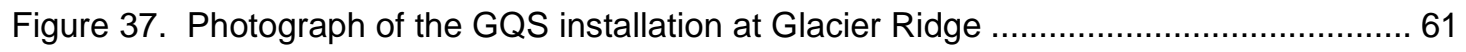

Figure 38. Methane concentration measurements at Glacier Ridge landfill 01/20/2010 ....... 61

Figure 39. Methane concentration measurements at Glacier Ridge landfill 10/11/2010 ....... 62

Figure 40. Comparison of GC and GQS predicted methane concentrations during WI glacier ridge landfill site testing. There is a continuous over-prediction of methane by GQS....... 62

Figure 41. Landfill gas collection well head. The wells have perforated pipes at the bottom

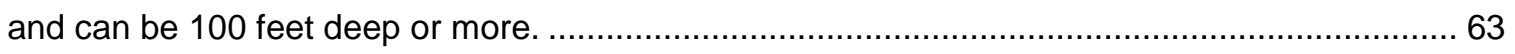

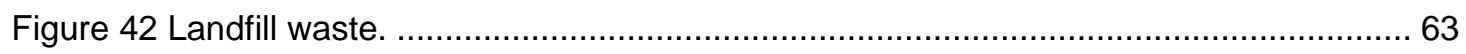

Figure 43. A lean burn, low BTU, internal combustion reciprocating stationary engine at the Bath Landfill, Steuben County, New York. As typically, this lean-burn engine is also turbocharged and aftercooled. This is a $\mathrm{V} 18,91 \mathrm{~L}$ engine producing $2 \mathrm{MW}$ power and can run safely on landfill

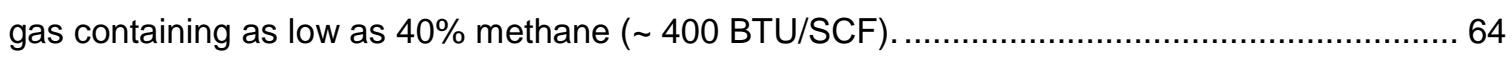

Figure 44. GQS setup at Bath Landfill, Steuben County, New York, ...................................... 65

Figure 45. Continuous monitoring of composition of landfill gas by GQS and GC ............... 66 
Figure 46. Continuous monitoring of heating value by GQS and GC.

Figure 47. (a) HPS-100C connected using multiple fittings. An arrangement of a smaller copper tube inside a larger tube facilitates direct exposure of MOSFET sensor to the gaseous stream and thus assists in reducing the gas diffusion time; (b) Experimental setup for studying the sensor characteristics.

Figure 48. PWM output for (a) pure nitrogen - indicates the baseline (b) pure hydrogen (c) pure methane.

Figure 49. PWM signal output for (a) hydrogen-nitrogen (b) methane-nitrogen (c) hydrogen-

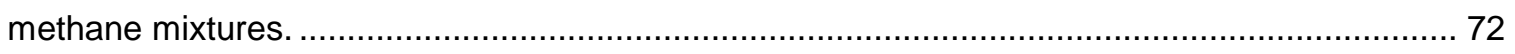

Figure 50. Testing of carbon monoxide sensor for drift in measurements............................. 74

Figure 51. Mechanical connections of hydrogen sensor HPS-100C to GQS. ...................... 74

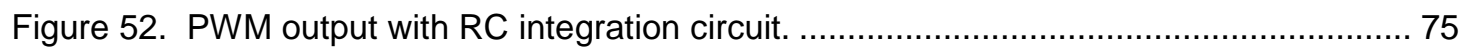

Figure 53. Analog signal output of HPS-100C on an oscilloscope. .................................... 76

Figure 54. Mechanical connections for CO sensor. ............................................................ 77

Figure 55. Integration of $\mathrm{CO}$ sensor with GQS data acquisition system................................ 78

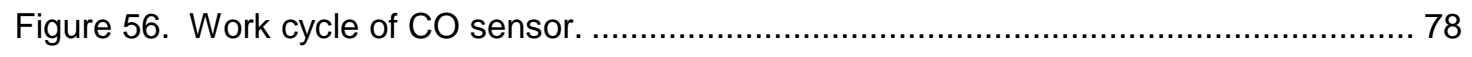

Figure 57. Integration of hydrogen and carbon monoxide sensors with GQS. ....................79

Figure 58. Hydrogen and carbon monoxide sensors testing setup schematic. ...................... 80

Figure 59. Hydrogen and carbon monoxide sensors testing setup photograph. ................... 80

Figure 60. Proportion of total variance explained by each principal component. ................... 84

Figure 61. Loading values for the first three components............................................... 85

Figure 62. Set and predicted properties of validation mixtures shown in Table 30. .............. 86

Figure 63. Near infrared absorption spectra of calibration mixtures shown in Table $31 \ldots \ldots . . .90$

Figure 64. Near infrared absorption spectra of validation mixtures shown in Table 32......... 90

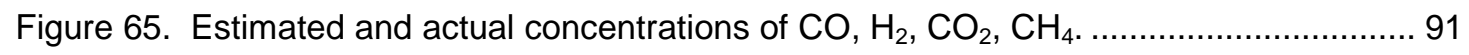

Figure 66. RMSE against the number of components used for developing a calibration

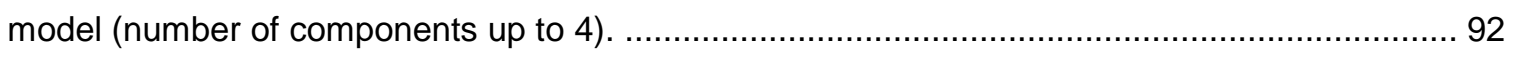

Figure 67. Set and measured compositions and heating values of natural gas blended with

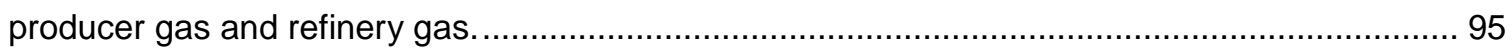

Figure 68 Raw Cylinder Pressure, Pin=1.5bar, N=1500rpm, ER=0.85, ST=13.4 CA BTDC, and diluent $=30 \% \mathrm{~N} 2$

Figure 69 Cylinder Pressure Processed Using 15-point moving average data filter, Pin=1.5bar, $\mathrm{N}=1500 \mathrm{rpm}, \mathrm{ER}=0.85, \mathrm{ST}=13.4 \mathrm{CA} \mathrm{BTDC}$, and diluent=30\%N2

Figure 70 Raw Heat Release Data Obtained by Processing the Filtered Cylinder Pressure Data, Pin=1.5bar, N=1500rpm, ER=0.85, ST=13.4 CA BTDC, and diluent=30\%N2 . 111

Figure 71 Filtered Heat Release Data, Pin=1.5bar, N=1500rpm, ER=0.85, ST=13.4 CA BTDC, and diluent $=30 \% \mathrm{~N} 2$ 111 
Figure 72 Effect of CO2 Addition on Knock Limited Spark Timing, N=1500 rpm, Pin=1.5 Bar, no knock observed with $60 \%$ CO2

Figure 73 Effect of CO2 Addition on Knock Limited Spark Timing, N=1500 rpm, Pin=2.0 Bar

Figure 74 Effect of Intake Pressure on Knock Limited Spark Timing, N=1500 rpm, no EGR, no diluents, no EGR. 114

Figure 75 Effect of Intake N2 on In-Cylinder Pressure, N=1500 rpm, Pin=1.5 bar, Pout=1.65 bar, $\mathrm{ST}=15, \mathrm{ER}=1.0$ 115

Figure 76 Effect of Diluents on Peak Pressure, N=1500 rpm, ER=1.0, Pin=1.5 bar, Pout=1.65 bar, ST=15 bTDC

Figure 77 Effect of Diluents on IMEP, N=1500 rpm, ER=1.0, Pin=1.5 bar, Pout=1.65 bar, $\mathrm{ST}=15 \mathrm{bTDC}$ 116

Figure 78 Effect of Diluents on BMEP, N=1500 rpm, ER=1.0, Pin=1.5 bar, Pout=1.65 bar, $\mathrm{ST}=15 \mathrm{bTDC}$ 116

Figure 79 Effect of Intake N2 on Heat Release Rate, N=1500 rpm, Pin=1.5 bar, Pout=1.65 bar, $\mathrm{ST}=15, \mathrm{ER}=1.0$

Figure 80 Effect of Intake $\mathrm{N}_{2}$ on Normalized Heat Release Rate, $\mathrm{N}=1500 \mathrm{rpm}, \mathrm{P}_{\text {in }}=1.5 \mathrm{bar}$, $P_{\text {out }}=1.65$ bar, $S T=15, E R=1.0$

Figure 81 Effect of Intake N2 on Mass Fraction Burned, N=1500 rpm, Pin=1.5 bar, Pout=1.65 bar, $\mathrm{ST}=15, \mathrm{ER}=1.0$

Figure 82 Effect of Diluents on Ignition Delay, N=1500 rpm, ER=1.0, Pin=1.5 bar, Pout=1.65 bar, ST=15 bTDC

Figure 83 Effect of Diluents on Combustion Duration, N=1500 rpm, ER=1.0, Pin=1.5 bar, Pout=1.65 bar, ST=15 bTDC

Figure 84 Effect of Diluents on COV IMEP, N=1500 rpm, ER=1.0, Pin=1.5 bar, Pout=1.65 bar, $\mathrm{ST}=15 \mathrm{bTDC}$

Figure 85 Effect of Diluents on $\mathrm{CO} 2$ Emissions (CO2 from the combustion of natural gas only), $\mathrm{N}=1500 \mathrm{rpm}, \mathrm{ER}=1.0, \mathrm{Pin}=1.5 \mathrm{bar}$, Pout=1.65 bar, ST=15 bTDC

Figure 86 Effect of Diluents on In-Cylinder Pressure, N=1500 rpm, Pin=1.5 bar, Pout=1.65 bar, $\mathrm{ST}=15, \mathrm{ER}=1.0$

Figure 87 Effect of Diluents on Heat Release Rate, N=1500 rpm, Pin=1.5 bar, Pout=1.65 bar, $\mathrm{ST}=15, \mathrm{ER}=1.0$

Figure 88 Effect of Diluents on Mass Fraction Burned, N=1500 rpm, Pin=1.5 bar, Pout=1.65 bar, $\mathrm{ST}=15, \mathrm{ER}=1.0$. 121

Figure 89 Effect of Intake Pressure on In-Cylinder Pressure, N=1500 rpm, Pout=Pin+1.15 bar, $\mathrm{ST}=15, \mathrm{ER}=1.0$, No Diluents 122 
Figure 90 Effect of Intake Pressure on Heat Release Rate, N=1500 rpm, Pout=Pin+1.15 bar, $\mathrm{ST}=15, \mathrm{ER}=1.0$, No Diluents

Figure 91 Effect of Intake Pressure on Normalized Heat Release Rate, N=1500 rpm, Pout=Pin+1.15 bar, ST=15, ER=1.0, No Diluents

Figure 92 Effect of Intake Pressure on Mass Fraction Burned, N=1500 rpm, Pout=Pin+1.15 bar, $\mathrm{ST}=15, \mathrm{ER}=1.0$, No Diluents

Figure 93 Effect of Intake Pressure on Heat Release Rate, N=1500 rpm, Pout=Pin+1.15 bar, $\mathrm{ST}=15, \mathrm{ER}=1.0, \mathrm{CO} 2=40 \%$ 124

Figure 94 Effect of Intake Pressure on Mass Fraction Burned, N=1500 rpm, Pout=Pin+1.15 bar, $\mathrm{ST}=15, \mathrm{ER}=1.0, \mathrm{CO} 2=40 \%$ 125

Figure 95 Effect of Intake Pressure on Normalized Heat Release Rate, $N=1500$ rpm, Pout=Pin+1.15 bar, ST=15, ER=1.0, CO2=40\% 125

Figure 96 Effect of Diluents on Peak Pressure, N=1500 rpm, ER=1.0, ST=15 bTDC. 126

Figure 97 Effect of Diluents on Peak Heat Release Rate, N=1500 rpm, ER=1.0, Pin=1.5 bar, Pout=1.65 bar, ST=15 bTDC. 126

Figure 98 Effect of Diluents on Normalized Peak Heat Release Rate, N=1500 rpm, ER=1.0, $\mathrm{ST}=15^{\circ} \mathrm{bTDC}$ 127

Figure 99 Effect of Intake Pressure on IMEP, N=1500 rpm, ER=1.0, Pout=Pin+0.15, ST=15 bTDC 127

Figure 100 Effect of Intake Pressure and the Addition of Diluents on BMEP, $N=1500$ rpm, $E R=1.0$, Pout=Pin+0.15, ST=15 bTDC 128

Figure 101 Effect of Intake Pressure on COV IMEP, N=1500 rpm, ER=1.0, Pout=Pin+0.15, ST=15 bTDC 128

Figure 102 Effect of Intake Pressure and the Addition of Diluents on Ignition Delay, N=1500 rpm, ER=1.0, Pout=Pin+0.15, ST=15 bTDC 129

Figure 103 Effect of Intake Pressure and the Addition of Diluents on Ignition Delay, N=1500 rpm, ER=1.0, Pout=Pin+0.15, ST=15 bTDC 129

Figure 104 Effect of Intake Pressure on NOx Emissions, $\mathrm{N}=1500$ rpm, ER=1.0, Pout=Pin+0.15, ST=15 bTDC 130

Figure 105 Effect of Intake Pressure on CO Emissions, N=1500 rpm, ER=1.0, Pout=Pin+0.15, $\mathrm{ST}=15 \mathrm{bTDC}$ 130

Figure 106 Effect of Intake Pressure on HC Emissions, N=1500 rpm, ER=1.0, Pout=Pin+0.15, $\mathrm{ST}=15 \mathrm{bTDC}$ 131

Figure 107 Effect of Intake Pressure on CO2 Emissions, $\mathrm{N}=1500 \mathrm{rpm}, \mathrm{ER}=1.0$, Pout=Pin+0.15, ST=15 bTDC 131

Figure 108 Effect of Intake Pressure on BMEP, N=1500 rpm, ER=0.87, Pout=Pin+0.15, $\mathrm{ST}=15 \mathrm{bTDC}$ 
Figure 109 Effect of Intake Pressure on Peak Pressure, $N=1500$ rpm, ER=0.87, Pout=Pin+0.15, ST=15 bTDC.

Figure 110 Effect of Intake Pressure on IMEP, N=1500 rpm, ER=0.87, Pout=Pin+0.15, ST=15 bTDC

Figure 111 Effect of Intake Pressure on Ignition Delay, N=1500 rpm, ER=0.87, Pout=Pin+0.15, ST=15 bTDC

Figure 112 Effect of Intake Pressure on Combustion Duration, N=1500 rpm, ER=0.87, Pout=Pin+0.15, ST=15 bTDC

Figure 113 Effect of Intake Pressure on NOx Emissions, N=1500 rpm, ER=0.87, Pout=Pin+0.15, ST=15 bTDC.

Figure 114 Effect of Intake Pressure on CO Emissions, $\mathrm{N}=1500 \mathrm{rpm}, \mathrm{ER}=0.87$, Pout=Pin+0.15, ST=15 bTDC

Figure 115 Effect of Intake Pressure on HC Emissions, $\mathrm{N}=1500 \mathrm{rpm}, \mathrm{ER}=0.87$, Pout=Pin+0.15, ST=15 bTDC.

Figure 116 Effect of Intake Pressure on CO2 Emissions, $\mathrm{N}=1500 \mathrm{rpm}, \mathrm{ER}=0.87$, Pout=Pin+0.15, ST=15 bTDC. 136

Figure 117 Effect of Intake Pressure on CO2 Emissions, $N=1500$ rpm, ER=0.87, Pout=Pin+0.15, ST=15 bTDC.

Figure 118 Effect of Intake Pressure on COV IMEP, N=1500 rpm, ER=0.87, Pout=Pin+0.15, $\mathrm{ST}=15 \mathrm{bTDC}$

Figure 119 Effect of Engine Speed on In-Cylinder Pressure, Pin=1.0 bar, Pout=1.11 bar, $\mathrm{ST}=15, \mathrm{ER}=0.8$, No Dilution

Figure 120 Effect of Engine Speed on Heat Release Rate, Pin=1.0 bar, Pout=1.11 bar, $\mathrm{ST}=15, \mathrm{ER}=0.8$, No Dilution 139

Figure 121 Effect of Engine Speed on Mass Fraction Burned, Pin=1.0 bar, Pout=1.11 bar, $\mathrm{ST}=15, \mathrm{ER}=0.8$, No Dilution .....

Figure 122 Effect of Engine Speed on BMEP, Pin=1.0, Pout=1.11, ST=15 bTDC, No dilution 140

Figure 123 Effect of Engine Speed on IMEP, Pin=1.0, Pout=1.11, ST=15 bTDC, No dilution 140

Figure 124 Effect of Engine Speed on Peak Pressure, Pin=1.0, Pout=1.11, ST=15 bTDC, No dilution 141

Figure 125 Effect of Engine Speed on Ignition Delay, Pin=1.0, Pout=1.11, ST=15 bTDC, No dilution 141

Figure 126: Effect of Engine Speed on Ignition Delay, Pin=1.0, Pout=1.11, ST=15 bTDC, No dilution 142 
Figure 127: Effect of Engine Speed on Thermal Efficiency, Pin=1.0, Pout=1.11, ST=15 bTDC, No dilution

Figure 128 Effect of Engine Speed on CO Emissions, Pin=1.0, Pout=1.11, ST=15 bTDC, No dilution 143

Figure 129 Effect of Engine Speed on HC Emissions, Pin=1.0, Pout=1.11, ST=15 bTDC, No dilution 143

Figure 130 Effect of Engine Speed on CO2 Emissions, Pin=1.0, Pout=1.11, ST=15 bTDC, No dilution 144

Figure 131 Effect of Engine Speed on Combustion Efficiency, Pin=1.0, Pout=1.11, ST=15 bTDC, No dilution 145

Figure 132 Effect of Engine Speed on NOx Emissions, Pin=1.0, Pout=1.11, ST=15 bTDC, No dilution 145

Figure 133 Effect of Engine Speed on COV IMEP, Pin=1.0, Pout=1.11, ST=15 bTDC, No dilution 146

Figure 134 Effect of Engine Speed on BMEP, Pin=1.0, Pout=1.11, ST=15 bTDC, ER=1.0 . 146 Figure 135 Effect of Engine Speed on Thermal Efficiency, Pin=1.0, Pout=1.11, ST=15 bTDC, $\mathrm{ER}=1.0$ 147

Figure 136 Effect of Engine Speed on IMEP, Pin=1.0, Pout=1.11, ST=15 bTDC, ER=1.0 ... 147

Figure 137 Effect of Engine Speed on Peak Pressure, Pin=1.0, Pout=1.11, ST=15 bTDC, $\mathrm{ER}=1.0$. 148

Figure 138 Effect of Engine Speed on Ignition Delay, Pin=1.0, Pout=1.11, ST=15 bTDC, $\mathrm{ER}=1.0$. 148

Figure 139 Effect of Engine Speed on Combustion Duration, Pin=1.0, Pout=1.11, ST=15 bTDC, ER=1.0 149

Figure 140 Effect of Engine Speed on NOx Emissions, Pin=1.0, Pout=1.11, ST=15 bTDC, $\mathrm{ER}=1.0$. 149

Figure 141 Effect of Engine Speed on CO Emissions, Pin=1.0, Pout=1.11, ST=15 bTDC, $E R=1.0$ (CO data for 1500 rpm with 40\% CO2 was not correct). 150

Figure 142 Effect of Engine Speed on HC Emissions, Pin=1.0, Pout=1.11, ST=15 bTDC, $\mathrm{ER}=1.0$ 150

Figure 143 Effect of Engine Speed on CO2 Emissions, Pin=1.0, Pout=1.11, ST=15 bTDC, $\mathrm{ER}=1.0$. 151

Figure 144 Effect of Engine Speed on Combustion Efficiency, Pin=1.0, Pout=1.11, ST=15 bTDC, ER=1.0 151

Figure 145 Effect of Engine Speed on COV IMEP, Pin=1.0, Pout=1.11, ST=15 bTDC, ER=1.0 152 
Figure 146 Effect of Spark Timing on In-Cylinder Pressure, Pin=1.0 bar, Pout=1.11 bar,

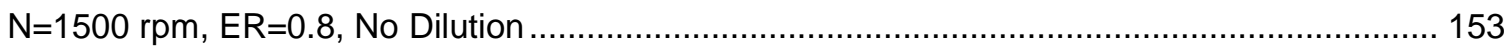

Figure 147 Effect of Spark Timing on Peak Pressure, Pin=1.0, Pout=1.11, ER=0.8 ........... 154

Figure 148 Effect of Spark Timing on Heat Release Rate, Pin=1.0 bar, Pout=1.11 bar, N=1500

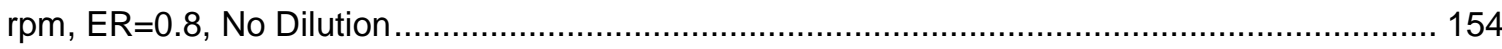

Figure 149 Effect of Spark Timing on Mass Fraction Burned, Pin=1.0 bar, Pout=1.11 bar,

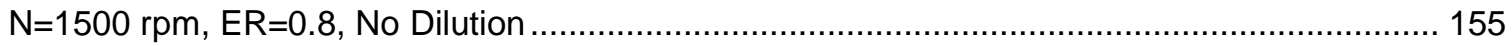

Figure 150 Effect of Spark Timing on BMEP, Pin=1.0, Pout=1.11, ER=0.8 …................ 155

Figure 151 Effect of Spark Timing on Thermal Efficiency, Pin=1.0, Pout=1.11, ER=0.8 ..... 156

Figure 152 Effect of Spark Timing on IMEP, Pin=1.0, Pout=1.11, ER=0.8....................... 157

Figure 153 Effect of Spark Timing on Peak Pressure, Pin=1.0, Pout=1.11, ER=0.8 ........... 157

Figure 154 Effect of Spark Timing on Ignition Delay, Pin=1.0, Pout=1.11, ER=0.8............ 158

Figure 155 Effect of Spark Timing on Ignition Delay, Pin=1.0, Pout=1.11, ER=0.8............ 158

Figure 156 Effect of Spark Timing on NOx Emissions, Pin=1.0, Pout=1.11, ER=0.8 ......... 159

Figure 157 Effect of Spark Timing on CO Emissions, Pin=1.0, Pout=1.11, ER=0.8 ........... 159

Figure 158 Effect of Spark Timing on HC Emissions, Pin=1.0, Pout=1.1, ER=0.8 ….......... 160

Figure 159 Effect of Spark Timing on CO2 Emissions, Pin=1.0, Pout=1.1, ER=0.8 ............ 161

Figure 160 Effect of Spark Timing on Combustion Efficiency, Pin=1.0, Pout=1.11, ER=0.8. 161

Figure 161 Effect of Spark Timing on COV IMEP, Pin=1.0, Pout=1.11, ER=0.8 .................. 162

Figure 162 Effect of Spark Timing on BMEP, Pin=1.0, Pout=1.11, ER=1.0 ….................. 162

Figure 163 Effect of Spark Timing on Thermal Efficiency, Pin=1.0, Pout=1.11, ER=1.0...... 163

Figure 164 Effect of Spark Timing on IMEP, Pin=1.0, Pout=1.11, ER=1.0........................ 163

Figure 165 Effect of Spark Timing on Peak Pressure, Pin=1.0, Pout=1.11, ST=15 bTDC,

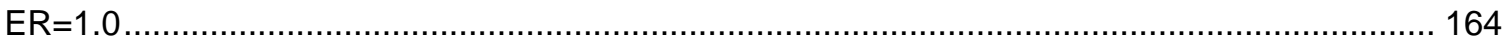

Figure 166 Effect of Spark Timing on Ignition Delay, Pin=1.0, Pout=1.11, ER=1.0 …......... 164

Figure 167 Effect of Spark Timing on Combustion Duration, Pin=1.0, Pout=1.11, ER=1.0 .. 165

Figure 168 Effect of Spark Timing on NOx Emissions, Pin=1.0, Pout=1.1, ER=1.0 ............ 165

Figure 169 Effect of Spark Timing on CO Emissions, Pin=1.0, Pout=1.11, ER=1.0 ........... 166

Figure 170 Effect of Spark Timing on HC Emissions, Pin=1.0, Pout=1.11, ER=1.0 ............ 166

Figure 171 Effect of Spark Timing on CO2 Emissions, Pin=1.0, Pout=1.11, ER=1.0 …..... 167

Figure 172 Effect of Spark Timing on Combustion Efficiency, Pin=1.0, Pout=1.11, ER=1.0. 167

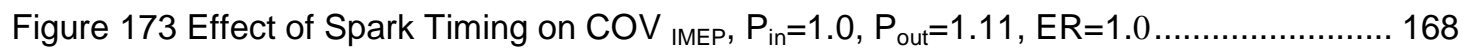




\section{List of Tables}

Table 1 Peak absorbance values and corresponding wavelengths in IR for natural gas

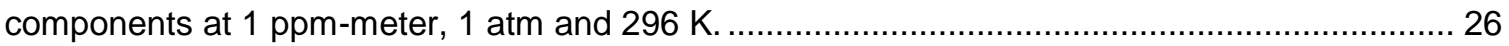

Table 2. Non-absorbing wavelength ranges selected for polynomial fitting.......................... 35

Table 3. Compositional variation of natural gas, landfill gas and their blends. ...................... 41

Table 4. Compositions and heating values of mixtures. Mixture 3 is a validation mixture and the remaining mixtures are used for calibration purpose.

Table 5. Set and measured compositions of validation mixture using number of principal components up to 3 .

Table 6. Root-mean-squared-error-of-prediction using number of principal components up to 3.

Table 7. Values of specific humidity measured by different methods.

Table 8. Details of the calibration mixtures of methane, carbon dioxide and water vapor prepared in the experiment.

Table 9. Details of validation mixtures. 52

Table 10. Compositions by volume of synthetic landfill gas mixtures to be used for calibration.

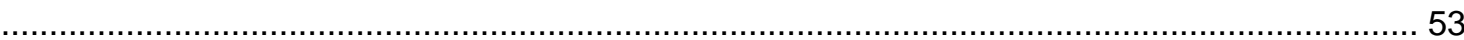

Table 11. Compositions by volume of synthetic landfill gas mixtures to be used for validation.

Table 12. Compositions by volume of synthetic landfill gas mixtures. Their near infrared absorption spectra are shown in Fig. 32.

Table 13. Wavelength ranges used for building CLS regression models for different component gases. 55

Table 14. CLS estimated methane and water vapor concentrations. ................................ 55

Table 15. PLS estimated compositions and heating values of validation mixtures. ............... 57

Table 16. Comparison of landfill gas compositions estimated using CLS on entire spectra

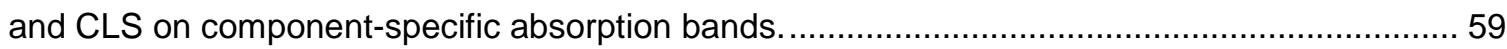

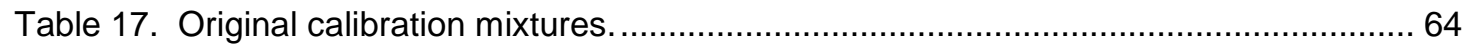

Table 18. Calibration mixture added to the existing GQS training data set during the field test.

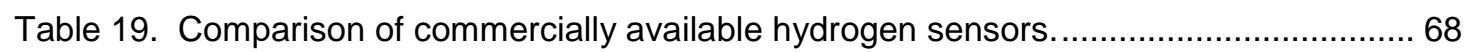

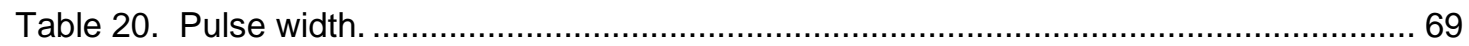

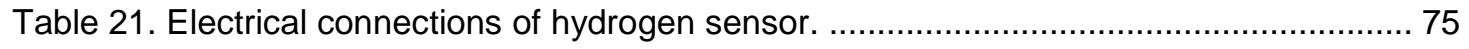

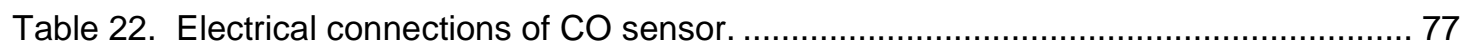

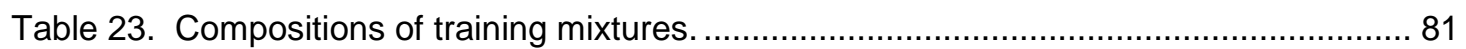

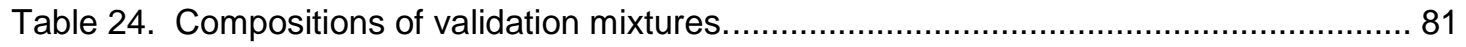

Table 25. Compositions and heating values of calibration and validation mixtures................. 83 


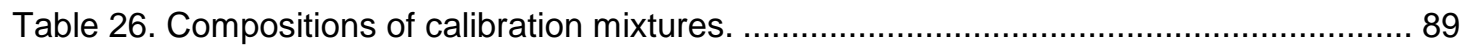

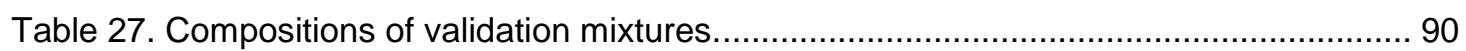

Table 28. Compositions and heating values of natural gas and selected opportunity fuels. .. 93

Table 29. Composition and heating value of natural gas blended with producer gas and

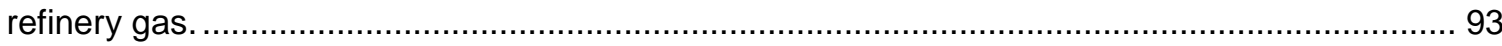

Table 30. RMSEP in measured compositions and heating values of natural gas blended

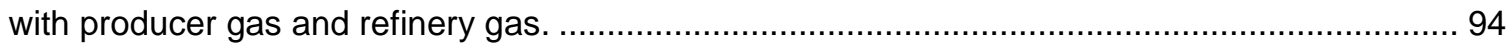

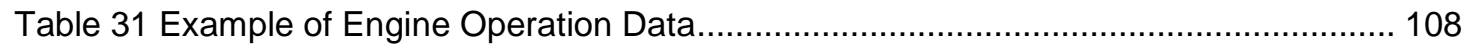

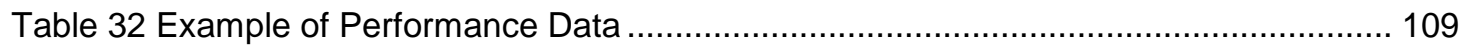

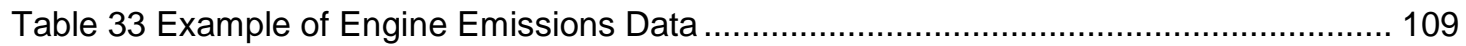

Table 34 Example of Cylinder Pressure and Engine Combustion Process Parameters ....... 112

Table 35 Test Matrix for Diluents Test, N=1500 rpm, ER=1.0, $P_{\text {in }}=1.5$ bar, Spark timing=15

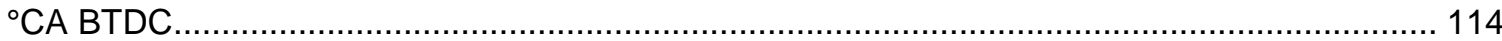

Table 36 Test Matrix for Diluents Test, N=1500 rpm, ER=1.0, $P_{\text {in }}=1.5$ bar, Spark timing=15

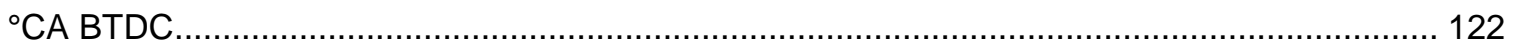

Table 37 Changing Speed, ER=0.8, No Dilution, $P_{\text {in }}=1$ bar, $S T=15$ deg bTDC ................... 138

Table 38 Changing Speed, ER=0.8, $\mathrm{CO}_{2}=40 \%, \mathrm{P}_{\text {in }}=1$ bar, ST=15 deg bTDC .................... 138

Table 39 Changing Spark Timing, Speed=1500 rpm, ER=0.8, No Dilution, $\mathrm{P}_{\mathrm{in}}=1$ bar ......... 152

Table 40 Changing Spark Timing, Speed=1500 rpm, ER=0.8, CO2=40\%, Pin=1 bar ......... 153 


\section{Abstract}

The project is addressing barriers to or opportunities for increasing distributed generation (DG)/combined heat and power (CHP) use in industrial applications using renewable/opportunity fuels. This project brings together novel gas quality sensor (GQS) technology with engine management for opportunity fuels such as landfill gas, digester gas and coal bed methane. By providing the capability for near real-time monitoring of the composition of these opportunity fuels, the GQS output can be used to improve the performance, increase efficiency, raise system reliability, and provide improved project economics and reduced emissions for engines used in distributed generation and combined heat and power. 


\section{EXECUTIVE SUMMARY}

The Project led to several major accomplishments including:

- Advanced development of a low-cost, near infrared sensor for real-time monitoring of the concentrations of methane and carbon dioxide in opportunity fuels such as landfill gas and digester gas from waste water treatment plants.

- Installed the developed sensor at two landfills and one waste water treatment plant where long-term testing was conducted to compare accuracy of the GQS versus a gas chromatograph (the industry standard for gas analysis).

o Agreement between measurements using the DOE supported sensor and the gas chromatograph were within one percentage point or better.

o Response time of the developed sensor was about one second, significantly better than a gas chromatograph.

o Very short response time and low cost allows use of GQS for industrial controls as well as engine controllers

- Expanded the capabilities of the aforementioned sensor to include measurement of hydrogen and carbon monoxide in opportunity fuels such as producer gas from gasification and pyrolysis of biomass.

- Collaboration with Continental Controls Corp. under California Energy Commission sponsored project PNG-07-008, Ultra-Low Emission Integrated CHP Technology Development. In this project, the scope included an evaluation of the feasibility of using the real-time, Gas Quality Sensor (GQS) to measure the heating value of the air/fuel mixture as a process variable for a higher resolution AFRC. Some of the sensor and engine performance data obtained from these tests would subsequently be used to populate a controls simulation model created under the project and based upon the software program VisSim.

- Collaboration with Southern California Gas to evaluate the performance of the GQS for measuring the concentration of methane in digester gas.

- Collaboration with Cummins on their efforts to integrate the GQS with an advanced controller for a Cummins engine for opportunity fuels that was being introduced into the US market.

- Collaboration with Caterpillar to test the capabilities of the GQS at GTI and compare it to heating value sensor developed by Ruhrgas (Germany).

- Identification of a commercial partner (C-M-R Group) for the GQS and negotiated (over two years) a Joint Development Agreement and Licensing Agreement for commercialization of the aforementioned sensor. CMR is a major worldwide company that provides design, manufacturing, and service of instrumentation and controls for offshore platforms and vessels, marine, engines and industrial applications. CMR Group serves as an engineering partner to the world's leading manufacturers of industrial engines offering complete electrical and electronic product integration for industrial diesel and natural gas engines applied to the most challenging environments, including: marine, shipbuilding, offshore platforms, energy and power generation facilities, gas exploration and compression, and off-highway vehicles.

- Publishing of three peer reviewed papers dealing with the DOE supported work. Papers were presented at ASME Internal Combustion Engines Division conferences in 2010, 2011, and 2012.

- Filing of U. S. Patent Applications: 
- METHOD AND APPARATUS FOR REAL-TIME FUEL GAS COMPOSITIONS AND HEATING VALUES

- METHOD OF ABSORBANCE CORRECTION IN A SPECTROSCOPIC HEATING VALUE SENSOR 


\section{Introduction}

\section{Background:}

This project brings together real-time, gas quality sensor technology with engine management for opportunity fuels. The proposed project is a unique industry effort that will improve the performance, increase efficiency, raise system reliability, and provide improved project economics and reduced emissions. GTI and project partners will:

Prime Mover System: 1) Develop performance requirements for a Gas Quality Sensor (GQS) to be integrated with air/fuel ratio engine control systems for landfill gas, digester gas from wastewater treatment plants, coal mine methane and producer gas containing hydrogen and carbon monoxide 2) Develop and test prototypes of the Gas Quality Sensor and air/fuel ratio controllers for reciprocating internal combustion engines, 3) Install and complete a 500 hour test of field ready hardware and software on two different $\sim 1$ MWe reciprocating IC engines operated on landfill gas and one $\sim 330 \mathrm{kWe}$ reciprocating engine operated on producer gas to demonstrate attainment of project goals and objectives, and 4) Commercialize the developed gas quality sensor, engine monitoring and control systems.

\section{A. Objective:}

The proposed project addresses increasing combined heat and power (CHP) use in industrial applications using renewable and opportunity fuels. The technical approach will integrate advanced real-time measurement of gas composition and heating value with engine control system improvements to address fuel quality issues that have hampered expanded use of opportunity fuels such as landfill gas, digester biogas, producer gas ${ }^{1}$ and coal mine methane (e.g., siloxanes in landfill gas). These advancements will provide an avenue for expanded use of these opportunity fuels for power generation/CHP, industrial fuel gas, and pipeline natural gas markets. These fuel monitoring and engine control advancements will address variable fuel gas quality issues that can otherwise impact engine performance, emissions, or reliability. This will help increase the application of combined heat and power using renewable and domestically derived opportunity fuels.

\section{B. Scope of Work:}

To advance the state of the art for commercially available technology for cleanup of opportunity fuels, the Team proposes to demonstrate that to demonstrate that GTI's Gas Quality Sensor technology can be integrated with advanced air-fuel ratio/engine controls to maintain engine performance, reliability, and emissions to the most stringent levels required..

\section{TASKS TO BE PERFORMED:}

\section{PHASE 1}

Task 2.0 Gas Quality Sensor (GQS) for Opportunity Fuels

1 A combustible mixture of carbon monoxide and hydrogen molecules, as well as other complex combustible hydrocarbons 
In this task, GTI will develop its patented and proprietary Gas Quality Sensor technology for realtime measurement of four different opportunity fuel compositions and heating values to provide the engine air/fuel ratio controllers with a necessary feed forward input.

Subtask 2.1 -Development of GQS specifications for landfill gas, waste water treatment biogas and coal mine methane.

During this subtask GTI team will work together with representatives of potential field test sites, engine O.E.M.s, and sensor and manufacturing partners to investigate variability of compositions and heating values of landfill gas, digester biogas from wastewater treatment, and coal bed methane), develop sensor cost and performance requirements including measurement accuracy, range, response time etc.

Subtask 2.2 -GQS Prototype Development- During this task GTI will design, build, and assemble prototype of Gas Quality Sensor (GQS) hardware and software for the aforementioned opportunity fuels.

Subtask 2.3-GQS Calibration and Bench Testing- During this task GTI will calibrate and test the prototype with mixtures representative of the typical gas compositions for the target application(s). For example, for landfill gas, the mixture composition would be primarily methane and carbon dioxide. Testing will be conducted at the GTI Combustion Sensors laboratory.

Subtask 2.4 GQS Engine Testing- During this task a proto-type of the GQS will be integrated with advanced air/fuel ratio control for reciprocating internal combustion engines and tested to verify that GQS performance requirements (e.g., accuracy, response time, repeatability) can be achieved. It is currently planned that this would involve up to two different manufacturers of air-fuel ratio control.

Subtask 2.5 GQS Field Testing In this subtask, and using results from subtask 2.4, GTI will make any necessary modifications to "field-capable" sensor hardware and software, develop field test plan(s), and execute the plan(s) in Phase 2 to collect long-term field-test data necessary to demonstrate the effectiveness of the pre-commercial GQS.

Subtask 2.6 Develop Gas Quality Sensor Specifications and Prototype for Producer Gas. In this subtask, work initially with engine O.E.M.s to specify the range of gas compositions and performance requirements for operating reciprocating internal combustion engines on producer gas from biomass gasification. Develop hardware and software specifications and estimated cost for developing and testing a prototype realtime sensor for reciprocating engines operated on producer gas from biomass gasification. Present results to DOE NETL and representatives from at least two engine O.E.M.s at a stage/gate review meeting.

Subtask 2.7 GQS Prototype Development for Producer Gas- In this subtask, GTI will design, build, and assemble prototype of Gas Quality Sensor (GQS) hardware and software for producer gas.

Subtask 2.8 GQS Calibration and Bench Testing for Producer Gas- During this task GTI will calibrate and test the prototype with mixtures representative of producer gas identified in Subtask 2.6. Testing will be conducted at the GTI Combustion Sensors laboratory. 
Subtask 2.9 GQS Engine Testing for Producer Gas- During this task a proto-type of the GQS for producer gas will be integrated with advanced air/fuel ratio control for reciprocating internal combustion engines and tested to verify that GQS performance requirements (e.g., accuracy, response time, repeatability) can be achieved. It is currently planned that this would involve up to two different manufacturers of air-fuel ratio control.

Subtask 2.10 GQS for Producer Gas Field Testing In this subtask, and using results from subtask 2.9, GTI will make any necessary modifications required for "fieldcapable" sensor hardware and software, develop field test plan(s), and execute the plan(s) in Phase 2 to collect long-term field-test data necessary to demonstrate the effectiveness of the pre-commercial GQS

\section{Task 3.0 AFRC for Opportunity Fuels}

Subtask 3.1 -Hardware development or modifications The current plan is to work with Cummins to integrate the GQS into their respective commercial Air Fuel Ratio Control (AFRC) hardware platforms for reciprocating engines operated on opportunity fuels., The hardware will be capable of being 'upfitted' to existing engines operated on landfill gas, biogas from wastewater treatment plants and coal-mine methane.

Subtask 3.2 -Software development and implementation Develop and implement software to integrate measured signals from the GQS and other engine sensors, if appropriate, to provide alarm and control functions necessary for improved AFRC.

Subtask 3.3-Control system prototypes Using results from above subtasks, develop commercial prototypes of advanced air fuel ratio control for opportunity fuels that uses signals from GQS, NOx/O2 sensor and other engine monitoring sensors.

\section{Task 4.0 EGR system for Opportunity Fuels}

In this task, WVU will develop and test the cooled exhaust gas recirculation system required for maintaining stoichiometric operation on the opportunity fueled field test engine with three-way catalyst to control emissions.

Subtask 4.1 - Literature review of low BTU gaseous fuel composition and their application in reciprocating engine. The research team will perform a detailed review of the composition and production volume of representative low BTU gaseous fuels with the focus on landfill gases, digest gas and coal mine methane. The requirement of the purification of low BTU fuels to allow successful burning will be addressed. The modification of the hardware and software needed for its burning in reciprocating engine will be reviewed. The potential to meet coming emission regulation and requirement to three-way catalyst converter will be examined. The combustion and emission characteristics of the low BTU fuels will also be summarized. The review results will be used to define the engine concepts to be developed. 
Subtask 4.2 - The development of numerical model to simulate the spark ignition (S.I.) engine operated on low BTU gaseous fuels. The onset of knock is one of the main barriers to the design of gaseous fuel engines. Due to its severe damage to the engine, it is difficult to examine experimentally the knock characteristics of low BTU fuels over wide range of changes to numerous operating conditions. In this research, WVU will develop a two-zone simulation model capable of predicting the performance and knock characteristics of S.I. engine operated on opportunity fuels with large amount of EGR. The model development work includes the application for large bore diameter, variable engine speed and the consideration of large amount of EGR. Numerous experiments will be conducted to provide extended basis for model development and its validation. The validated model will be used to predict the performance, emission and combustion characteristics of large bore spark ignition engine operated on opportunity fuels. The effect of compression ratio, speed, load, fuel composition, EGR rate and its cooling on engine performance will be examined.

Subtask 4.3 - Design, fabricate and installation of EGR control system. The application of cooled EGR has been demonstrated as effective approach of suppressing the onset of knock of S.I. engine operated on stoichiometric mixture. The research engine employed in this a nominal $50 \mathrm{kWe}$ single cylinder engine located at GTI that is configured and capable of operated either lean combustion or stoichiometric with EGR valve and EGR cooler. WVU will send research assistants to GTI to conduct testing under the technical direction of GTI consultant Dr. Daniel Mather of Digital Engines, LLC. Testing will evaluate the effect of cooled EGR on NOx emissions and the onset of knock. WVU will design and evaluate proper EGR strategies for best engine performance and emission characteristics while suppressing the onset of knock. Results with be compared with the currently preferred lean burn configuration used for opportunity fuels.

Subtask 4.4 - Development of engine control system. The aforementioned research engine will operated on stoichiometric mixture of low BTU gaseous fuels. The development of suitable engine control system is crucial to engine optimization in both engine performance and exhaust emissions. WVU proposes to develop an innovative engine control system aiming of the optimized control of EGR rate and ignition timing. The signal of $\mathrm{O}_{2}$ concentration in exhaust gas, variation in fuel heating value measured by a GQS, engine load and the tendency to knock will be used as input signal. The output signal of the engine controller will include EGR rate and optimized spark timing. In this research, the tendency to knock will be detected either by a fast response thermocouple embedded in the engine combustion chamber or knock sensor installed on engine block. The engine control system developed will also be used to optimize the exhaust gas composition required by a three-way catalyst to minimize the emissions of $\mathrm{NO}_{\mathrm{x}}, \mathrm{CO}$ and unburned hydrocarbon.

Subtask 4.5 - Prototype engine controller design and evaluation WVU will support GTI in designing the prototype engine controller and its evaluation in the GTI laboratory. It is expected that prototype engine controller will include: 1) BTU sensor for detecting the variation of the heating value of gaseous fuels; 2) Cooled EGR system; 3) Engine Control System; 4) After-treatment system; 5) $\mathrm{O}_{2}$ sensor installed in exhaust system; 6)Knock detection system and its suppression strategies. WVU will support GTI in integrating these systems and evaluate their response to engine operating conditions.

Subtask 4.6 Experimental Testing and Analysis. The experiment will be conducted in GTI's engine research laboratory. WVU will analyze the experimental data to derive its 
combustion and emission characteristic. These data will be interpreted to provide better understanding to the combustion process of the low BTU gaseous fuels and serve as basis for $\mathrm{Go} / \mathrm{No}$ Go decision on further testing of prototype engine controller.

\section{Task 5.0 Prototype Commercial Gas Quality Sensor for Opportunity Fueled Engines}

Subtask 5.1 - Integration of subsystems Collaborate with commercialization partner for Gas Quality Sensor, to incorporate software and hardware into an integrated prototype system for operation on biogas opportunity fuel compositions.

Subtask 5.2 - Prototype testing and validation Test commercial prototype system in laboratory to validate performance and to confirm that satisfies requirements for biogas fueled reciprocating engines.

PHASE 2

Task 6.0 Field Evaluation of Integrated fuel gas cleanup with heat recovery on $1 \mathrm{MWe}$ engine with cooled EGR and Advanced Engine Monitoring and Control System for Opportunity Fuel

Subtask 6.1 Equipment installation and shakedown Install advanced engine controller at the host site. Complete start-up and commissioning testing.

Subtask. 6.2 Long-term monitoring plan. Develop Long-Term Monitoring Plan (LTMP) consistent with appropriate DOE recommended protocols. Provide continuous emissions monitoring system (CEMS).

Subtask 6.2 Complete 500 hour performance test. Monitor CHP engine-system performance for $\approx 500$ hours.

\section{Task 7.0 Reporting}

Prepare and submit required Quarterly “Technology Status Assessment,” and Final reports.

\section{Task 8.0- Project Management and Planning.}

Establish and maintain a project management plan to ensure timely achievement of milestones within approved budgets. 


\section{Task 2- DEVELOPMENT OF GAS QUALITY SENSOR FOR OPPORTUNITY FUELS}

\section{1- Development of GQS Specifications for Landfill Gas}

\subsubsection{Carbon dioxide detection capability of gas quality sens or}

To investigate carbon dioxide detection capabilities, the near infrared absorption spectra for methane and carbon dioxide were measured using a NIR spectrometer at a pressure of 1.01 bar (1 atm), temperature of $300 \mathrm{~K}$ for $30 \mathrm{~cm}$ path length. The spectrometer has $12.5 \mathrm{~nm}$ full width at half maximum. The synthetic molecular spectra for methane, carbon dioxide, carbon monoxide were generated using the LINEPAK algorithm. All the synthetic spectra were generated at a pressure of 1.01 bar (1 atm), temperature of $296 \mathrm{~K}, 30 \mathrm{~cm}$ path length, using instrument width of $12.5 \mathrm{~nm}$ and truncated Gaussian function. Figs. 1-5 show the absorbance spectra of methane, ethane, carbon monoxide and carbon dioxide in the spectral region of 1000 to $5000 \mathrm{~nm}$.

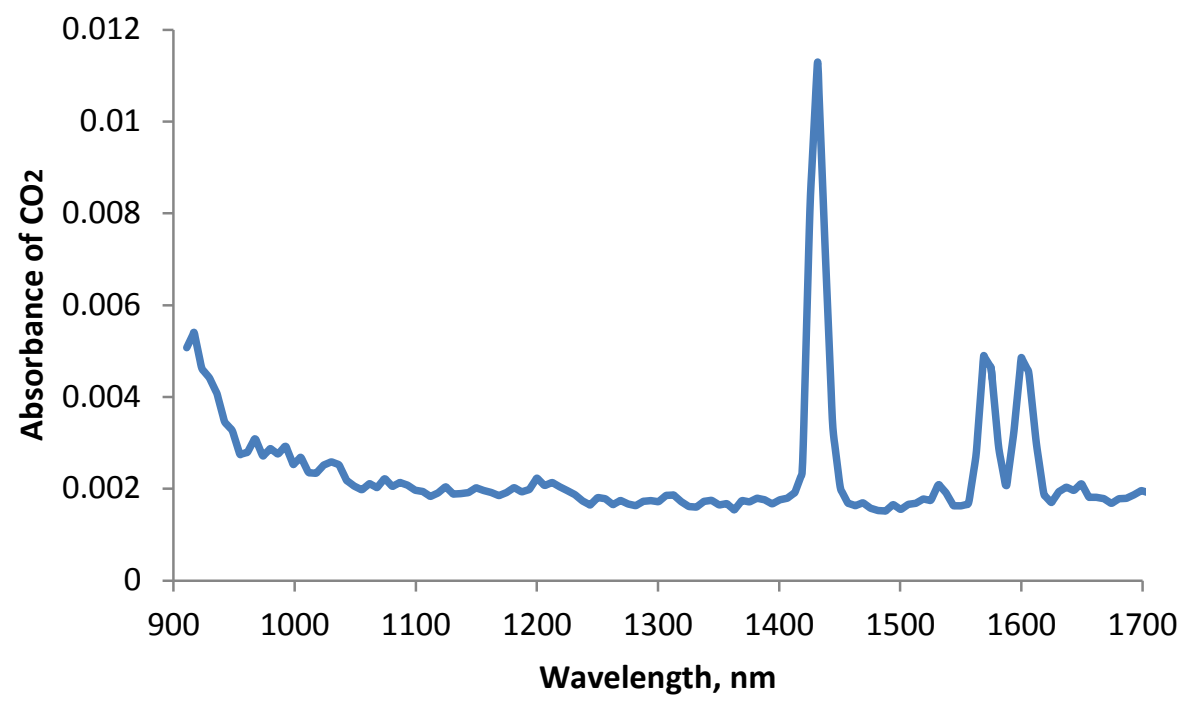

Figure 1 Absorption of carbon dioxide. 


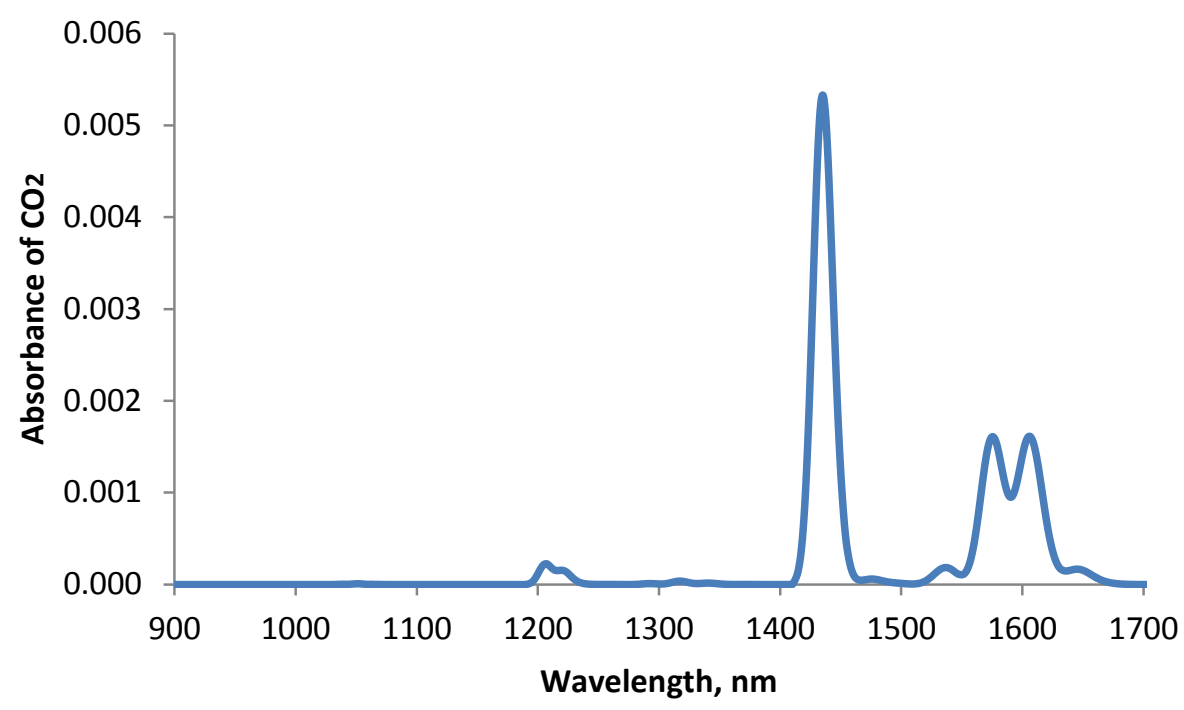

Figure 2 Synthetic absorption spectra of carbon dioxide.

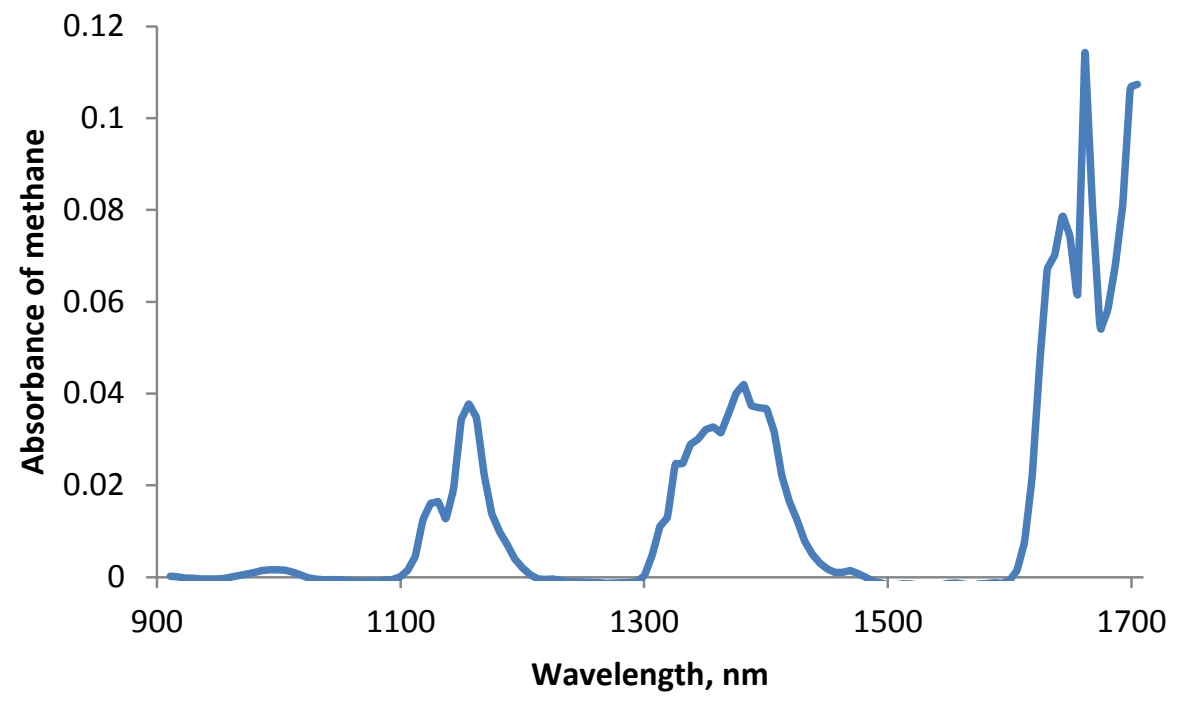

Figure 3 Absorption of methane. 


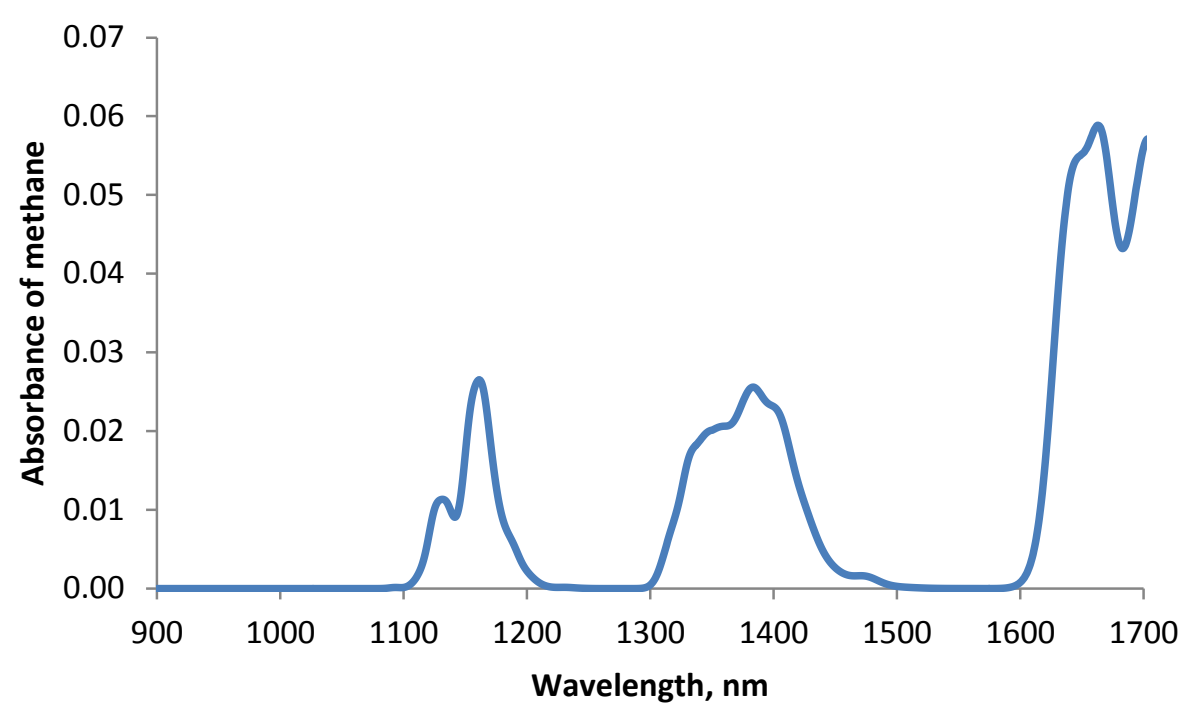

Figure 4 Synthetic absorption spectra of methane

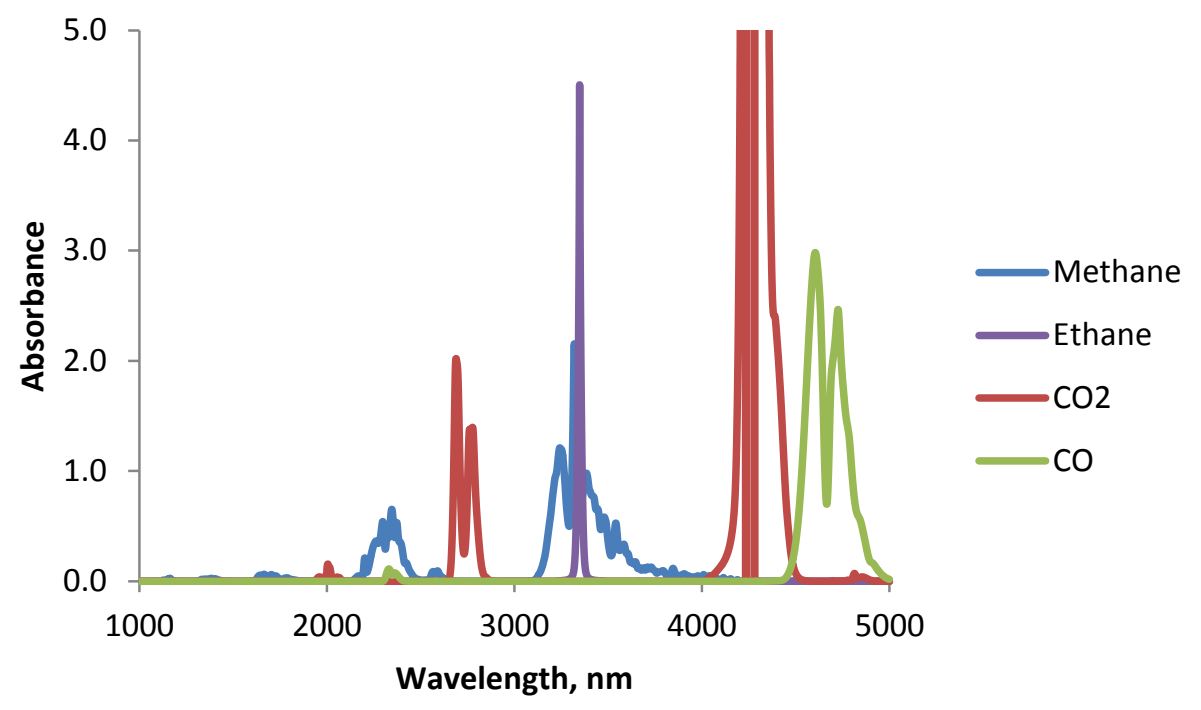

Figure 5 Synthetic absorption spectra of methane, ethane, carbon dioxide and carbon monoxide

From Fig. 5, it is clear that methane and carbon dioxide have distinct absorption bands in the nearinfrared region (spectral region of 900 to $5000 \mathrm{~nm}$ ). These characteristics can be utilized to detect carbon dioxide present in a natural gas mixture.

Fig. 6 shows the IR absorption spectra of pure species - methane, ethane, propane, butane and carbon dioxide obtained using the PNNL database in the spectral range of $1500 \mathrm{~nm}$ to $5000 \mathrm{~nm}$ for 1 ppm-meter concentration of each individual component at a pressure of $1 \mathrm{~atm}$ and a temperature of $296 \mathrm{~K}$. The PNNL database contains the high-resolution $\left(0.1 \mathrm{~cm}^{-1}\right)$ quantitative pressure-broadened infrared spectra of several hundred gas-phase compounds. The spectral resolution is sufficient to bring out all sharp features.

From Fig. 6, it is clear that hydrocarbons and carbon dioxide have distinct absorption bands in this spectral range. They have higher absorption in $2000 \mathrm{~nm}-3000 \mathrm{~nm}$ and $3000 \mathrm{~nm}-4000 \mathrm{~nm}$ range than in a range of $1000 \mathrm{~nm}-2000 \mathrm{~nm}$, since these are the second and third harmonics. Hydrocarbons have good absorption bands at approximately $2400 \mathrm{~nm}$ and $3350 \mathrm{~nm}$. Fig. 7 shows the absorbance plotted on a logarithmic scale. This gives a clearer picture of all the individual absorption bands. It can be seen that 
absorption spectra of propane and butane are quite similar in the entire spectral range. Table 1 lists the peak absorbance values and corresponding wavelengths for various components.

Table 1 Peak absorbance values and corresponding wavelengths in IR for natural gas components at 1 ppm-meter, $1 \mathrm{~atm}$ and $296 \mathrm{~K}$.

\begin{tabular}{|c|c|c|}
\hline Component & Wavelength, $\mathbf{n m}$ & Absorbance \\
\hline Methane & 3240 & 0.00200 \\
\hline Ethane & 3348 & 0.00226 \\
\hline Propane & 3369 & 0.00123 \\
\hline Butane & 3371 & 0.00089 \\
\hline $\begin{array}{c}\text { Carbon } \\
\text { Dioxide }\end{array}$ & 4234 & 0.01578 \\
\hline
\end{tabular}

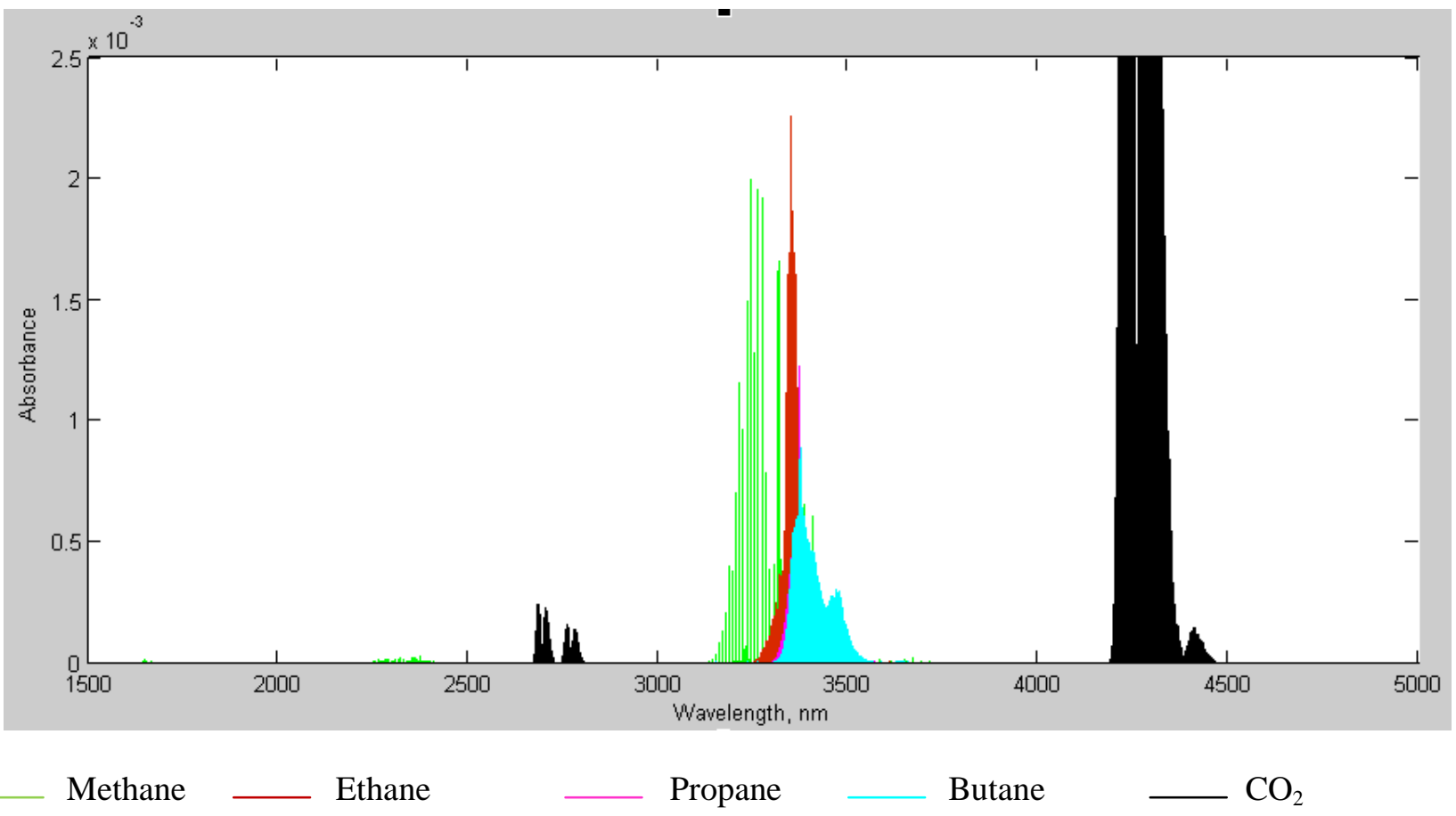

Figure 6. Absorbance of natural gas components (1 ppm-meter, $296 \mathrm{~K}$ ) in IR from PNNL database. 


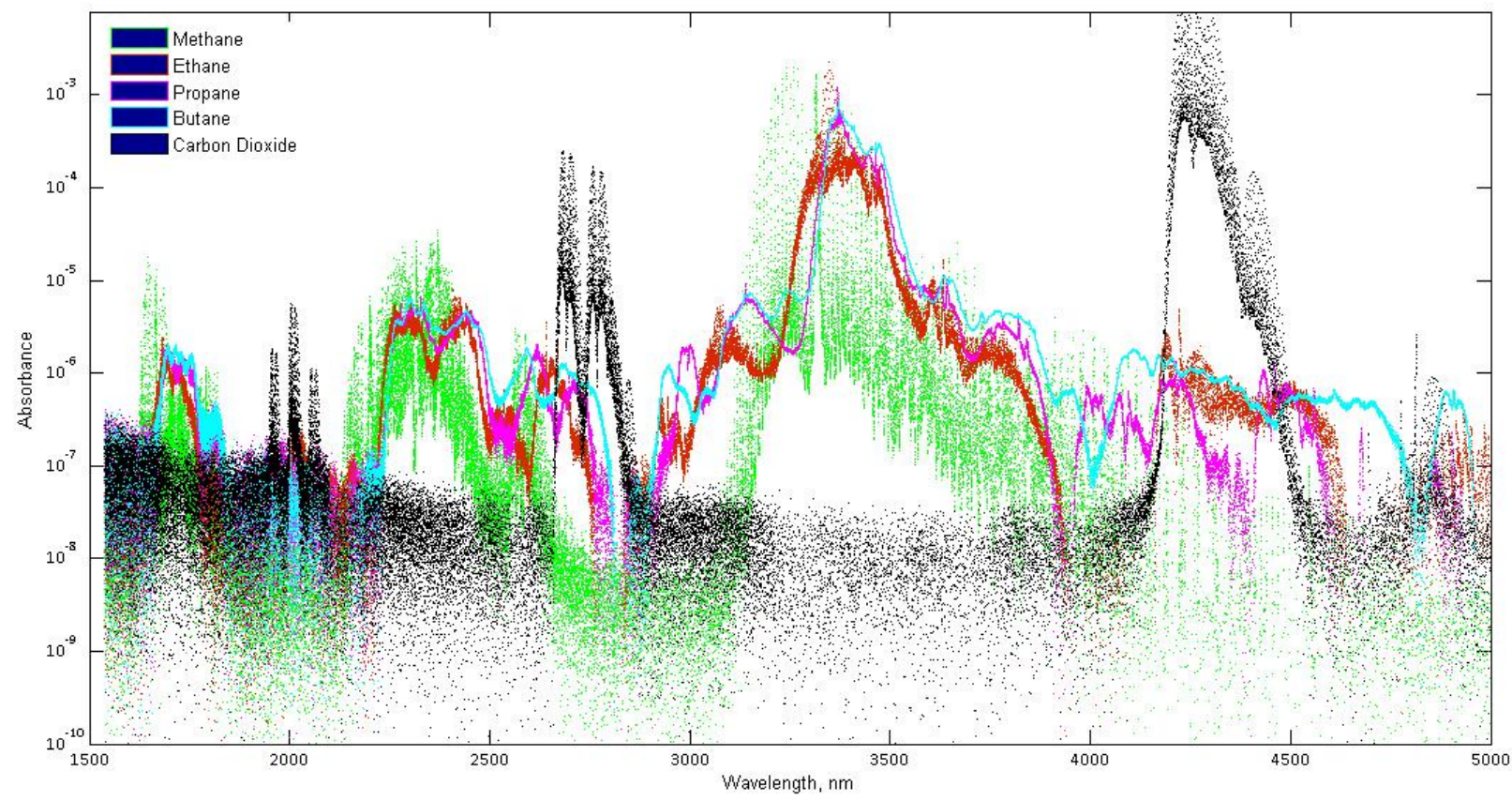

Figure 7. Absorbance of natural gas components (1 ppm-meter, $296 \mathrm{~K})$ on logarithmic scale in IR from PNNL database.

Thus, the spectral ranges $2000 \mathrm{~nm}-3000 \mathrm{~nm}$ or $3000 \mathrm{~nm}-4000 \mathrm{~nm}$ (or the entire $1000 \mathrm{~nm}$ to 4000 $\mathrm{nm}$ range) can be used for simultaneous quantitative detection of all these components.

A series of tests was performed on the spectrometer to check if the absorbance remains constant over a period of few days. Five tests were conducted on each day on two pure gases - carbon dioxide and methane. Only carbon dioxide or methane was passed through the fuel cell at the pressure of one atmosphere and $300 \mathrm{~K}$ temperature and absorbance spectra were recorded. The integration time and sample average were kept constant at 0.0005 seconds and 50 respectively for all the tests on all the days. A graph of absorbance with test number was plotted for selected wavelengths. The wavelengths were selected so as to cover the major absorption bands of the two gases in the near infrared region. Figs. 8 and 9 show these plots for carbon dioxide and methane, respectively. From Fig.8, we can see a continuous drift in the absorbance value during a set of tests conducted on each day. Due to the same reason, from Fig. 9, the absorbance of methane does not remain constant on all the days. Also, the absorbance is found to be negative at some of the wavelengths, e. g., $1560 \mathrm{~nm}$ and $1569 \mathrm{~nm}$ for methane. The absorbance should be zero at these wavelengths. 


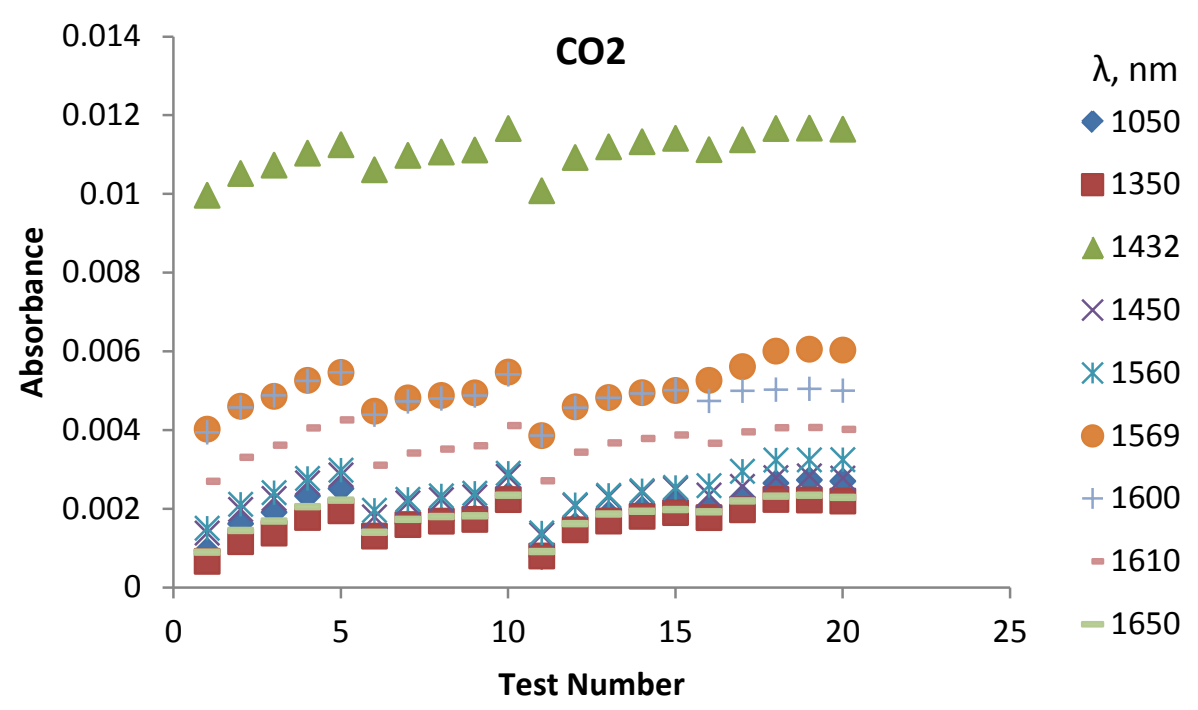

Figure 8. Absorbance of $\mathrm{CO}_{2}$ increases due to spectrometer drift during a set of tests conducted during 4 days ( 5 tests per day).

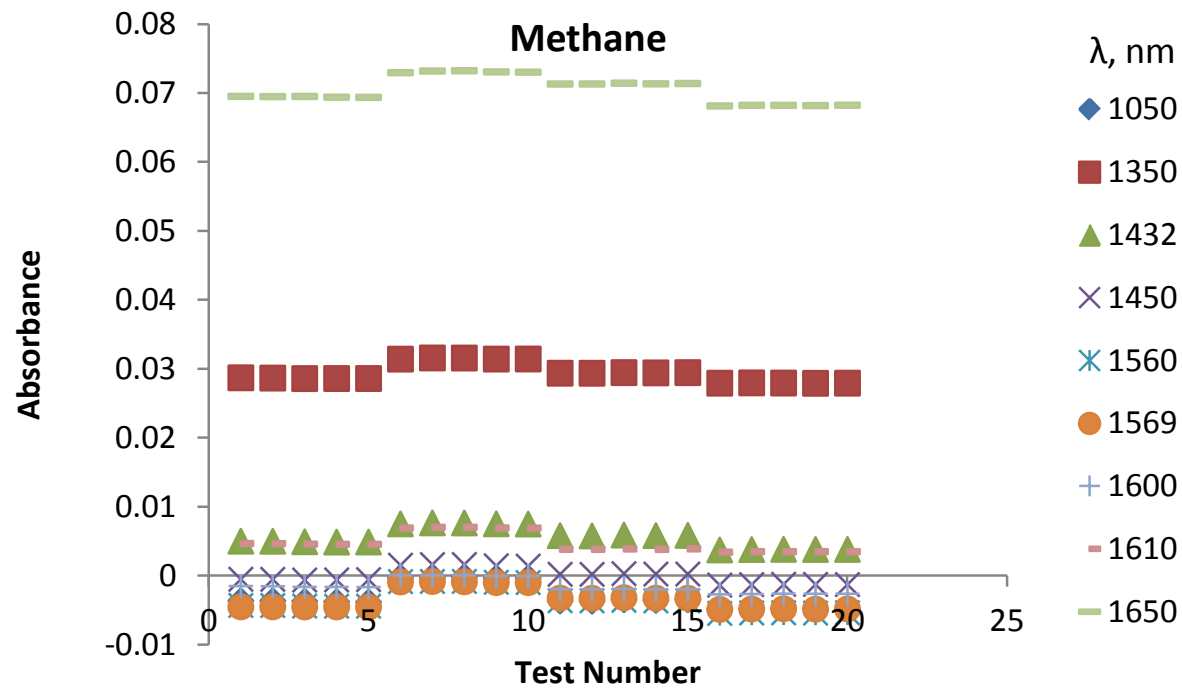

Figure 9. Variation of methane absorbance. 


\section{2-GQS Prototype Development for Landfill Gas}

\subsection{1-Improvement in and support of data acquisition for control software module}

The data acquisition and control software module was modified to improve $\mathrm{CO}_{2}$ detection in the spectral range from 1 to 2 microns. The modifications of the program algorithm involve addition of $\mathrm{CO}_{2}$ calibration and detection capabilities as well as modifications to the concentration prediction and BTU calculation module.

It was proposed to correct a spectrometer drift mathematically in the BTU software; by adding an error to the absorbance values such that the absorbance becomes zero at the wavelengths like $1560 \mathrm{~nm}, 1569$ $\mathrm{nm}$ etc. where carbon dioxide or methane does not absorb light. This error is added to the entire absorbance spectrum and this corrected absorbance spectrum is used as an input to the PCR and PLS methods to predict the concentrations and heating value of natural gas. Eq. (1) can be used the correct the absorbance spectrum. Eq. (2) gives the error in absorbance units (AU) to be added to the entire spectrum.

$$
A_{\text {corrected }}=A_{\text {measured }}+\Delta A
$$

Where

$$
\Delta A=-\left(\frac{\sum A_{\lambda}}{n}\right)
$$

And $A_{\lambda}$ is the absorbance at any wavelength in the considered spectral region if it is less than zero; $n$ is the number of such wavelengths. Figs. 10 and 11 show the graphs of absorbance corrected using Eq. (1) with test number. It can be easily seen that the absorbance becomes constant in all the tests.

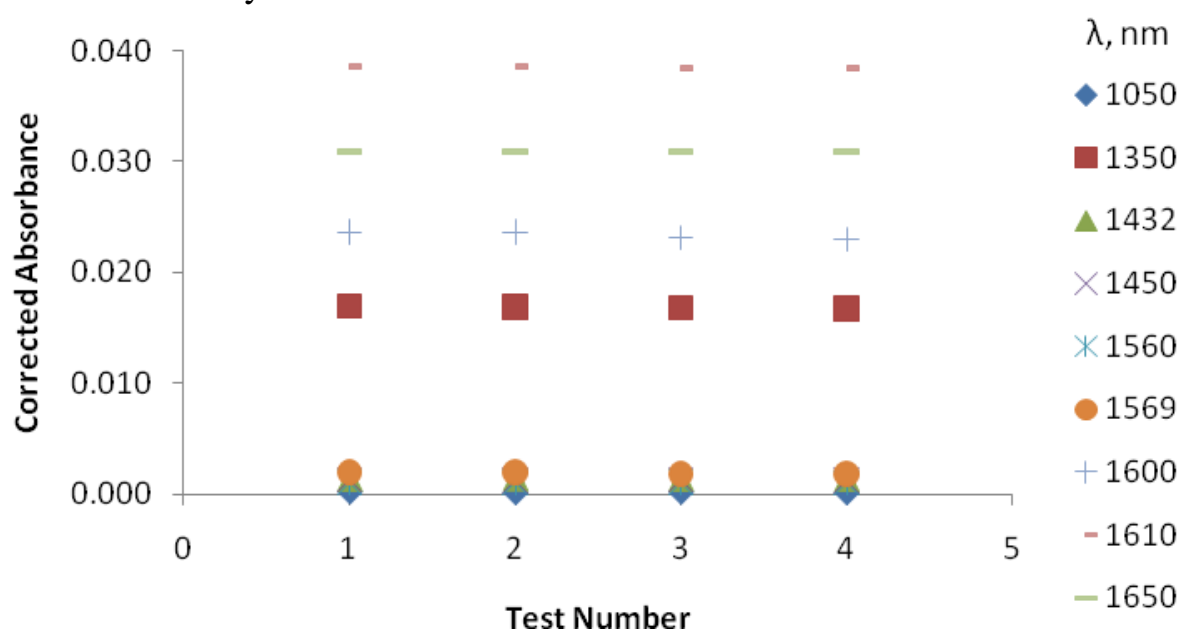

Figure 10. Absorbance of carbon dioxide corrected using Eq. (1).

From Fig. 10 and Fig. 11, it is clear that spectrometer drift can be compensated in the BTU sensor software and stability in the predicted properties of natural gas can be achieved. The wavelengths where the absorbance should be zero are selected carefully and an average value of absorbances at all such wavelengths can be added as an error to the entire absorbance spectrum. 


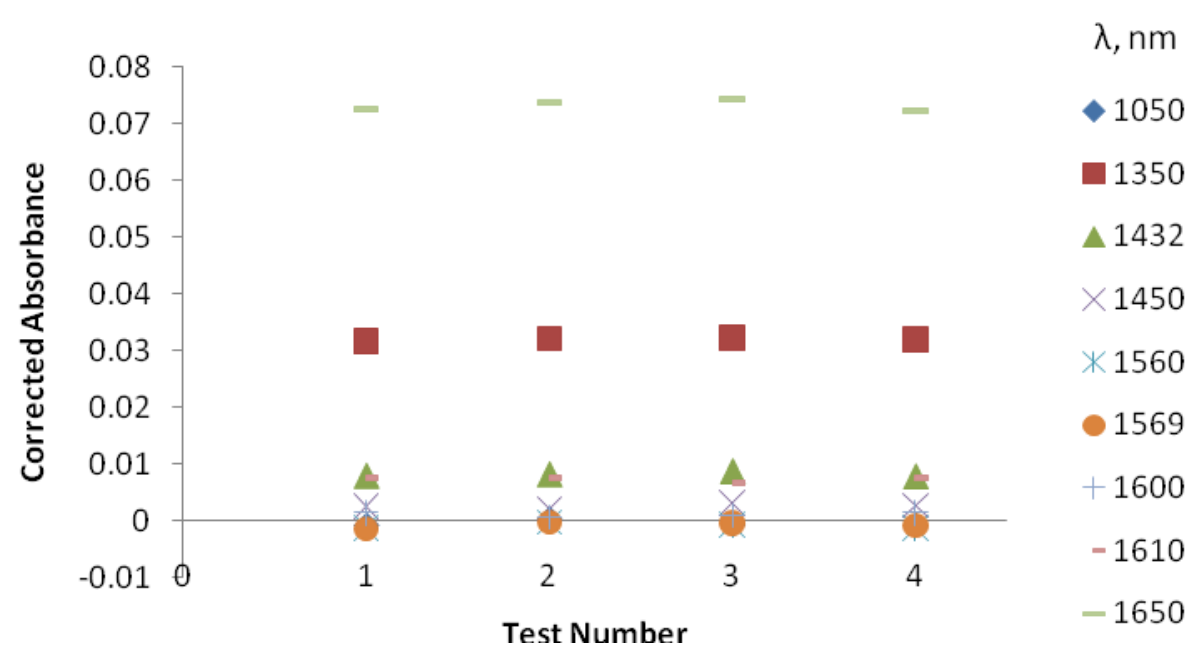

Figure 11. Absorbance of methane corrected using Eq. (1).

\subsection{2-Mathematical model for handling the temporal drift of spectral detector}

An absorption spectrum can be corrected by fitting a polynomial curve to the absorbances measured at non-absorbing wavelengths. The absorbance error can be estimated at each wavelength using the polynomial function. The absorbance spectrum corrected using this method gives more accurate results than simply using the average of absorbances at non-absorbing wavelengths.

Fig. 12 shows the absorption spectrum of carbon dioxide measured in a stability test. The spectrum is recorded in the wavelength range of $911 \mathrm{~nm}$ to $1705 \mathrm{~nm}$. Carbon dioxide has absorption peaks near $1200 \mathrm{~nm}, 1432 \mathrm{~nm}, 1569 \mathrm{~nm}$ and $1600 \mathrm{~nm}$. Apart from these absorption bands, at non-absorbing wavelengths, the absorbance should be zero. Fig. 13 shows the ideal (synthetic) absorption spectrum of carbon dioxide. This spectrum is calculated using the infrared absorption cross sections provided in the HITRAN 2008 database for the same set of parameters, one atmospheric pressure and a temperature of $300 \mathrm{~K}$.

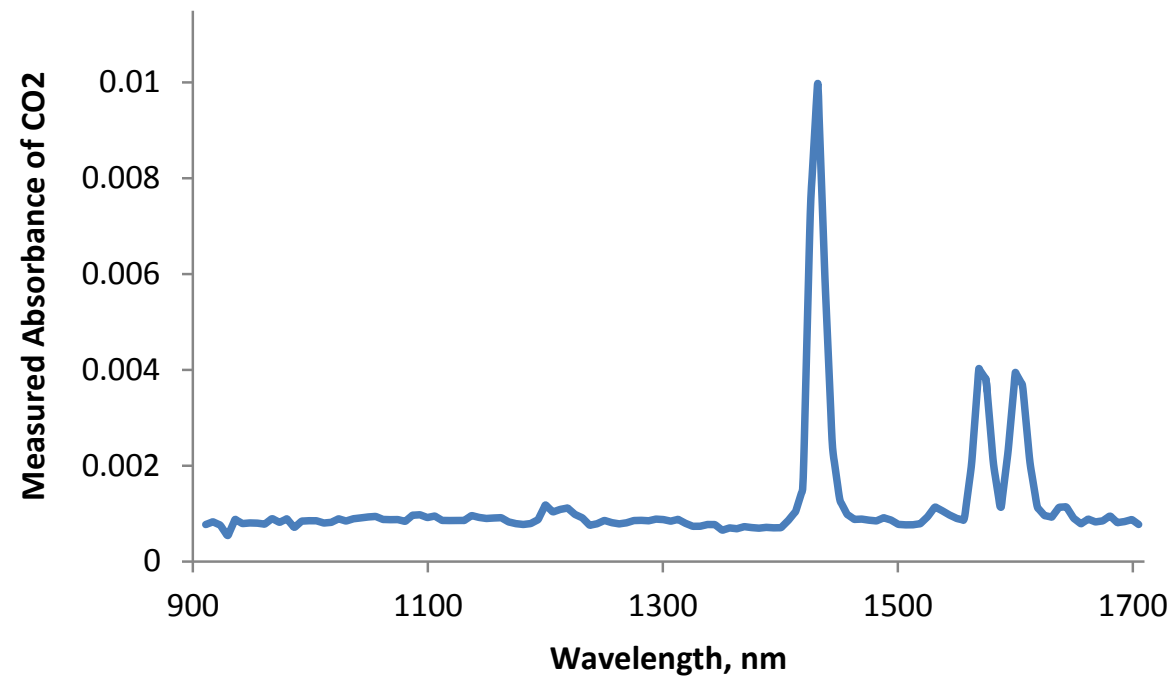

Figure 12. Measured absorption spestrum of carbon dioxide. 


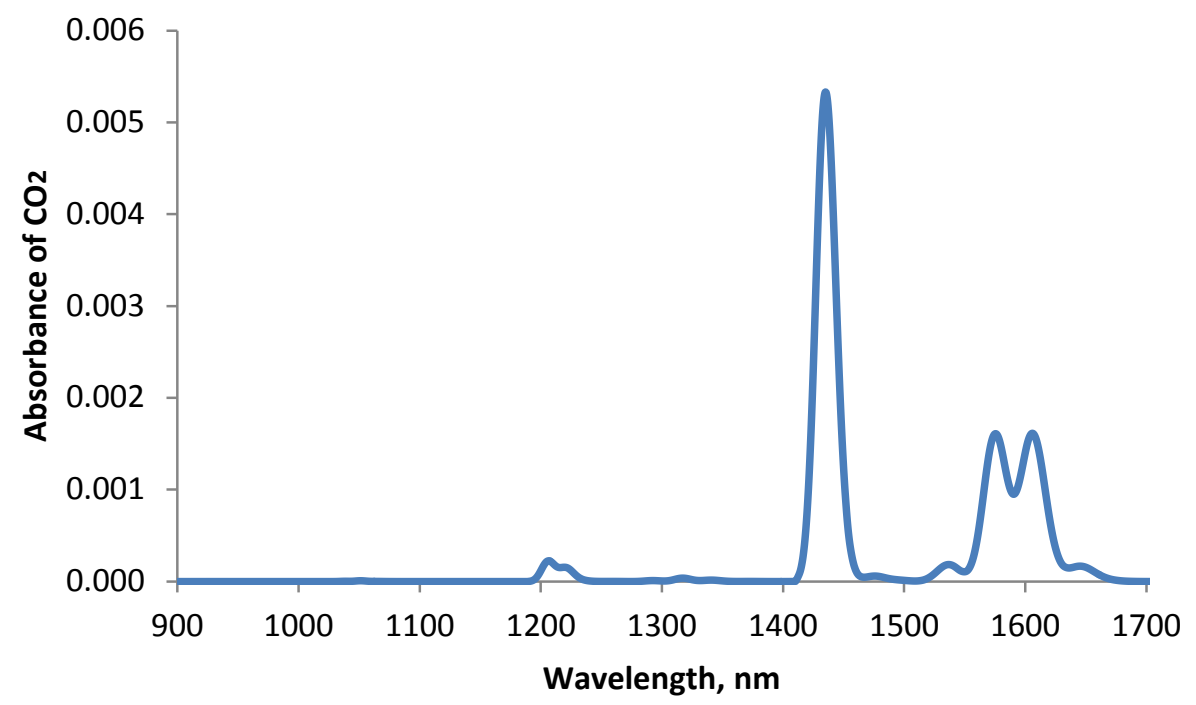

Figure 13. Synthetic absorption spectrum of carbon dioxide.

From Fig. 12 and Fig. 13, it is clear that the entire absorbance spectrum is shifted upwards. This is a result of the detector drift, background noise, light source temperature fluctuations, and, hence, light intensity variation. Thus, the amount of upward or downward shift of the spectrum depends upon several factors, for example, the duration for which the spectrometer and/or light source is continuously running. In order to achieve stability in predicting the fuel properties, this absorbance spectrum needs to be corrected. The absorbance error can be calculated in several ways depending upon the desired accuracy and complexity level. An average value of absorbances at non-absorbing wavelengths can be considered as the absorbance error. Alternatively, a polynomial curve can be fitted to the absorbances measured at non-absorbing wavelengths. This polynomial function can then be utilized to calculate absorbance error at each wavelength. It is found that a polynomial function gives better prediction of the absorbance error. Fig. 14 shows a $9^{\text {th }}$ order polynomial curve fitted to absorbances at non-absorbing wavelengths. This function gives the error at each wavelength that needs to be subtracted from measured absorbance to get true absorbance. Fig. 15 shows the measured absorbance spectra and absorbance spectra corrected using polynomial function. The corrected absorbance spectrum (shown in Fig. 15) closely resembles the synthetic spectrum of carbon dioxide (shown in Fig. 13). From Fig. 16, we can compare the results of both methods - polynomial curve fitting and linear average. It is clear that the polynomial curve fitting gives better estimate of absorbance error. 


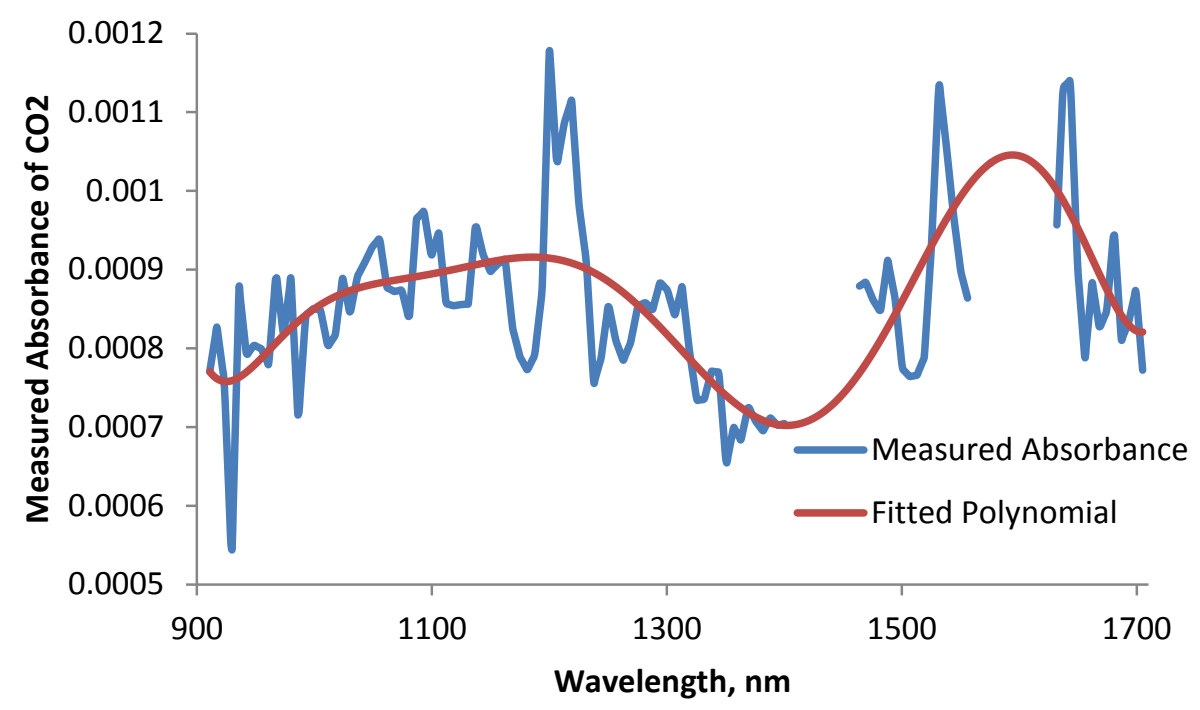

Figure 14. A polynomial curve fitted to the absorbances measured at non-absorbing wavelengths.

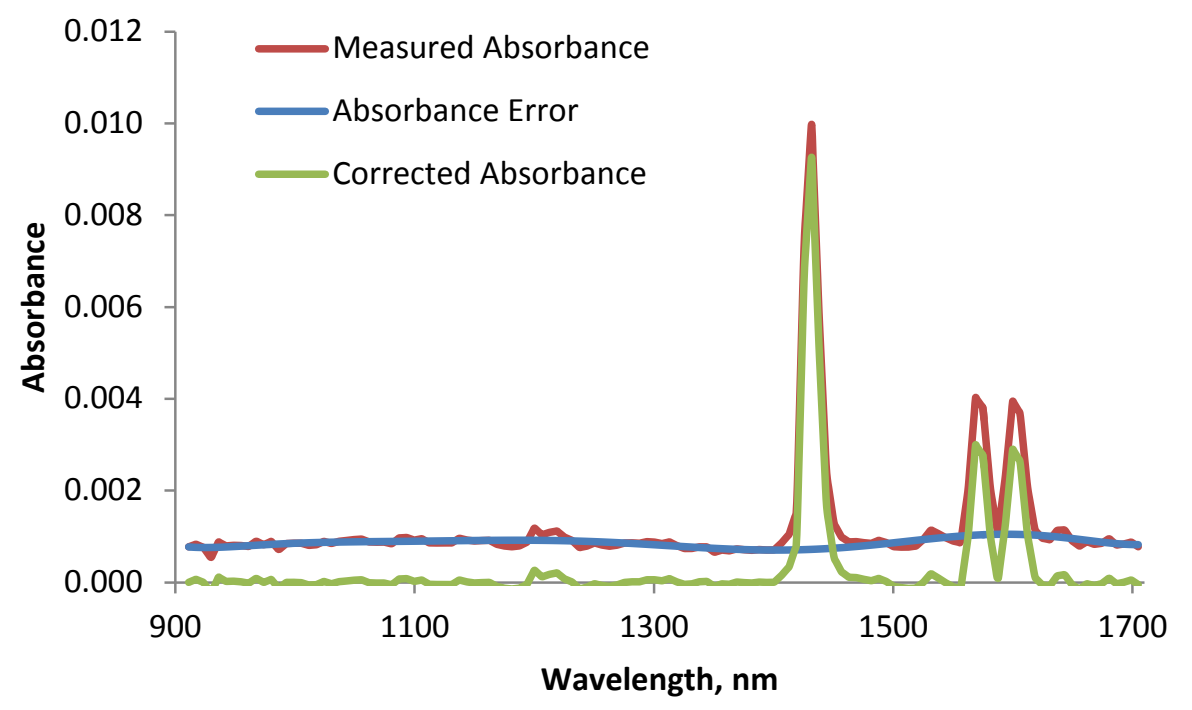

Figure 15. Absorbance correction using polynomial curve fitting. 


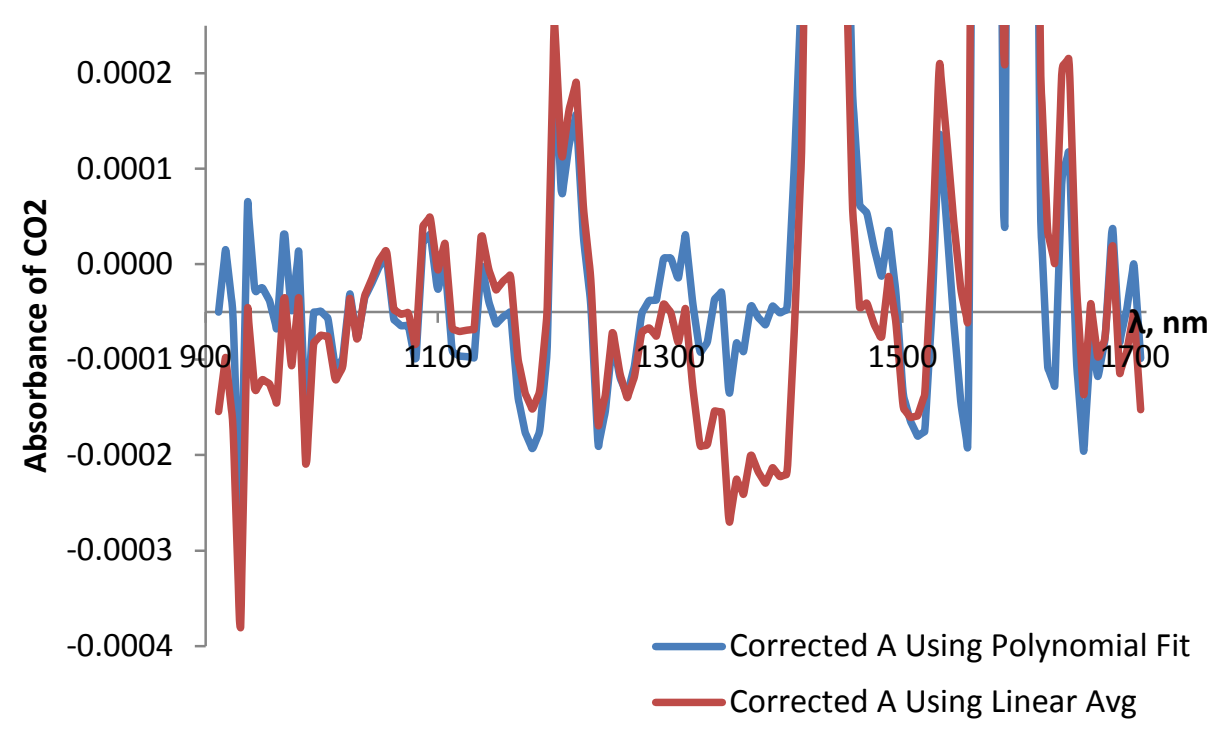

Figure 16. Comparison of absorption spectra corrected using polynomial function and linear average.

\subsubsection{Modifications of the GQS software}

GQS software was modified to improve Mass Flow Control section of the software. This section is frequently used during sensor testing and calibration. The improved version of the software is operator friendly, incorporates automatic savings of the last controller settings, and also automatically stores the calibration settings that can be further recalled on demand.

The planned GQS software modification was performed by Mr. Rumega, original developer of the software. Overall goal of the software modification was to streamline software logic that was partially violated during the implementation of software by other developers. For example, modification of pressure and temperature correction and temperature measurements led to some minor unpredictable delays in program execution. The specific implemented tasks are listed below:

- Add needed functionality and correspondingly modify graphic interface to add $\mathrm{CO}_{2}$ measurement capabilities and to improve sensor stability

- Add automatic logging of the calibration temperature and pressure

- Add optional automatic logging of the cell temperature and temperature correction algorithm operating in a real time mode

- Make GQS software operator friendly by optimizing "Excel Import/Export" section in "Configuration and Calibration" and by creating "Group" function in the flow control subroutine.

- Modify software to work with Hamamatsu spectrometer

The modifications of the mass flow control subroutine are reflected in Fig. 17. 


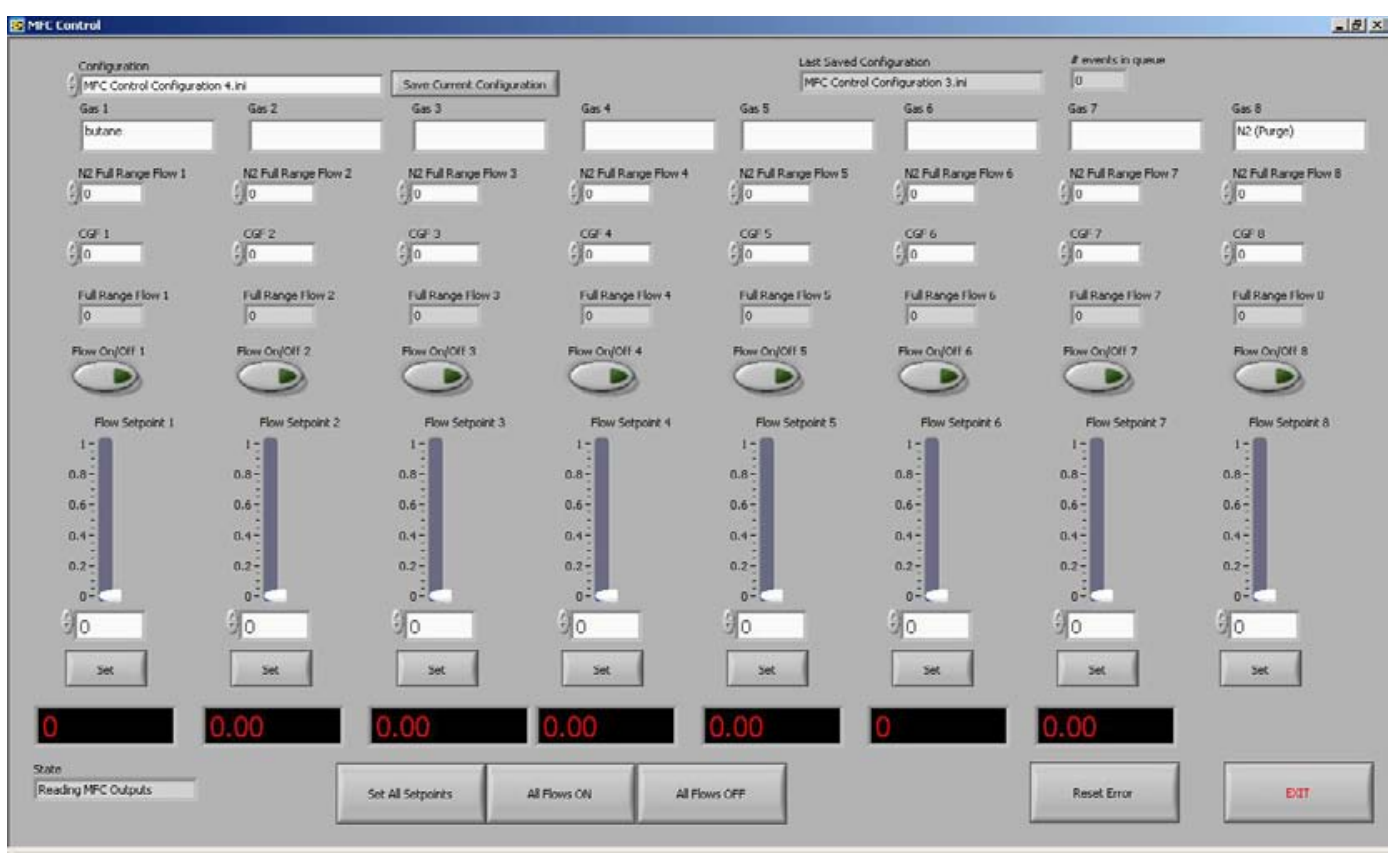

Figure 17. Screenshot of the MFC control screen.

The GQS software was also updated to include the temporal drift correction algorithm. The absorbance values need to be corrected to account for optical instabilities such as variation in light source temperature, reference intensity, detector sensitivity drift and background noise. The absorbance values at non-absorbing wavelengths are utilized to quantify the error due to these instabilities as illustrated previously. These absorbance errors are utilized to calculate the true absorbance spectrum. Fig. 18 shows the absorption spectra from which non-absorbing wavelengths are selected.

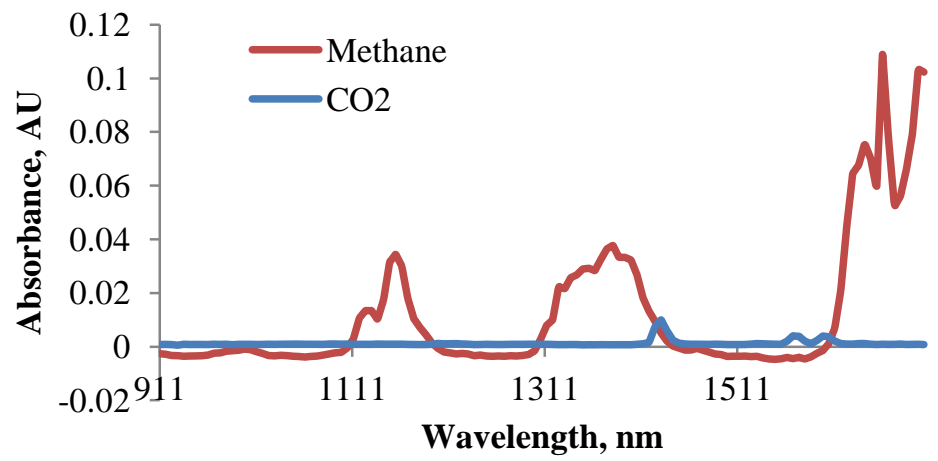

Figure 18. Absorption spectra of methane and carbon dioxide.

Table 2 shows the non-absorbing wavelength ranges selected and the number of wavelengths in each of these ranges. The detector array has 128 elements and a linear dispersion $6.25 \mathrm{~nm} /$ pixel. A total of 173 wavelengths out of 795 wavelengths are taken into consideration to estimate the absorbance error. The order of polynomial is selected as 9, considering computational complexity and time. Also the number of wavelengths is very large compared to the order of polynomial, improving the probability of a minimum residual error and the best fit. 
Table 2. Non-absorbing wavelength ranges selected for polynomial fitting.

\begin{tabular}{ccc}
$\lambda_{1}$ & $\lambda_{2}$ & $\begin{array}{c}\text { Number of } \\
\text { wavelengths }\end{array}$ \\
\hline 911 & 950 & 40 \\
1070 & 1100 & 31 \\
1250 & 1300 & 51 \\
1500 & 1550 & 51 \\
\hline
\end{tabular}

Total number of wavelengths

A $9^{\text {th }}$ order polynomial is fitted to the absorbance values at these selected wavelengths by minimizing the mean squared error and the best fit polynomial coefficients are utilized to calculate the absorbance error $A^{*}(\lambda)$ at each wavelength in the considered wavelength range $(911 \mathrm{~nm}$ to $1705 \mathrm{~nm})$. The absorbance error $A^{*}(\lambda)$ is then subtracted from the measured absorbance $A^{\prime}(\lambda)$ to get true absorbance $A(\lambda)$.

$$
A(\lambda)=A^{\prime}(\lambda)-A^{*}(\lambda)
$$

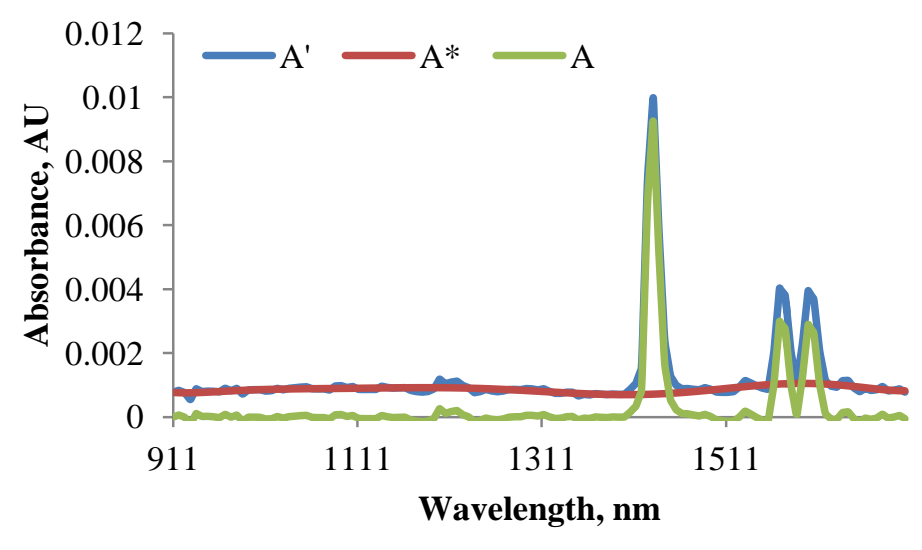

Figure 19. Absorption spectrum of carbon dioxide corrected using Eq. (3). 


\section{3-GQS Calibration and Bench Testing for Landfill Gas}

\subsection{1-Minimizing the GQS calibration requirements}

Calibration requirements for the gas quality sensor were analyzed. As already reported, the NIR spectra of hydrocarbons and carbon dioxide are linear with density in the considered pressure range. This linearity suggests that a calibration data set containing the NIR spectra of pure gases, viz., methane, ethane, propane, butane and carbon dioxide, should be adequate for predicting the properties of gas mixtures.

In order to study the feasibility of calibrating the gas quality sensor with pure species, we need to verify and validate the reproducibility of spectra of mixtures using the spectra of pure species. The NIR spectra of pure carbon dioxide and binary mixtures of CP grade carbon dioxide and CP grade nitrogen were recorded. The mixtures were prepared using MKS mass flow control system. The mixtures were prepared using $75,50,25,10,5$ and $1 \%$ carbon dioxide by volume and balance nitrogen. The mixture flow rate was maintained constant at 1000 SCCM (standard cubic cm per minute). The total pressure of each mixture was constant during the experiment at approximately 14.3 psi. The background and reference intensity are acquired before measuring the spectrum of each mixture. The recorded spectra were corrected to standard pressure $(14.7 \mathrm{psi})$ and temperature $(293.15 \mathrm{~K})$. The spectra were also corrected using the drift correction algorithm. Carbon dioxide has absorption bands in 1180 to $1230 \mathrm{~nm}$, 1400 to 1450 and 1525 to $1650 \mathrm{~nm}$. A $9^{\text {th }}$ order polynomial is fitted to the absorbances measured at all the other wavelengths in the considered range of 911 to $1705 \mathrm{~nm}$ and absorbance error is calculated. The absorbance errors are subtracted from the measured absorbances to get true absorbances at respective wavelengths. In order to compute the spectrum of a mixture, the spectrum of pure carbon dioxide is weighted using the volume fraction of carbon dioxide in that mixture.

Fig. 20 shows the measured and calculated absorption spectra of three mixtures containing 75, 50 and $25 \%$ carbon dioxide and balance nitrogen. For the other three mixtures, which contained 10, 5 and 1\% carbon dioxide, the absorption of carbon dioxide goes to a very low level and noise becomes comparable to the absorption signal. Hence, these spectra are not shown in Fig. 20. It can be seen that the absorption of carbon dioxide decreases with decreasing volume fraction of carbon dioxide in the mixture.

It is clear that the spectra of binary mixtures of carbon dioxide and nitrogen are well reproducible using the spectrum of pure carbon dioxide. This is applicable to mixtures of methane, ethane, propane, butane and carbon dioxide as well. The sum of the weighted spectra of pure species gives the spectrum of a mixture. 

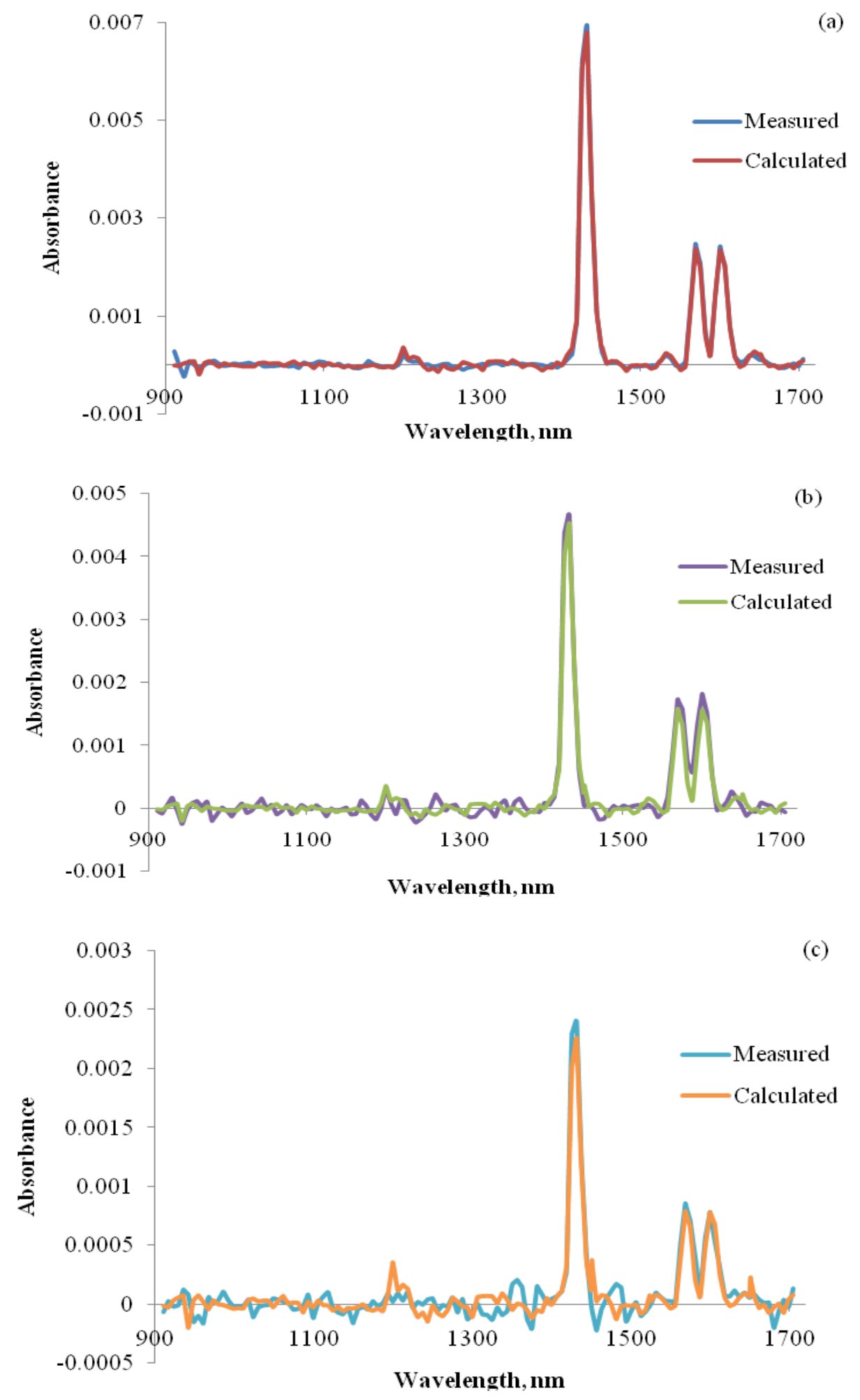

Figure 20. Comparison of measured and calculated NIR absorption spectra of binary mixtures of (a) $75 \%$ (b) $50 \%$ (c) $25 \%$ carbon dioxide and balance nitrogen. 


\subsection{2-Testing of Long-term drift with GQS measurements}

From earlier field testing results, it was found that the drift correction using polynomial fitting method did not have expected repeatability in the predicted results. This was probably because of the lack of nonabsorbing wavelengths at uniform spectral intervals in the considered range. The drift correction algorithm was again updated to improve accuracy in the estimated absorbance error. The polynomial fitting method was completely removed from the program. The minimum absorbance in the spectrum is assumed to be the absorbance error and is subtracted from all the absorbances to achieve a stable absorption spectrum at all times. If $A_{0}(\lambda)$ is absorbance measured at a wavelength $\lambda$, and $A_{\min }$ is the minimum value of measured absorbance in the entire considered spectrum, then true absorbances $A_{c}(\lambda)$ are estimated using Eq. (4).

$$
A_{c}(\lambda)=A_{0}(\lambda)-A_{\text {min }}
$$

Fig. 21 compares the GQS and GC measurements over a period of one hour (short-term) and Fig. 22 compares those measurements during a complete day (long-term). The data shows that the GQS predicted methane concentrations deviate by $\pm 0.5 \%$ compared to the GC measurements. However, for carbon dioxide, this deviation is approximately $\pm 5 \%$. It seems that the error is primarily due to spectrometer drift. The large error associated with carbon dioxide concentration can be attributed to its low absorption signal and statistical analysis needs to be done to check if the accuracy can be improved further. 


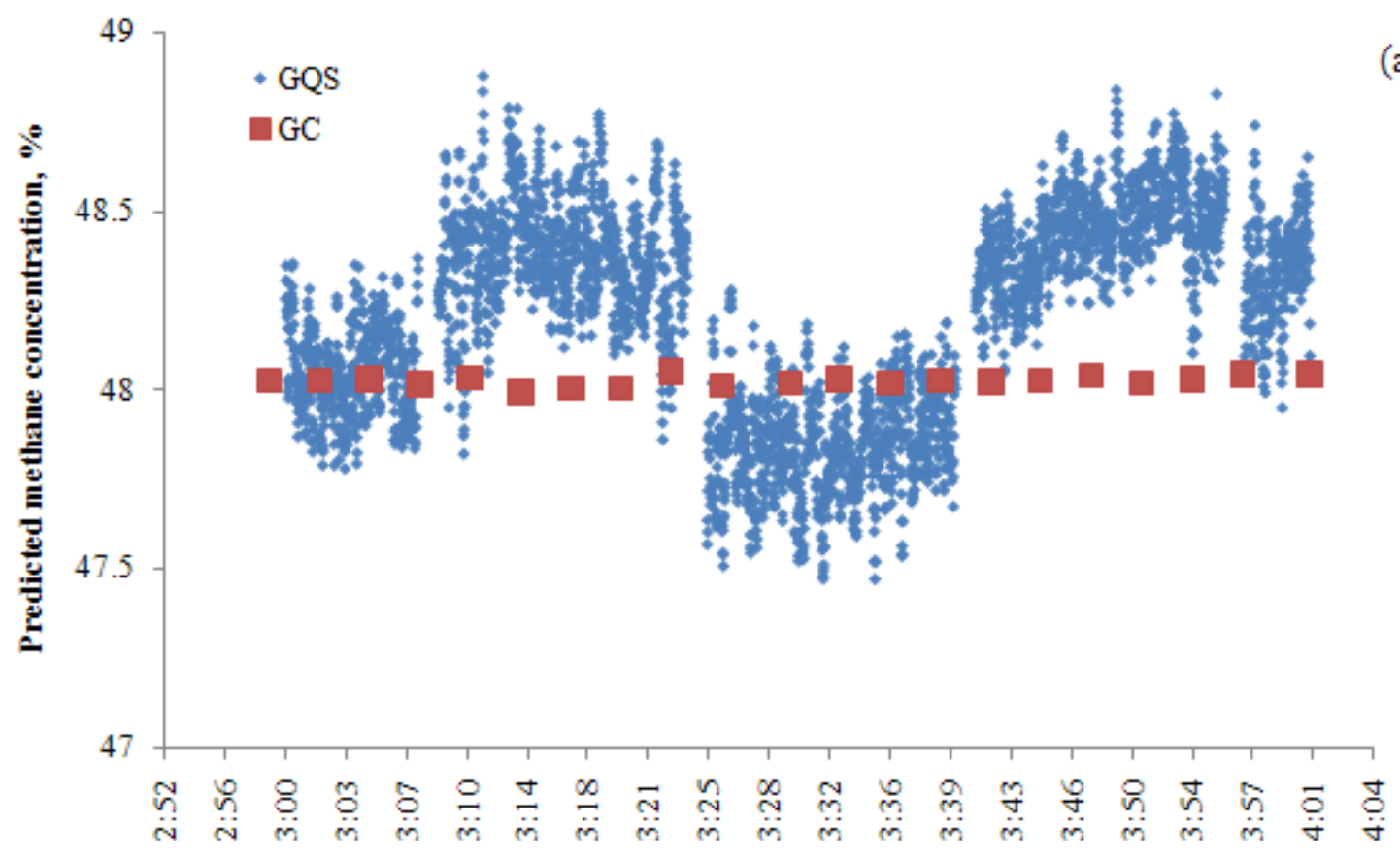

(a)

Time,hh:mm

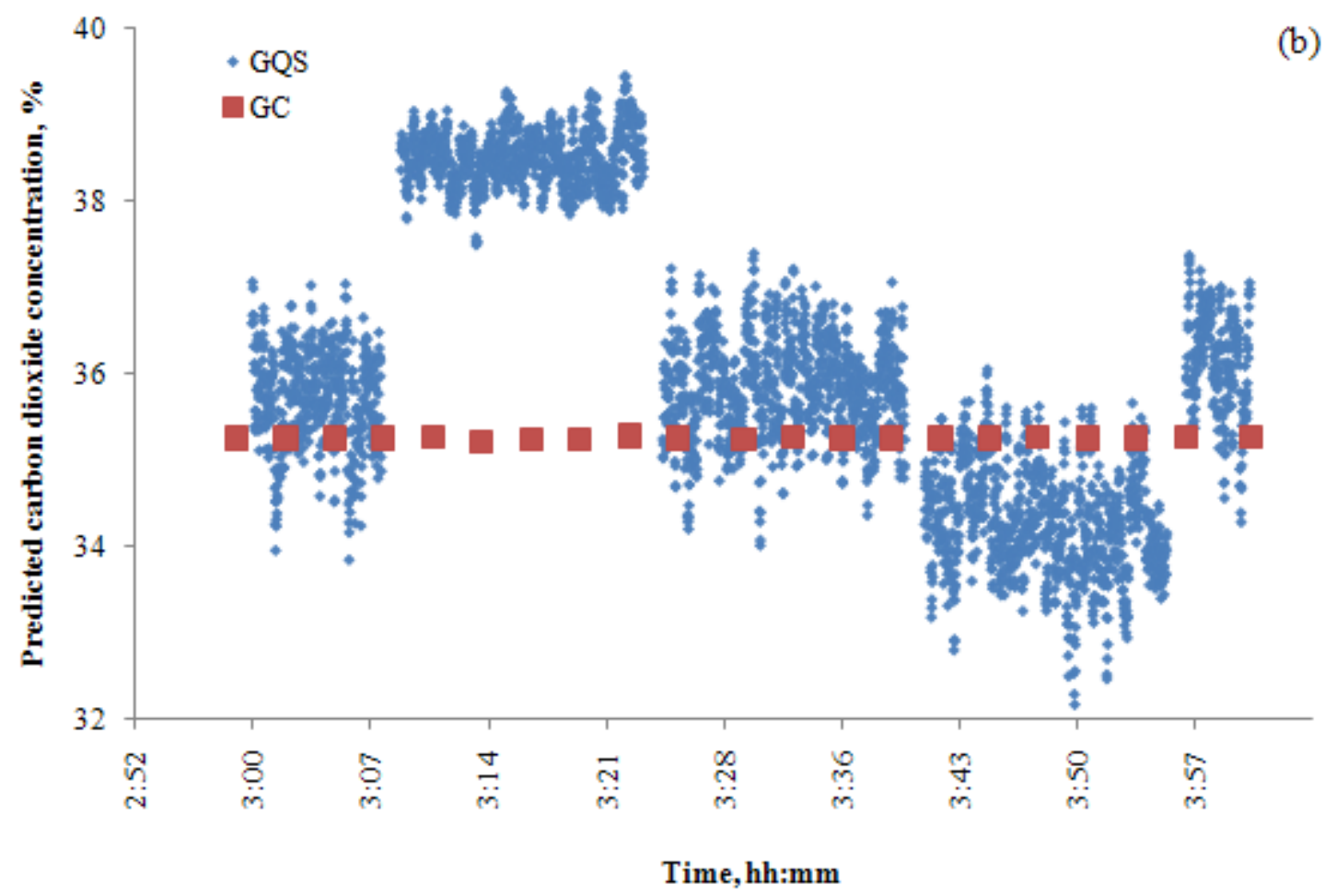

Figure 21. Comparison of GQS and GC measurements over a period of one hour: (a) methane, (b) carbon dioxide. 


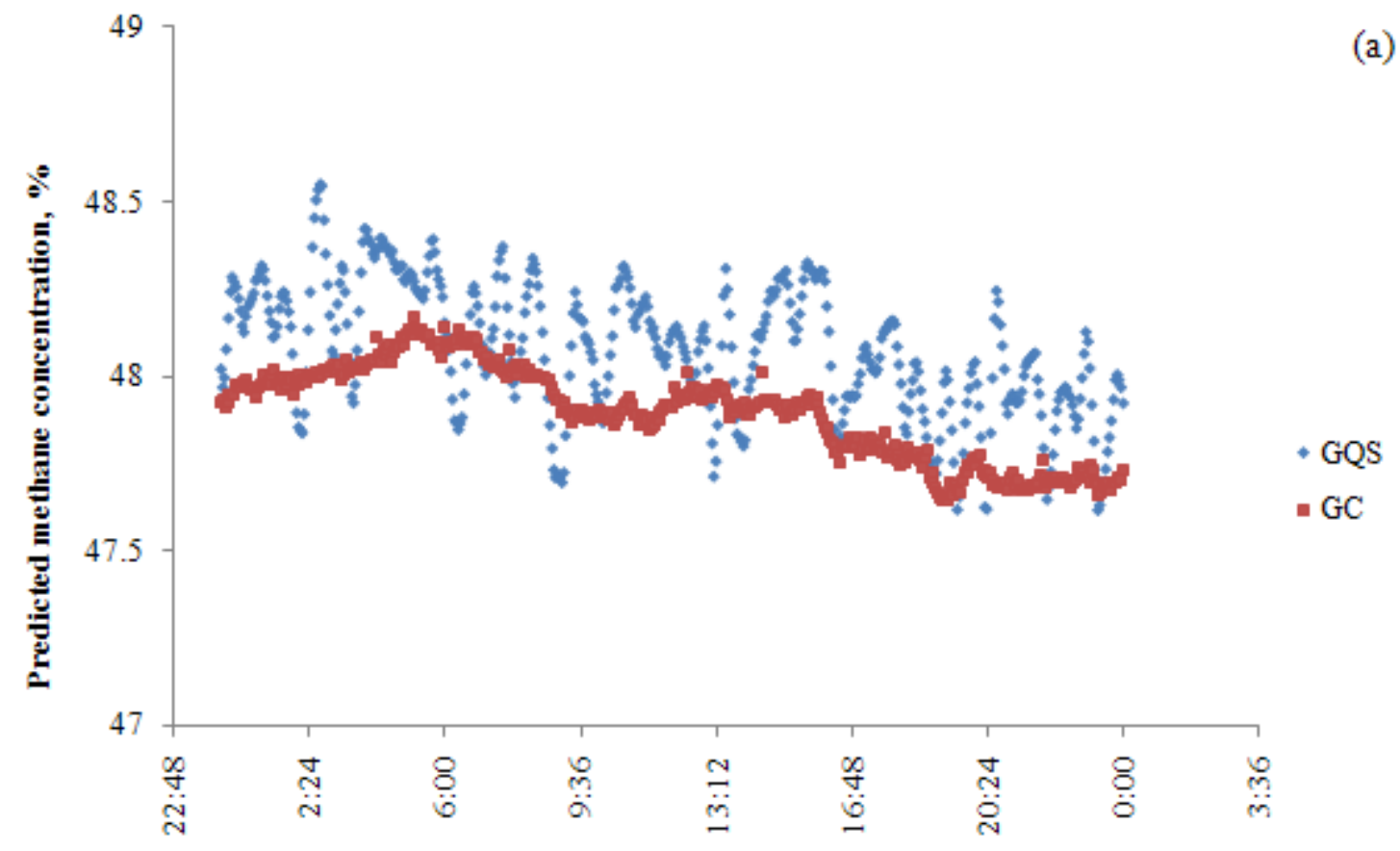

Time, hh:mm

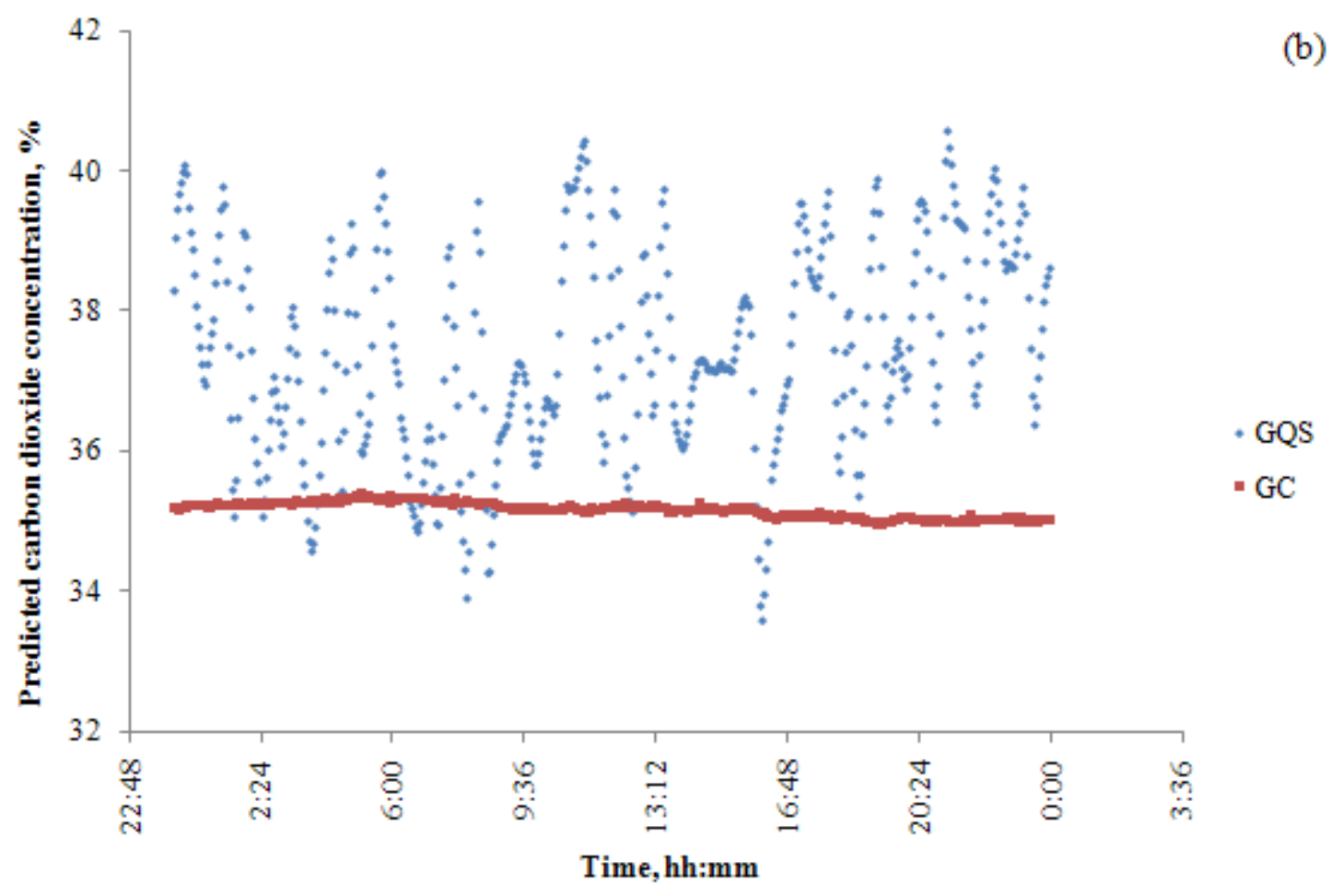

Figure 22.- Comparison of GQS and GC measurements over a period of one day: (a) methane, (b) carbon dioxide. 


\subsubsection{Experiments with blends of natural gas and landfill gas}

For natural gas - landfill gas blends, the mixture compositions are selected such that they have adequate heating value for use in engines or turbines. The volumetric ratio of natural gas and landfill gas in the mixtures is selected as 75:25 resulting in heating value range 670 to $890 \mathrm{BTU} / \mathrm{SCF}$. The possible concentration ranges of individual gas components in natural gas and landfill gas are taken into consideration to compute the corresponding compositional variation of the resulting blends. Table 3 shows the compositional variation of natural gas, landfill gas and their 75:25 blend. For efficient calibration, it is necessary that the mixtures should be uniformly distributed in the considered concentration ranges. To achieve this, the concentration of each gas component in the mixtures is varied by a step given in Table 3. This step is computed for each gas component considering its concentration range and the number of mixtures. The number of mixtures is selected as 40 . Of these 40 mixtures, 20 mixtures are calibration mixtures and the remaining mixtures are used for validation purpose. As the concentrations of higher hydrocarbons are very low in these mixtures, the total fuel flow rate is increased to 3 liter/sec from usual 1 liter/s, to improve accuracy in mixture preparation.

Table 3. Compositional variation of natural gas, landfill gas and their blends.

\begin{tabular}{|c|c|c|c|c|c|c|c|c|}
\hline & & \multicolumn{6}{|c|}{ Concentration of gas components, \% } & \multirow{2}{*}{$\begin{array}{c}\text { HV } \\
\text { BTU/ } \\
\text { SCF } \\
\end{array}$} \\
\hline & & $\mathrm{CH}_{4}$ & $\mathrm{C}_{2} \mathrm{H}_{6}$ & $\mathrm{C}_{3} \mathrm{H}_{8}$ & $\mathrm{C}_{4} \mathrm{H}_{10}$ & $\mathrm{CO}_{2}$ & $\mathbf{N}_{2}$ & \\
\hline \multirow{2}{*}{ Natural gas } & Min & 80 & 1.5 & 0.1 & 0.02 & 0.1 & 0.7 & 755.42 \\
\hline & Max & 95 & 5.1 & 1.5 & 0.6 & 1 & 5.6 & 1001.06 \\
\hline \multirow{2}{*}{ Landfill gas } & Min & 45 & 0 & 0 & 0 & 30 & 2 & 409.5 \\
\hline & Max & 60 & 0 & 0 & 0 & 60 & 20 & 546 \\
\hline \multirow{4}{*}{$\begin{array}{l}\text { Blend } \\
\text { (75\% NG and } \\
\text { 25\% LFG) }\end{array}$} & & 71.2 & & 0.07 & & 7.57 & 1.02 & \\
\hline & Min & & 1.125 & 5 & 0.015 & 5 & 5 & 668.94 \\
\hline & Max & $\begin{array}{l}86.2 \\
5\end{array}$ & 3.825 & $\begin{array}{l}1.12 \\
5\end{array}$ & 0.45 & $\begin{array}{l}15.7 \\
5\end{array}$ & 92 & 88729 \\
\hline & Step & 0.38 & 0.07 & 0.03 & 0.01 & 0.21 & 0.21 & 5.60 \\
\hline
\end{tabular}

Partially complete experimental data, available by the end of September, is used for preliminary analysis in order to get an estimate of the sensor's accuracy in measuring the blend properties. Table 4 shows the compositions of those mixtures. Mixtures 1, 2, 4 and 5 are used for calibration, while mixture 3 is used for validation. Figs. 23 and 24 show the near infrared absorption spectra of calibration and validation mixtures respectively. The spectra are very similar to each other as the mixture compositions do not vary significantly. The spectra resemble the spectra of methane, as it is the primary component in the mixtures with relatively low concentrations of higher hydrocarbons and carbon dioxide. The experimental data is then used to develop a regression model using the principal components regression (PCR) method. The developed calibration model is used to compute the composition and heating value of validation mixture. Table 5 shows the set and measured composition of validation mixture using number of principal components up to 3. Table 6 shows the root-mean-squared-error-of-prediction (RMSEP) computed using the following equation: 


$$
R M S E P=\left[\frac{\sum\left(y_{\text {actual }}-y_{\text {predicted }}\right)^{2}}{N}\right]^{\frac{1}{2}}
$$

As only one validation mixture is used in this case, the RMSEP represents the difference between set and measured concentration or heating value. It is clear from Table 6 that the sensor algorithm gives reasonable accuracy in predicting the composition of $75 \%$ natural gas - $25 \%$ landfill gas blend.

Table 4. Compositions and heating values of mixtures. Mixture 3 is a validation mixture and the remaining mixtures are used for calibration purpose.

\begin{tabular}{cccccc} 
& $\mathbf{1}$ & $\mathbf{2}$ & $\mathbf{3}$ & $\mathbf{4}$ & $\mathbf{5}$ \\
\hline $\mathbf{C H}_{\mathbf{4}}, \mathbf{\%}$ & 71.25 & 72.04 & 72.83 & 73.62 & 74.41 \\
$\mathbf{C}_{\mathbf{2}} \mathbf{H}_{\mathbf{6}}, \mathbf{\%}$ & 1.13 & 1.27 & 1.41 & 1.56 & 1.7 \\
$\mathbf{C}_{\mathbf{3}} \mathbf{H}_{\mathbf{8}}, \mathbf{\%}$ & 0.08 & 0.14 & 0.19 & 0.25 & 0.3 \\
$\mathbf{C}_{\mathbf{4}} \mathbf{H}_{\mathbf{1 0}}, \mathbf{\%}$ & 0.02 & 0.04 & 0.07 & 0.09 & 0.11 \\
$\mathbf{C O}_{\mathbf{2}}, \mathbf{\%}$ & 15.75 & 15.32 & 14.89 & 14.46 & 14.03 \\
$\mathbf{N}_{\mathbf{2}}, \mathbf{\%}$ & 11.77 & 11.19 & 10.61 & 10.03 & 9.45 \\
$\mathbf{H V}$ & & & & & \\
$\mathbf{B T U} / \mathbf{S C F}$ & 669.29 & 680.78 & 692.32 & 703.98 & 715.23
\end{tabular}

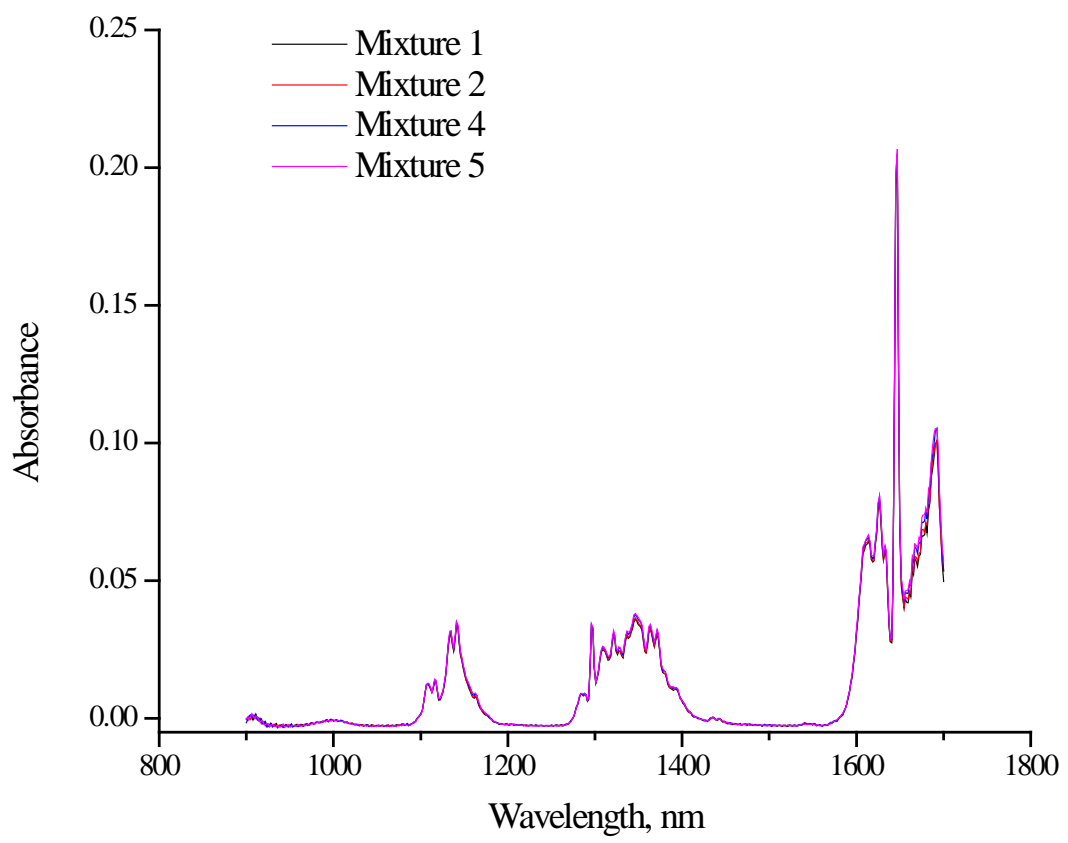
13.

Figure 23. Near infrared absorption spectra of calibration mixtures 1, 2, 4 and 5 shown in Table 


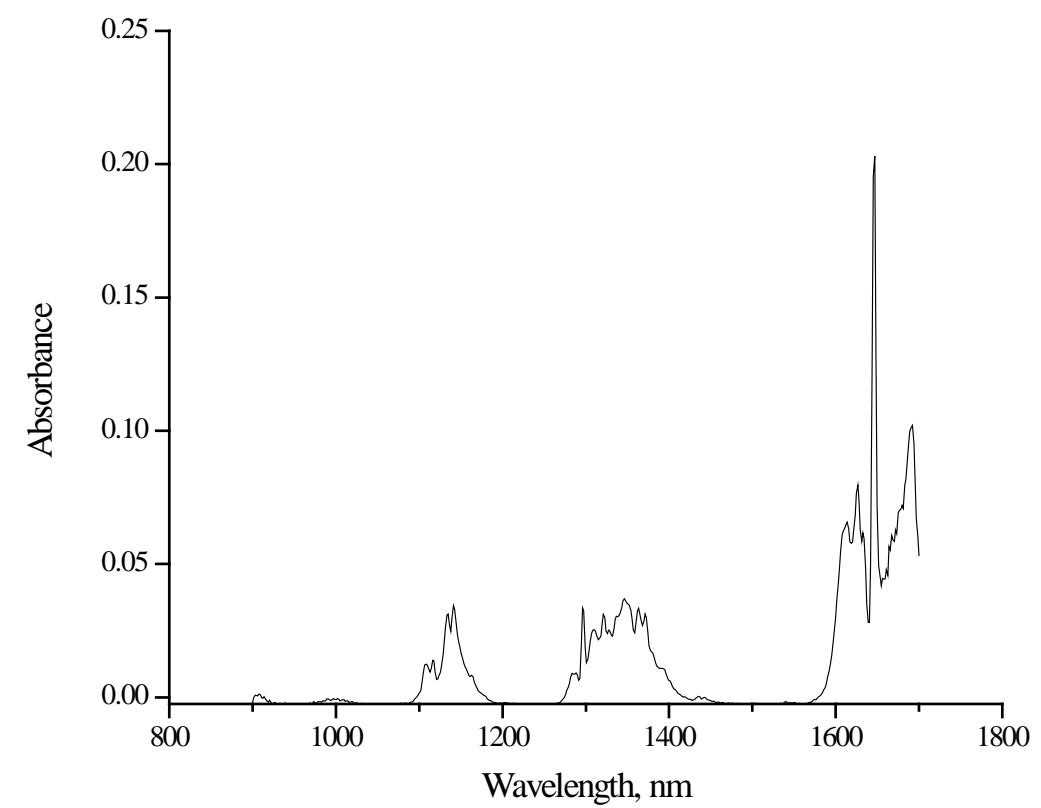

Figure 24. Near infrared absorption spectra of validation mixture (mixture 3) shown in Table 13.

Table 5. Set and measured compositions of validation mixture using number of principal components up to 3 .

\begin{tabular}{ccccc} 
& Set & \multicolumn{3}{c}{ Measured } \\
& & $\mathbf{n = 1}$ & $\mathbf{n = 2}$ & $\mathbf{n = 3}$ \\
\hline $\mathbf{C H}_{\mathbf{4}}, \mathbf{\%}$ & 72.83 & 9 & 9 & 6 \\
$\mathbf{C}_{\mathbf{2}} \mathbf{H}_{\mathbf{6}}, \mathbf{\%}$ & 1.41 & 1.4018 & 1.4012 & 1.4022 \\
$\mathbf{C}_{\mathbf{3}} \mathbf{H}_{\mathbf{8}}, \mathbf{\%}$ & 0.19 & 0.1874 & 0.1873 & 0.1880 \\
$\mathbf{C}_{\mathbf{4}} \mathbf{H}_{\mathbf{1 0}}, \mathbf{\%}$ & 0.07 & 0.0629 & 0.0624 & 0.0626 \\
$\mathbf{C O}_{\mathbf{2}}, \mathbf{\%}$ & 14.89 & 8 & 3 & 2 \\
$\mathbf{H V}$, & & & & \\
$\mathbf{B T U / S C F}$ & 692.32 & 691.25 & 691.22 & 691.31
\end{tabular}


Table 6. Root-mean-squared-error-of-prediction using number of principal components up to 3.

\begin{tabular}{|c|c|c|c|}
\hline & \multicolumn{3}{|c|}{ RMSEP } \\
\hline & $n=1$ & $n=2$ & $n=3$ \\
\hline $\mathrm{CH}_{4}, \%$ & 0.0731 & 0.0741 & 0.0684 \\
\hline $\mathrm{C}_{2} \mathrm{H}_{6}, \%$ & 0.0082 & 0.0088 & 0.0078 \\
\hline $\mathrm{C}_{3} \mathrm{H}_{8}, \%$ & 0.0026 & 0.0027 & 0.0020 \\
\hline $\mathrm{C}_{4} \mathrm{H}_{10}, \%$ & 0.0071 & 0.0076 & 0.0074 \\
\hline $\begin{array}{c}\mathrm{CO}_{2}, \% \\
\mathrm{HV}\end{array}$ & 0.0398 & 0.0403 & 0.0372 \\
\hline BTU/SCF & 1.0700 & 1.1000 & 1.0100 \\
\hline
\end{tabular}

\subsubsection{Experiments with landfill gas mixtures containing water vapor}

\section{NIR absorbance of water vapor}

Water is known to have strong absorption near 1400 in a wide absorption band and weaker absorption near 1150 and $950 \mathrm{~nm}$. Some spectral features from these absorption bands of water may interfere with hydrocarbons and may impose a challenge in accurate identification of these species using quantitative analyses, if calibration mixtures do not contain water vapor as one of the components. Fig. 25 shows the equilibrium water vapor pressure on a logarithmic scale as a function of temperature $\left(-50\right.$ to $\left.50{ }^{\circ} \mathrm{C}\right)$. The equilibrium water vapor pressure increases almost linearly in the considered temperature range. Fig. 26 shows the simulated absorption spectra of water at $100 \%$ relative humidity at various temperatures in the wavelength range 900 to $1700 \mathrm{~nm}$ for an instrumental profile width of $12.5 \mathrm{~nm}$ and $50 \mathrm{~cm}$ optical path length. From Fig. 26, we can see that water has absorption bands of increasing intensity with increasing wavelength. The strongest absorption is in the range 1300 to $1500 \mathrm{~nm}$ and interferes with the absorption band of hydrocarbons in this wavelength range. Also, the order of magnitude of absorbance is comparable to that of pure methane or propane at atmospheric pressure. The other two absorption bands, also, overlap with the absorption bands of hydrocarbons in the respective wavelength ranges. 


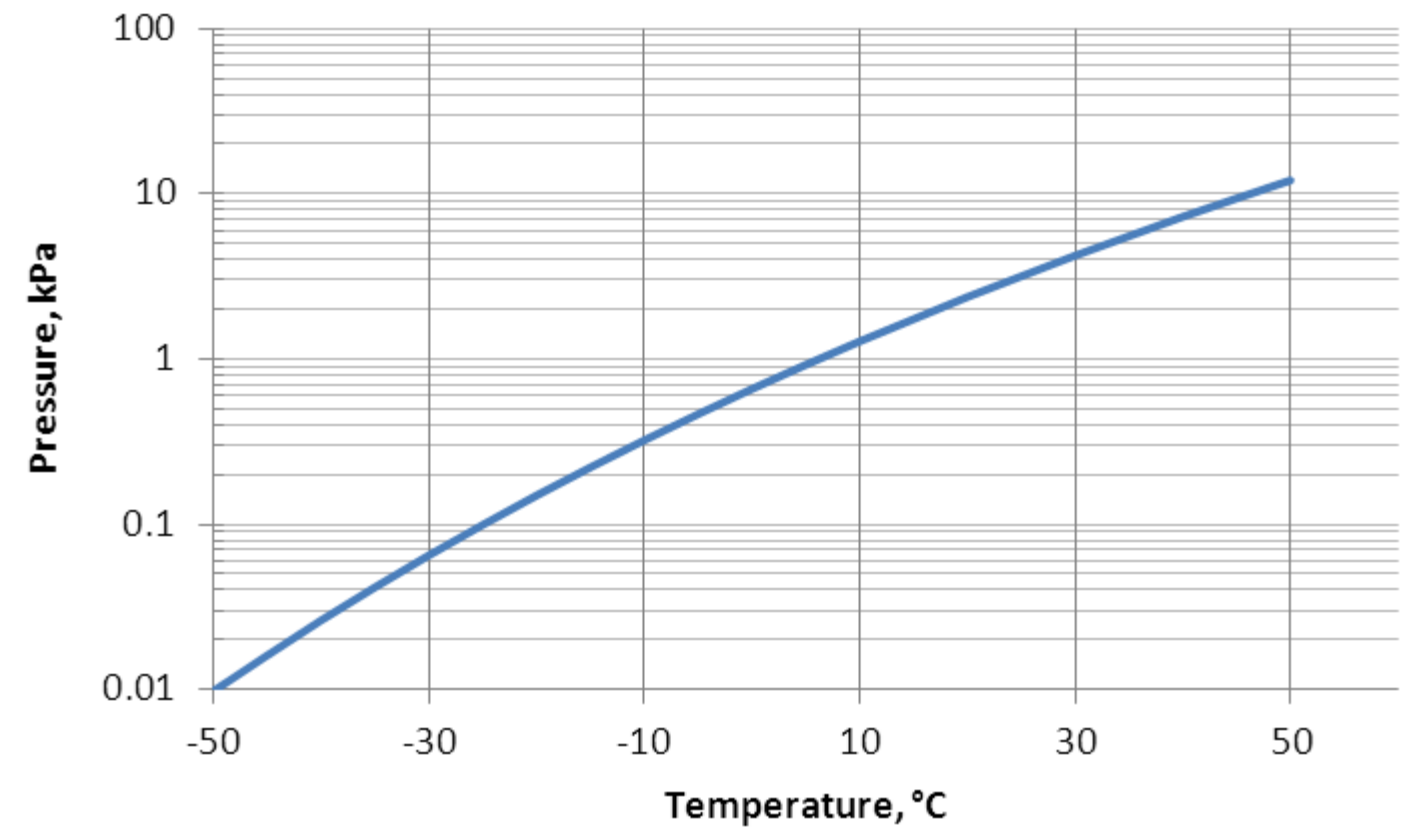

Figure 25. Equilibrium water vapor pressure as a function of temperature.

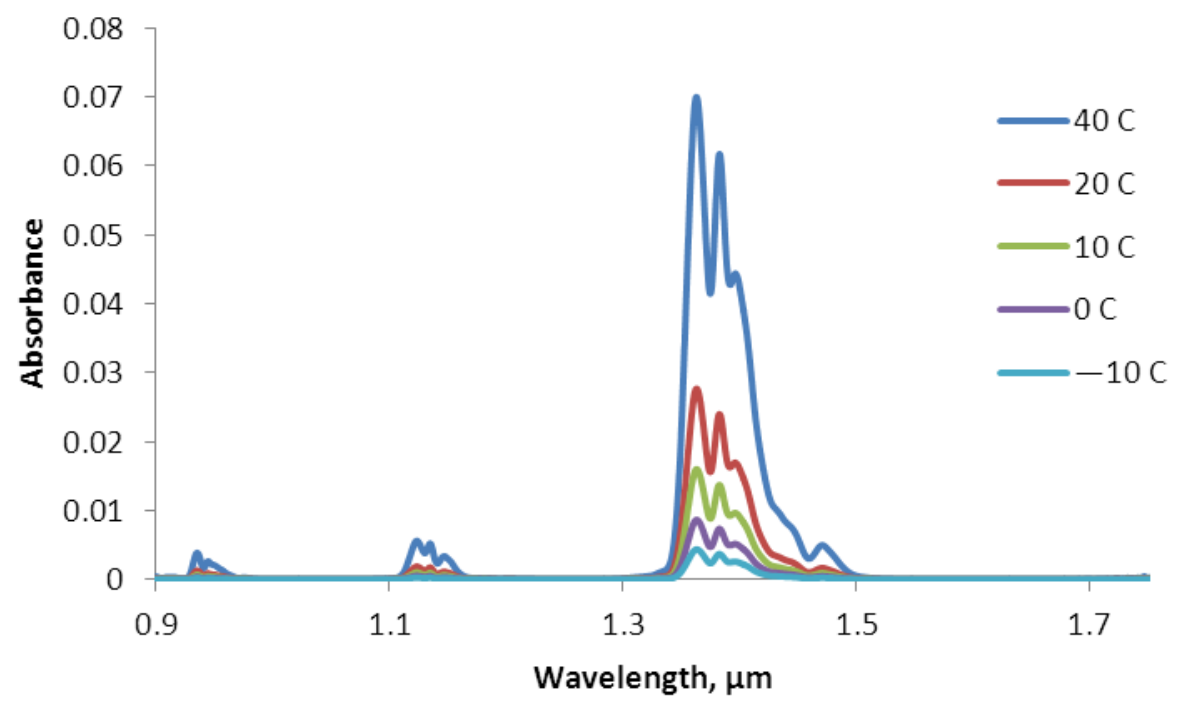

Figure 26. NIR spectra of water at $100 \%$ relative humidity for various temperatures.

\section{Experimental setup}

Fig. 27 shows the experimental setup used for characterization of fuel mixtures containing water vapor. The setup is slightly different from the existing GQS setup with addition of a couple of new devices - a midget glass bubbler inserted in a temperature controlled water bath and a heating system for the optical cell. Three gases - methane, propane and carbon dioxide are considered for initial experimentation. The fuel mixtures of predetermined compositions prepared using the mass flow control system and are allowed to flow through a glass bubbler (Ace Glass Inc., 7533-19) containing water. It has 
safe removable hose connections at its inlet and outlet. The impinger nozzle has sintered glass filter having 70 - 100 micron holes. The cylinder has encircling graduations from 0 to $25 \mathrm{ml}$ in $5 \mathrm{ml}$ divisions. This helps in measuring the amount of water absorbed by the fuel over a period of time. The bubbler is kept in a temperature controlled water bath. Water in the bath is heated to a desired temperature. The gas tubing after the bubbler is heated using a heating rope so that water vapor does not get condensed. The optical cell is enclosed in a cylindrical aluminum enclosure having 4.26" internal diameter and 0.12 " wall thickness. Three long screws inserted from outside the enclosure hold the cell on the central axis of the enclosure. The enclosure is heated to the desired temperature using three band heaters. The temperature of band heaters is maintained using a temperature controller. The optical cell gets heated due to free convection heat transfer from the enclosure. Some insulating material needs to be inserted surrounding the lens holders to avoid heating of the lenses. A three-way valve is used to switch the flow between fuel and inert gas.

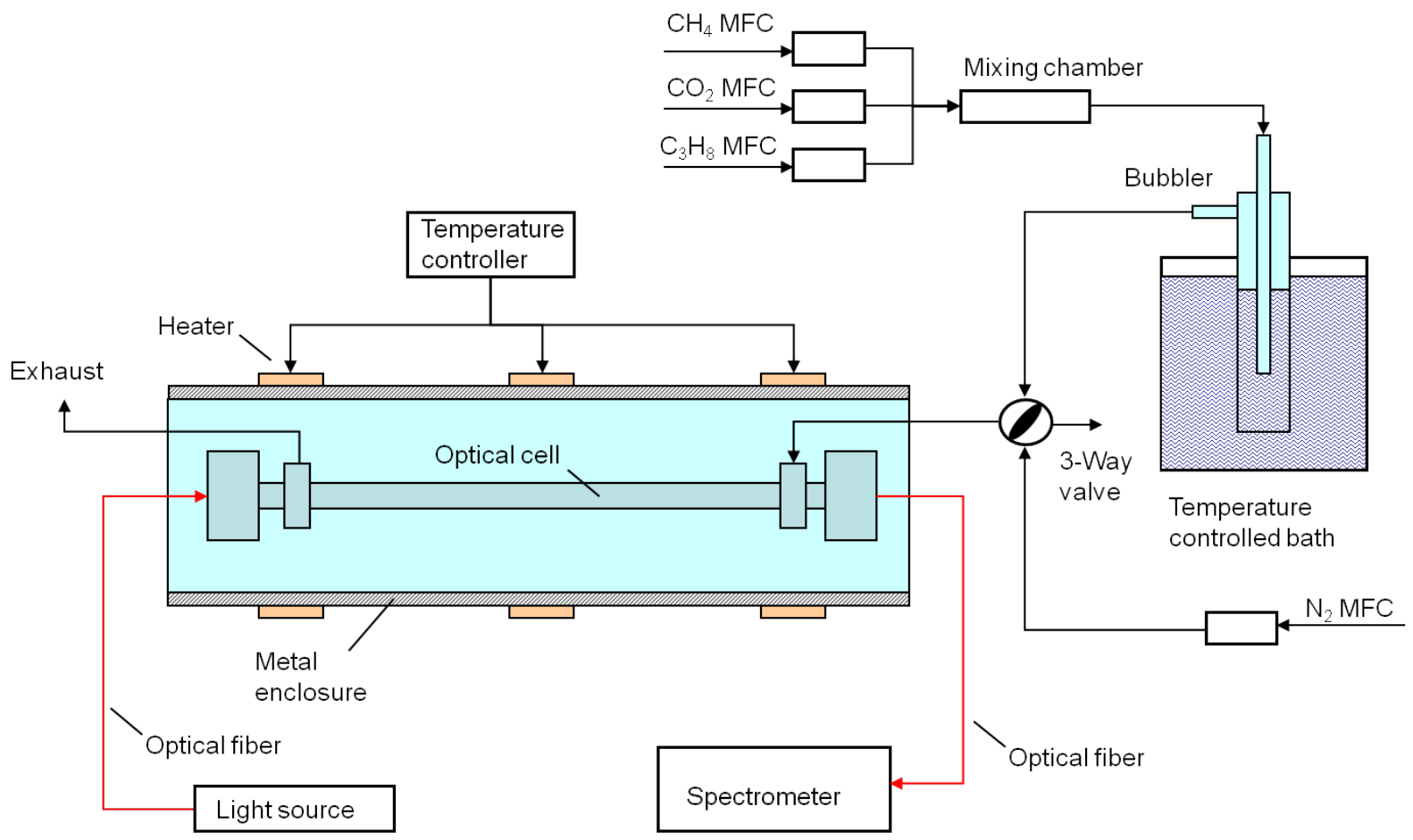

Figure 27. Experimental setup for preparation and characterization of hydrocarbon fuel mixtures containing water vapor.

Fig. 28 shows the experimental apparatus developed for preparing hydrocarbon fuel mixtures containing water vapor. An autotransformer (Variac ${ }^{\mathrm{TM}}$ ) is used for controlled heating of heating tape. The tape can be heated to desired temperature by adjusting the supply voltage.

The temperature of water in water bath, aluminum enclosure and optics cell are measured using three thermocouples connected to NI9211. The goal is to heat the gaseous fuel mixture uniformly to a predetermined temperature. It may be required to maintain aluminum enclosure at a slightly higher temperature than the desired gas temperature considering the losses due to radiation during the heat transfer process. The tubing connected after the optics cell is not heated; instead a small container is connected after the exit from the optics cell, so that condensed water gets collected in that container. This container can be removed from the system and drained whenever required. The collimating lens holder is surrounded by an insulating material.

The temperature and relative humidity of the fuel mixture are measured by the humidity meter (Omega, HX93AC). The humidity meter provides the measurements in the form of an analog current output on a scale of 4 to $20 \mathrm{~mA}$. These current outputs are measured using a National Instruments analog input module NI9203. Fig. 29 shows electrical connections of humidity meter to NI9203. 


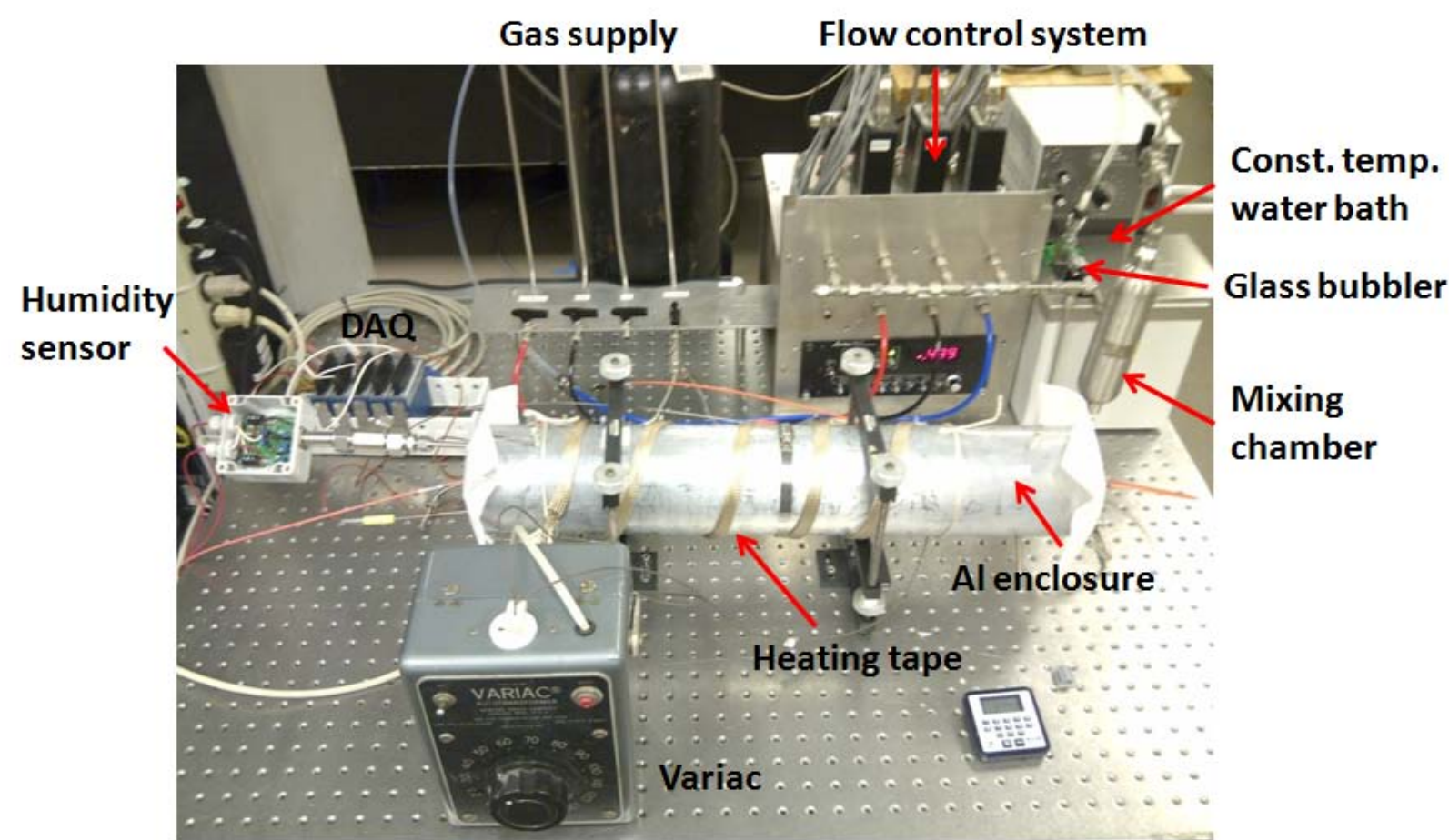

Figure 28. Photo of the experimental setup for preparation and characterization of hydrocarbon fuel mixtures containing water vapor. The main parts include flow control system, gas heating system and data acquisition system.

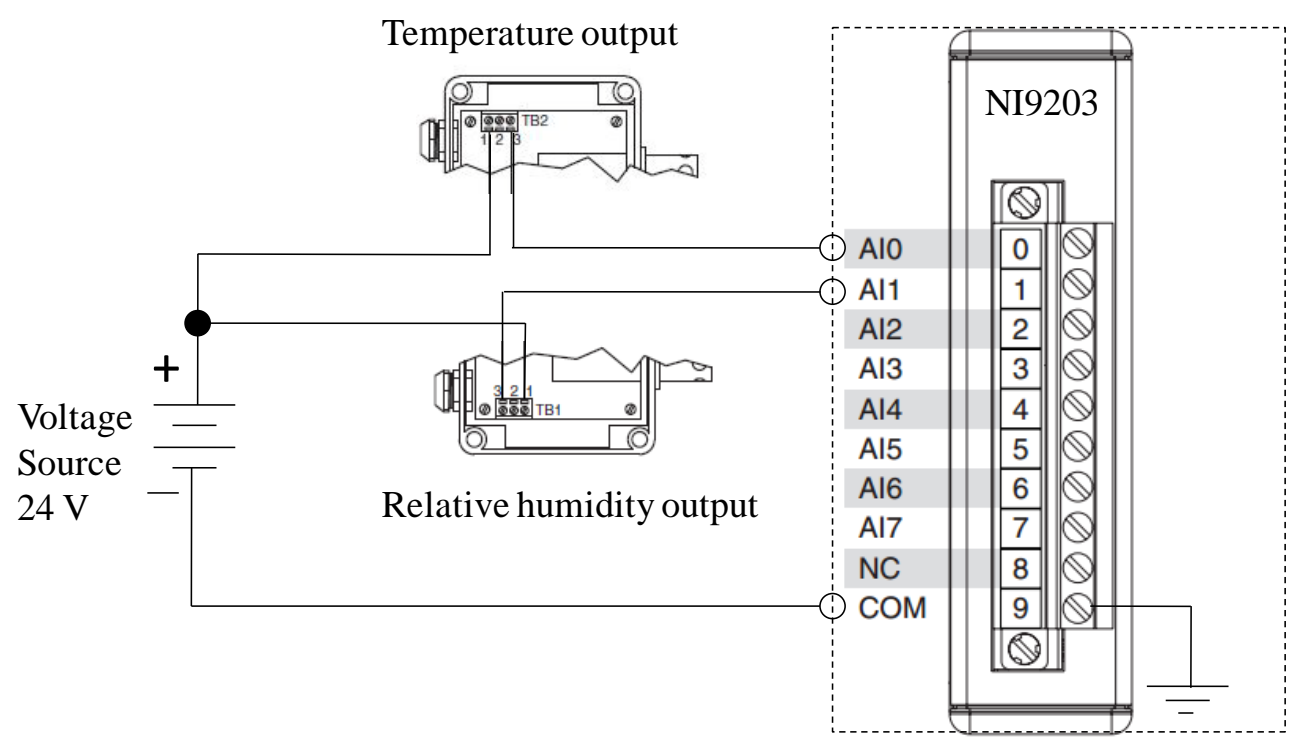

Figure 29. Electrical connections of Omega humidity sensor HX93AC to analog input module NI9203. The humidity sensor provides the temperature and relative humidity measurements on a scale of 4 to $20 \mathrm{~mA}$ current.

Near infrared absorption spectrum of water

One of the most challenging issues in quantitative characterization of hydrocarbon fuel mixtures using near infrared absorption spectroscopy is the presence of water vapor in the fuel. Water vapor is known to 
have significant absorption in the near infrared region and its presence can severely affect the absorption spectrum of the fuel mixture. In the previous study, we have compared the absorption of water vapor (computed numerically) to hydrocarbons and carbon dioxide. This study suggested that the gas quality sensor has the potential to detect and quantify water vapor in fuels.

The experimental setup consists of a constant temperature water bath, midget glass bubbler, heating system and a humidity sensor. The goal is to measure the absorption spectrum of water and compare it to the absorption of other fuel components. The gas is humidified by allowing it to flow through the glass bubbler which is filled with water and is kept immersed in a constant temperature water bath. All the tubing and water in the bath are maintained at approximately $45^{\circ} \mathrm{C}$. This is the temperature at which we want to measure the spectrum of water vapor. Heating the tubing to this temperature is also required in order to ensure that water vapor does not get condensed. The humidity level of nitrogen is measured using the humidity sensor. In this experiment, the flow rate of nitrogen was 500 SCCM (standard cubic centimeter per minute) and its relative humidity was $50 \%$ as measured by the humidity sensor. The reference intensity was also measured at $45^{\circ} \mathrm{C}$ of dry nitrogen.

Fig. 30 shows the absorption spectrum of water vapor in nitrogen at $50 \%$ relative humidity and $45^{\circ} \mathrm{C}$. It is clear from Fig. 30 that water has three distinct absorption bands, with stronger absorption bands in longer wavelength regions. The strongest band in the region 1300 to $1500 \mathrm{~nm}$ overlaps with absorption bands of other hydrocarbons. The peak absorption is approximately half of the peak absorption of methane. The presence of water vapor thus further complicates the overlapping region of absorption bands near 1300 to $1500 \mathrm{~nm}$. However, this strong absorption signal of water vapor may assist in estimating its concentration with a good accuracy.

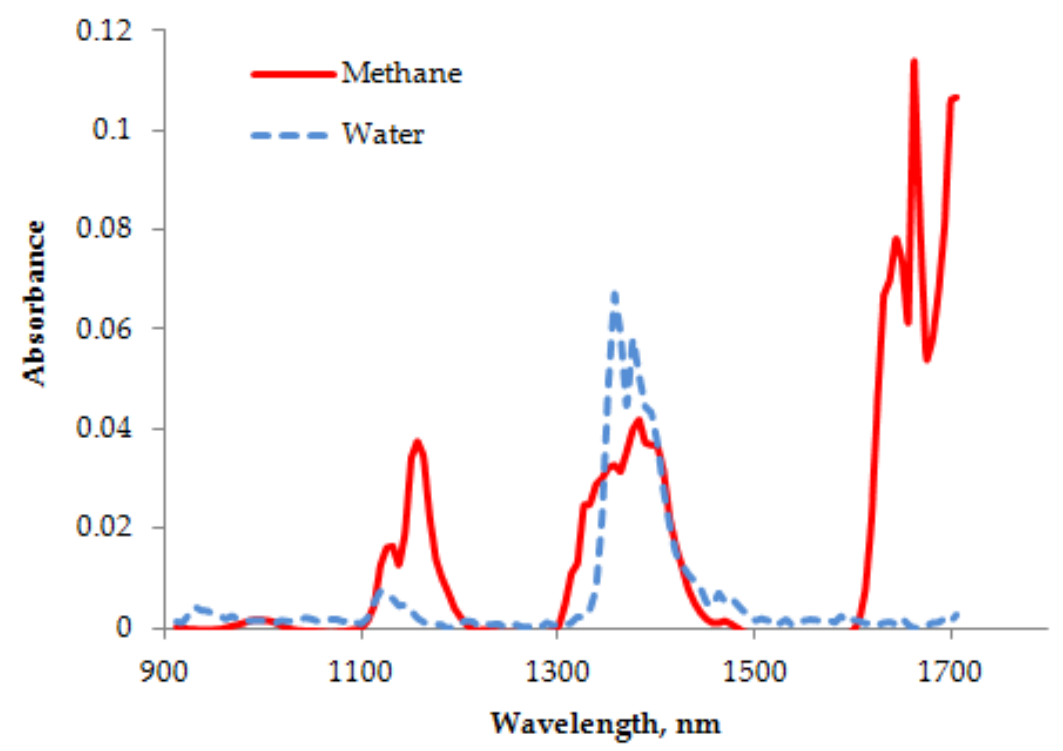

Figure 30. The near absorption spectra of pure methane and water vapor. Methane is at 1 bar and $25{ }^{\circ} \mathrm{C}$. Water vapor is present in nitrogen at $50 \%$ relative humidity and $45{ }^{\circ} \mathrm{C}$.

\section{Humidity sensor testing}

The Omega humidity sensor has an error of $\pm 2.5 \%$ at $22^{\circ} \mathrm{C}\left(72{ }^{\circ} \mathrm{F}\right)$ from 20 to $80 \%$ relative humidity (RH), $\pm 3.1 \%$ at $22{ }^{\circ} \mathrm{C}$ below 20 and above $80 \%$. The error further increases with temperature at a rate of $\pm 0.1 \% \mathrm{RH} / \mathrm{F}$. According to this, the sensor error at $55{ }^{\circ} \mathrm{C}$ could be evaluated as $8.5 \%$ for a relative humidity range from 20 to $80 \%$. This is a large error compared to the errors in the GQS estimated concentrations of other components. In order to achieve reasonable prediction accuracy, it is important to accurately measure the amount of water vapor in the calibration mixtures. 
For a preliminary analysis, the mass of water vapor is calculated using the relative humidity measured by the sensor. Then, it is compared to the mass of water evaporated from the glass bubbler during a given time interval. In this experiment, initially the midget glass bubbler was filled with $25 \mathrm{ml}$ of water. Nitrogen was humidified by allowing it to flow through the bubbler. The flow rate of nitrogen was controlled using the flow control system and maintained constant at 0.5 NLM (liters per minute) for approximately 2 hours. The water bath and optics cell were maintained at a constant temperature of $55^{\circ} \mathrm{C}$. The background and reference intensity were measured before the experiment at the same temperature $\left(55^{\circ} \mathrm{C}\right)$ of nitrogen.

During the experiment, the relative humidity was approximately constant at $34 \%$ for most of the duration. The amount of water evaporated from the bubbler was approximately $4.5 \mathrm{ml}$.

$$
P_{\text {sat } @ 55^{\circ} \mathrm{C}}=15.76 \mathrm{kPa}
$$

The partial pressure of water vapor can then be calculated as

$$
P_{\mathrm{H}_{2} \mathrm{O}}=\phi \times P_{\text {sat } @ 55^{\circ} \mathrm{C}}=0.34 \times 15.763 \mathrm{kPa}=5.36 \mathrm{kPa}
$$

Assuming that the total pressure of the mixture is $101.3 \mathrm{kPa}$, the specific humidity can be calculated as

$$
\omega=\frac{m_{\mathrm{H}_{2} \mathrm{O}}}{m_{N_{2}}}=\frac{M_{\mathrm{H}_{2} \mathrm{O}}}{M_{N_{2}}} \frac{P_{\mathrm{H}_{2} \mathrm{O}}}{P_{N_{2}}}=0.643 \frac{P_{\mathrm{H}_{2} \mathrm{O}}}{P_{a}-P_{\mathrm{H}_{2} \mathrm{O}}}=0.036
$$

The flow control system is calibrated at $0{ }^{\circ} \mathrm{C}(273.15 \mathrm{~K})$ and $101.3 \mathrm{kPa}$. Thus, the mass of nitrogen is

$$
m_{N_{2}}=\frac{101.3 \times 10^{3} \mathrm{~Pa} \times 0.5 \times 10^{-3} \frac{\mathrm{m}^{3}}{\mathrm{~min}} \times\left(\frac{7500}{60} \mathrm{~min}\right)}{296.8 \frac{\mathrm{J}}{\mathrm{kg} . \mathrm{K}} \times 273.15 \mathrm{~K}}=0.078 \mathrm{~kg}
$$

Now, the mass of water vapor can be calculated using Eqs. (6) and (7),

$$
m_{v}=\omega \times m_{N_{2}}=0.036 \times 78 \mathrm{~g}=2.8 \mathrm{~g}<4.5 \mathrm{~g} \text { as measured from the bubbler }
$$

Concurrently, from the simulated absorption spectrum of water vapor, the peak absorbance 0.0504 AU occurs at $\sim 1360 \mathrm{~nm}$ and from the experimentally measured spectrum, the peak is $0.0873 \mathrm{AU}$ at $\sim 1360$ nm. From Eq. (7), the specific humidity at $34 \% \mathrm{RH}$ and $55{ }^{\circ} \mathrm{C}$ is 0.036 . Thus, we can calculate the expected specific humidity of the gas mixture from the experimentally measured peak absorbance as follows.

$$
\begin{gathered}
\omega=0.036 \times \frac{\text { Peak absorbance from experimental spectrum }}{\text { Peak absorbance from simulated spectrum }} \\
=0.036 \times \frac{0.0873}{0.0504}=0.06
\end{gathered}
$$

Thus, these preliminary calculations show that the humidity of the mixture may be underestimated by the humidity sensor. A comparison of the experimentally measured and theoretically computed absorption spectra of water vapor also leads us to a similar conclusion (Fig. 31). The amount of water evaporated from the bubbler can be measured during a given time interval and this data can be used to re-calibrate the humidity sensor and reduce the error in RH measurement. 


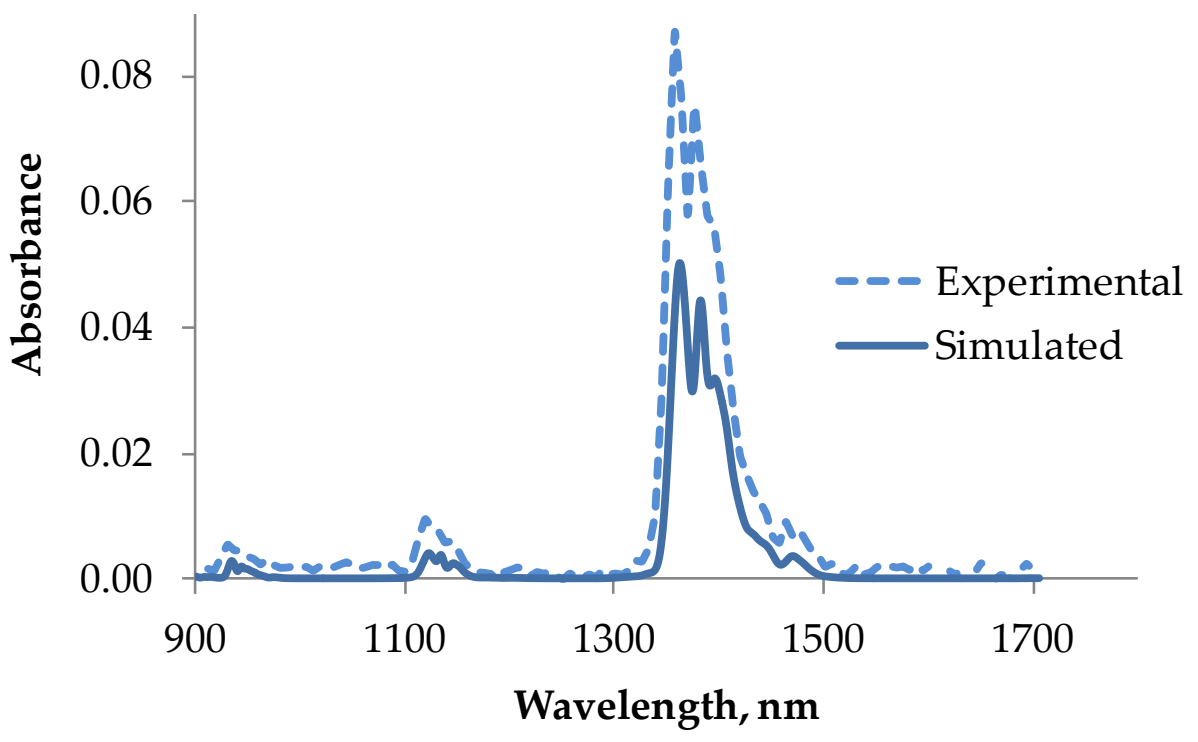

Figure 31. The near infrared absorption spectra of water vapor. Water vapor is present in nitrogen at $34 \%$ relative humidity and $55{ }^{\circ} \mathrm{C}$. The comparison of experimental and simulated spectra suggests that the humidity sensor has a significant error in RH measurement.

A comparison of specific humidity values obtained by different methods is given in Table 7. 
Table 7. Values of specific humidity measured by different methods.

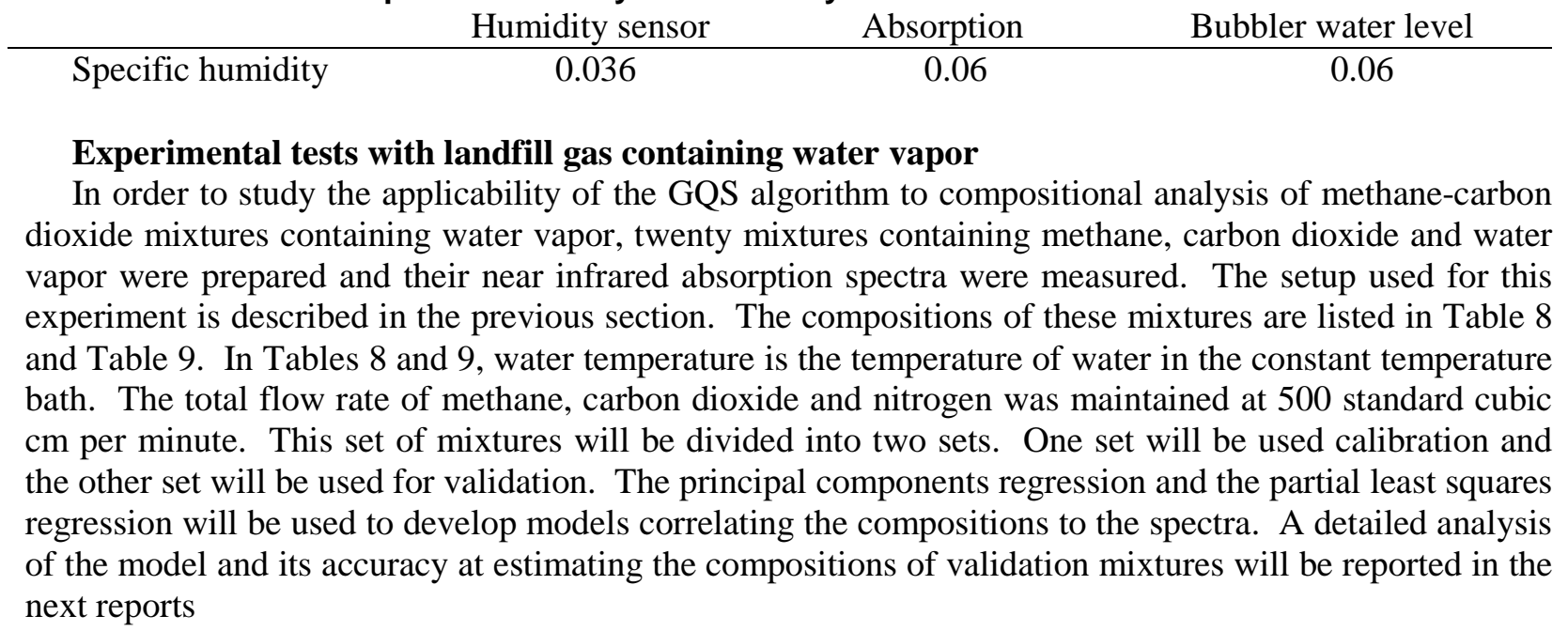


Table 8. Details of the calibration mixtures of methane, carbon dioxide and water vapor prepared in the experiment.

\begin{tabular}{|r|r|r|r|r|r|r|}
\hline \multirow{2}{*}{$\begin{array}{c}\text { Mixtu } \\
\text { re \# }\end{array}$} & $\begin{array}{r}\text { Bath } \\
\text { water temp., }\end{array}$ & \multicolumn{3}{|c|}{ Flow rates, $\mathrm{cm}^{3} / \mathrm{min}$} & \multicolumn{2}{|c|}{$\begin{array}{c}\text { Humidity sensor } \\
\text { measurements }\end{array}$} \\
\cline { 3 - 8 } & ${ }^{\circ} \mathrm{C}$ & $\mathrm{CH}_{4}$ & $\mathrm{CO}_{2}$ & $\mathrm{~N}_{2}$ & $\begin{array}{r}\mathrm{RH}, \\
\%\end{array}$ & Temp., ${ }^{\circ} \mathrm{C}$ \\
\hline 1 & 30 & 290 & 175 & 35 & 14 & 48 \\
\hline 2 & 35 & 200 & 200 & 100 & 14 & 47 \\
\hline 3 & 40 & 300 & 150 & 50 & 20.5 & 47 \\
\hline 4 & 45 & 285 & 175 & 40 & 22 & 47 \\
\hline 5 & 50 & 245 & 195 & 60 & 53.5 & 47 \\
\hline 6 & 55 & 165 & 240 & 95 & 73 & 49 \\
\hline 7 & 55 & 175 & 275 & 50 & 63.5 & 49 \\
\hline 8 & 55 & 205 & 255 & 40 & 58 & 49 \\
\hline 9 & 55 & 100 & 350 & 50 & 52 & 49 \\
\hline 10 & 55 & 185 & 220 & 95 & 72 & 50 \\
\hline
\end{tabular}

Table 9. Details of validation mixtures.

\begin{tabular}{|l|l|l|l|l|l|l|}
\hline 11 & 30 & 155 & 285 & 60 & 14 & 48 \\
\hline 12 & 35 & 215 & 205 & 80 & 15 & 48 \\
\hline 13 & 40 & 200 & 245 & 55 & 21 & 47 \\
\hline 14 & 45 & 190 & 260 & 50 & 25 & 47 \\
\hline 15 & 50 & 275 & 165 & 60 & 54 & 47 \\
\hline 16 & 55 & 150 & 325 & 25 & 68 & 49 \\
\hline 17 & 55 & 250 & 185 & 65 & 60 & 49 \\
\hline 18 & 55 & 225 & 225 & 50 & 55 & 49 \\
\hline 19 & 55 & 175 & 270 & 55 & 51 & 49 \\
\hline 20 & 55 & 235 & 190 & 75 & 72 & 50 \\
\hline
\end{tabular}

Using the measurements shown by the humidity sensor, the compositions of landfill gas mixtures can be determined. The partial pressure of water vapor is first calculated from the relative humidity and temperature as measured by the humidity sensor. The mixture is assumed to flow at atmospheric pressure. Thus, the total pressure of methane, carbon dioxide and nitrogen can be calculated. Knowing their flow rates in the mixture, their partial pressures can be estimated. Finally, the volume fractions of methane, carbon dioxide, nitrogen and water vapor in the mixtures can be calculated from their partial pressures. These concentrations (shown in Table 10 and Table 11) are then used in building regression models correlating the near infrared absorption spectra to the mixture compositions. The concentrations of carbon dioxide changed between 18 to 59\%, methane between 29 to $66 \%$, water vapor between 1 to $9 \%$, balanced by nitrogen. 
Table 10. Compositions by volume of synthetic landfill gas mixtures to be used for calibration.

\begin{tabular}{|c|c|c|c|c|}
\hline Mixture \# & $\% \mathrm{CO}_{2}$ & $\%{ }^{\mathrm{CH}_{4},}$ & $\mathrm{~N}_{2}, \%$ & $\%$ \\
\hline 1 & 57.12 & 34.47 & 6.89 & 1.51 \\
\hline 2 & 39.43 & 39.43 & 19.71 & 1.44 \\
\hline 3 & 58.74 & 29.37 & 9.79 & 2.10 \\
\hline 4 & 55.71 & 34.21 & 7.82 & 2.26 \\
\hline 5 & 46.31 & 36.86 & 11.34 & 5.49 \\
\hline 6 & 30.27 & 44.03 & 17.43 & 8.27 \\
\hline 7 & 32.48 & 51.04 & 9.28 & 7.20 \\
\hline 8 & 38.31 & 47.65 & 7.47 & 6.57 \\
\hline 9 & 18.82 & 65.88 & 9.41 & 5.89 \\
\hline 10 & 33.83 & 40.23 & 17.37 & 8.57 \\
\hline
\end{tabular}

Table 11. Compositions by volume of synthetic landfill gas mixtures to be used for validation.

\begin{tabular}{|c|c|c|c|c|}
\hline $\begin{array}{ll} & \text { Mixture } \\
\text { \# } & \\
\end{array}$ & $\%{ }^{\mathrm{CO}_{2},}$ & $\%{ }^{\mathrm{CH}_{4},}$ & $\mathrm{~N}_{2}, \%$ & $\mathrm{H}_{2} \mathrm{O}, \%$ \\
\hline 11 & 30.53 & 56.14 & 11.82 & 1.51 \\
\hline 12 & 42.30 & 40.34 & 15.74 & 1.62 \\
\hline 13 & 39.14 & 47.94 & 10.76 & 2.15 \\
\hline 14 & 37.03 & 50.67 & 9.74 & 2.56 \\
\hline 15 & 51.95 & 31.17 & 11.34 & 5.54 \\
\hline 16 & 27.69 & 59.99 & 4.61 & 7.71 \\
\hline 17 & 46.60 & 34.48 & 12.12 & 6.80 \\
\hline 18 & 42.20 & 42.20 & 9.38 & 6.23 \\
\hline 19 & 32.98 & 50.88 & 10.36 & 5.78 \\
\hline 20 & 42.97 & 34.74 & 13.71 & 8.57 \\
\hline
\end{tabular}

Fig. 32 shows the near infrared absorption spectra of a couple of synthetic landfill gas mixtures whose compositions are given in Table 12. It is clear from Fig. 32 that methane and water have a strong overlap in their absorption bands in 1300 to $1500 \mathrm{~nm}$ range. Also, the relatively weak absorption band of carbon dioxide near this region has been completely hidden under the relatively stronger bands of methane and water. 
Table 12. Compositions by volume of synthetic landfill gas mixtures. Their near infrared absorption spectra are shown in Fig. 32.

\begin{tabular}{|c|r|r|r|r|}
\hline $\begin{array}{r}\text { Mixtu } \\
\text { re \# }\end{array}$ & $\begin{array}{r}\mathrm{CO}_{2}, \\
\%\end{array}$ & $\begin{array}{r}\mathrm{CH}_{4}, \\
\%\end{array}$ & $\begin{array}{r}\mathrm{N}_{2}, \\
\%\end{array}$ & $\begin{array}{r}\mathrm{H}_{2} \mathrm{O}, \\
\%\end{array}$ \\
\hline 1 & 57.1 & 34.4 & 6.8 & \\
& 2 & 7 & 9 & 1.51 \\
\hline 2 & 46.6 & 34.4 & 12. & \\
& 0 & 8 & 12 & 6.80 \\
\hline
\end{tabular}

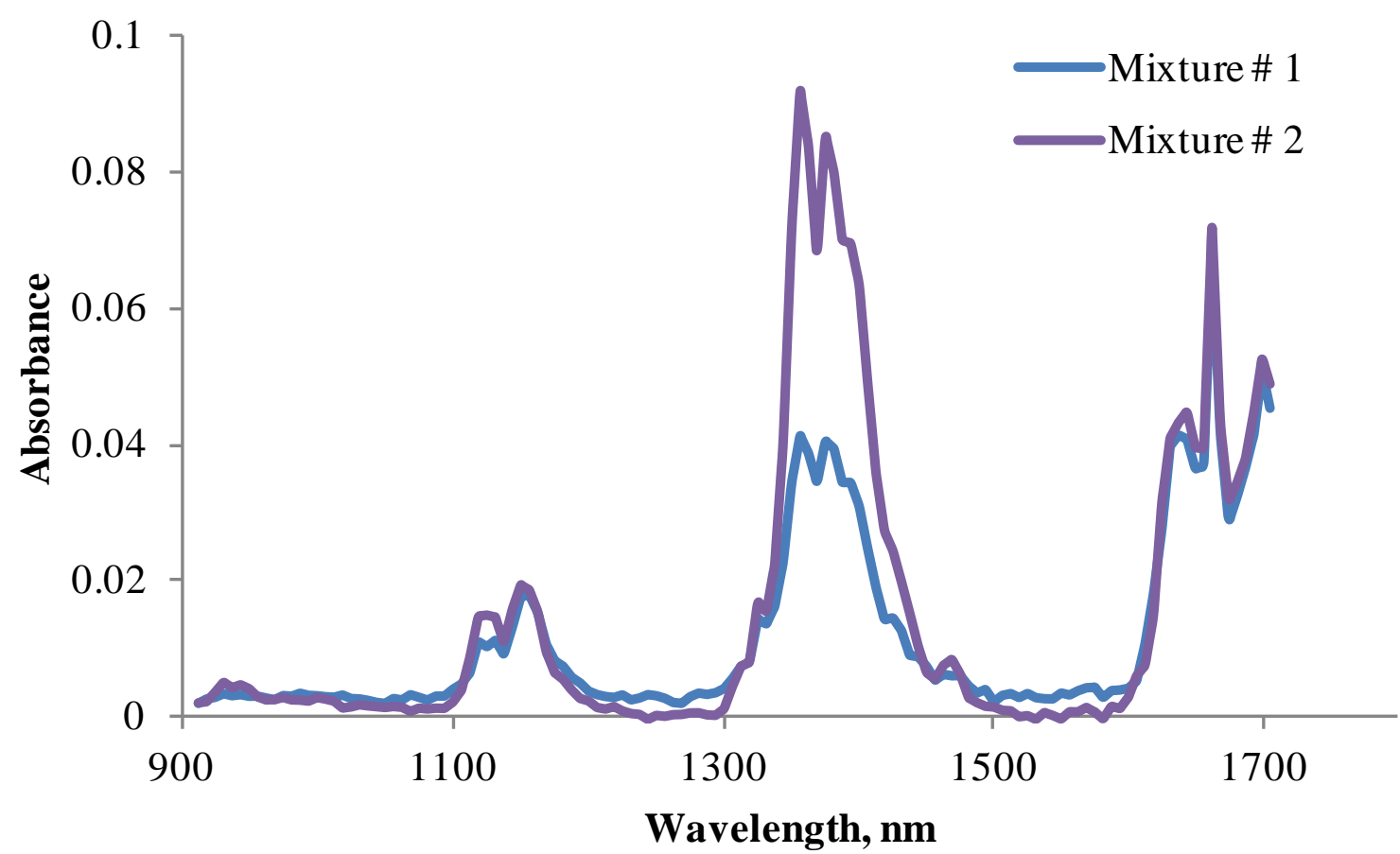

Figure 32. Near infrared absorption spectra of synthetic landfill gas mixtures.

\section{Classical Least Squares regression on component-specific absorption bands to estimate landfill gas composition}

A statistical regression model is developed using the classical least squares (CLS) regression. For each component, the wavelength ranges shown in Table 13 are utilized for building the models. These wavelengths are selected such that only the target component has absorption features in that range and there is no interference from other components. PLS Toolbox software is used to perform all computations.

Table 14 shows the estimated methane and water vapor concentrations in synthetic landfill gas mixtures. As carbon dioxide has very weak absorption in the considered wavelength region, the error in estimated carbon dioxide is the largest. Thus, the estimated carbon dioxide concentrations are not shown here.

To study the accuracy in the CLS estimated compositions, the following procedure is used. From the estimated concentrations, the weighted spectra of methane and water vapor are calculated. These weighted spectra are then added to estimate the spectra of validation mixtures. These computed spectra are then subtracted from the experimentally measured spectra of validation mixtures. From the difference spectra shown in Fig. 33, it can be seen that the residual absorbance values are within \pm 0.005 absorbance units, which is very likely due to the spectrometer noise. 
Table 13. Wavelength ranges used for building CLS regression models for different component gases.

\begin{tabular}{|c|c|}
\hline Component & Wavelength range, $\mathbf{n m}$ \\
\hline $\mathrm{CH}_{4}$ & 1600 to 1705 \\
\hline $\mathrm{CO}_{2}$ & 1550 to 1590 \\
\hline $\mathrm{H}_{2} \mathrm{O}$ & 1325 to 1400 \\
\hline
\end{tabular}

Table 14. CLS estimated methane and water vapor concentrations.

\begin{tabular}{|c|c|c|}
\hline $\begin{array}{c}\text { Mixture } \\
\#\end{array}$ & $\mathbf{C H}_{\mathbf{4}}, \mathbf{\%}$ & $\mathbf{H}_{\mathbf{2}} \mathbf{O}, \mathbf{\%}$ \\
\hline 1 & 55.00 & 2.51 \\
\hline 2 & 60.42 & 2.47 \\
\hline 3 & 53.88 & 3.34 \\
\hline 4 & 60.64 & 3.64 \\
\hline 5 & 61.52 & 6.20 \\
\hline 6 & 66.15 & 6.86 \\
\hline 7 & 71.51 & 7.81 \\
\hline 8 & 61.45 & 7.72 \\
\hline 9 & 80.13 & 7.11 \\
\hline 10 & 61.82 & 7.01 \\
\hline 11 & 75.63 & 2.67 \\
\hline 12 & 63.45 & 2.64 \\
\hline 13 & 54.60 & 3.35 \\
\hline 14 & 78.72 & 4.03 \\
\hline 15 & 58.73 & 6.78 \\
\hline 16 & 80.63 & 7.67 \\
\hline 17 & 58.15 & 7.75 \\
\hline 18 & 66.17 & 7.52 \\
\hline 19 & 73.44 & 6.99 \\
\hline 20 & 56.06 & 7.74 \\
\hline
\end{tabular}




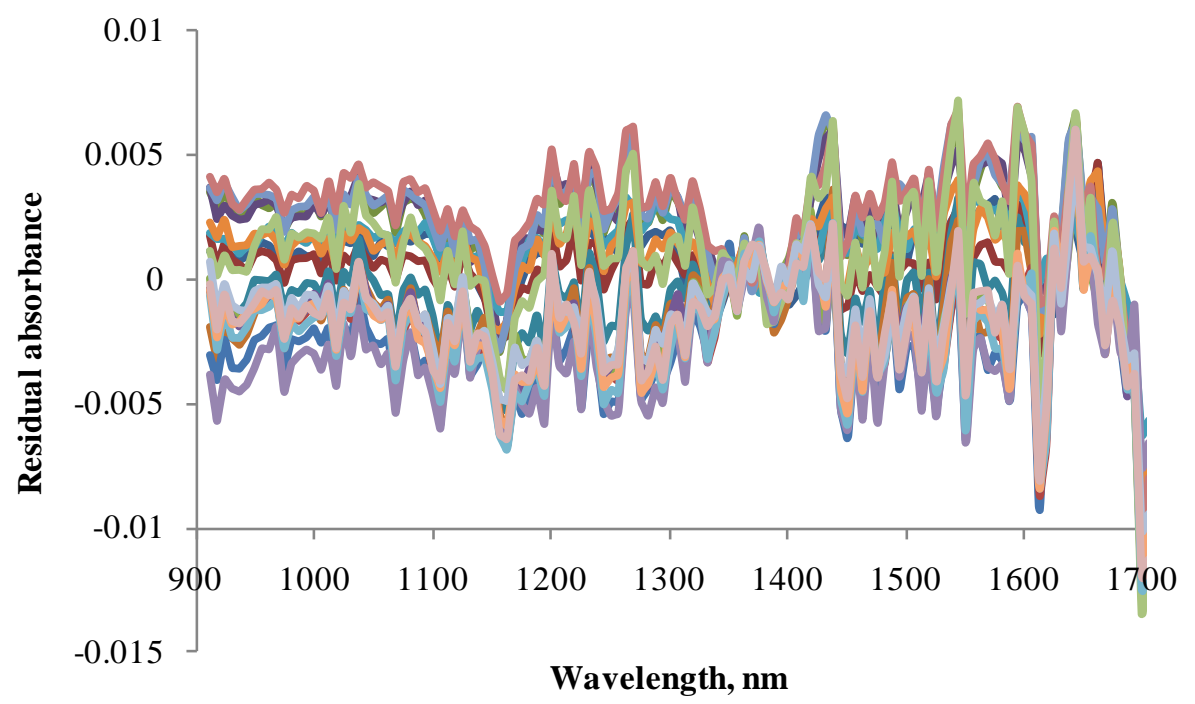

Figure 33. Residual absorbances computed by subtracting the absorption spectra of experimentally measured validation mixtures from the spectra of mixtures shown in Table 28.

\section{Principal components regression and partial least squares regression to estimate landfill gas composition}

Statistical regression models are developed using the principal components regression (PCR) and the partial least squares (PLS) regression on the entire spectra (900 to $1700 \mathrm{~nm}$ ) of landfill gas. PLS Toolbox software is used to perform all computations. Calibration database consisted of five spectra: spectra of pure methane, carbon dioxide and water vapor; methane - water vapor mixture and carbon dioxide water vapor mixture. The compositions of methane - water vapor and carbon dioxide - water vapor mixtures are verified against numerical spectra of known mixtures. The PCR and PLS estimated compositions and hearing values are very similar. Thus, only the PLS estimations are shown here.

Table 15 shows the estimated methane, water vapor and carbon dioxide concentrations in synthetic landfill gas mixtures. Using the estimated concentrations, the spectra of validation mixtures are computed by adding the weighted spectra of pure methane, water vapor and carbon dioxide. These computed spectra are then subtracted from the experimentally measured spectra of validation mixtures. From the difference spectra shown in Fig. 34, it can be seen that the residual spectra look very similar to the absorption spectra of water. Also, comparing the predictions to CLS predictions reported in the previous section, it is clear that the PCR/PLS underestimates the concentration of water vapor in the mixtures. 
Table 15. PLS estimated compositions and heating values of validation mixtures.

\begin{tabular}{|c|c|c|c|c|}
\hline Mixture \# & $\mathbf{C H}_{\mathbf{4}}, \mathbf{\%}$ & $\mathbf{H}_{\mathbf{2}} \mathbf{O}, \mathbf{\%}$ & $\mathbf{C O}_{\mathbf{2}}, \mathbf{\%}$ & $\mathbf{B T U} / \mathbf{S C F}$ \\
\hline 1 & 56.31 & 1.54 & 28.13 & 569.34 \\
\hline 2 & 61.95 & 1.52 & 24.33 & 626.34 \\
\hline 3 & 57.88 & 1.53 & 27.07 & 585.20 \\
\hline 4 & 65.78 & 1.51 & 21.75 & 665.00 \\
\hline 5 & 72.62 & 1.50 & 17.15 & 734.14 \\
\hline 6 & 79.02 & 1.48 & 12.83 & 798.93 \\
\hline 7 & 86.82 & 1.46 & 7.58 & 877.78 \\
\hline 8 & 76.19 & 1.49 & 14.74 & 770.30 \\
\hline 9 & 94.46 & 1.44 & 2.43 & 955.00 \\
\hline 10 & 74.86 & 1.49 & 15.64 & 756.80 \\
\hline 11 & 78.64 & 1.48 & 13.09 & 795.02 \\
\hline 12 & 65.76 & 1.51 & 21.77 & 664.80 \\
\hline 13 & 58.76 & 1.53 & 26.48 & 594.05 \\
\hline 14 & 86.06 & 1.46 & 8.09 & 870.02 \\
\hline 15 & 71.76 & 1.50 & 17.72 & 725.50 \\
\hline 16 & 95.95 & 1.44 & 1.43 & 970.04 \\
\hline 17 & 72.74 & 1.50 & 17.06 & 735.40 \\
\hline 18 & 80.71 & 1.48 & 11.70 & 815.95 \\
\hline 19 & 87.09 & 1.46 & 7.40 & 880.44 \\
\hline 20 & 70.72 & 1.50 & 18.42 & 715.03 \\
\hline
\end{tabular}

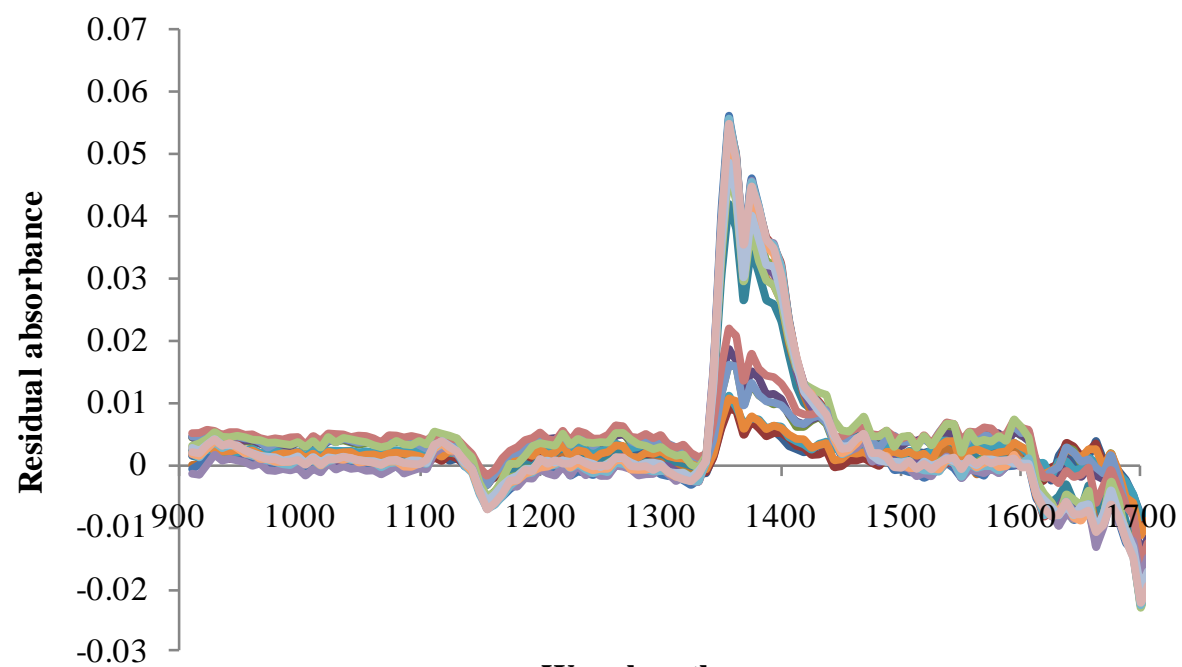

Wavelength, nm

Figure 34. Residual absorbances obtained by subtracting the spectra of mixtures shown in Table 29 from the experimentally measured validation spectra.

\section{Classical least squares regression on entire near infrared spectra to estimate landfill gas composition}

A statistical regression model is developed using the classical least squares (CLS) regression on the entire near infrared absorption spectra of landfill gas mixtures. Calibration database consisted of five spectra: three spectra of pure methane, carbon dioxide and water vapor; methane - water vapor mixture 
and carbon dioxide - water vapor mixture. To ensure accurate calibration, the spectra of methane - water vapor and carbon dioxide - water vapor mixtures are verified against numerical spectra of known mixtures. PLS Toolbox software is used to perform all computations.

The estimated carbon dioxide concentrations are not reasonable, which is most likely due to the very weak absorption of carbon dioxide compared to methane and water vapor. Thus, they are not shown here. Table 16 shows the estimated methane and water vapor concentrations in synthetic landfill gas mixtures. The estimated heating values will have the same accuracy as estimated methane concentration, as methane is the only component contributing towards the heating value. Table 16 also shows the comparison of landfill gas compositions estimated using the CLS on component-specific absorption bands and CLS on the entire near infrared absorption spectra.

Using the estimated concentrations, the spectra of validation mixtures are computed from the spectra of pure methane and water vapor. These computed spectra are then subtracted from the experimentally measured spectra of validation mixtures. From the difference spectra shown in Fig. 35, it can be seen that the residual absorbances are within \pm 0.005 absorbance units, which is very likely due to the spectrometer noise.

Comparing these estimated compositions to the compositions estimated by CLS on specific absorption bands (described in the previous section), it is clear that methane is underestimated, whereas water vapor is overestimated by the current method. The overestimation of methane is also clear from Fig. 35, where the residual absorbances have larger values $(\sim 0.01 \mathrm{AU})$ in the band near $1700 \mathrm{~nm}$.

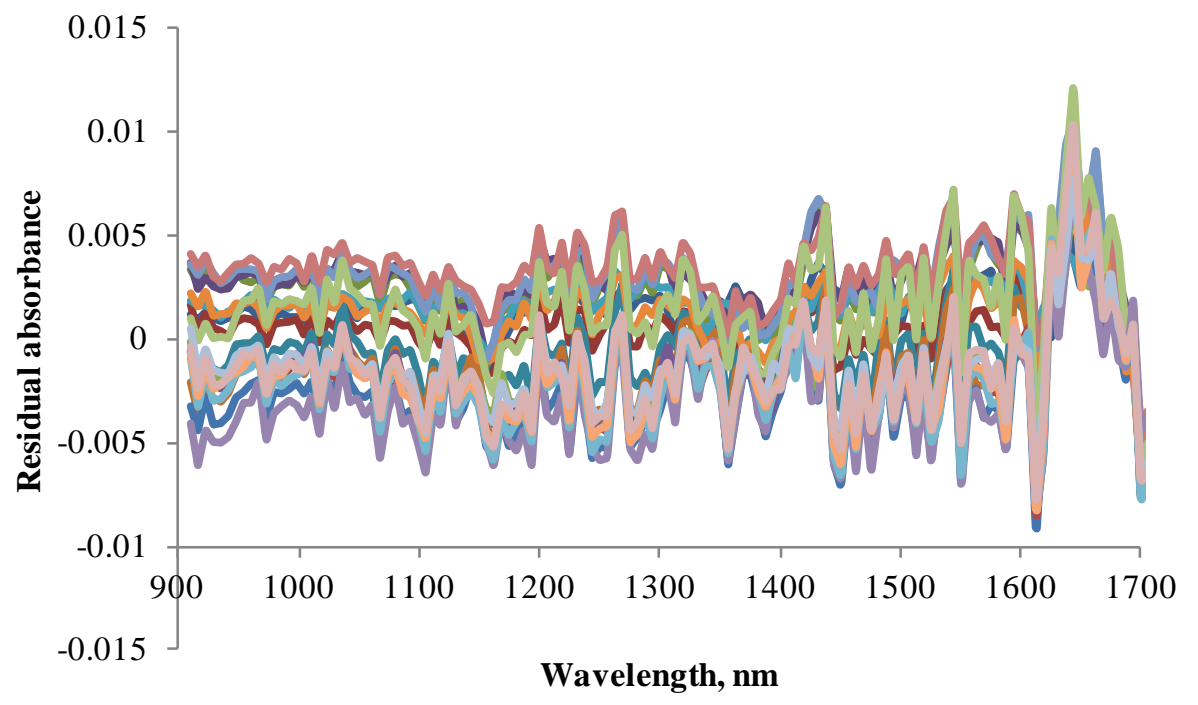

Figure 35. Residual absorbances computed by subtracting the absorption spectra of experimentally measured validation mixtures from the spectra of mixtures shown in Table 16 (columns 1 and 2). 
Table 16. Comparison of landfill gas compositions estimated using CLS on entire spectra and CLS on component-specific absorption bands.

\begin{tabular}{|c|c|c|c|c|c|c|}
\hline \multirow{2}{*}{$\begin{array}{l}\text { Mixt } \\
\text { ure }\end{array}$} & \multicolumn{2}{|c|}{ CLS on entire spectra } & \multicolumn{2}{|c|}{$\begin{array}{l}\text { CLS on component- } \\
\text { specific absorption bands }\end{array}$} & \multicolumn{2}{|c|}{ Difference } \\
\hline & $\begin{array}{l}\mathrm{CH}_{4}, \% \\
\text { (1) }\end{array}$ & $\begin{array}{l}\mathrm{H}_{2} \mathrm{O}, \% \\
\text { (2) }\end{array}$ & $\begin{array}{l}\mathrm{CH}_{4}, \% \\
(3)\end{array}$ & $\begin{array}{l}\mathrm{H}_{2} \mathrm{O}, \% \\
\text { (4) }\end{array}$ & (1) - (3) & $(2)-(4)$ \\
\hline 1 & 52.33 & 2.46 & 55.00 & 2.51 & -2.67 & -0.05 \\
\hline 2 & 57.58 & 2.74 & 60.42 & 2.47 & -2.84 & 0.27 \\
\hline 3 & 48.40 & 3.49 & 53.88 & 3.34 & -5.48 & 0.15 \\
\hline 4 & 55.58 & 3.67 & 60.64 & 3.64 & -5.05 & 0.03 \\
\hline 5 & 56.52 & 6.63 & 61.52 & 6.20 & -5.01 & 0.43 \\
\hline 6 & 61.30 & 7.40 & 66.15 & 6.86 & -4.86 & 0.55 \\
\hline 7 & 67.16 & 8.45 & 71.51 & 7.81 & -4.35 & 0.64 \\
\hline 8 & 56.07 & 8.35 & 61.45 & 7.72 & -5.37 & 0.63 \\
\hline 9 & 76.32 & 7.60 & 80.13 & 7.11 & -3.81 & 0.49 \\
\hline 10 & 56.82 & 7.64 & 61.82 & 7.01 & -5.00 & 0.62 \\
\hline 11 & 73.27 & 2.64 & 75.63 & 2.67 & -2.36 & -0.03 \\
\hline 12 & 60.16 & 2.82 & 63.45 & 2.64 & -3.29 & 0.18 \\
\hline 13 & 48.87 & 3.49 & 54.60 & 3.35 & -5.73 & 0.14 \\
\hline 14 & 73.71 & 4.07 & 78.72 & 4.03 & -5.01 & 0.03 \\
\hline 15 & 51.44 & 7.12 & 58.73 & 6.78 & -7.29 & 0.34 \\
\hline 16 & 76.95 & 8.24 & 80.63 & 7.67 & -3.68 & 0.58 \\
\hline 17 & 52.80 & 8.39 & 58.15 & 7.75 & -5.36 & 0.64 \\
\hline 18 & 61.36 & 8.09 & 66.17 & 7.52 & -4.81 & 0.57 \\
\hline 19 & 69.18 & 7.47 & 73.44 & 6.99 & -4.26 & 0.48 \\
\hline 20 & 50.47 & 8.33 & 56.06 & 7.74 & -5.59 & 0.59 \\
\hline
\end{tabular}

\subsection{GQS Engine Testing}

\subsection{GQS Field Testing}

\subsubsection{Testing at Glacier Ridge landfill}

Figs. 36 and 37 show an overall layout and a photograph of the GQS installation at the Veolia Environmental Services Glacier Ridge landfill gas, Veolia Environmental Services in Horicon, WI respectively. The experimental setup included a sample conditioning system and GQS with a computer for data acquisition and control. A gas chromatograph was utilized to verify the concentrations of the landfill gas components. 


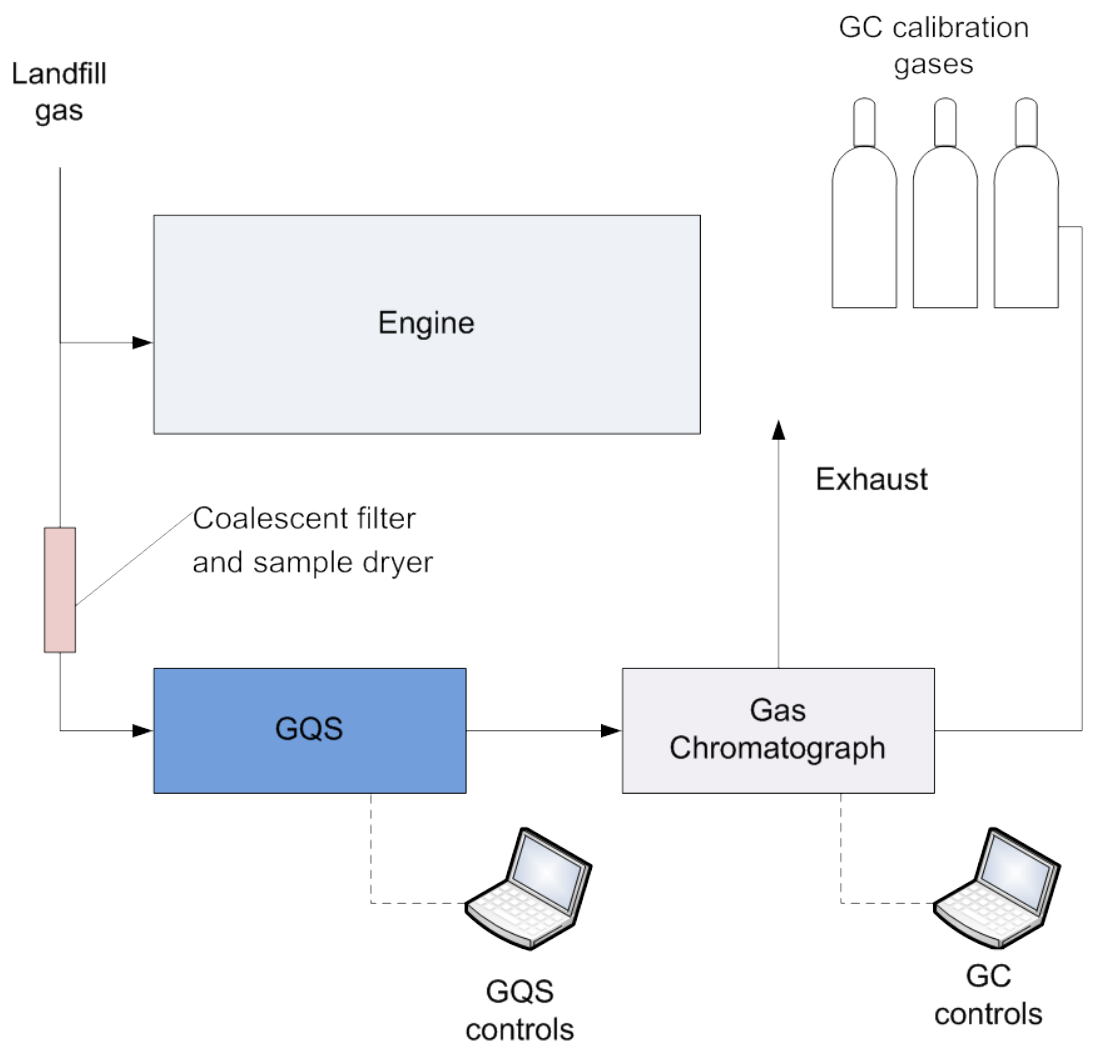

Figure 36. Schematic of the GQS installation at Glacier Ridge.

The GQS sensor and GC were set up to sample methane concentrations in the landfill gas supply to the engines. During last quarter the project team continued sampling of the Glacier Ridge landfill gas with GQS and GC. The GQS software was modified to improve the sensor accuracy. The polynomial fitting method previously used in the drift correction algorithm was completely replaced with the "minimum absorbance subtraction" approach. The minimum absorbance is assumed to be the error caused by the light source and /or spectrometer drift. Fig. 38 shows comparison of GC and GQS measurements of methane concentrations in the landfill gas obtained after the implementation of the new correction algorithm. 


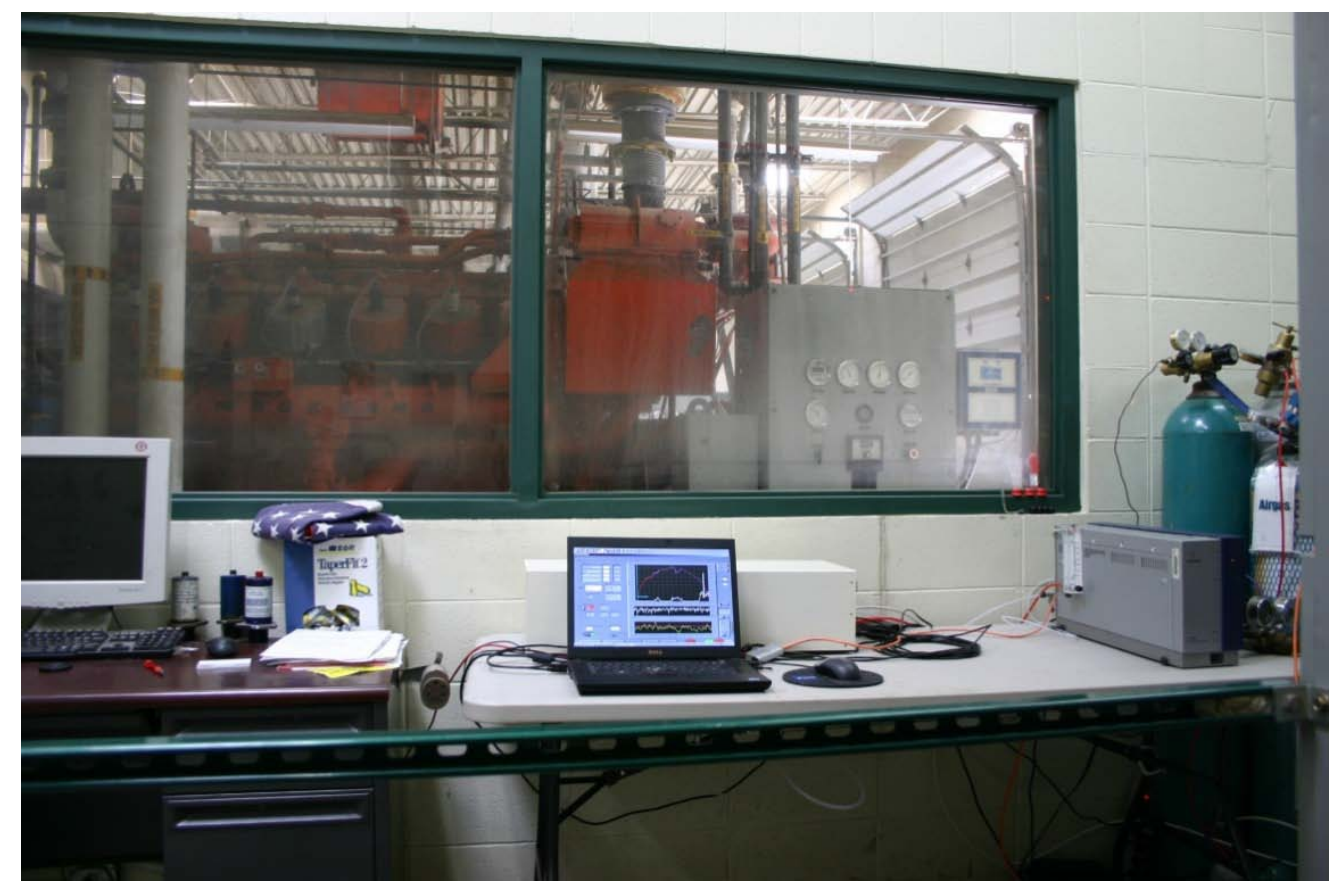

Figure 37. Photograph of the GQS installation at Glacier Ridge

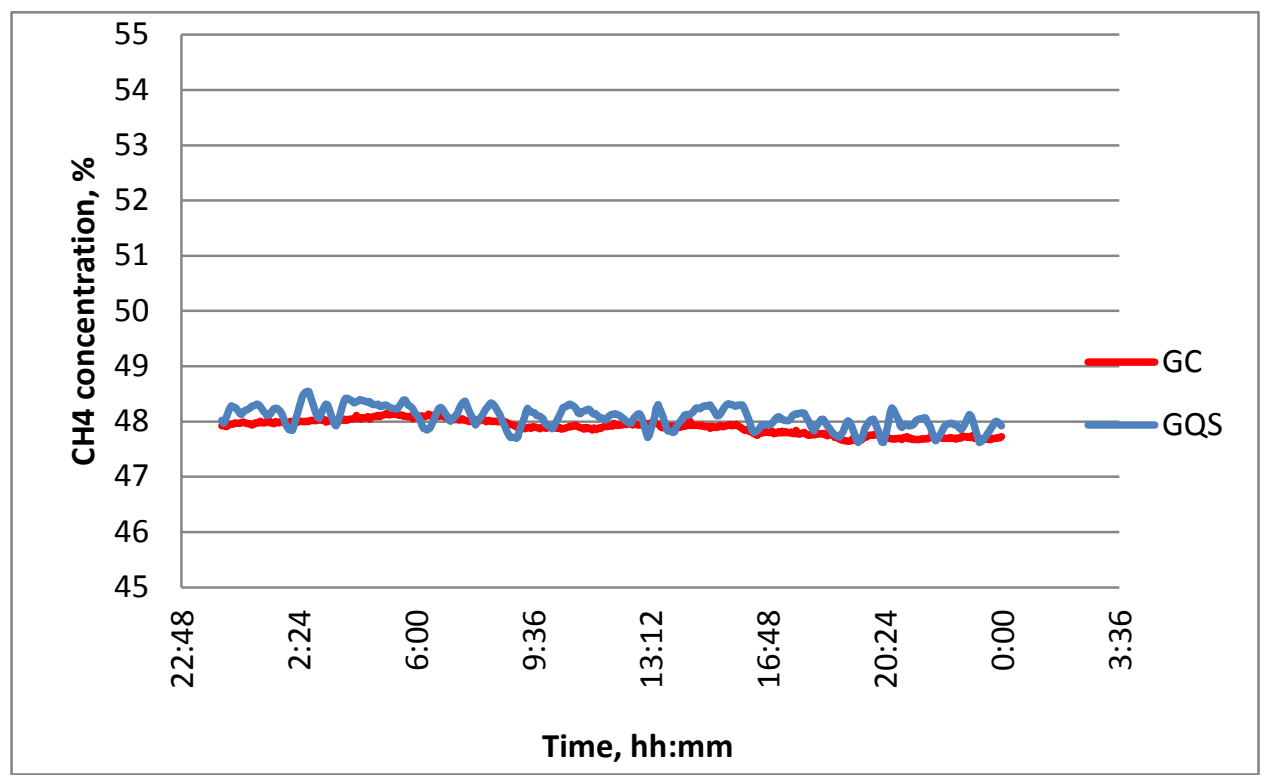

Figure 38. Methane concentration measurements at Glacier Ridge landfill 01/20/2010.

The comparison of the data obtained during January 2010 (Fig. 38) with the measurements taken during the testing conducted in October 2010 (Fig. 39) clearly demonstrates significantly better agreement between the GC and GQS measurements. 


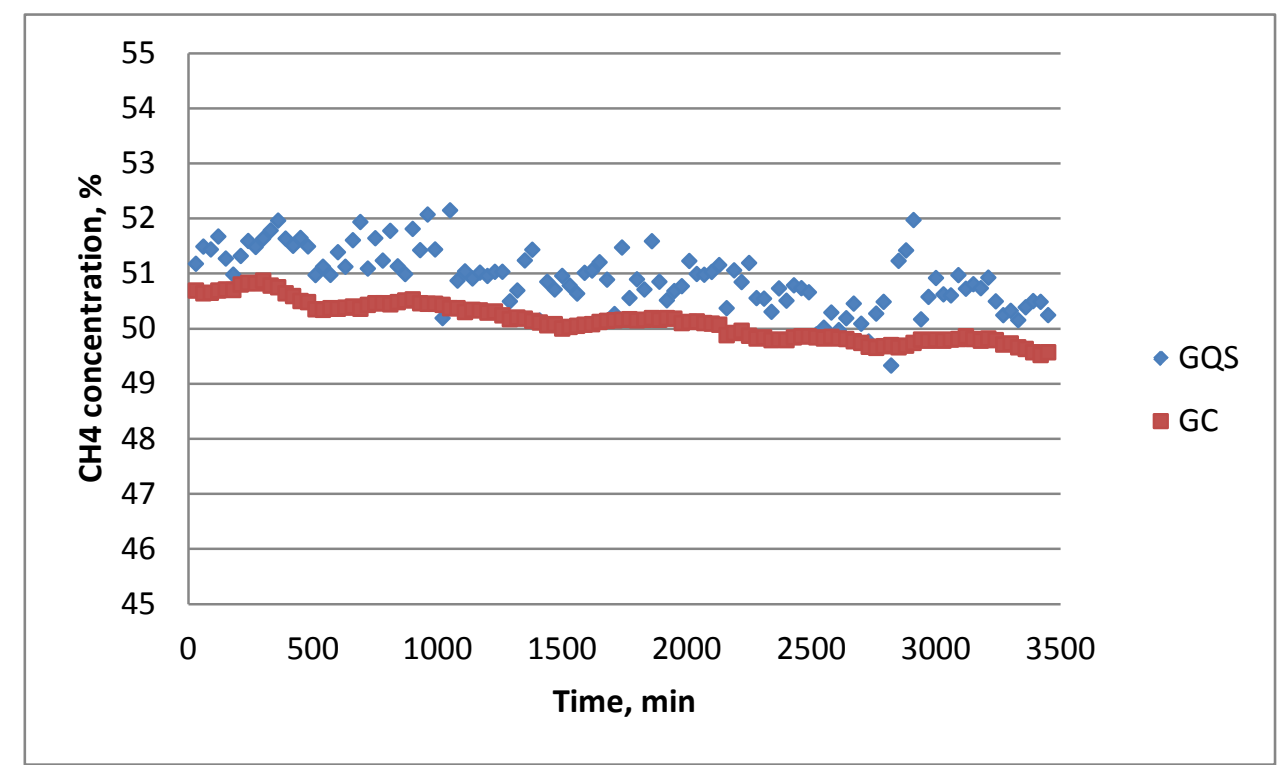

Figure 39. Methane concentration measurements at Glacier Ridge landfill 10/11/2010.

It was hypothesized that a high humidity of the landfill gas mixture can result in over-prediction of the concentrations of hydrocarbons (as observed in WI Glacier Ridge landfill testing). Fig. 40 shows the comparison of gas chromatograph and GQS results and it is clear that, during the entire testing, methane is continuously over-predicted by an approximately constant amount, which has occurred, most probably, due to the presence of water vapor. For better accuracy, it is recommended to dehumidify the fuel mixture, before it is passed through the absorption cell for composition measurement.

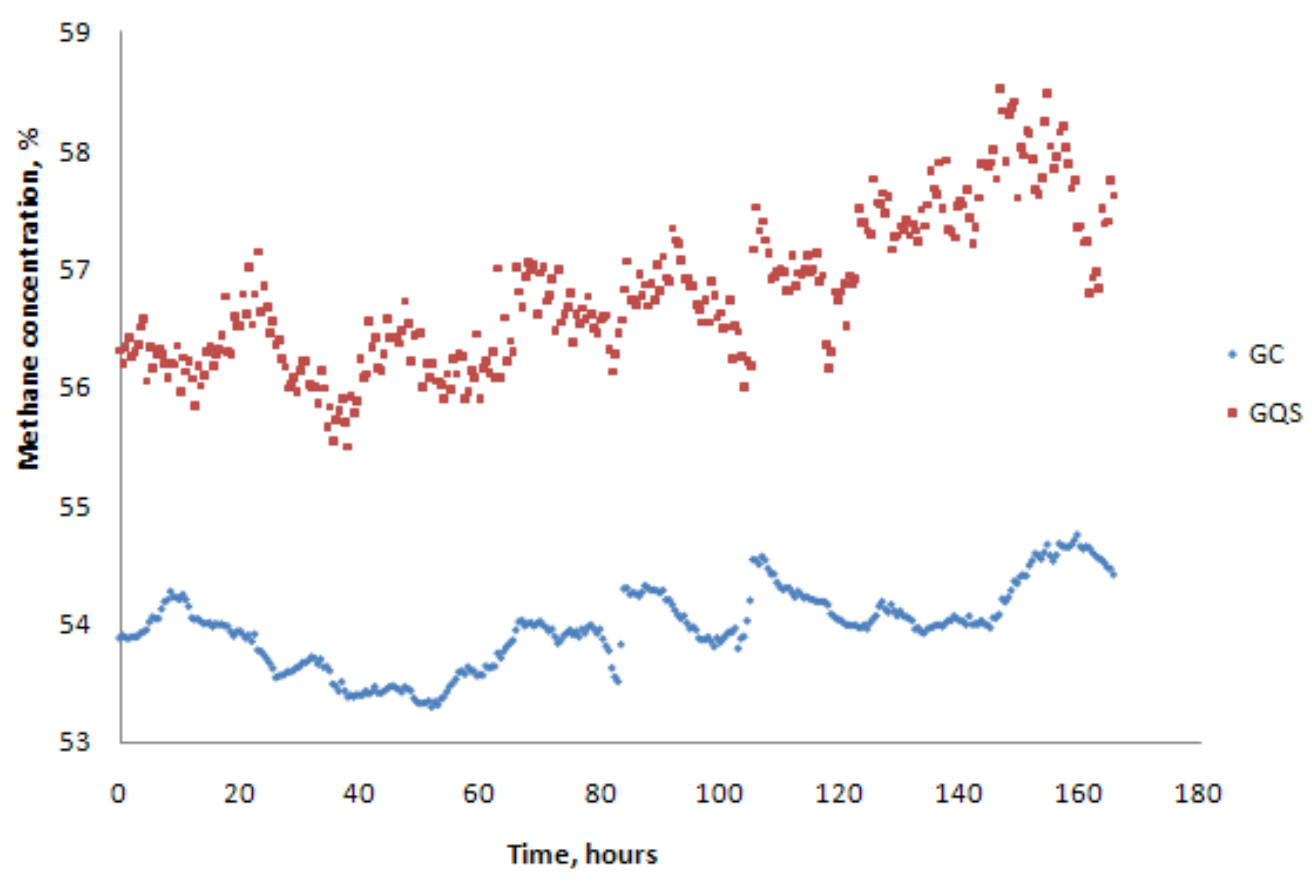

Figure 40. Comparison of GC and GQS predicted methane concentrations during WI glacier ridge landfill site testing. There is a continuous over-prediction of methane by GQS. 


\subsubsection{Field testing at Steuben county landfill site}

The Bath Landfill at Steuben County, New York has a Landfill-Gas-To-Energy (LFGTE) project [1]. The landfill accepts solid waste, construction and demolition debris, contaminated recyclables, household waste etc for burial (Fig. 41). The facility includes landfill gas collection wells (Fig. 42), collection system piping, blower and power generation unit. Vertical gas collection wells are drilled into the deepest parts of the landfill and are capped with well heads. The well heads allow measurement and control of the gas flow rate. As the landfill gas flows through the piping system, it gets condensed and is removed using condensate knockout structures. The gas composition has a wide variation due to varying subsurface conditions, such as type of waste, temperature and moisture level. After condensate removal, the gas consists of 40 to $50 \%$ methane, 30 to $60 \%$ carbon dioxide, 10 to $20 \%$ nitrogen and balance oxygen. The gas is then drawn into the power generation unit using the blower and is combusted in two lean burn, low BTU, internal combustion reciprocating engines shown in Fig. 43.

For continuous process control purpose, the concentration of methane in the landfill gas is measured using the gas quality sensor in real-time. This information is then converted into a proportionate analog signal on a scale of 4 to $20 \mathrm{~mA}$. No methane in the gas corresponds to a current of $4 \mathrm{~mA}$ and $100 \%$ methane corresponds to $20 \mathrm{~mA}$. The current is then fed to the ECM, which has a calibration matrix correlating the current input to methane concentration. Depending on the current input, ECM will control the air fuel ratio going to the engine [2]. By optimizing the air fuel ratio, higher combustion efficiency and reduced emissions can be obtained. When methane falls below $40 \%$ or in other words, when input current goes below $10.15 \mathrm{~mA}$, the engine shuts down itself.

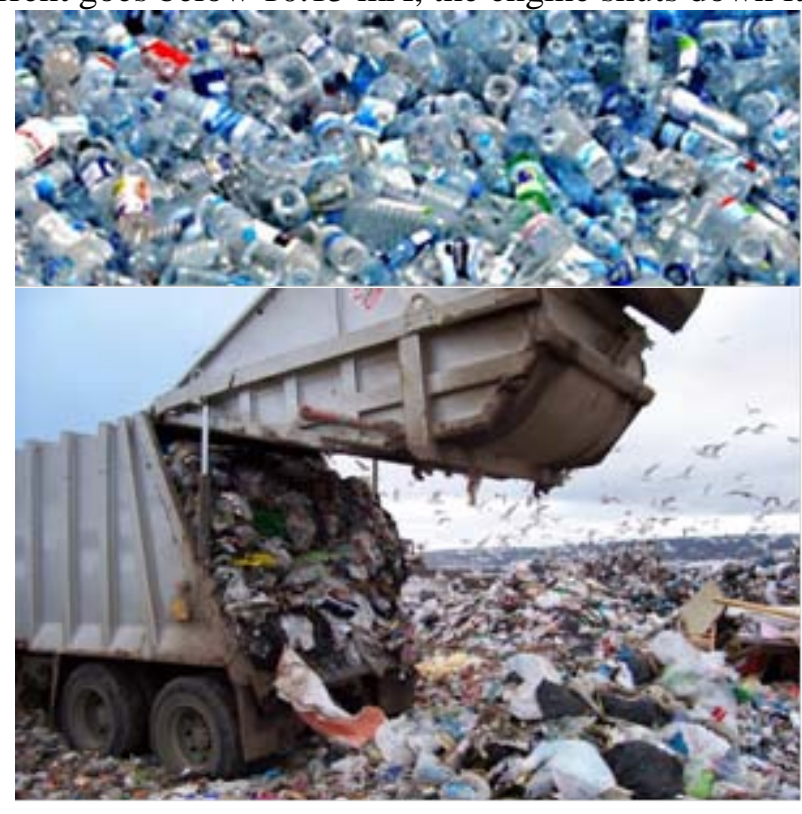

Figure 42 Landfill waste.

Fig. 44 shows the GQS setup in a blower room. A dehumidifier is included in the setup before the fuel flow cell to dehumidify the landfill gas. The gas then flows through the flow cell and finally goes to the exhaust. The gas flow rate is maintained at 4 SCFH ( $\sim 2$ standard liters per minute) using a rotameter. The GQS working cycle consists of purging and measurement phases. Purging is necessary to minimize the drift in measured light intensity. Also, after purging phase ends, due to the presence of humidifier before the fuel flow cell, the GQS requires slightly longer time ( 10 seconds) to reach to its full 
response. The GQS software is updated to feed the last measured methane concentration to the ECM during purging phase for uninterrupted operation of the engine. A post-purging delay (before resuming feed-forward) needs to be added to the algorithm. Before purging, the supply of analog signal to the ECM is cut off manually, the sensor is purged and then again the feed forward is started.

The existing calibration data set has 47.2 to $56.52 \%$ methane and 35.1 to $37.77 \%$ carbon dioxide (Table 17). It is observed during the test that the GC measured compositions of landfill gas are close to the existing calibration limit of the GQS, thus, one calibration mixture having composition listed in Table 18 is added to this data set. The calibration model is developed using the first two PCA/PLS factors and is used for estimating the composition and heating value of landfill gas. The GQS measured methane concentration is observed to vary between 44 to $49 \%$ during the test and is found to be close to GC measured methane concentration.

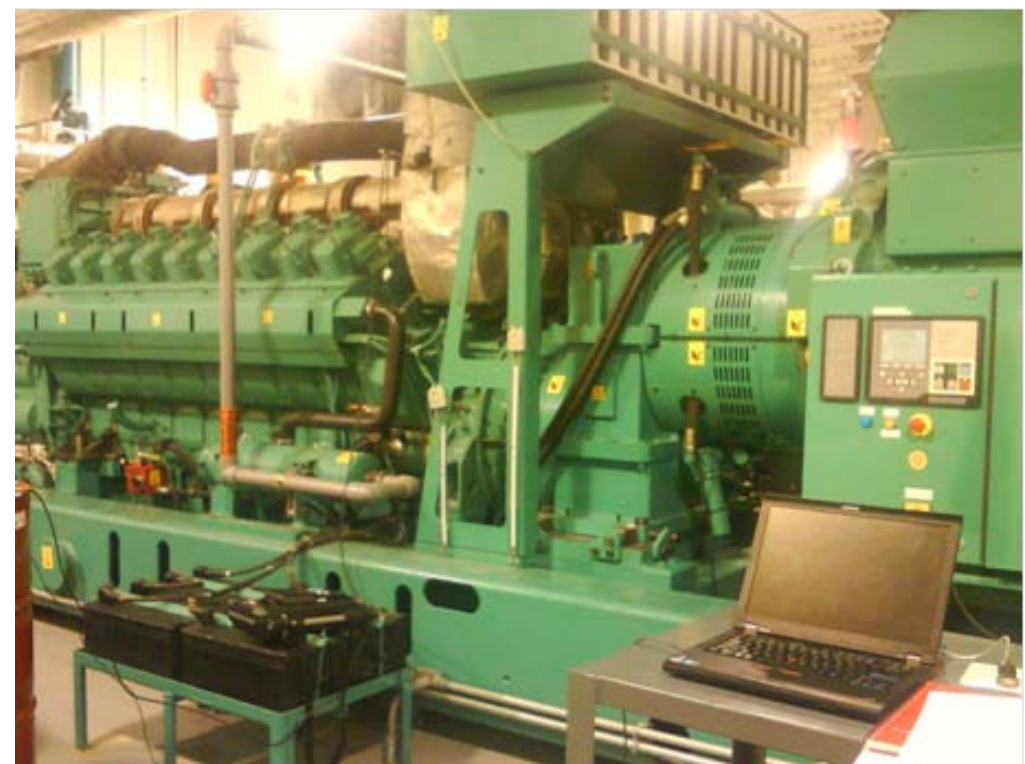

Figure 43. A lean burn, low BTU, internal combustion reciprocating stationary engine at the Bath Landfill, Steuben County, New York. As typically, this lean-burn engine is also turbocharged and aftercooled. This is a V18, $91 \mathrm{~L}$ engine producing $2 \mathrm{MW}$ power and can run safely on landfill gas containing as low as $40 \%$ methane ( 400 BTU/SCF).

Table 17._ Original calibration mixtures.

\begin{tabular}{|c|c|c|c|}
\hline $\begin{array}{c}\text { Sr. } \\
\text { No. }\end{array}$ & $\begin{array}{c}\text { Meth } \\
\text { ane }\end{array}$ & $\begin{array}{c}\text { Carbon } \\
\text { dioxide }\end{array}$ & Heating value, BTU/SCF \\
\hline 1 & 52.84 & 36.89 & 534.46 \\
\hline 2 & 56.52 & 37.77 & 571.73 \\
\hline 3 & 55.2 & 37.36 & 558.36 \\
\hline 4 & 52.44 & 36.68 & 530.41 \\
\hline 5 & 51.88 & 36.47 & 524.74 \\
\hline 6 & 51.4 & 36.5 & 520 \\
\hline 7 & 51.2 & 36.5 & 518 \\
\hline 8 & 49 & 35.7 & 497 \\
\hline 9 & 47.9 & 35.4 & 486.6 \\
\hline 10 & 47.6 & 35.3 & 483.7 \\
\hline 11 & 47.2 & 35.1 & 478.8 \\
\hline 12 & 48.92 & 35.64 & 494.77 \\
\hline
\end{tabular}


Table 18. Calibration mixture added to the existing GQS training data set during the field test.

\begin{tabular}{|c|c|c|c|}
\hline$\#$ & $\begin{array}{c}\text { Metha } \\
\text { ne }\end{array}$ & $\begin{array}{c}\text { Carbon } \\
\text { dioxide }\end{array}$ & Heating value, BTU/SCF \\
\hline 13 & 49.83 & 35.6 & 508.88 \\
\hline
\end{tabular}

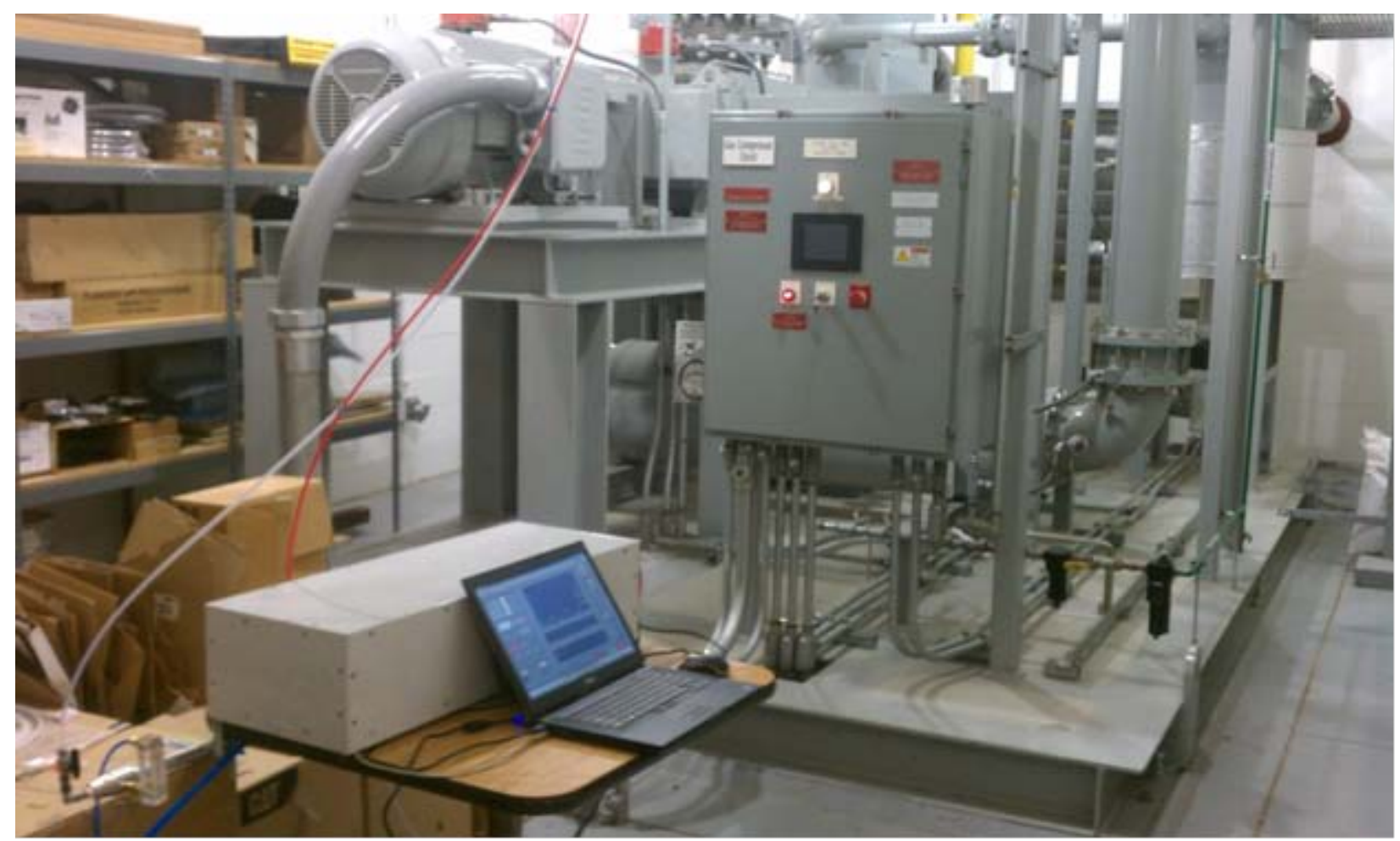

Figure 44. GQS setup at Bath Landfill, Steuben County, New York,

Fig. 45 and Fig. 46 show the composition and heating value of landfill gas monitored continuously at the site for approximately five hours, using a gas chromatograph and the gas quality sensor concurrently. The GQS measurements match closely with the GC measurements. As during the testing, automated purging is turned off and it is done manually at unequal intervals of time, there is a particular pattern in the predicted measurements. Also, it is observed during the testing that after the sensor box gets heated to its operational temperature of $40{ }^{\circ} \mathrm{C}$, the predicted measurements have relatively lesser drift (approximately, in the last 60 to 90 minutes of testing). This lesser drift in the predicted measurements is possibly due to thermal stability in spectrometer and light source achieved by this time. These observations suggest that an important parameter in sensor operation is warm up time of all the hardware in the sensor housing. Further experimental investigation is necessary in order to accurately determine the reasons for particular pattern observed in the predicted measurements. 


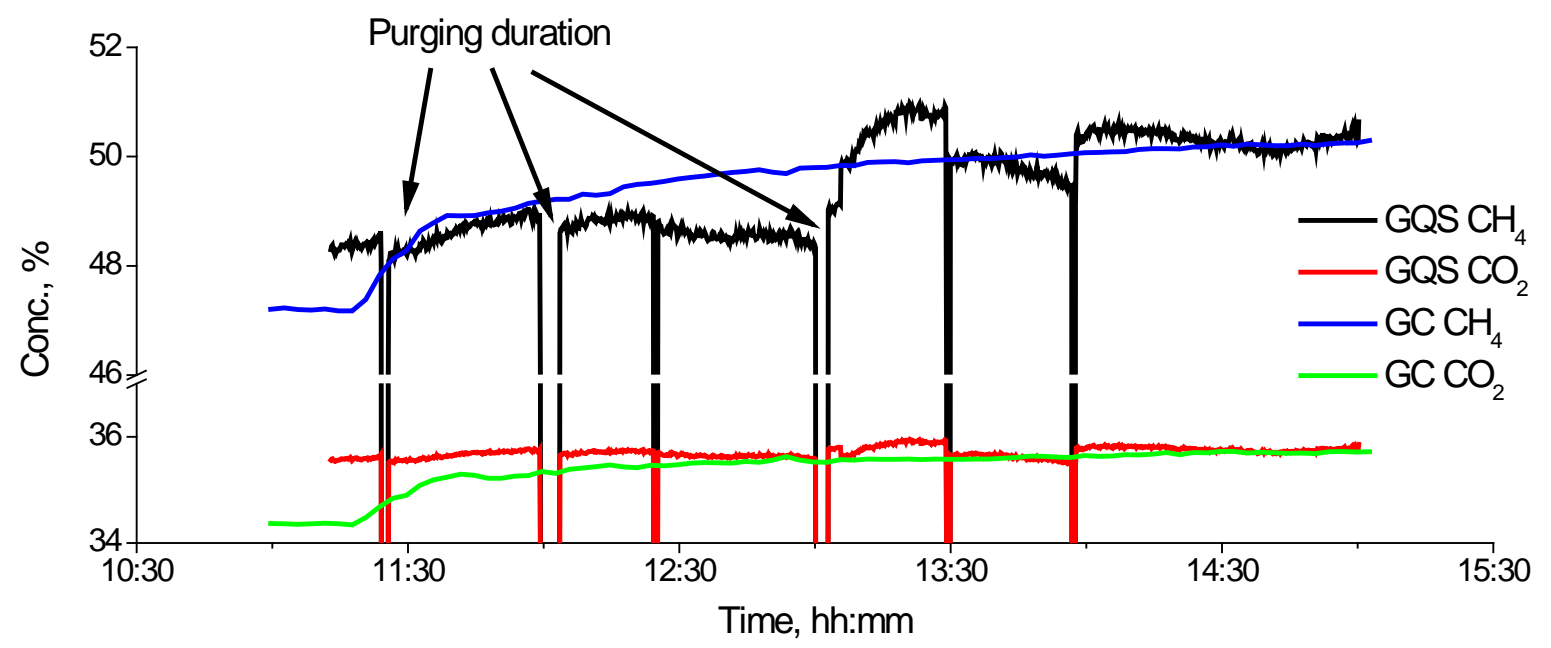

Figure 45. Continuous monitoring of composition of landfill gas by GQS and GC.

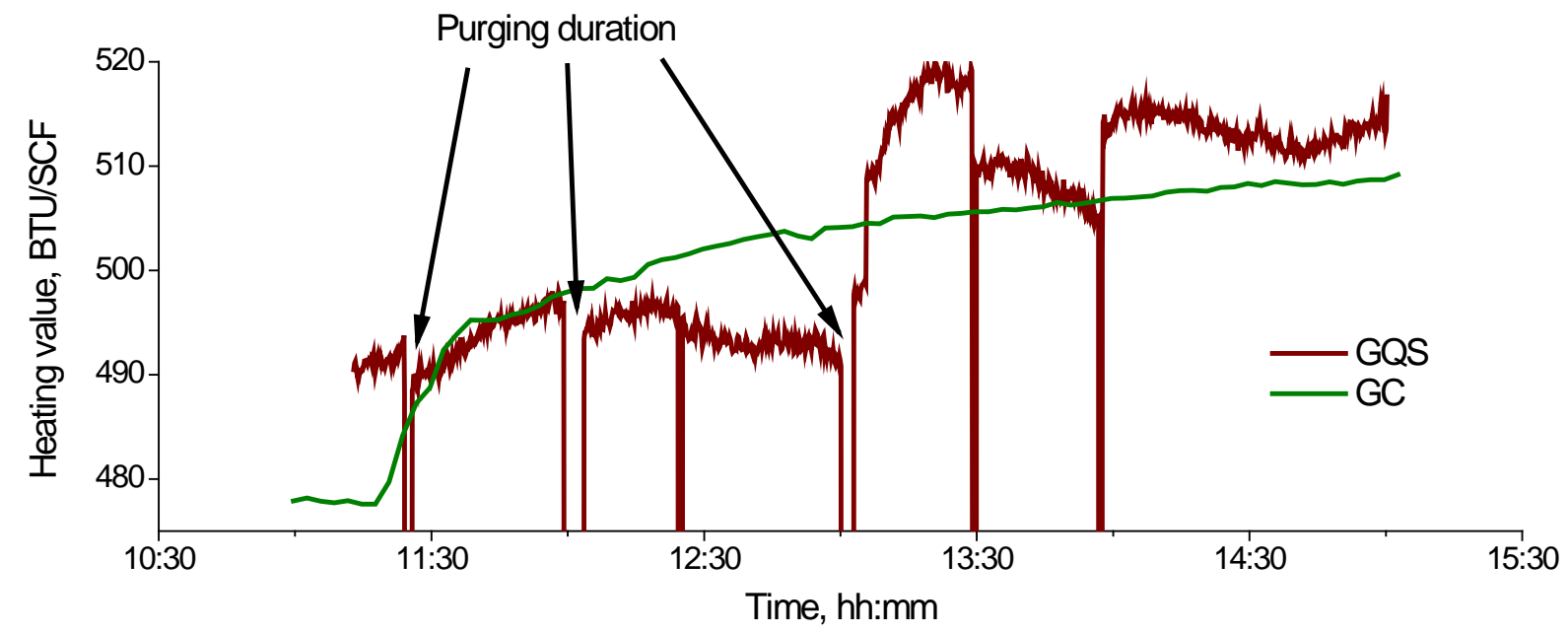

Figure 46. Continuous monitoring of heating value by GQS and GC. 


\subsection{Development of Gas Quality Sensor Specifications for Producer Gas}

\subsubsection{Specifications of commercially available hydrogen sensors}

Apart from hydrocarbons, one of the important components of a natural/landfill gas mixture is hydrogen. Gaseous hydrogen, being a homonuclear diatomic molecule, does not possess permanent electric dipole moment to directly absorb radiation. Thus, neither rotational nor vibrational transitions produce an oscillating dipole moment and associated dipole moment radiation. As a result, hydrogen does not exhibit rotation or rotation-vibration spectra. Hence, hydrogen in hydrocarbon fuel mixtures cannot be detected using the gas quality sensor (GQS). For accurate determination of the compressibility factor and mixture composition, it becomes necessary to integrate an existing hydrogen sensing technology with the GQS and enhance the sensor algorithm accordingly.

Most of the commercially available hydrogen sensors are based on absorption of hydrogen by palladium, forming palladium hydride. As a result of this absorption process, the characteristics of a transistor (in a MOSFET sensor) or a capacitor (in a MOS capacitor sensor) change and this change can be quantified as a measurement of the amount of hydrogen present. The disadvantages of these sensors include cross-sensitivity to other gases, limited detection range, high temperature operation, susceptibility to humidity variation etc. For example, a metal oxide semiconductor sensor requires the presence of oxygen to detect and measure hydrogen. These sensors are cross-sensitive to other reducing gases, as well. For selecting a suitable hydrogen sensing technology for use with the GQS, a comparative study of commercially available hydrogen sensors was conducted. The criteria used for comparison of the sensors were cross-sensitivity, accuracy, response time, operation conditions and cost. Table 19 summarizes the specifications of these sensors. From Table 19, it is clear that some of the sensors can tolerate very small amounts carbon monoxide and hydrogen sulfide. Most of the sensors can tolerate pressures up to 50 psi and temperatures up to $50{ }^{\circ} \mathrm{C}$. Our process streams fall well within this pressure and temperature range.

The response times of these sensors vary between 30 to 60 seconds, except for a MOSFET sensor, which has the fastest response (less than 5 seconds). Also, depending on the sensing technology used, the costs of these sensors may vary between USD 700 to 5000. (The cost data for all the sensors is not available as of now.) For example, a palladium based MOS sensor (HY OPTIMA 730, H2Scan) costs approximately USD 5000; however, a MOSFET sensor (HPS100, Applied Sensor) costs approximately USD 700, without considerable loss of accuracy. Thus, a MOSFET sensor seems to be the most suitable sensor to be used with GQS for measurement of hydrogen concentration in hydrocarbon fuel mixture. 
Table 19. Comparison of commercially available hydrogen sensors.

\begin{tabular}{|c|c|c|c|c|c|c|}
\hline $\begin{array}{l}\text { Working } \\
\text { principle }\end{array}$ & Product name & Cross-sensitivity & Accuracy & $\begin{array}{l}\text { Respons } \\
\text { e time }\end{array}$ & $\begin{array}{l}\text { Operation } \\
\text { conditions }\end{array}$ & Price (USD) \\
\hline $\begin{array}{l}\text { Pd based MOS } \\
\text { sensor }\end{array}$ & \begin{tabular}{lr}
\multicolumn{2}{c}{ HY-OPTIMA } \\
730 & In-Line \\
Process & Hydrogen \\
Monitor (H2Scan)
\end{tabular} & $\begin{array}{l}100 \mathrm{ppm} \text { of } \mathrm{CO} \text {, } \\
1000 \mathrm{ppm} \mathrm{H}_{2} \mathrm{~S}\end{array}$ & $\begin{array}{l}\quad \pm 0.3 \% \text { absolute } \\
\text { for } 0.5 \text { to } 10 \% \mathrm{H}_{2} \\
\pm 1 \% \text { absolute for } 10 \\
\text { to } 100 \% \mathrm{H}_{2}\end{array}$ & sec $^{t 90}<30$ & $\begin{array}{l}\text { pressure upto } \\
100 \text { psig }\end{array}$ & 4981 \\
\hline $\begin{array}{l}\text { MOSFET and } \\
\text { thermal } \\
\text { conductivity }\end{array}$ & $\begin{array}{c}\text { HPS100 } \\
\text { (Applied Sensor) }\end{array}$ & $\begin{array}{l}\quad \text { No detection } \\
\text { towards } \mathrm{HCs}, \mathrm{N}_{2} \text {, } \\
\mathrm{NO}_{\mathrm{x}}, \mathrm{CO}_{2}, \mathrm{CO} \text { and } \\
\mathrm{H} 2 \mathrm{~S} \\
\text { Humidity influence }< \\
1 \% \text { typical }\end{array}$ & $\pm 2 \%$ typical & $\begin{array}{l}\quad t 90<5 \\
\text { sec, speed of } \\
\text { recovery }<5 \\
\text { sec }\end{array}$ & $\begin{array}{l}\quad-40 \text { to }+90{ }^{\circ} \mathrm{C} \text {, } \\
\text { upto } 3 \text { bar, } 5 \text { to } \\
100 \% \\
\text { including } \\
\text { condensation }\end{array}$ & 700 \\
\hline \begin{tabular}{l}
\multicolumn{1}{c}{ Difference } \\
between high \\
thermal \\
conductivity of $\mathrm{H}_{2}$ \\
and reference gas
\end{tabular} & $\begin{array}{l}\text { Hycision } 10 \text { (C } \\
\text { Squared) }\end{array}$ & & $\pm 2 \%$ & $\begin{array}{l}\mathrm{t} 90<60 \\
\text { sec }\end{array}$ & $\begin{array}{l}0 \text { to } 50{ }^{\circ} \mathrm{C}, 0 \\
\text { to } 95 \% \mathrm{RH}, 100 \\
\mathrm{cc} / \mathrm{min} \text { to } 300 \\
\mathrm{cc} / \mathrm{min} \text {, } \\
\text { temperature } \\
\text { compensated }\end{array}$ & \\
\hline $\begin{array}{l}\quad \text { Change in } \\
\text { resistance of a thin } \\
\text { Pd-Ni film }\end{array}$ & $\begin{array}{l}\text { Model } 2230 \text { In- } \\
\text { line Hydrogen } \\
\text { Analyzer } \\
\text { (Teledyne } \\
\text { Analytical } \\
\text { Instruments) }\end{array}$ & $\begin{array}{l}\text { ppm level CO } \\
\text { tolerance }\end{array}$ & $\begin{array}{l} \pm 0.5 \% \mathrm{H}_{2} \text { at } 10 \% \\
\mathrm{H}_{2} \text { or } 3.2 \% \mathrm{H}_{2} \text { at } \\
100 \% \mathrm{H}_{2}\end{array}$ & $\begin{array}{l}\mathrm{t} 90=30 \\
\text { sec max }\end{array}$ & $\begin{array}{l}-20 \text { to } 40{ }^{\circ} \mathrm{C} \text {, } \\
14 \text { bar gage, } 0.1 \\
\text { to } 50 \text { slpm }\end{array}$ & 5000 \\
\hline & $\begin{array}{l}\text { Optical } \\
\text { hydrogen sensor } \\
\text { (Baltic Fuel Cells, } \\
\text { Germany) }\end{array}$ & $\begin{array}{l}\quad \text { None to } \mathrm{CO}_{2}, \mathrm{~N}_{2} \text {, } \\
\mathrm{O}_{2} \text {, saturated } \\
\text { hydrocarbons, inert } \\
\text { gases }\end{array}$ & $\begin{array}{l}(0.1 * \text { indication } \\
\text { value } \% \text { by volume }\end{array}$ & sec $^{\mathrm{t} 90}<60$ & $\begin{array}{l}-15 \text { to } 50{ }^{\circ} \mathrm{C} \text {, } \\
750 \text { to } 1750 \mathrm{hPa} \\
(10.88 \mathrm{psi} \text { to } \\
25.38 \mathrm{psi}), 0 \text { to } \\
80 \% \mathrm{RH}, \text { non- } \\
\text { condensing, } 0 \text { to } \\
1000 \mathrm{sccm} / \mathrm{min}\end{array}$ & \\
\hline
\end{tabular}




\subsubsection{Response time and cross-sensitivity of hydrogen gas sensor}

The HPS-100C (Applied Sensor Inc.) is a module for measuring the concentration of hydrogen in a gaseous mixture and is calibrated with carbon dioxide as the background gas. According to the specifications, the sensor should have a response time of less than 5 seconds and it should not be crosssensitive to hydrocarbons. The sensor was tested to determine whether it is compatible for integration with the gas composition sensor. The most important characteristics of the sensor for us are the response time and cross-sensitivity to other gases, such as hydrocarbons. The sensor is an open flow unit (and not flow-through) and gives a PWM (pulse width modulation) output signal with a $255 \mu$ s period. The pulse widths for different types of messages are shown in Table 20. The signal can be measured by connecting the sensor output to a digital storage oscilloscope. The pulse width is expected to increase linearly with hydrogen concentration.

Table 20. Pulse width.

\begin{tabular}{|c|c|}
\hline $\begin{array}{c}\text { Message } \\
\text { type }\end{array}$ & $\begin{array}{c}\text { Pulse } \\
\text { width }\end{array}$ \\
\hline Error & $10 \mu \mathrm{s}$ \\
\hline $\begin{array}{c}0 \% \\
\text { hydrogen }\end{array}$ & $20 \mu \mathrm{s}$ \\
\hline $\begin{array}{c}100 \% \\
\text { hydrogen }\end{array}$ & $240 \mu \mathrm{s}$ \\
\hline
\end{tabular}

Fig. 47a shows the fitting system used for connecting the sensor to PTFE tubing (the sensor has a metric thread). A $1 / 8$ inch copper tube passes through multiple fittings having larger diameters, up to the surface of a MOSFET in the hydrogen sensor. This helps in reducing the gas diffusion time, if the sensor were directly connected on-line. The gas stream passes through this copper tube and then to the exhaust. Fig. 47b shows the sensor connected to a digital storage oscilloscope and a power supply. The gas is supplied at a desired flow rate using MKS mass flow controllers.

From Table 20, the baseline (or reference) is a pulse width of $20 \mu \mathrm{s}$, when no hydrogen is present. However, due to some unknown reasons, the sensor showed approximately $36 \mu$ s pulse (Fig. 48a). One of the possible reasons is that the sensor surface might have been altered due to exposure to methane.

In order to study the response time characteristics, the sensor was exposed to pure hydrogen flowing at 0.5 SLM through PTFE tubing. As soon as, the sensor is exposed to pure hydrogen, the pulse width starts increasing and reaches a value of $219.2 \mu \mathrm{s}$ in approximately 40 seconds (Fig. 48b) and remains constant at this value. However, the expected maximum pulse width corresponding to pure hydrogen is $240 \mu \mathrm{s}$, according to the specifications (Table 20). The presence of tubing and a mixing chamber, having a volume of 1 standard liter (comparable with that of the GQS) also contributes towards the longer than expected response time.

Similarly, in order to verify the selectivity to hydrogen or cross-sensitivity to methane, the sensor was exposed to a stream of pure methane at the same flow rate (0.5 SLM). Unexpectedly, the pulse width started increasing and stabilized at $66.2 \mu \mathrm{s}$ (Fig. 48c). This signal seems to be reproducible, which suggests a possibility that cross-sensitivity may be mathematically correctable in the GQS algorithm. 


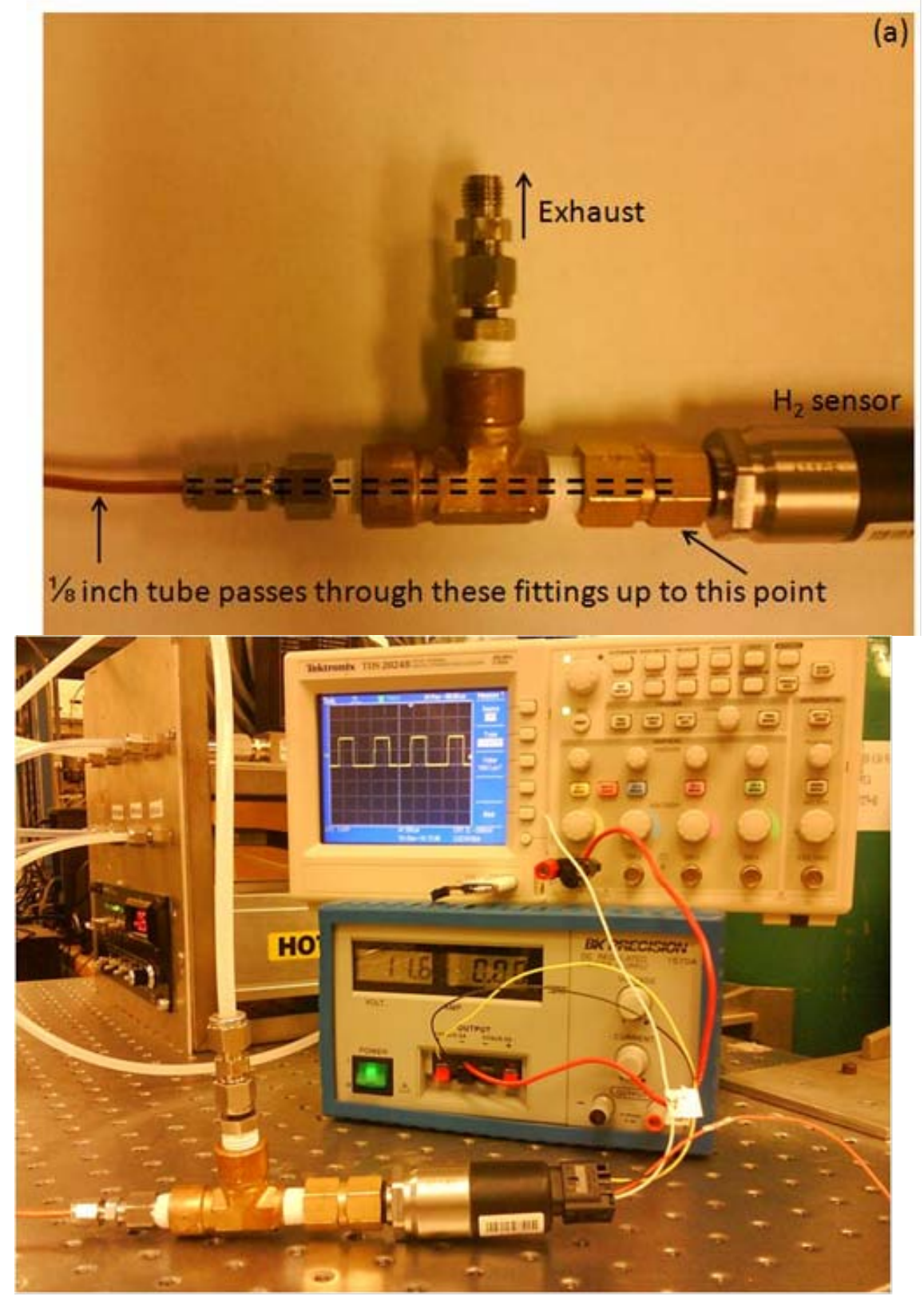

Figure 47. (a) HPS-100C connected using multiple fittings. An arrangement of a smaller copper tube inside a larger tube facilitates direct exposure of MOSFET sensor to the gaseous stream and thus assists in reducing the gas diffusion time; (b) Experimental setup for studying the sensor characteristics. 

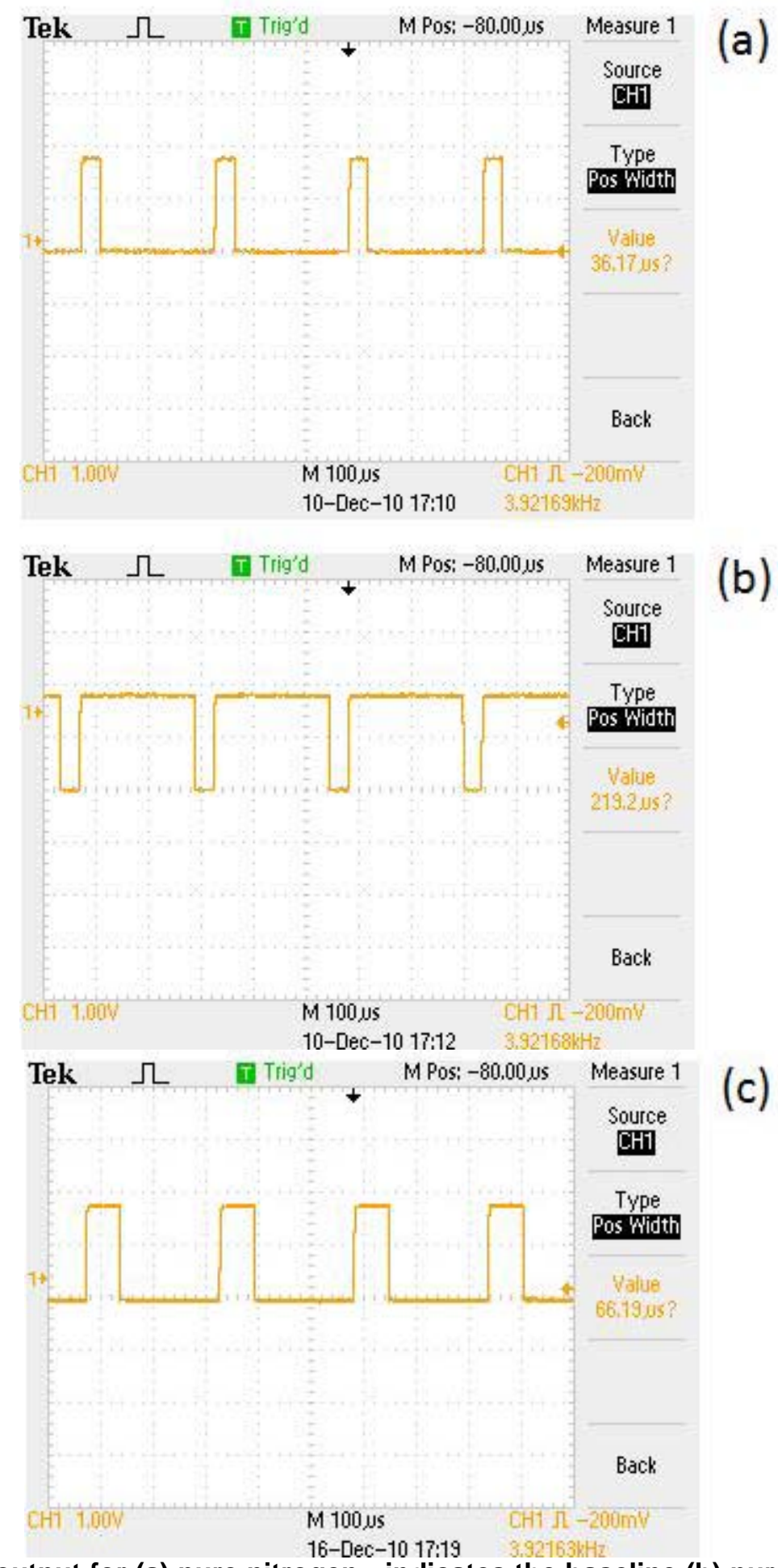

Figure 48. PWM output for (a) pure nitrogen - indicates the baseline (b) pure hydrogen (c) pure methane.

The linearity in response and cross-sensitivity to methane were studied by measuring the sensor output for hydrogen-nitrogen, hydrogen-methane and methane-nitrogen (Fig. 49). All the mixtures were flowed at 1000 SCCM. 

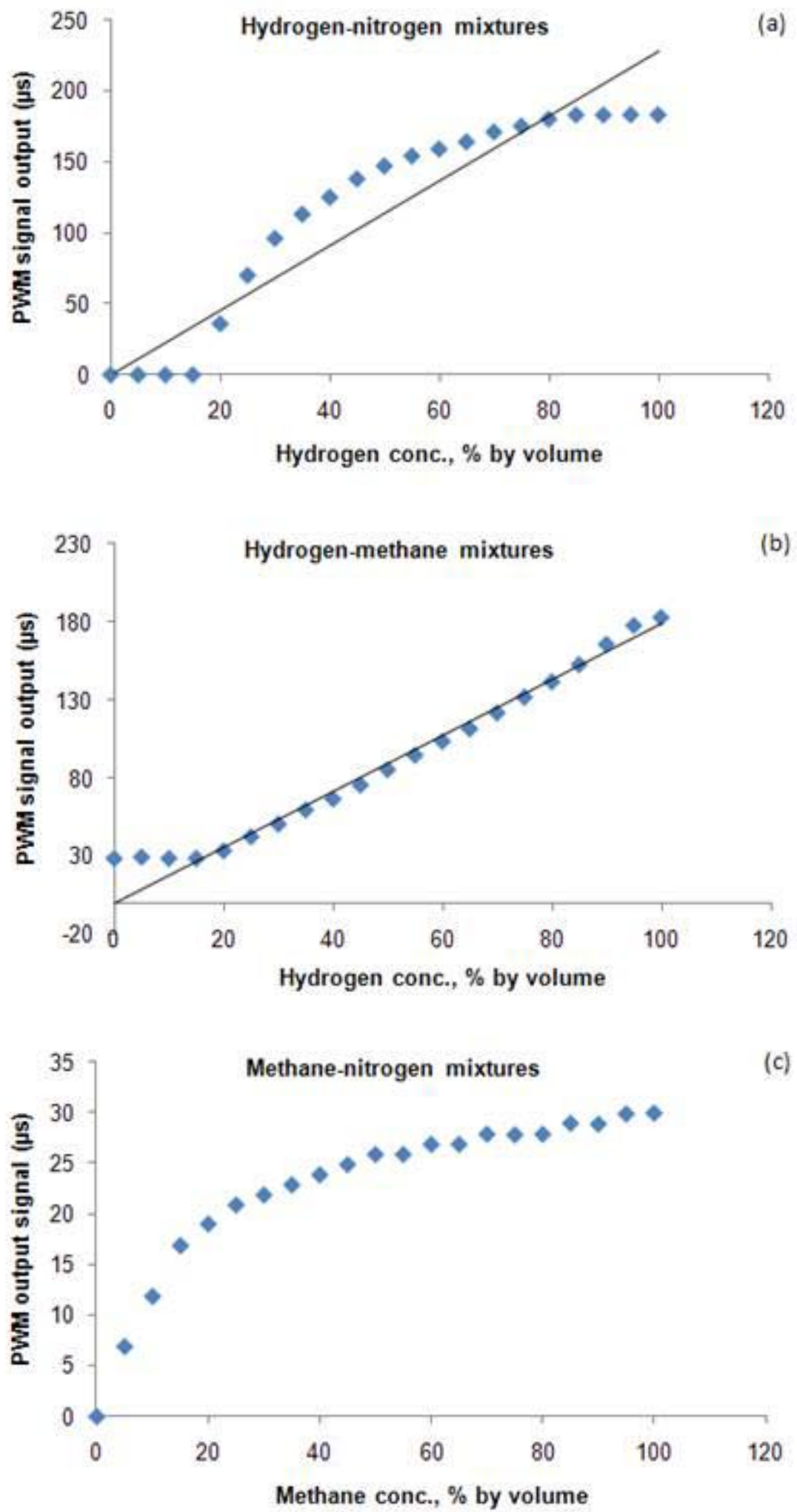

Figure 49. PWM signal output for (a) hydrogen-nitrogen (b) methane-nitrogen (c) hydrogenmethane mixtures. 
MKS mass flow controllers were used for preparing the mixtures. It has been found that at high flow rates or sudden exposure to high flow rate, there is a possibility that MOSFET sensor surface might get damaged. The flow controllers had maximum ratings of 5000, 5000 and 2000 SCCM and were used for hydrogen, methane and nitrogen respectively. The abscissa in Fig. 49 is the PWM signal output (baseline of $36.2 \mu$ s subtracted from the measured pulse width). Figs. 49a and 49b show that at lower hydrogen concentrations (up to $15 \%$ by volume), the PWM signal output is almost constant and starts increasing thereafter. There is a possibility that at lower hydrogen concentrations, a relatively large error is associated with the mass flow controllers and the pulse width does not increase with increase in hydrogen concentration. From 15 to approximately 50\%, there is a steep rise in the pulse width and then, at higher concentrations, it increases slowly. Fig. 49b shows that for hydrogen-methane mixtures, the response is quite linear in the entire range of concentrations, except again at lower hydrogen concentrations. Fig. 49c shows that at lower methane concentrations, the sensor is very sensitive to methane, the pulse width increases rapidly and at higher methane concentrations, it increases slowly.

\subsubsection{Response time and cross-sensitivity of carbon monoxide sensor}

Carbon monoxide sensor (Madur, Inc.) works on the principle of optical detection of carbon monoxide from a mixture of gases. According to the specifications, the sensor requires less than 45 seconds for producing $90 \%$ of the output signal and it is not cross-sensitive to hydrocarbons. The sensor was tested to determine whether it is compatible for integration with the gas composition sensor. The most important characteristics of the sensor for us are the response time and cross-sensitivity to other gases, such as hydrocarbons. The sensor has an absorption cell similar to the GQS and gives current (4 to $20 \mathrm{~mA}$ ) and voltage $(0$ to $10 \mathrm{~V})$ output signal. The analog output is expected to increase linearly with the concentration of carbon monoxide.

Laboratory tests showed that the sensor was not cross-sensitive to methane and propane. In order to test long-term stability of the measurements, pure carbon monoxide was allowed to flow through the sensor for 12 hours and the measured carbon monoxide concentration was monitored. The work cycle for the sensor was set at 120 minutes - 15 minutes for ventilation (equivalent to purging for the GQS), and 105 minutes of measurements. These are the settings recommended by the manufacturer. Fig. 50 shows carbon monoxide measurements monitored over a period of 12 hours, completing 6 work cycles. It was observed that, the sensor took less than 30 seconds to reach its peak concentration value (94 to 95\%) from zero and the same duration to reach zero from peak concentration. The peak concentration, sometimes, showed a fluctuation of $\pm 1 \%$. The data can be logged once every 30 seconds either to a memory card or to a computer. Fig. 50 shows the measured concentration as a function of time. It is clearly seen that the graph is a straight line parallel to the time axis. The measured concentration was approximately constant during the entire period and there was no drift observed. This suggests that the sensor is suitable for integration with the gas quality sensor for characterization of producer gas. 


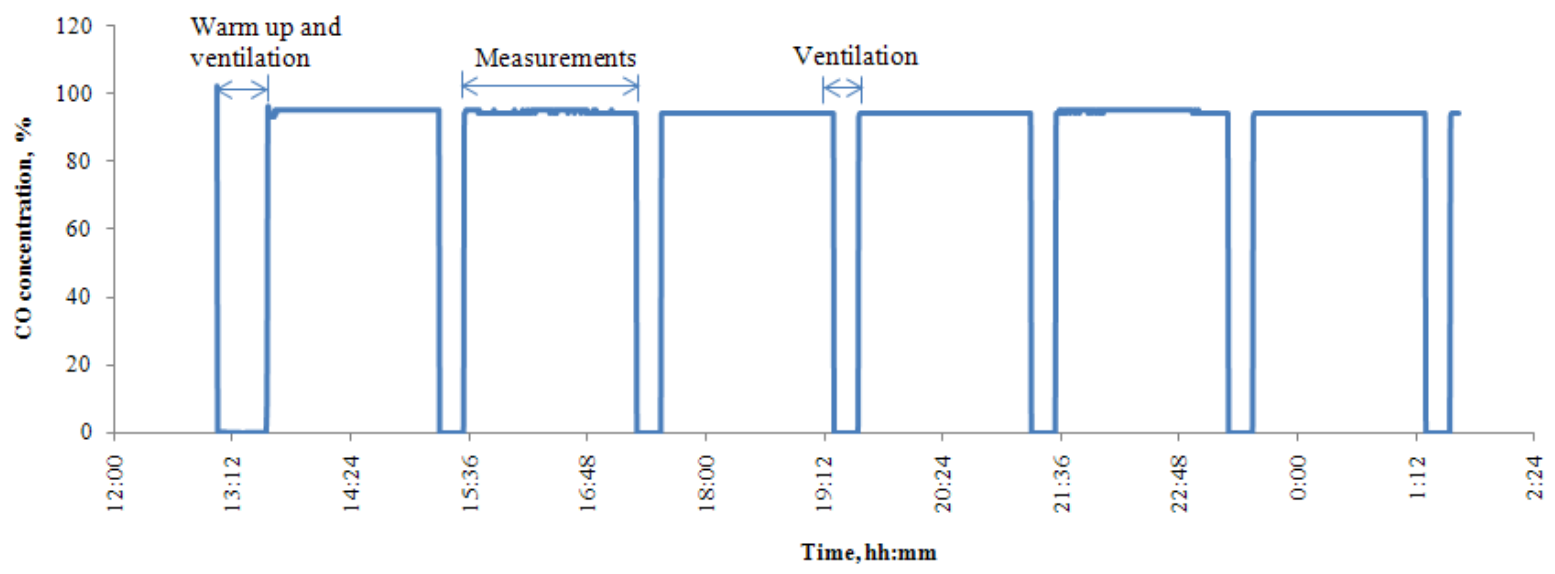

Figure 50. Testing of carbon monoxide sensor for drift in measurements.

\subsection{GQS Prototype Development for Producer Gas}

This section of the document describes the plan for integration of hydrogen and carbon monoxide sensors with the gas quality sensor. Mechanical and electrical connections and the procedure to collect experimental data are explained.

\subsubsection{Hydrogen sensor testing}

\section{Mechanical connections:}

Fig. 51 shows the mechanical connections of hydrogen sensor. A 1/8 inch tube passes through larger tubing up to a point, close to the sensing surface of hydrogen sensor. This is necessary to reduce diffusion time and hence, decrease the response time of the sensor. The flow rate can be between 1 to 2 liters per minute and the pressure should be between 0.3 to 3 bar (or 4.35 to 43.5 psi). Precaution should be taken, as it has been observed that, high flow rates may damage the sensing surface of the sensor.

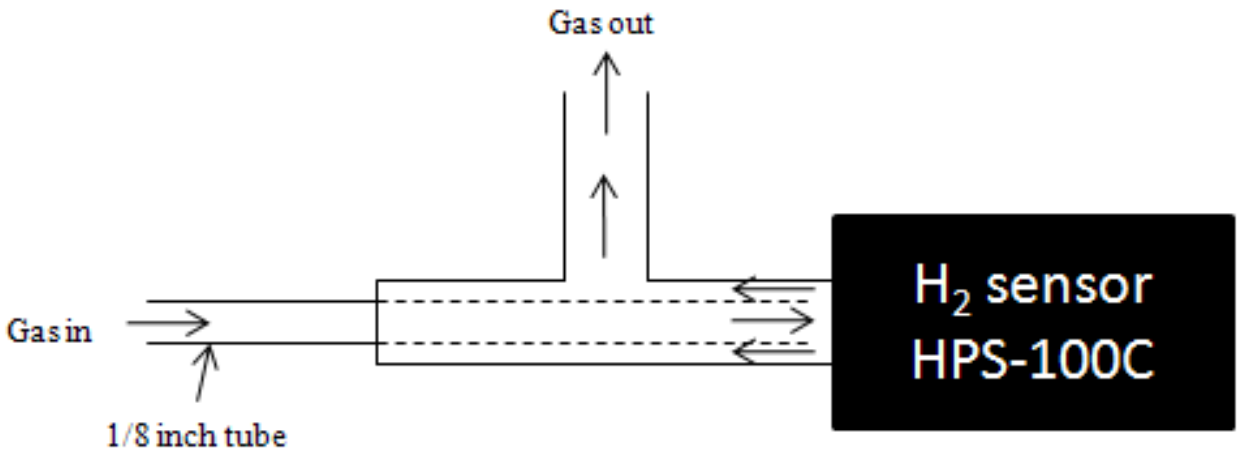

Figure 51. Mechanical connections of hydrogen sensor HPS-100C to GQS.

\section{$\underline{\text { Electrical connections }}$}


Table 21 shows the electrical connections of hydrogen sensor. The three pins of the sensor are labeled as VCC, GND and V0. The sensor needs a voltage supply in the range 8.5 to 16 volts. The sensor gives an analog output signal in the form of voltage in the range 0.7 to 1.7 volts, corresponding to $0 \%$ to $100 \%$ hydrogen.

Table 21. Electrical connections of hydrogen sensor.

\begin{tabular}{|r|cc|}
\hline \multicolumn{1}{|c|}{$\mathbf{P}$} & \multicolumn{3}{|c|}{ Function } \\
\hline in & \multicolumn{3}{|c|}{$\begin{array}{ll}\text { Vcc } \\
\text { Volts) }\end{array}$} & $(8.5$ & to & 16 \\
\hline 2 & GND & \\
\hline 3 & $\begin{array}{c}\text { Output } \\
\text { (voltage) }\end{array}$ & signal \\
\hline
\end{tabular}

The HPS-100C is calibrated with carbon dioxide as the background gas. The sensor provides a PWM (pulse width modulation) signal having a $255 \mu$ s period. The pulse width output should be converted to analog (current or voltage) signal, which can be given as an input to the existing data acquisition system and all the data can be concurrently processed in the GQS algorithm for predicting the fuel properties. One of the most common ways to convert the PWM into an analog signal is to connect a RC filter (resistance in series and a capacitance in parallel) with the PWM output as shown in Fig. 52.

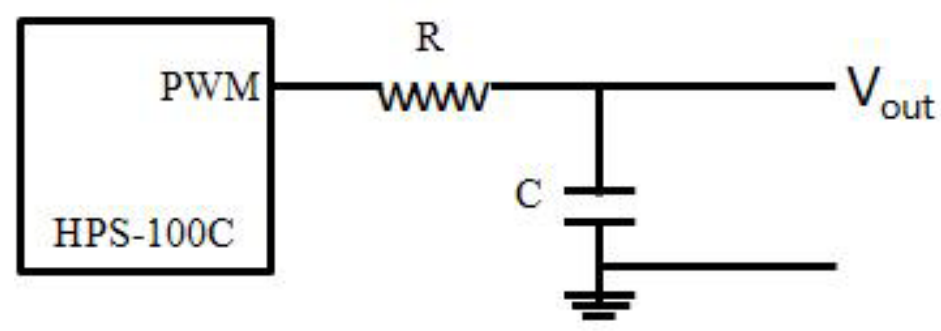

Figure 52. PWM output with RC integration circuit.

A resistance of $100 \mathrm{k} \Omega$ in series and a capacitance of $10 \mathrm{nF}$ in parallel were connected with the PWM output. With this resistance and capacitance, we will get a resolution, $t=R \times C=10^{5} \Omega \times 10^{-8} \mathrm{~F}=1 \mathrm{~ms}$, which is adequate for accurate measurement of output voltage, in this case (as the sensor response is not very fast). When nitrogen was flowing, the output voltage (baseline or reference), was found to be approximately $0.7 \mathrm{~V}$ and for pure hydrogen, it was approximately $1.7 \mathrm{~V}$. In addition to the mean output voltage, the rise time and fall time of the PWM signal was measured (Fig. 53) using an oscilloscope. The rise time was found to be approximately 40 seconds. This also includes the time taken by the gas to flow through the entire tubing and a mixing chamber (which has a volume of 1 standard liter, approximately the same as that of the GQS). The actual response time is expected to be less than 40 seconds. The fall time or the time required for the sensor to go back to the baseline is approximately 60 seconds and is more than the rise time. 


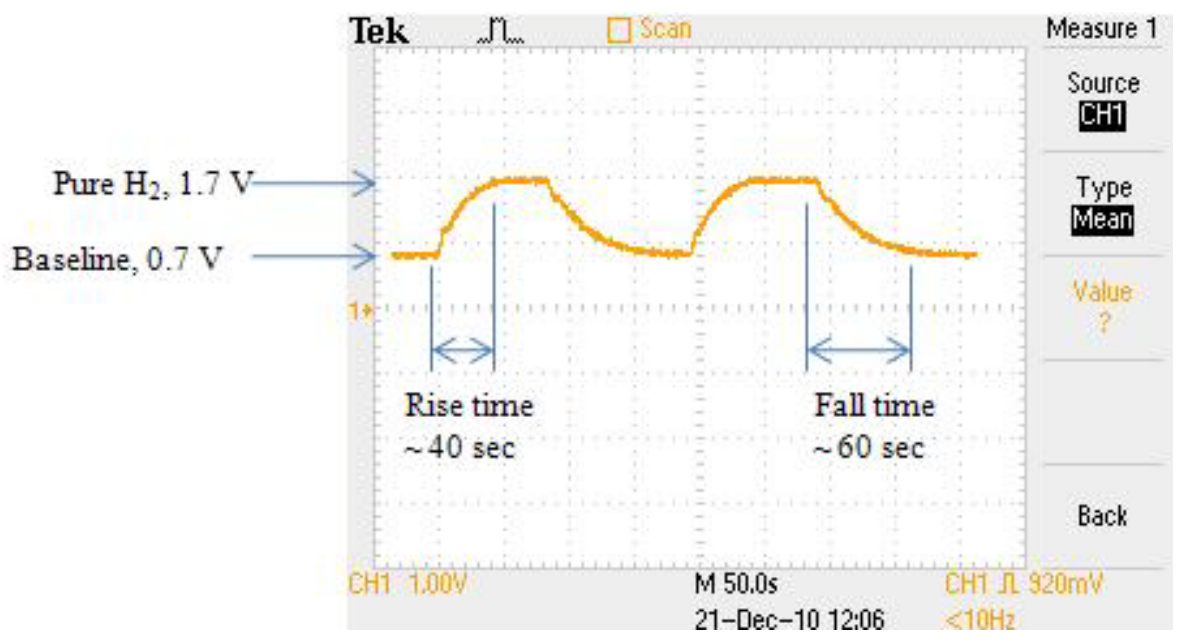

Figure 53. Analog signal output of HPS-100C on an oscilloscope.

The analog output was concurrently measured using a NI9201 analog input module. The measurements by oscilloscope and NI9201 were compared and found to be in agreement with each other. The NI data acquisition system gives more precise measurements. Also, by selecting suitable resistance and capacitance, desired resolution and hence, accuracy in the measurement of analog signal can be achieved.

\section{Data acquisition}

The voltage output of the sensor can be connected to the existing data acquisition system, which has a voltage input (NI9201 or similar) module. The pin 3 of the senor should be connected to one of the available channels on NI9201 or similar module and the pin 2 (GND) should be connected to COM of NI9201 in the data acquisition system. The output of the sensor can be read in the Measurement and Automation Explorer, by creating a task in Data Neighborhood $\rightarrow$ NI-DAQmx Tasks.

\section{Preliminary testing:}

The linearity in response, response time and cross-sensitivity to methane can be studied by measuring the sensor output for hydrogen-nitrogen, hydrogen-methane and methane-nitrogen mixtures. The total mixture flow rate can be between 1 to 2 liters per minute, as mentioned in the previous section. The cylinders of hydrogen, methane and nitrogen should be connected to mass flow controllers in order to prepare the mixtures for sensor testing. It has been observed that at high flow rates or sudden exposure to high flow rate, there is a possibility that MOSFET sensor surface might get damaged. The sensor output should be recorded for three types of mixtures - hydrogen-methane, hydrogen-nitrogen and methanenitrogen mixtures. For hydrogen-methane and hydrogen-nitrogen mixtures, start with 5\% hydrogen 95\% methane or nitrogen; increase the concentration of hydrogen in steps of $5 \%$ and equivalently, decrease methane or nitrogen concentration in steps of $5 \%$ for each subsequent mixture. Similarly, for methane-nitrogen mixtures, start with a mixture of 5\% methane - 95\% nitrogen; increase the concentration of methane in steps of 5\% and decrease nitrogen concentration to balance the mixture flow rate. For each mixture, the output voltage signal is recorded to an excel spreadsheet. The net output of the sensor is calculated using Eq. 9.

$$
\text { Net output }=\text { Voltage output for mixture-voltage output for pure nitroge }
$$

From previous measurements, the reference voltage (corresponding to the flow of pure nitrogen) is found to be approximately 0.7 volts. The net output is then plotted as a function of hydrogen or methane concentration. 


\subsubsection{Carbon monoxide sensor testing}

Mechanical connections:

CO sensor can be connected to experimental setup using 1/4 inch PTFE tubes as shown in Fig. 54 . It has a gas inlet and an outlet. The outlet can be connected to the GQS. Inside CO sensor, there is an absorption cell very similar to that of GQS.

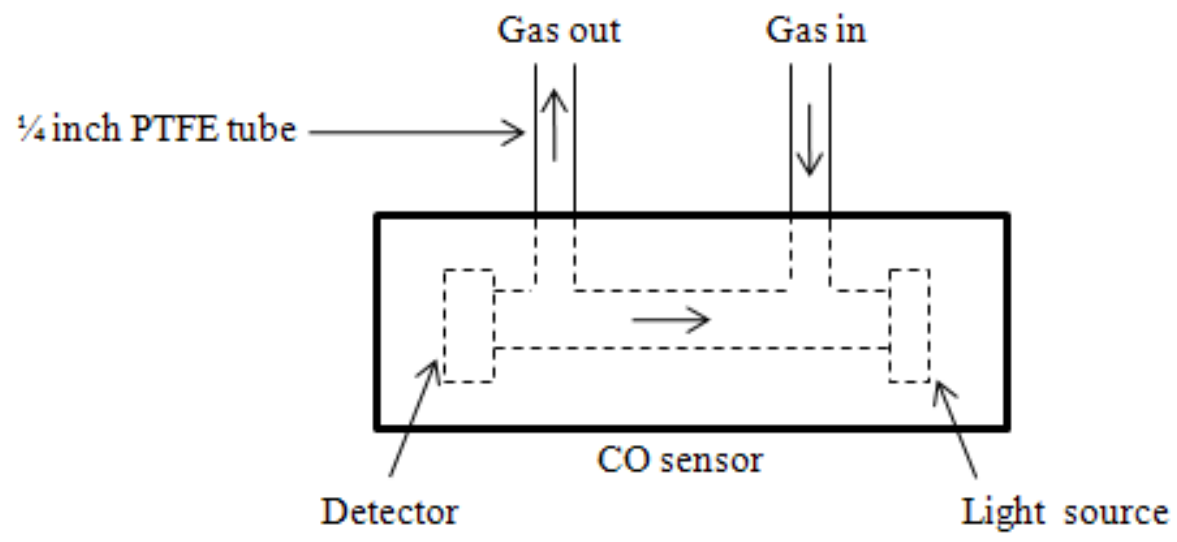

Figure 54. Mechanical connections for CO sensor.

\section{Electrical connections:}

Table 22 shows the electrical connections for power supply and to the data acquisition system. The five pins of the sensor are labeled as purge 1, purge 2, +ve, GND, current output and voltage output. The purge 1 and purge 2 should be connected to the channel of a relay module (NI9481). The sensor needs a voltage supply in the range 13 to $30 \mathrm{VDC}$ or 12 to $24 \mathrm{VAC}$.

Table 22. Electrical connections of CO sensor.

\begin{tabular}{|l|l|}
\hline Pin & \multicolumn{1}{|c|}{ Connection } \\
\hline Purge 1 & Relay module - pin 1 \\
\hline Purge 2 & Relay module - pin 2 \\
\hline +ve & $\begin{array}{l}\text { Power supply } \\
\text { (13 to 30 VDC or 12 to 24 } \\
\text { VAC) }\end{array}$ \\
\hline GND & Ground \\
\hline $\begin{array}{c}\text { Current } \\
\text { output }\end{array}$ & NI9203 \\
\hline $\begin{array}{c}\text { Voltage } \\
\text { output }\end{array}$ & NI9201 \\
\hline
\end{tabular}

\section{Data acquisition}

Fig. 55 shows connections for integrating CO sensor with the data acquisition system of GQS. The pins labeled as current and voltage should be connected NI9203 and NI9201 respectively. The output of the sensor was read in the Measurement and Automation Explorer, by creating a task in Data Neighborhood $\rightarrow$ NI-DAQmx Tasks. The sensor gives output signals in the form of voltage (0 to $10 \mathrm{~V})$ and current (4 to $20 \mathrm{~mA}$ ), corresponding to $0 \%$ to $100 \%$ carbon monoxide. 


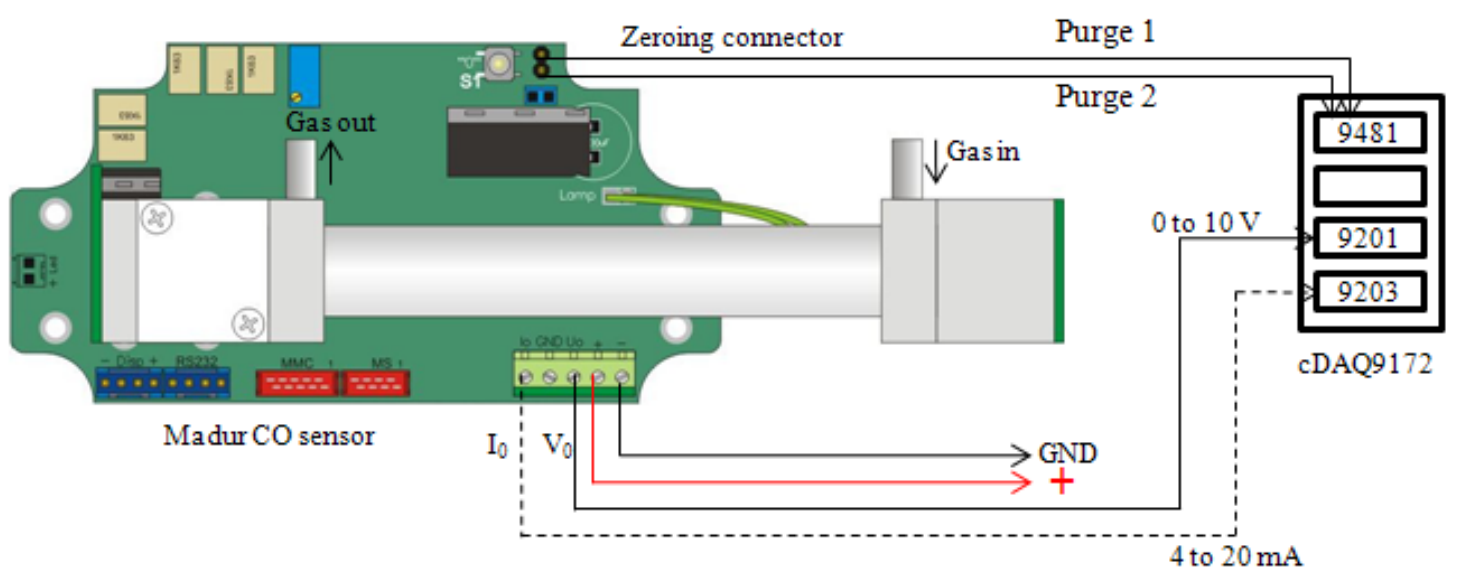

Figure 55. Integration of CO sensor with GQS data acquisition system.

Fig. 56 shows the work cycle of the sensor with the recommended settings. The sensor requires 15 minutes for warm up. Ventilation should be allowed for 15 minutes after every 1 hour and 45 minutes of measurements. Thus, the total work cycle comprises of 2 hours. To start zeroing procedure of CO sensor, the purge 1 and purge 2 are shorted by turning the channel of relay module ON/OFF. These settings can be modified using the software provided with the sensor. The software can be installed from the compact disk, also provided with the sensor. The sensor can be controlled and its output data can be acquired using this software. A flash memory card is provided with the sensor and it should be always plugged into the sensor for continuous storage of the results. The data in the memory card can be read in the software and can be exported to a spreadsheet file.

\begin{tabular}{l|l|l|l}
\hline 15 minutes 15 minutes $1 \mathrm{~h} 45 \mathrm{~min}$ & $15 \mathrm{~min}$ & $1 \mathrm{~h} 45 \mathrm{~min}$ \\
\hline & & \\
\hline Warm up & Ventilation Measurements & Ventilation Measurements ...
\end{tabular}

Figure 56. Work cycle of CO sensor.

\section{Preliminary testing}

To test the sensor for cross-sensitivity to hydrocarbons and carbon dioxide, it should be exposed to pure methane, ethane, propane, butane, other hydrocarbon gases available in the lab and carbon dioxide. To test its linearity, carbon monoxide-nitrogen mixtures can be prepared and the sensor output can be recorded. The mixtures can be prepared such that the concentration of carbon monoxide in the first mixture is $5 \%$, balance by remaining (95\%) nitrogen. The concentration of carbon monoxide is increased in steps of 5\% in subsequent mixtures, decreasing nitrogen concentration in the same step (5\%). A graph of set and predicted carbon monoxide concentration gives us an idea of linearity in the sensor's response. 


\subsubsection{Integration of hydrogen and carbon monoxide sensors with GQS}

Fig. 57 shows the setup for integrating hydrogen and carbon monoxide sensors with the GQS. The hydrogen sensor can be connected after the flow control system. Thus, the mixtures prepared using the flow control system pass through the hydrogen sensor first. The outlet of hydrogen sensor should be connected to the inlet of carbon monoxide sensor and the outlet of carbon monoxide sensor is connected to the inlet of GQS. The order in which these sensors are connected before the GQS do not make impact on the experimental measurements. The electrical connections for power supply and data acquisition remain the same as explained in the previous sections.

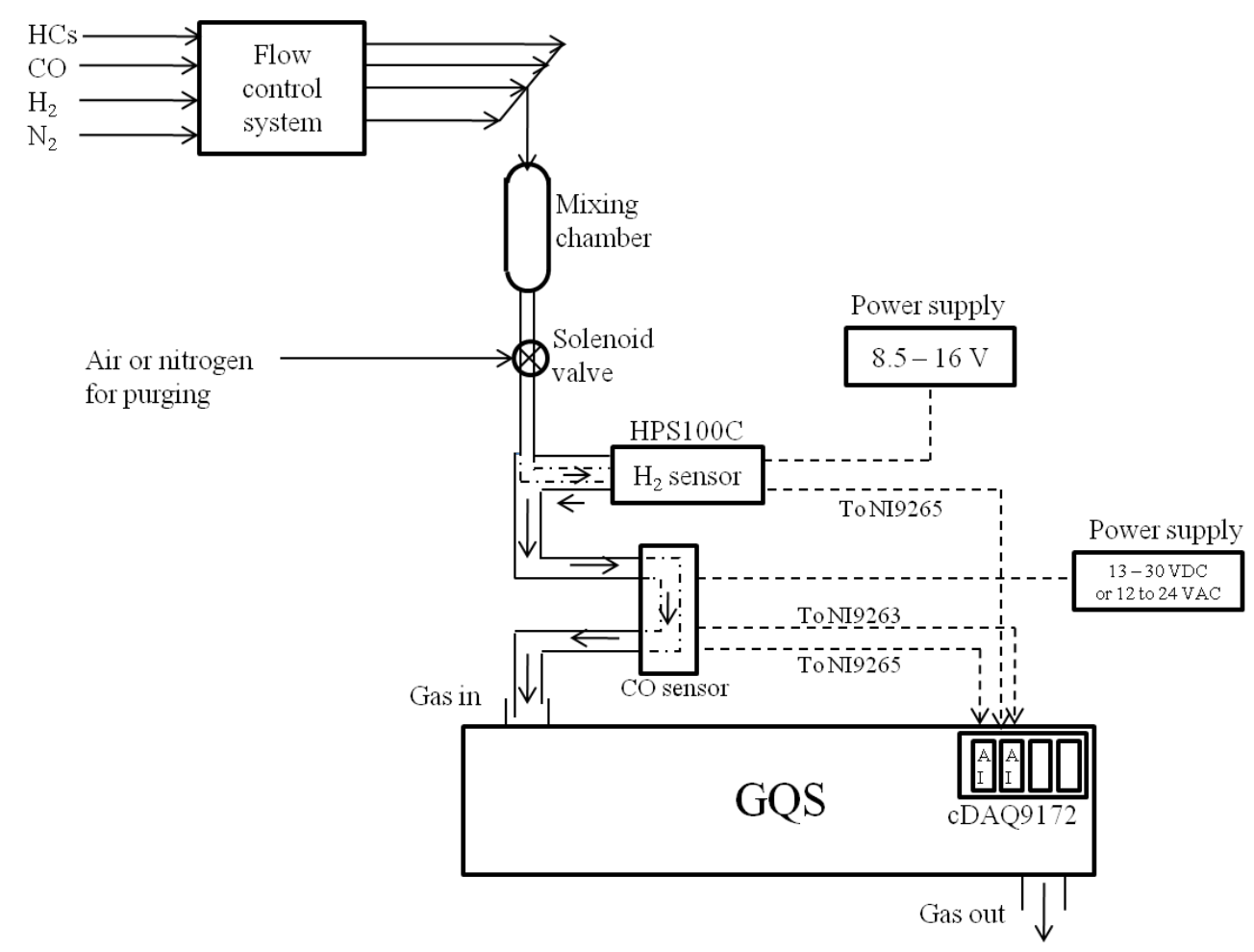

Figure 57. Integration of hydrogen and carbon monoxide sensors with GQS.

Figs. 58 and 59 show the schematic and photograph, respectively, of the experimental setup assembled at the GTI lab for the hydrogen and carbon monoxide sensor evaluation. The objectives for the sensors evaluation tests to be conducted next quarter will include assessments of the response time and accuracy for each sensor. 


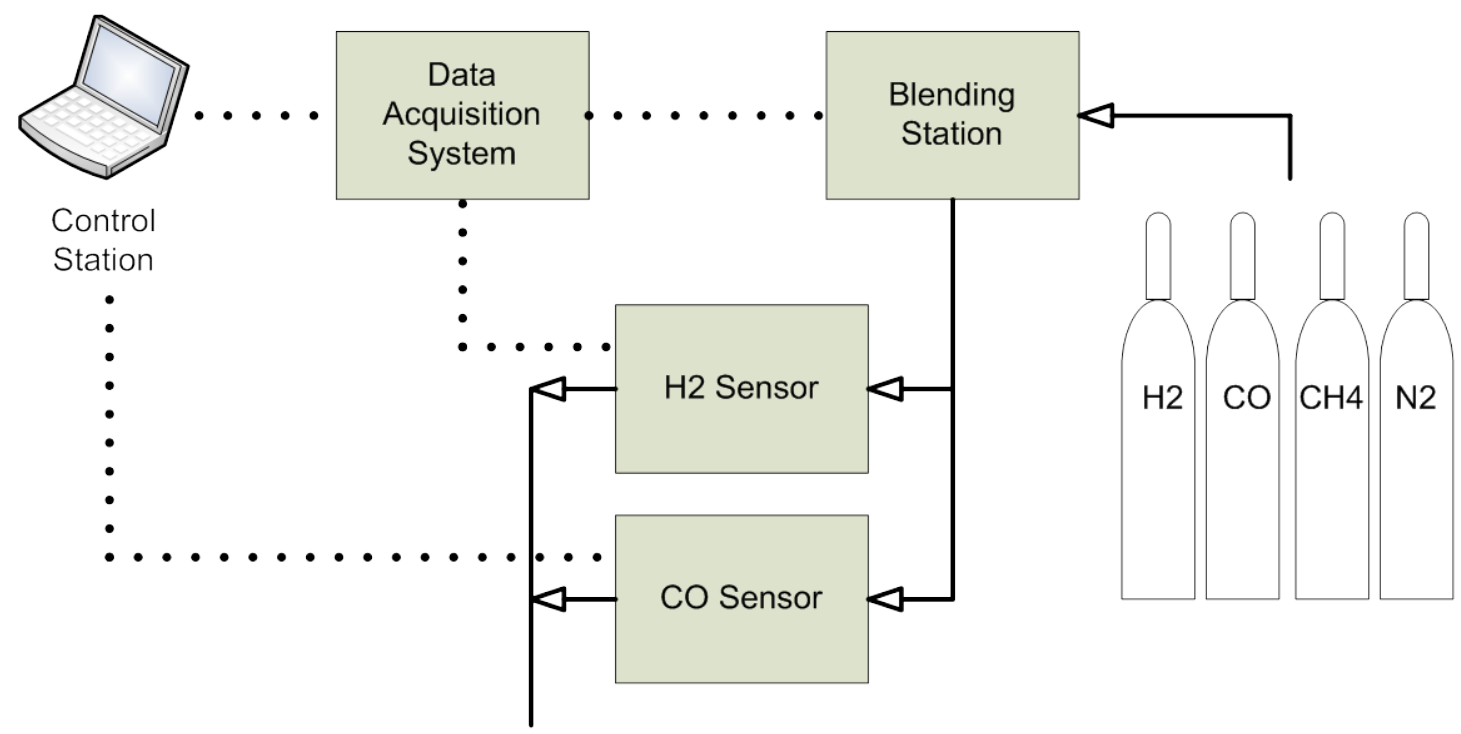

Exhaust

Figure 58. Hydrogen and carbon monoxide sensors testing setup schematic.

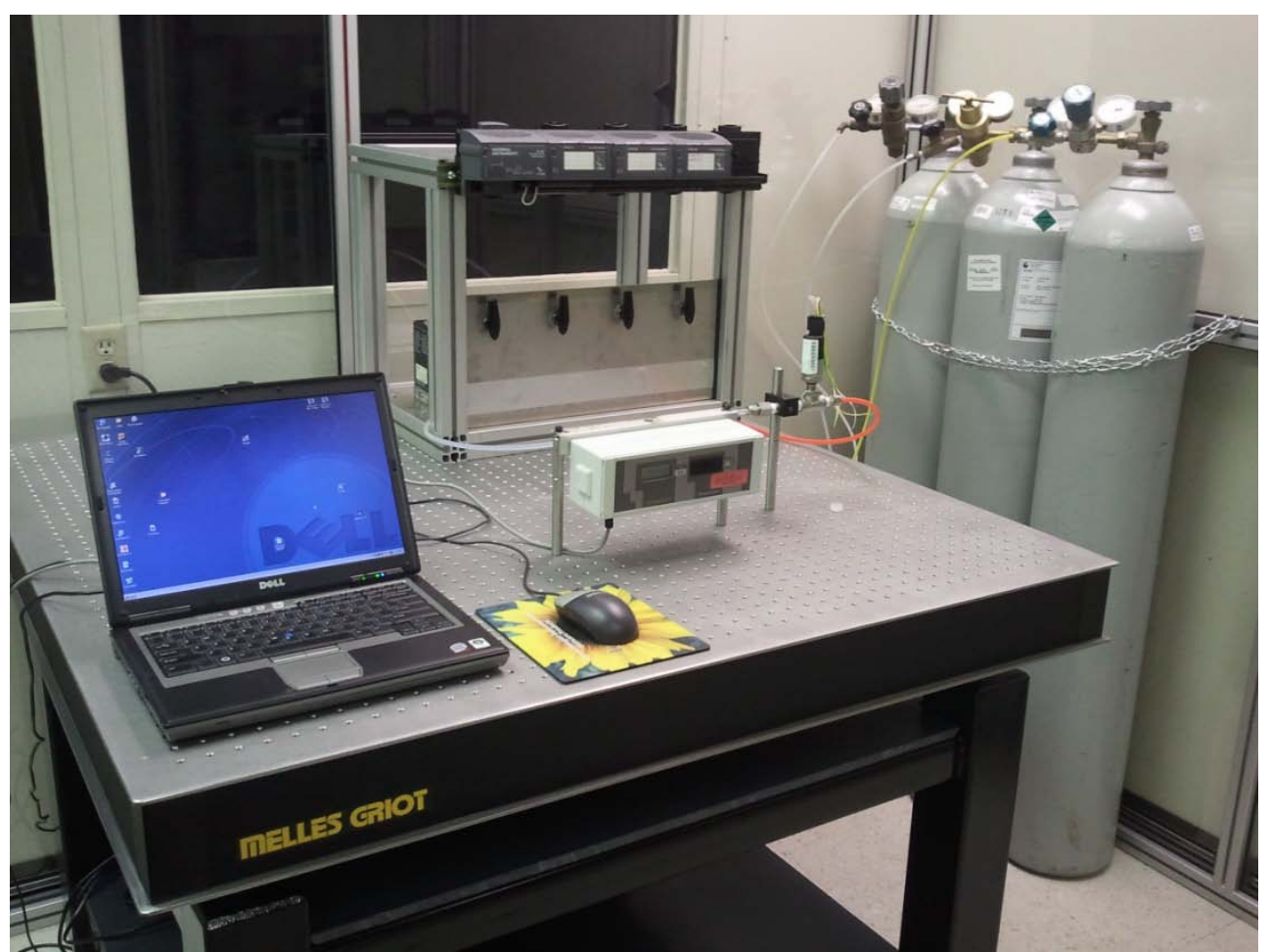

Figure 59. Hydrogen and carbon monoxide sensors testing setup photograph. 


\subsection{GQS Calibration and Bench Testing for Producer Gas}

\subsubsection{Training and validation mixtures}

Table 23 shows the pre-determined compositions for training mixtures. The mixtures are selected considering the accuracy of hydrogen and carbon monoxide sensors. Carbon monoxide has a very weak absorption in the NIR. It has a peak absorption of approximately 0.01 absorbance units near $1400 \mathrm{~nm}$ at atmospheric pressure and temperature conditions and from previous GQS tests on landfill gas, it is clear that at low concentrations of carbon dioxide, prediction accuracy is also low. Thus, the concentration of carbon dioxide in the training mixtures is kept as high as possible. The selected carbon dioxide concentration range is 40 to $50 \%$. Methane has a peak absorption 10 times higher than that of carbon dioxide. Thus, the concentration of methane is selected in the range 5 to $10 \%$. Hydrogen sensor HPS100C is cross-sensitive to methane and shows linearity in estimated hydrogen concentration above $20 \%$. For hydrogen, we have selected 20 to $40 \%$ range. Carbon monoxide sensor uses optical detection and seems to be not cross-sensitive to other gases. In this case, its concentration is selected between 10 to $15 \%$. The mixture is balanced by pure nitrogen. Similarly, Table 29 shows the pre-determined compositions of validation mixtures. The compositions of validation mixtures need to different from those of training mixtures, but, the concentration ranges of individual gases have to be the same, as required by multivariate statistical methods to be used in the analysis.

Table 23. Compositions of training mixtures.

\begin{tabular}{|c|c|c|c|c|c|c|}
\hline$\#$ & Gas & $\begin{array}{c}\text { Mixtu } \\
\text { re 1 }\end{array}$ & $\begin{array}{c}\text { Mixture } \\
\mathbf{2}\end{array}$ & $\begin{array}{c}\text { Mixtur } \\
\text { e 3 }\end{array}$ & $\begin{array}{c}\text { Mixtur } \\
\text { e 4 }\end{array}$ & $\begin{array}{c}\text { Mixture } \\
\mathbf{5}\end{array}$ \\
\hline 1 & Methane & 7 & 6 & 5 & 8 & 10 \\
\hline 2 & Carbon dioxide & 40 & 42 & 45 & 47 & 50 \\
\hline 3 & Hydrogen & 40 & 35 & 30 & 25 & 20 \\
\hline 4 & $\begin{array}{c}\text { Carbon } \\
\text { monoxide }\end{array}$ & 12 & 15 & 14 & 12 & 10 \\
\hline 5 & Nitrogen & 1 & 2 & 6 & 8 & 10 \\
\hline
\end{tabular}

Table 24. Compositions of validation mixtures.

\begin{tabular}{|c|c|c|c|c|c|c|}
\hline$\#$ & Gas & $\begin{array}{c}\text { Mixtu } \\
\text { re 1 }\end{array}$ & $\begin{array}{c}\text { Mixture } \\
\text { 2 }\end{array}$ & $\begin{array}{c}\text { Mixtur } \\
\text { e 3 }\end{array}$ & $\begin{array}{c}\text { Mixtur } \\
\text { e 4 }\end{array}$ & $\begin{array}{c}\text { Mixture } \\
\mathbf{5}\end{array}$ \\
\hline 1 & Methane & 9 & 8 & 5 & 10 & 6 \\
\hline 2 & Carbon dioxide & 45 & 49 & 40 & 43 & 41 \\
\hline 3 & Hydrogen & 32 & 21 & 32 & 22 & 39 \\
\hline 4 & $\begin{array}{c}\text { Carbon } \\
\text { monoxide }\end{array}$ & 12 & 11 & 15 & 15 & 13 \\
\hline 5 & Nitrogen & 2 & 10 & 8 & 10 & 1 \\
\hline
\end{tabular}

\subsubsection{Experimental procedure}

- Make sure that all mechanical and electrical connections are correct and gases (methane, hydrogen, carbon dioxide, carbon monoxide and nitrogen) are connected to mass flow controllers.

- Switch ON spectrometer and its light source for warming up.

- Open spectrometer software and Measurement and Automation Explorer (MAX).

- Make sure that the data from spectrometer can be exported to an excel spreadsheet. 
- Go to Measurement and Automation Explorer $\rightarrow$ Data Neighborhood $\rightarrow$ NI-DAQmx Tasks and create a task to read pressure, temperature, current and voltage outputs from hydrogen and carbon monoxide sensors.

- In the task window $\rightarrow$ Configuration $\rightarrow$ Acquisition Mode, select continuous samples from dropdown menu.

- Open MFC software and switch ON the flow of nitrogen.

- Switch ON CO sensor and record the current time. CO sensor needs 15 minutes for warm up.

- After 15 minutes, record the current time as ventilation time. Every two hours after this ventilation time, nitrogen should be allowed to flow through the system for 15 minutes and no experimental measurements are to be made during this ventilation phase.

- Switch OFF light source and capture background for spectrometer. Export background data to excel. (We will need one background and reference data for analysis)

- Switch ON light source and capture reference intensity. Export reference intensity data to excel.

- After 15 minutes (measured starting from ventilation time), input the flow rates of individual gases in the MFC software to prepare the first calibration mixture. Start the flow of this gas mixture through the system.

- Once the flow of gas and absorption spectrum stabilizes, export absorption spectrum data to an excel spreadsheet. Also, read pressure and temperature from MAX and record them in the same spreadsheet.

- Once the output signals from hydrogen and carbon monoxide sensors stabilize in the task window in MAX, record these values in excel spreadsheet.

- Check the current time frequently during the experiment and make sure that during ventilation phase of carbon monoxide sensor, only nitrogen flows through the system. Ventilation phase occurs after every 2 hours for 15 minutes, as mentioned in the previous steps. So, the measurements can be made during 1 hour and 45 minutes in each work cycle of 2 hours.

- Capture the background and reference for spectrometer again and input the flow rates of gases for the second calibration mixture.

- Switch ON the gases using the MFCs, wait for the flow and absorption spectrum to stabilize. Export absorption spectrum to excel spreadsheet. Also, record pressure and temperature in the same spreadsheet.

- Once the analog output signals from hydrogen and carbon monoxide sensors stabilize, record their values in the spreadsheet.

- Repeat the procedure in a similar way for all subsequent mixtures and record the experimental measurements in the spreadsheet.

During the experiment, keep checking the current time frequently and make sure that only nitrogen flows through the system during ventilation phase of carbon monoxide sensor and during this phase, no measurements can be made.

\subsubsection{Preliminary experiments with producer gas}

This section describes the preliminary experiments performed on producer gas mixtures to validate the GQS algorithm. Table 25 shows the compositions and heating values of calibration and validation mixtures. Ten mixtures were used each for calibration and validation. The minimum concentrations are selected so that measurable signal is produced for each gas (except nitrogen). The heating values of methane and hydrogen are taken to be 1010 BTU/SCF and 325 BTU/SCF respectively.

The experimental data is organized into a matrix $\boldsymbol{X}$. The first column of matrix $\boldsymbol{X}$ represents the analog output of hydrogen sensor for a given mixture. This analog output is a measure of the concentration of hydrogen in that particular mixture. Each subsequent column of $\boldsymbol{X}$ represents the absorbance of the mixture at a particular wavelength. Thus, each row of matrix $\boldsymbol{X}$ represents the 
measurements for a given mixture. Similarly, the composition and heating value of each mixture are arranged in rows in another matrix $\boldsymbol{Y}$. The PCR and PLS methods are then used to fit a regression model to the data. The fitted model correlates the experimental measurements or independent variables (absorbances and analog output of hydrogen sensor) to the fuel properties or dependent variables (concentration of each gas and total heating value). The model is then used to estimate the properties of unknown mixtures from their measured spectra. For data processing RGui software [3] is used. There are a number of other commercial softwares, such as, SAS, Unscrambler, PLS Toolbox, which provide environment for statistical computing.

The results of the PCR and PLS were very similar for predicting the fuel properties. Thus, only the PCR method is discussed here. Fig. 60 shows the plot of the proportion of the total variance explained by each principal component. It is clear from this graph that the first principal component accounts for most of the variation in the data. The subsequent components account for a very small portion of the remaining variability in the data.

Table 25. Compositions and heating values of calibration and validation mixtures.

\begin{tabular}{|c|c|c|c|c|c|}
\hline & Mix \# & $\mathrm{CH}_{4}, \%$ & $\mathrm{CO}_{2}, \%$ & $\mathbf{H}_{2}, \%$ & HV, BTU/SCF \\
\hline \multirow{10}{*}{ لَّ } & 1 & 8.5 & 60 & 21 & 154.1 \\
\hline & 2 & 9.5 & 58 & 23 & 170.7 \\
\hline & 3 & 10.5 & 56 & 25 & 187.3 \\
\hline & 4 & 11.5 & 54 & 27 & 203.9 \\
\hline & 5 & 12.5 & 52 & 29 & 220.5 \\
\hline & 6 & 13.5 & 50 & 31 & 237.1 \\
\hline & 7 & 14.5 & 48 & 33 & 253.7 \\
\hline & 8 & 15.5 & 46 & 35 & 270.3 \\
\hline & 9 & 16.5 & 44 & 37 & 286.9 \\
\hline & 10 & 17.5 & 42 & 39 & 303.5 \\
\hline \multirow{10}{*}{ 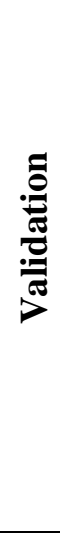 } & 1 & 9 & 59 & 22 & 162.4 \\
\hline & 2 & 10 & 57 & 24 & 179 \\
\hline & 3 & 11 & 55 & 26 & 195.6 \\
\hline & 4 & 12 & 53 & 28 & 212.2 \\
\hline & 5 & 13 & 51 & 30 & 228.8 \\
\hline & 6 & 14 & 49 & 32 & 245.4 \\
\hline & 7 & 15 & 47 & 34 & 262 \\
\hline & 8 & 16 & 45 & 36 & 278.6 \\
\hline & 9 & 17 & 43 & 38 & 295.2 \\
\hline & 10 & 18 & 41 & 40 & 311.8 \\
\hline
\end{tabular}

Fig. 61 shows the plot of loadings corresponding to the first three principal components. The loading vector for the first component resembles the spectrum of methane. The loading value for the first variable (analog output of hydrogen sensor) is a large value compared to the loading values for the absorbances. This is because the magnitude of analog output (1.1 to $1.34 \mathrm{~V})$ of hydrogen sensor is large compared to the absorbances. The plot of regression coefficients has a very similar shape as the plot of loading values and is not shown here.

Fig. 62 shows the set and predicted properties of validation mixtures shown in Table 30, using 4 principal components. All the points lie on a $45^{\circ}$ line passing through the origin. Thus, the set and predicted properties are very close to each other. The root mean squared error (RMSE) is calculated using Eq. (5). Y-actual and y-predicted are the set and predicted concentrations and heating values respectively. 
$N$ is the total number of mixtures (ten, in this case) used for validation. RMSE provides a good quantitative measure of predictive power of the methods used. It represents the absolute deviation of predicted value from true value. The RMSE for methane was $0.5 \%$ and that for hydrogen and carbon dioxide was 1\% each, while for heating value, it was 8 BTU/SCF. The same level of accuracy was achieved with the PLS method.

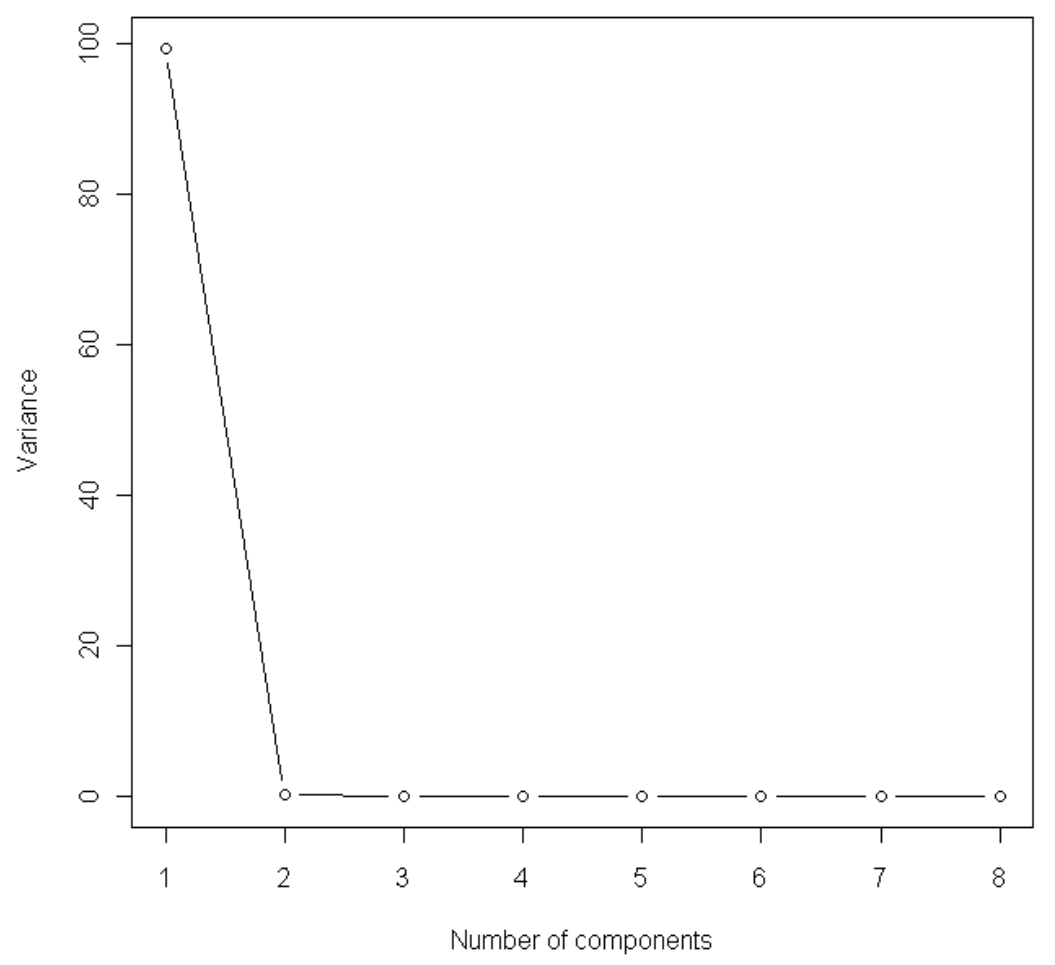

Figure 60. Proportion of total variance explained by each principal component. 


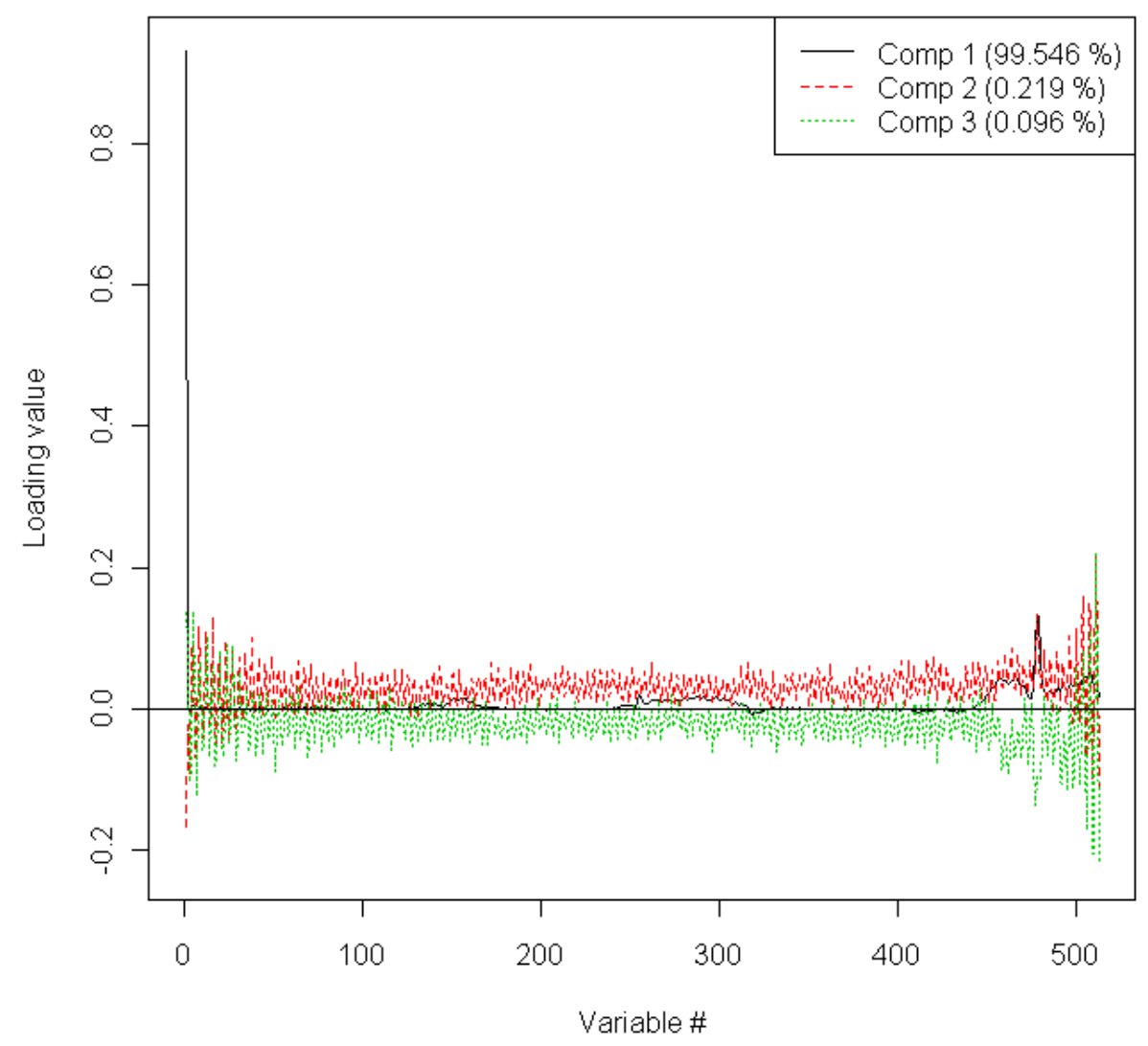

Figure 61. Loading values for the first three components. 


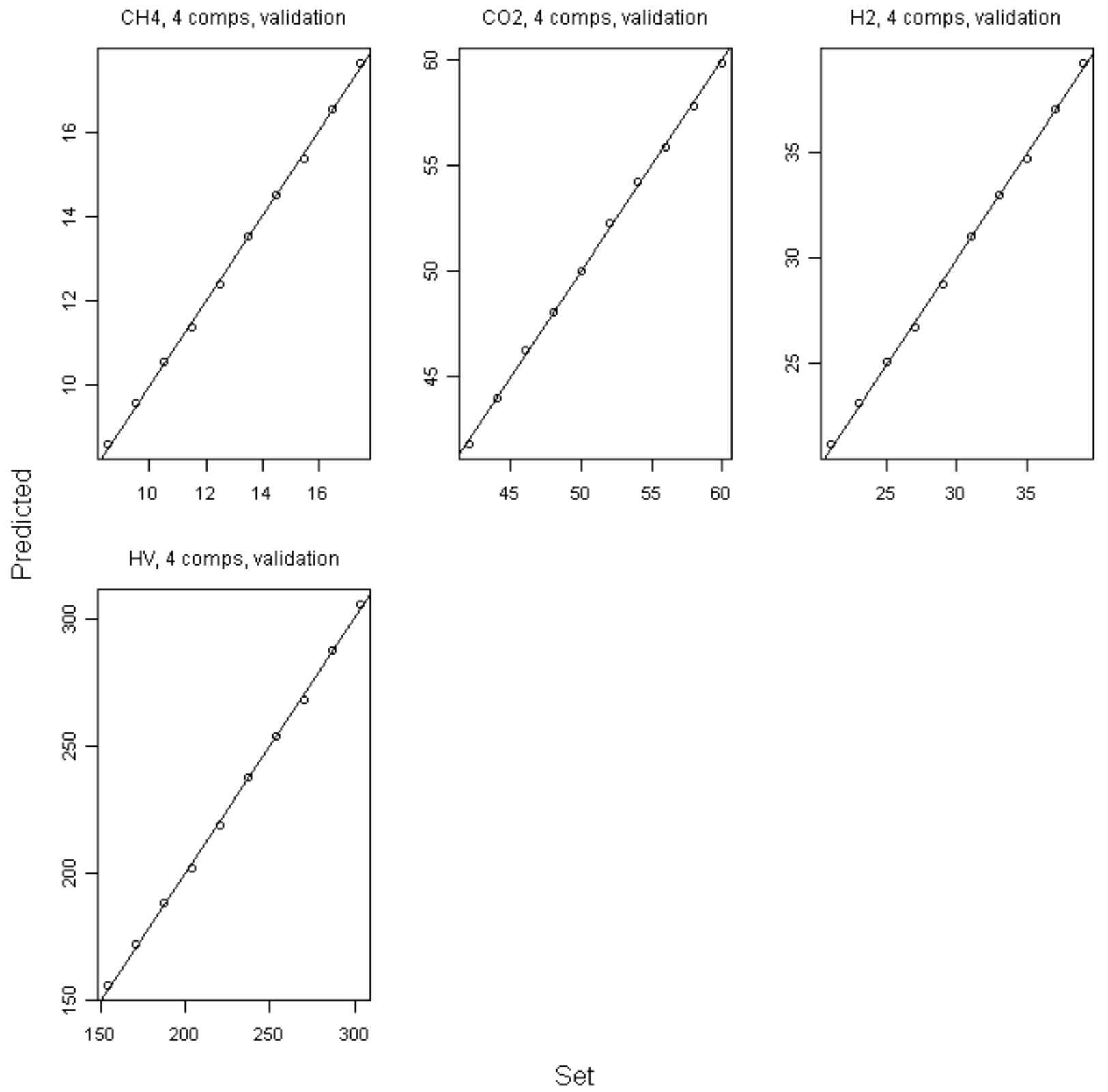

Figure 62. Set and predicted properties of validation mixtures shown in Table 30.

In order to improve stability in the GQS measurements, it is important to study the nature of long term drift and its effects on the predicted composition and heating value. The GQS software was recently updated to include a capability to record the absorption spectra, pressure, temperature, composition and heating value in binary format, on regular specified time intervals. Binary format was selected because it is the fastest and takes the least memory space on disk. The binary files will consist of back to back records of the following structure [4]:

- 16 byte (128 bit) date/timestamp

- $\quad$ Four IEEE double precision 64 bit floating point numbers with the values for measured concentrations.

- $\quad$ Measured HV from concentrations (Double precision)

- $\quad$ Measured HV Directly (Double precision)

- $\quad$ Gas Temperature (Double precision) 
- $\quad$ Pressure (Double precision)

- $\quad$ Array of double precision numbers containing the temperature and pressure corrected absorbances (before drift correction). The 8 byte values of the elements themselves are preceded with a 4 byte number containing the number of elements in the array.

LabVIEW uses Big Endian format for its binary numbers, while MATLAB on Windows uses Little Endian format by default. Thus, LABVIEW writes the least significant byte to the file first. Moreover, in the array all the elements themselves are written in reverse order.

The following short MATLAB program is used to read binary data, convert it to human readable form and export to an excel spreadsheet. The code was verified by exporting 3500 records from a binary file to an excel spreadsheet.

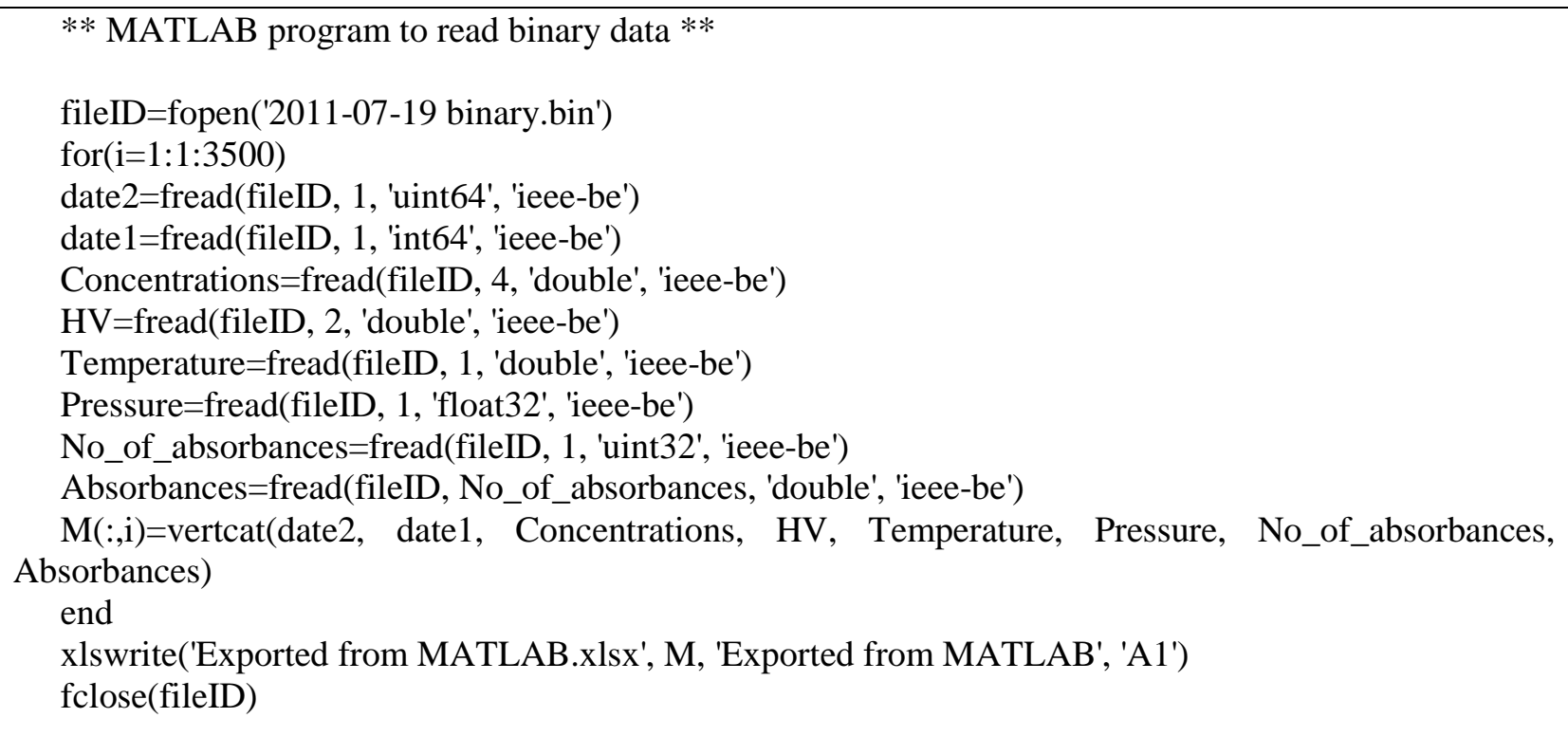

In order to improve stability in the GQS measurements, it is important to account for the instrumental drift. There are a few methods proposed in the literature [5] to account for instrumental drift in multivariate calibration models. The drift correction methods are generally categorized into two groups implicit and explicit correction methods. In implicit correction methods, the calibration data is modified to account for drift, whereas, in explicit correction methods, the drift subspace is estimated based on calibration and drift correction data and a statistical model is developed, which will be less sensitive to drift. The following is a program developed in R statistical software, which can be used for processing the spectral data using various calibration models. The code will be modified to implement several variations of the principal components regression (PCR) and the partial least squares (PLS) methods proposed in the literature [5-12]. The results of all these methods will be compared against conventional PCR/PLS and GC measurements to select the best method for our purpose. 


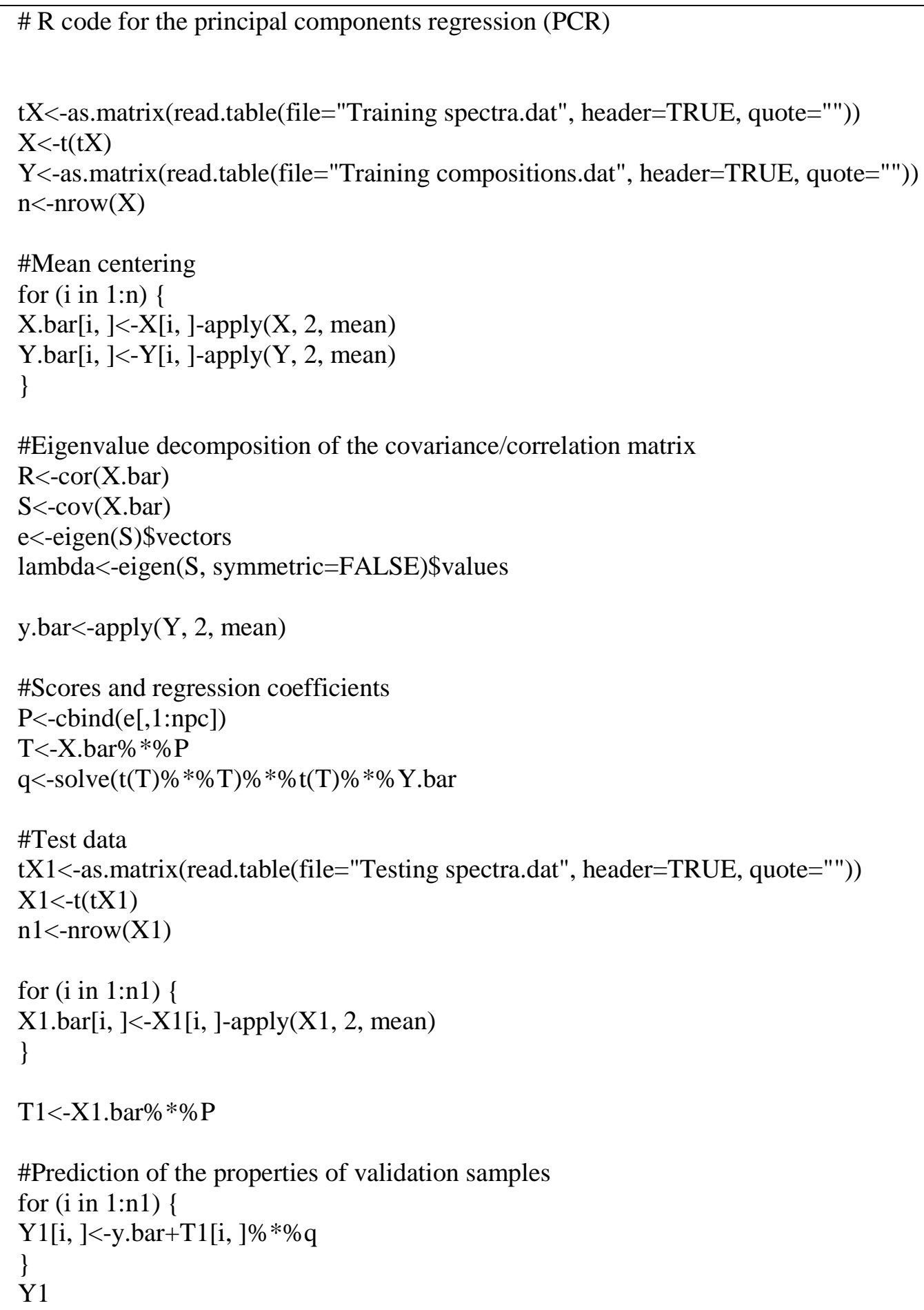

write.table(Y1, file = "PCR predicted properties.txt", append=TRUE, quote $=$ TRUE, sep = " ", eol = "\n", na = "NA", dec = ".", row.names = TRUE, col.names = TRUE, qmethod = c("escape", "double"), fileEncoding = "") 
The composition of producer gas changes depending on biomass feed stocks. The calibration mixtures are selected considering the typical composition of producer gas obtained from a downdraft gasifier using wood as the baseline feedstock and 7\%,13\%, 20\% and 40\% dried distiller's grains with soluble (DDGS) [13]. Validation mixtures have compositions similar to calibration mixtures. Table 26 and Table 27 show the compositions of calibration and validation mixtures respectively. Nitrogen is the major component of producer gas, with small amounts of carbon monoxide, carbon dioxide and methane. The heating values of methane, carbon monoxide and hydrogen are computed using the data available in CRC handbook of chemistry and physics as 39.81, 12.63 and $12.75 \mathrm{MJ} / \mathrm{m}^{3}$. Fig. 63 and Fig. 64 show the near infrared absorption spectra of calibration and validation mixtures. All the spectra are very similar as methane and carbon dioxide concentrations do not vary significantly among the mixtures. The concentrations of hydrogen and carbon monoxide are measured using off-the-shelf sensors. The voltage outputs of hydrogen and carbon monoxide sensors and the near infrared absorption spectra of mixtures are arranged in a matrix. The data is mean centered and a calibration model is developed using the principal components regression (PCR). The model is then utilized to estimate the compositions of validation mixtures. Fig. 65 shows the estimated and actual heating values and concentrations of carbon monoxide, hydrogen, carbon dioxide and methane. It is clear from Fig. 65 that the compositions and heating values are estimated with reasonable accuracy. Suppose yset and ymeasured and are the set and measured properties and $N$ is the number of validation mixtures (five in this case), then, the root mean squared errors of prediction (RMSEP) are computed using Eq. (5).

Fig. 66 shows the RMSE plotted against the number of components used for building calibration model. The RMSE for carbon dioxide is the largest compared to other concentrations, as carbon dioxide has very weak absorption in the considered wavelength range, whereas, heating value has the highest accuracy.

Table 26. Compositions of calibration mixtures.

\begin{tabular}{ccccccc}
$\begin{array}{c}\text { Mixture } \\
\#\end{array}$ & $\mathrm{~N}_{2}, \%$ & $\mathrm{CO}, \%$ & $\mathrm{H}_{2}, \%$ & $\begin{array}{l}\mathrm{CO}_{2}, \\
\%\end{array}$ & $\begin{array}{l}\mathrm{CH}_{4}, \\
\%\end{array}$ & $\mathrm{HV}, \mathrm{MJ} / \mathrm{m}^{3}$ \\
\hline 1 & 52.9 & 16.9 & 11.3 & 13.6 & 5.3 & 5.68 \\
2 & 52 & 17.7 & 9.5 & 14.5 & 6.3 & 5.95 \\
3 & 52.5 & 16.3 & 10.4 & 14.9 & 5.9 & 5.73 \\
4 & 55.5 & 15.9 & 9 & 14 & 5.6 & 5.38 \\
5 & 62.6 & 12.5 & 7 & 12.8 & 5.1 & 4.50
\end{tabular}


Table 27. Compositions of validation mixtures.

\begin{tabular}{ccccccc}
$\begin{array}{c}\text { Mixture } \\
\#\end{array}$ & $\mathrm{~N}_{2}, \%$ & $\mathrm{CO}, \%$ & $\mathrm{H}_{2}, \%$ & $\begin{array}{l}\mathrm{CO}_{2}, \\
\%\end{array}$ & $\begin{array}{l}\mathrm{CH}_{4}, \\
\%\end{array}$ & $\mathrm{HV}, \mathrm{MJ}^{3} \mathrm{~m}^{3}$ \\
\hline 1 & 61.7 & 13 & 7.3 & 12.8 & 5.2 & 4.64 \\
2 & 57.5 & 14.6 & 8.9 & 13.3 & 5.7 & 5.25 \\
3 & 54.6 & 15.3 & 9.2 & 14.9 & 6 & 5.49 \\
4 & 53.5 & 16.1 & 10.5 & 13.7 & 6.2 & 5.84 \\
5 & 51.9 & 17.4 & 11 & 14.2 & 5.5 & 5.79
\end{tabular}

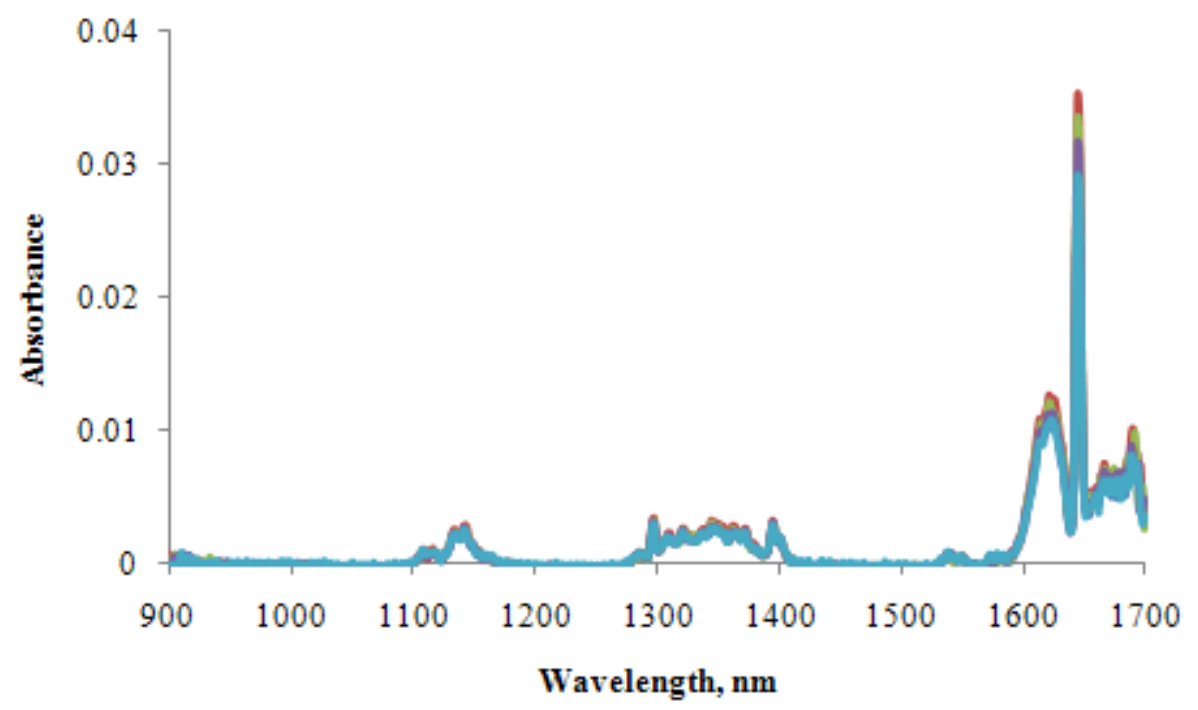

Figure 63. Near infrared absorption spectra of calibration mixtures shown in Table 31.

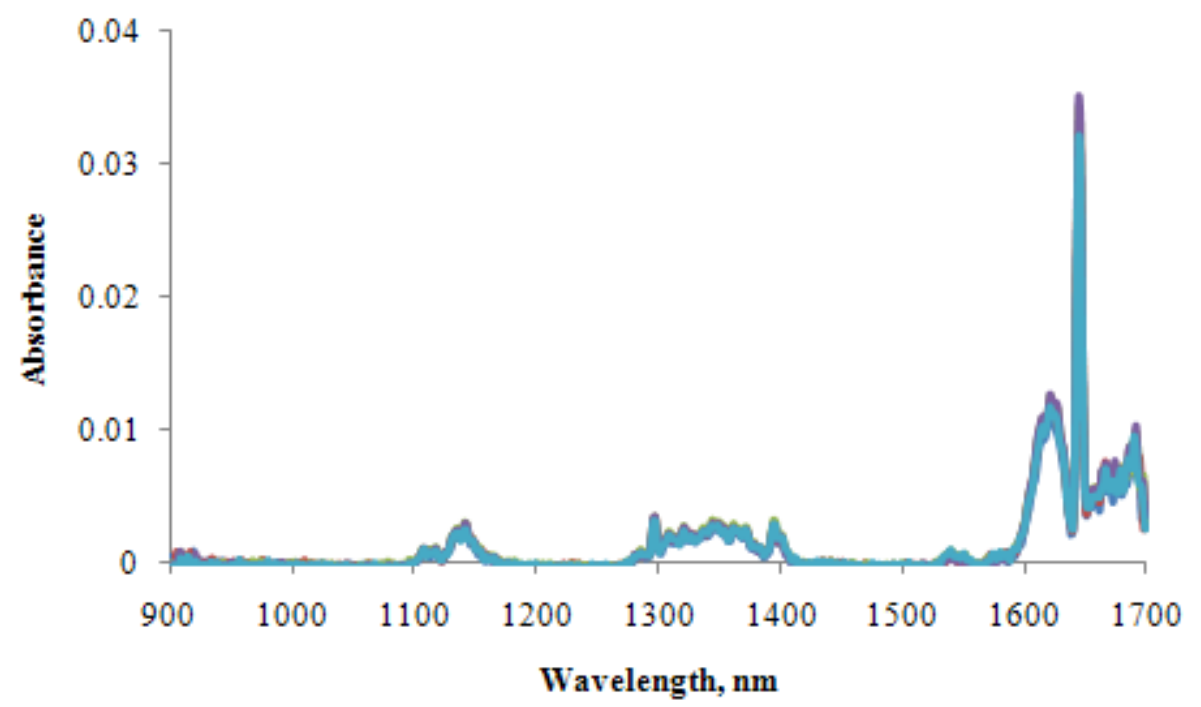

Figure 64. Near infrared absorption spectra of validation mixtures shown in Table 32. 

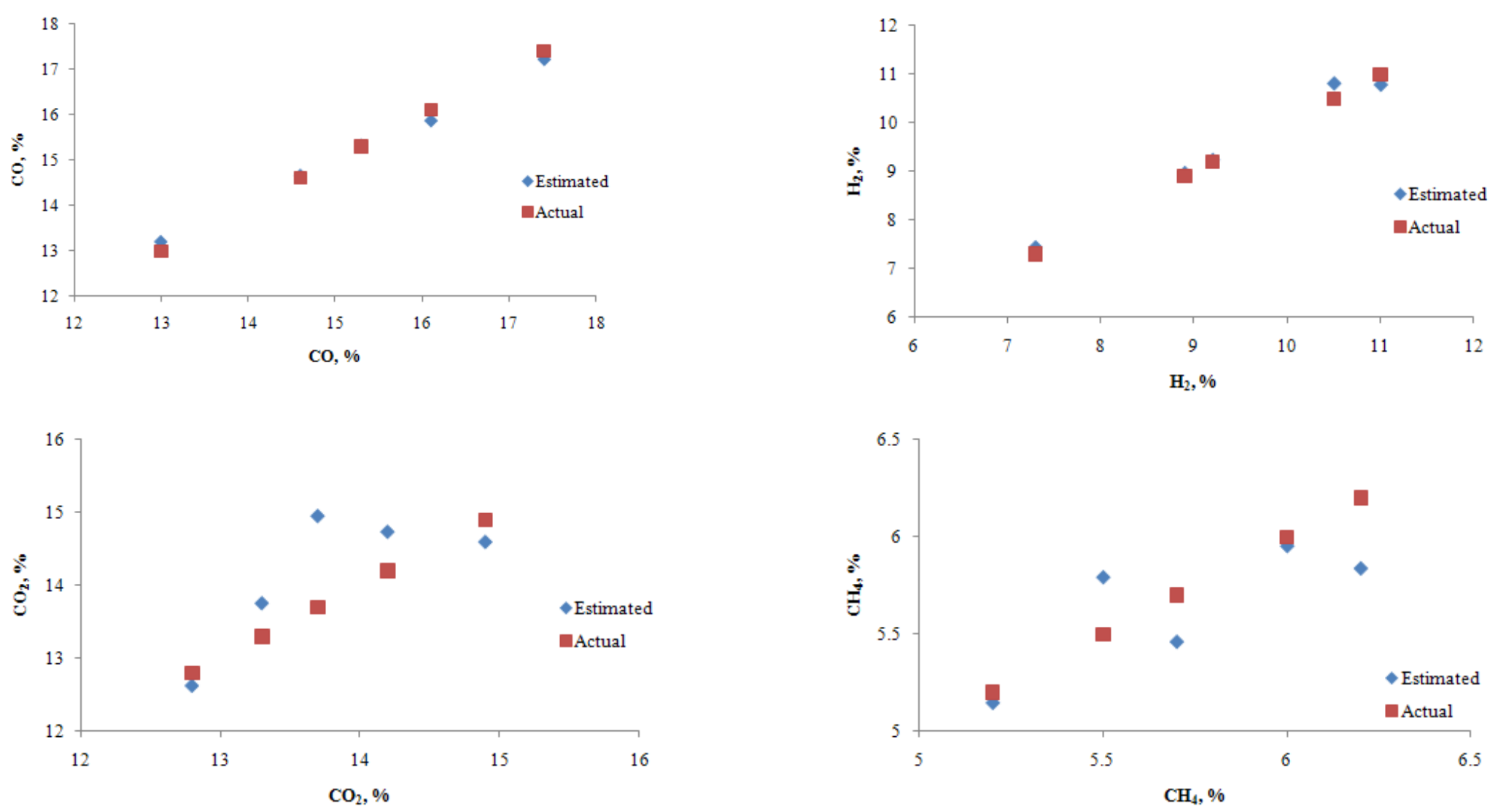

Figure 65. Estimated and actual concentrations of $\mathrm{CO}, \mathrm{H}_{2}, \mathrm{CO}_{2}, \mathrm{CH}_{4}$. 


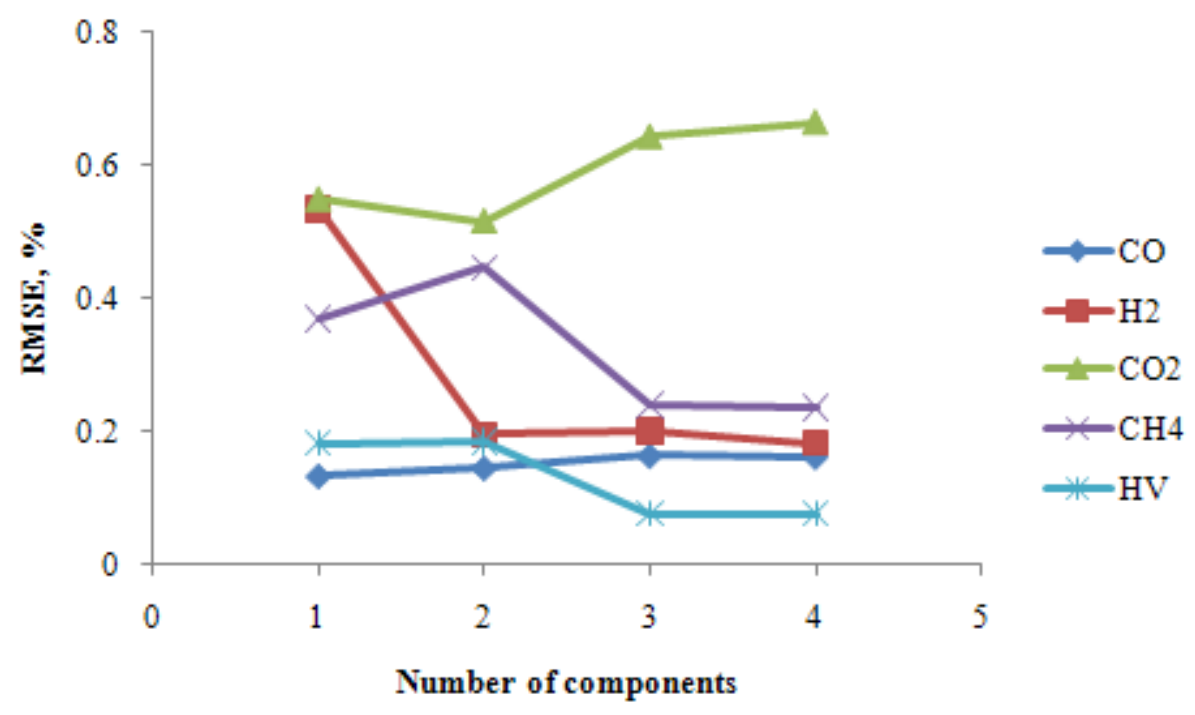

Figure 66. RMSE against the number of components used for developing a calibration model (number of components up to 4 ).

\subsubsection{Characterization of opportunity fuel blends}

Two opportunity fuels - producer gas and refinery gas - are considered for experimental purposes.

Table 28 shows the ranges of concentrations and heating values of natural gas and selected opportunity fuels. Methane varies in a wide concentration range in natural gas and refinery gas. Higher hydrocarbons have relatively small variation. Carbon monoxide is present only in producer gas. Hydrogen is a major component in both of the opportunity fuels. The selected concentration ranges for various gas components and the resulting heating values of the blends are listed in Table 28.

Forty mixtures approximating the compositions of these blends are prepared using the mass flow control system. The concentrations of individual gas components are varied uniformly in the entire considered ranges. The NIR absorption spectra and outputs of hydrogen and carbon monoxide sensors for these mixtures are measured. The experimental data is divided into two sets - one for calibration and the other for validation, each set having 20 mixtures. The validation points lie within the span of calibration points. Moreover, the validation points lie in between calibration points in order to assess interpolating ability of the model. The PCR/PLS regression models are developed from the set of calibration mixtures and used for estimating the compositions and heating values of validation mixtures.

Fig. 67 shows the set (actual) and measured properties of validation mixtures. The measured properties of the blends are in close agreement with their actual properties. Table 35 shows the RMSEP in predicted concentrations and heating value. It is clear that all the components along with heating value are predicted with sufficiently high accuracy.

Fig. 67(a) shows the set and measured methane. The blends contained 41 to $60 \%$ methane. The data reported in Fig. 67(a) shows that the predicted methane concentrations are close to a straight line passing through the origin. The error in predicted methane is $0.36 \%$. This is a good accuracy over a wide concentration range. 
Table 28. Compositions and heating values of natural gas and selected opportunity fuels.

\begin{tabular}{|c|c|c|c|}
\hline & Natural & Producer & Refinery \\
\hline & gas & gas & gas \\
\hline $\mathrm{CH}_{4}, \%$ & $80-95$ & $5-7$ & $23-41$ \\
\hline $\mathrm{C}_{2}$ to $\mathrm{C}_{4}, \%$ & $1.6-7.2$ & $0.3-0.6$ & $11-24$ \\
\hline $\mathrm{CO}_{2}, \%$ & $0.1-1$ & $12-15$ & $0-0.1$ \\
\hline $\mathrm{CO}, \%$ & 0 & $12-17$ & $0.5-0.9$ \\
\hline $\mathrm{H}_{2}, \%$ & 0 & $7-12$ & $22-35$ \\
\hline $\mathrm{N}_{2}, \%$ & $0.7-5.6$ & $39-42$ & $7-11$ \\
\hline $\mathrm{HV}, \mathrm{MJ} / \mathrm{m}^{3}$ & $28-37$ & $4-6$ & $17-34$ \\
\hline
\end{tabular}

Table 29. Composition and heating value of natural gas blended with producer gas and refinery gas.

\begin{tabular}{lll}
\hline $\begin{array}{c}\text { Mixture } \\
\text { property }\end{array}$ & Min & Max \\
\hline $\begin{array}{l}\text { Methane, } \\
\%\end{array}$ & 41 & 60 \\
$\begin{array}{l}\text { Ethane, } \\
\%\end{array}$ & 1 & 20 \\
$\begin{array}{l}\text { Hydroge } \\
\text { n, }\end{array}$ & 1 & 20 \\
$\begin{array}{c}\text { Carbon } \\
\text { dioxide, } \%\end{array}$ & 1 & 20 \\
$\begin{array}{c}\text { Carbon } \\
\text { monoxide }\end{array}$ & 1 & 20 \\
$\begin{array}{l}\text { Heating } \\
\text { value, } \\
\text { MJ/m }\end{array}$ & 18 & 32 \\
\hline
\end{tabular}


Table 30. RMSEP in measured compositions and heating values of natural gas blended with producer gas and refinery gas.

\begin{tabular}{lc}
\hline Mixture property & $R M S E P$ \\
\hline Methane & $0.36 \%$ \\
Ethane & $0.11 \%$ \\
Hydrogen & $0.33 \%$ \\
Carbon monoxide & $0.84 \%$ \\
Carbon dioxide & $1.19 \%$ \\
Heating value & $0.1 \mathrm{MJ} / \mathrm{m}^{3}$ \\
\hline
\end{tabular}


(a)

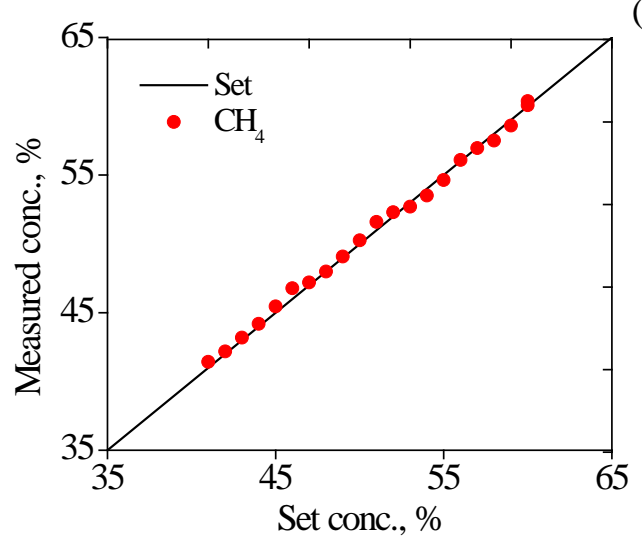

(b)

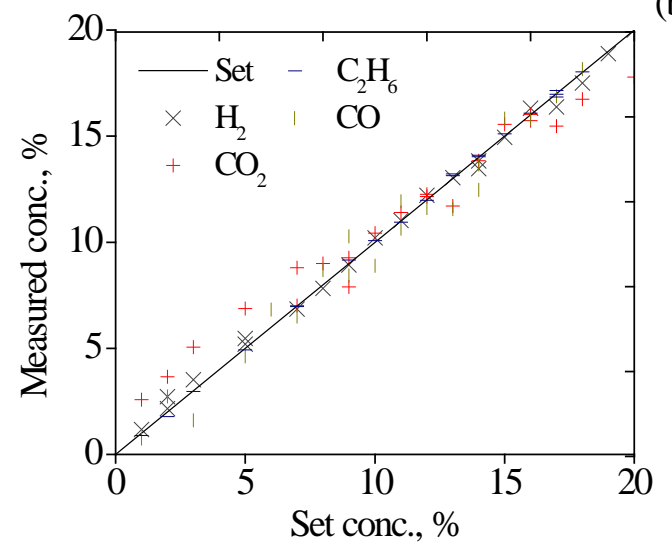

(c)

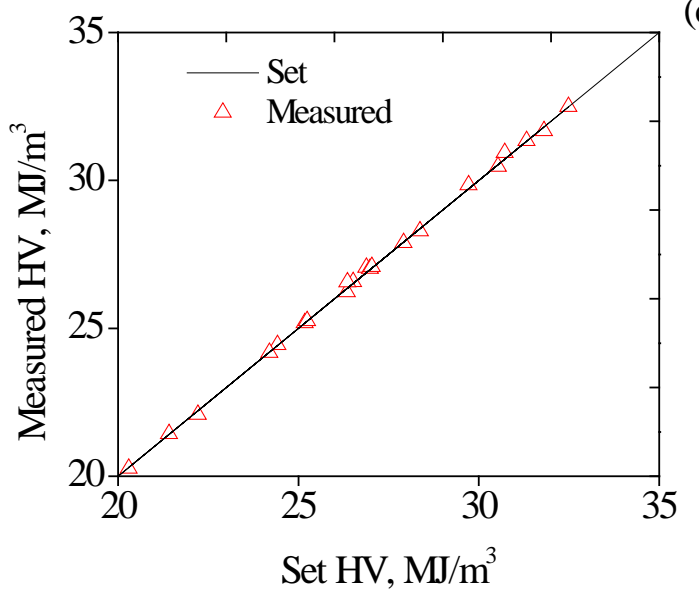

Figure 67. Set and measured compositions and heating values of natural gas blended with producer gas and refinery gas.

Fig. 67(b) shows the set and predicted ethane, hydrogen, carbon monoxide and carbon dioxide. All of these components are varied between 1 to 20\% (Table 28). Of these gases, ethane has the highest prediction accuracy $(0.11 \%)$ due to its strong absorption properties in the considered wavelength range as compared to carbon monoxide and carbon dioxide. Carbon monoxide and hydrogen are also well predicted despite of strong interference from hydrocarbons. When hydrogen and carbon monoxide concentrations are computed directly from the sensor 
outputs, the errors are $37.5 \%$ and $1.7 \%$ respectively, which are larger than the errors in the PCR/PLS predicted hydrogen and carbon monoxide. The error in directly computed hydrogen concentration is large because hydrogen sensor is highly cross-sensitive to methane.

Fig. 67(c) shows that the heating values are also measured with a good accuracy $( \pm 0.1$ $\mathrm{MJ} / \mathrm{m}^{3}$ ). For future measurements, an appropriate number of factors has to be selected for the PCR and PLS models. For this purpose, a graph of RMSEP against the number of factors will be plotted and the number of factors corresponding to the minimum RMSEP will be selected. Thus, the number of factors can differ for each property (concentration or heating value). In this case, a maximum of five factors are required to achieve minimum RMSEP.

\subsection{GQS Engine Testing for Producer Gas}

As indicated in Quarterly Report to DOE NETL, it was not possible to secure an engine to test the GQS on producer gas. The budget originally planned for this work was directed toward improving the performance of the GQS for biogas compositions and securing a commercial partner.

\subsection{GQS for Producer Gas Field Testing}

As indicated in Quarterly Report to DOE NETL, it was not possible to secure a producer gas field site to test the GQS on producer gas. The budget originally planned for this work was directed toward improving the performance of the GQS for biogas compositions and securing a commercial partner.

\section{References for Section 2}

1. http://www.cityofbath.com/recycling_pages_area68.html?m_id=513\&cat_id=68

2. Sudharsan Mukundan, Cummins Power Generation, private communication.

3. R Development Core Team (2011). R: A language and environment for statistical computing. R Foundation for Statistical Computing, Vienna, Austria. ISBN 3-900051-07-0, URL http://www.R-project.org/.

4. Stanislav Rumega, email communication.

5. P. Gujral, M. Amrhein, B. Wise and D. Bonvin, "Framework for explicit drift correction in multivariate calibration models”, Journal of Chemometrics, 24, 534-543 (2010).

6. B. Hemmateenejad and S. Karimi, "Construction of stable multivariate calibration models using unsupervised segmented principal component regression”, Journal of Chemometrics, 25, 139-150 (2011).

7. S. Andersen, G. Runger, "Partitioned partial least squares with application to a batch fermentation process”, Journal of Chemometrics, 25, 159-168 (2011).

8. G. Toth, "Destruction of normal distribution in small samples by centering and scaling”, Journal of Chemometrics, 25, 247-253 (2011).

9. W. Ni, S. Brown, R. Man, “Stacked PLS for calibration transfer without standards”, Journal of Chemometrics, 25, 130-137 (2011). 
10. V. Taavitsainen, “Ridge and PLS based rational function based regression”, Journal of Chemometrics, 24, 665-673 (2010).

11. T. Naes, T. Isaksson, T. Fearn, and T. Davies, "A User-Friendly Guide to Multivariate Calibration and Classification”, NIR Publications, Chichester, UK (2002).

12. A. Gowen, G. Downey, C. Esquerre and C. O'Donnell, "Preventing over-fitting in PLS calibration models of near-infrared (NIR) spectroscopy data using regression coefficients", Journal of Chemometrics, 25, 375-381 (2010).

13. S. Sethuraman, C. Huynh, and S .Kong, "Producer gas composition and $\mathrm{NO}_{x}$ emissions from a pilot-scale biomass gasification and combustion system using feedstock with controlled nitrogen content”, Energy Fuels 2011; 25: 813-822. 


\section{Task 2- Summary of GQS Development}

The achievements involved advances in both the sensor and software development. The $\mathrm{CO}_{2}$ detection capabilities were established and analyzed in the spectral range from 1 to 2 microns. The National Instrument software controlling the sensor was modified to include $\mathrm{CO}_{2}$ detection. The test results performed jointly by the NCSU and GTI groups proved the $\mathrm{CO}_{2}$ detection in the range from 10 to $50 \%$ with accuracy better than $3 \%$.

It was established that the absorption spectra can be corrected mathematically by fitting a polynomial function to the absorbance values measured at non-absorbing wavelengths to estimate absorbance error at each wavelength in the considered wavelength range. These corrected spectra are then processed in the GQS software to predict the fuel properties. The higher the order of the polynomial function, greater will be the accuracy achieved in correcting the absorbances. However, this is limited by computational complexity and time. The GQS software was updated to include the temporal drift correction algorithm. The GQS software was also modified to improve Mass Flow Control module. This section is frequently used during sensor testing and calibration. The improved version of the software is operator friendly, incorporates automatic savings of the last controller settings, and also automatically stores the calibration settings that can be further recalled on demand. Also, the sensor calibration requirements were analyzed during this period. It was concluded that a single calibration data set consisting of the NIR spectra of pure species, is adequate for reproducing the spectra of mixtures and predicting their properties. This eliminates the necessity to consider the compositional variation of the fuel mixtures to be tested.

Considering the accuracy, response time, operation conditions and cost, a MOSFET sensor (HPS100, Applied Sensor) was recommended for integration with GQS for measuring the concentration of hydrogen in hydrocarbon fuel mixtures. The measured hydrogen concentration can be utilized to re-compute the compressibility factor and composition of the mixture.

Water has significant spectral interference with hydrocarbons in the near infrared region. At $100 \%$ relative humidity, the absorption of water is comparable to the absorption of hydrocarbons at atmospheric pressure. Hence, it is recommended to dehumidify a landfill gas mixture, before it is passed through GQS for measuring its properties. The other possible remedy is to include water vapor (in small quantities) as one of the components in the calibration mixtures.

The HPS-100C was tested for response time and cross-sensitivity to methane. The sensor response is slow relative to the gas composition sensor. At low hydrogen concentrations (approximately up to 15\%), the sensor does not show any increase in pulse width with increasing concentration. A possible reason for this may be the error associated with mixture preparation. The sensor is cross-sensitive to methane; however, the response to the presence of methane is reproducible and hence, cross-sensitivity seems to be mathematically correctable in the GQS algorithm. The PWM signal of HPS-100C can be converted to analog signal with desired resolution and accuracy and can be readily measured using the existing GQS data acquisition system. The measured analog signal and absorption spectrum of fuel mixture will be stored in the sensor training database. The data will be processed to compute regression coefficients and to estimate the composition of unknown fuel mixtures containing hydrogen.

A literature review of methods/principles used for oxygen measurement was completed. It is clear from the review that electrochemical sensors will be the most suitable for use with the gas quality sensor for monitoring the concentration of oxygen in fuels.

The PCR and PLS methods have been applied for the analysis of mixtures having compositions similar to producer gas. Only the first few principal components are required to represent most of the variation in the data. A reasonable accuracy has been achieved, despite, the cross sensitivity of hydrogen sensor to methane. It can be concluded that the method can be 
extended to more complex sensor system, involving cross sensitive measurements from different sources.

Capability of the GQS software to log binary data has been validated. Data from binary files created by the GQS software can be successfully read using MATLAB.

A program has been developed using $\mathrm{R}$ software for implementation of various multivariate calibration models including implicit and explicit drift correction methods. The prediction results of these calibration models will be compared with GC measurements and the best method suitable for GQS will be selected.

The potential issue in accurate characterization of producer gas and natural gas - landfill gas blends is low concentrations of higher hydrocarbons and carbon dioxide, hence, their weak absorption signals and strong spectral interference among them. However, multivariate regression analysis has shown that a reasonable accuracy can be achieved in estimating the composition and heating value of these types of fuel mixtures.

This study has shown that the measurements from several sources, all of which are crosssensitive to multiple gases, can be processed collectively using multivariate regression methods to accurately predict the compositions and heating values of complex mixtures formed by blending producer gas and refinery gas with natural gas.

The composition and heating value of landfill gas measured in real-time using the GQS can be provided as a feed forward input to an engine control module. Further experimental investigation is required in order to study the drift pattern in spectral measurements and its effect on statistical fluctuations in the predicted fuel properties.

An experimental setup comprising the existing GQS, humidifier and heating system has been developed to prepare and characterize fuel mixtures containing water vapor. Further experimentation is necessary in order to assess the performance of this apparatus at humidifying the fuel mixtures to the desired levels.

The experimental setup is developed for preparing mixtures of methane, carbon dioxide, nitrogen and water vapor. Further experimentation is necessary in order to determine what humidity levels can be achieved using this setup.

The near infrared absorption spectrum of water vapor in nitrogen was measured using the modified gas quality sensor setup. The absorption bands of water vapor overlap with the absorption bands of hydrocarbons in the wavelength range 1300 to $1500 \mathrm{~nm}$. The strong absorption signal of water vapor suggests that it can be accurately quantified. Further statistical analysis is required in order to determine the accuracy in estimating the concentration of water vapor. Also, the accuracy of humidity sensor plays an important role in accurate quantification of water vapor and further investigation is required in order to determine its reliability.

Preliminary experimental analysis suggests that the humidity sensor may have significant error associated with $\mathrm{RH}$ measurement. A detailed error analysis is required, considering errors in temperature and flow measurements, in order to determine RH error and to obtain an accurate calibration data.

The experimental data consisting of the compositions and near infrared absorption spectra of the mixtures of methane, carbon dioxide, nitrogen and water vapor has been collected. Further data analysis is required in order to gain an understanding of feasibility of measuring water vapor fraction in methane-carbon dioxide mixtures.

Synthetic landfill gas mixtures having a uniform variation in the concentrations of methane, carbon dioxide and water vapor have been obtained using the modified gas quality sensor setup.

The near infrared absorption spectra of synthetic landfill gas mixtures are measured. There is a strong spectral interference between methane, carbon dioxide and water vapor in the wavelength range 1300 to $1500 \mathrm{~nm}$. A further statistical analysis is required in order to evaluate the accuracy in estimating the composition of landfill gas from their spectra.

Using the classical least squares regression on specific absorption bands, the concentrations of methane and water vapor in landfill gas mixtures can be estimated with a reasonable accuracy. 
However, carbon dioxide concentrations are difficult to evaluate using this method. When the CLS is used on the entire spectra, methane is underestimated. Methane and carbon dioxide are probably estimated with a reasonable accuracy by the PCR/PLS. However, water vapor is underestimated. The PCR and PLS produce very similar results. To determine the accuracy and precision of these measurements, further investigation is required. 


\subsection{Task 3.0 AFRC for Opportunity Fuels}

3.1 -Hardware development or modifications The plan was to work with Cummins to integrate the GQS into their commercial Air Fuel Ratio Control (AFRC) hardware platform for reciprocating engines operated on opportunity fuels. This work was attempted while Cummins had one of their engines installed at the Steuben County landfill in Bath, NY. Due to timing and budget constraints at both GTI and Cummins, there was only limited opportunity to test their AFRC with a signal supplied from the GQS..

3.2 -Software development and implementation There was not sufficient funding available at Cummins to develop and implement software to integrate measured signals from the GQS into their AFRC. In a separate project funded by the California Energy Commission that provided match funding to this DOE sponsored project, GTI proposed to work with Continental Controls Corp. to integrate the GQS into their advanced AFRC system. Unfortunately, this proposal was rejected because at the time GTI did not have a commercial partner for the GQS.

3.3-Control system prototypes GTI was unable to secure the commercialization partner for integrating the GQS into an AFRC system. Now that a commercial partner for the GQS is secured, GTI and the partner plan to work with engine OEMs toward this goal.

\subsection{Task 4.0 EGR system for Opportunity Fuels}

\section{1 - Literature review of low BTU gaseous fuel composition and their application in reciprocating engine.}

Waste gases from landfills, waste digesters, coal beds, farm waste, animal waste, and pyrolysis gas are cause for both environmental and safety concerns. Landfill gases, when vented into open air, cause air pollution that can be harmful to local residents living near the landfill. Coal bed methane can become trapped in enclosed spaces in coal mines, which causes explosions in the presence of a spark or other ignition source. In many cases, the waste gases are burned in open flames to dispose of the gases without venting them into the atmosphere. Waste gases from these sources contain methane $\left(\mathrm{CH}_{4}\right)$, hydrogen $\left(\mathrm{H}_{2}\right)$, and other hydrocarbons fuels. Although the concentrations of $\mathrm{CH}_{4}, \mathrm{H}_{2}$, and other hydrocarbons in waste gas are usually less than ideal, the gases can still be utilized in a variety of energy conversion devices. Utilizing waste gases as fuel provides both a cheap source of fuel and a method of disposing of potentially harmful gases. Since the gases have lower heating values than most gaseous fuels, they are commonly referred to as low-BTU fuels. The most commonly used devices for producing mechanical or electrical energy from low-BTU fuels are reciprocating engines, turbines, and fuel cells. 
Low-BTU fuels from waste gas are readily available in the U.S. and various locations around the world. One estimate from the European Commission estimated in 2007 that more than 94 billion cubic meters of methane from landfills each year [a]. In the same year, the U.S. Environmental Protection Agency (EPA) estimated that landfills in the U.S. could produce 2 quadrillion BTUs each year. Coal bed gas could provide another 37 billion cubic meters of methane each year. According to the U.S. EPA, there were 600 landfills in the U.S. that could support landfill gas utilization projects but did not have a project in place as of 2006 [b]. The typical landfill produces usable waste gas for approximately 20 years [c]. Federal funding for the development and operation of landfill gas utilization projects may be available in the U.S., which would reduce the cost for the project operator [b].

There are currently many low-BTU fuel utilization projects worldwide. In the UK, Viridor Waste Management operates a 3.5 MW generator using landfill gas. In the Canary Islands, a generator using digester gas produces heat and electricity. In Australia, coal gas is used to operate a $12 \mathrm{MW}$ electric generator. In Italy, a system of generators operating on landfill gas from Ca'asprete Landfill generates $1 \mathrm{MW}$ of electricity [c]. The Calabasas Landfill in Los Angeles County, California uses microturbines to produce electricity from low-BTU landfill gas [d].

\section{Composition}

Most low-BTU fuels contain $\mathrm{CH}_{4}, \mathrm{H}_{2}$, or a combination of the two and a large concentration of inert gases (primarily $\mathrm{N}_{2}$ and/or $\mathrm{CO}_{2}$ ). Most low-BTU fuels fall into one of two main categories: methane based fuels and hydrogen based fuels. Although some low-BTU fuels contain both $\mathrm{CH}_{4}$ and $\mathrm{H}_{2}$, they are classified by the component that provides the most energy in the fuel.

Waste digesters, landfills, and coal seams and mines produce methane based low-BTU fuels [a]. Past research has shown that the average landfill gas contains between $45 \%-60 \% \mathrm{CH}_{4}$ by volume and the remainder is mostly $\mathrm{CO}_{2}$ with trace amounts of other gases $[\mathrm{c}][\mathrm{e}][\mathrm{f}][\mathrm{g}][\mathrm{h}]$. This corresponds to heating values ranging from $16.8-20.5 \mathrm{MJ} / \mathrm{m}^{3}$. Standard natural gas has average heating value of $38 \mathrm{MJ} / \mathrm{m}^{3}$ [i]. The heating value of landfill gas can fluctuate as much as $30 \%$ with changes in weather, damage in the gas collection system, and changes in other conditions in the landfill [j]. One landfill in Los Angeles County, California emits waste gas with $\mathrm{CH}_{4}$ concentrations as low as $25 \%$ [d], which is about $9.3 \mathrm{MJ} / \mathrm{m}^{3}$. Methane concentrations below $30 \%$ require the use of specially designed microturbines developed for low-BTU fuels. Kawai, et al tested fuels ranging from $30 \% \mathrm{CH}_{4}$ to $100 \% \mathrm{CH}_{4}$ in a boiler [k]. The boiler was capable of using low-BTU fuels with heating values as low as $12 \mathrm{MJ} / \mathrm{m}^{3}$. Another source of methane based lowBTU fuel comes from anaerobic decomposition of manure. The manure biogas studied by Tippayawong, et al is primarily composed of $\mathrm{CH}_{4}(65 \%)$ and $\mathrm{CO}_{2}(26 \%)$, with small amounts of sulfur [l]. This manure biogas has a heating value of $24.5 \mathrm{MJ} / \mathrm{kg}$, which is about half of the heating value of methane.

Hydrogen based low-BTU fuels include chicken manure pyrolysis gas and gasified lignite coal. Chicken manure pyrolysis gas studied by Serio, et al contains approximately $15 \% \mathrm{CH}_{4}, 5 \%$ $\mathrm{C}_{2} \mathrm{H}_{4}$, and $40 \% \mathrm{H}_{2}[\mathrm{~m}]$. Lignite coal gas was simulated by Lalk and Blacksmith as $15.7 \% \mathrm{H} 2$, 2.6\% $\mathrm{CH} 4,0.2 \% \mathrm{C} 2 \mathrm{H} 6,20.9 \% \mathrm{CO}$ and the rest is composed $\mathrm{CO}_{2}$ and $\mathrm{N}_{2}$ [i]. Gas from lignite coal has heating values about $10 \%-15 \%$ of the heating value of standard natural gas.

Wood biomass pyrolysis gas can be either hydrogen based or methane based. Research by Kawasaki and Yamane studied simulated low-BTU wood pyrolysis gas [n]. One simulated pyrolysis gas is composed of $50 \% \mathrm{H}_{2}, 20 \% \mathrm{CH}_{4}$, and $30 \%$ inert gases, and the other simulated gas is composed of $40 \% \mathrm{H}_{2}, 10 \% \mathrm{CH}_{4}$, and $50 \%$ inert gases. Low-BTU fuels researched by Ando, et al consist of both a hydrogen based gas and a methane based gas [o]. The two main types of lowBTU fuels tested in this research are hydrogen-rich gas $\left(12 \% \mathrm{H}_{2}, 0 \% \mathrm{CH}_{4}\right)$ and methane-rich gas (5.7\% $\mathrm{H}_{2}, 7.2 \% \mathrm{CH}_{4}$ ), which have approximately the same heating value. Both of these fuels have heating values ranging from $3.8-5.0 \mathrm{MJ} / \mathrm{m}^{3}$, which is about $1 / 10$ of the heating value of natural gas. 


\section{Contaminants}

Contaminants commonly found in low-BTU fuels include ammonia, sulfur, vinyl chloride, dichlorobenzene, trichlorofluoromethane, DMS, COS, and $\mathrm{H}_{2} \mathrm{~S}$, particulate matter, and siloxanes. Ammonia in low-BTU fuels can corrode metallic components of IC engines [a]. Sulfur in lowBTU fuels can cause buildup in IC engine cylinders and can destroy lubricating oils in the engine and can cause wear in both IC engines and turbines [a][h]. The halogen and sulfur compounds must be removed from landfill gas to meet purity requirements for use in some fuel cells that can be damaged by impurities in the fuel [h]. He, et al developed a catalytic/sorption hybrid process that removes halogen and sulfur compounds from landfill gas [h]. Pierpaoli and Diotallevi use a dehumidifier to remove sulfur from landfill gas [c]. The same researchers pass landfill gas through a filter to remove particulate matter from the fuel.

Siloxanes are compounds that contain silicon, oxygen, and methane and they are commonly found in landfills and waste digesters [p]. They cause the presence of silica powder in low-BTU fuels, which leads to deposits of silicon dioxide in engines, turbines, or other combustors that utilize low-BTU fuels [a][d][p]. This can cause undesirable wear in the engine. In order to prevent costly maintenance, siloxanes must be removed from biogas before combustion. Siloxanes also cause catalyst deactivation, which can hinder emissions reduction in engines and prevents use of low-BTU fuels in fuel cells [p]. The most common siloxane detection method is gas chromatography and mass spectrometry using methanol impingers, metal canister sampling, or tedlar bag sampling. Siloxane detection is possible at levels as low as 10-20 ppb. Methods of siloxane removal include carbon adsorption, refrigeration, liquid absorption, and silica gel. Pierpaoli and Diotallevi use carbon filters to remove siloxanes from the landfill gas [c]. The Calabasas Landfill in Los Angeles County, California reduces siloxane content by passing the landfill gas through a chiller and carbon adsorption filters [d]. The carbon filters must be replaced periodically to keep siloxanes out of the combustion gas, which adds to the cost of electricity production.

\section{Low-BTU Fuel Utilization in IC Engines}

As a result of the compositions and contaminants, many low-BTU fuels are best suited for use in reciprocating internal combustion (IC) engines. Some engines designed for low-BTU fuels can operate on methane based fuels that contain as little as $30 \% \mathrm{CH}_{4}$ [a]. Engines can tolerate impurities, including siloxanes, ammonia, and sulfur, better than other energy conversion devices. Engines operating on low-BTU fuels can meet many of the world's emissions regulations with little to no aftertreatment devices. Low-BTU fuels can be used as the only fuel in spark-ignition (SI) engines and in dual fuel compression ignition (CI) engines. Concerns with using low-BTU fuels in IC engines include both engine performance and exhaust emissions. The engine must have enough power output and high enough brake thermal efficiency to make the use of low-BTU fuels cost effective. Exhaust emissions must meet environmental restrictions required by local and national laws.

\section{SI Engine Performance}

Bade, Shrestha and Naryanan tested low-BTU landfill gas in an SI engine [e]. In their experiments $12^{\circ}$ BTDC produced more indicated power than any other spark timing. The highest indicated power occurred at stoichiometric combustion for all spark timings and all compression ratios. They found that increasing the compression ratio increases the indicated power. The peak pressure increases with increasing compression ratio. The COV of indicated power is below 5\% when the engine is operated at equivalence ratios between $0.8-1.0$, but increases above $5 \%$ for all other equivalence ratios. Operation of the engine outside this equivalence ratio range should be avoided because the combustion is too unstable. Peak pressure is also highest at equivalence ratios between 0.8-1.0. The combustion duration and ignition delay are lowest for equivalence ratios between 0.8-1.0. 
Macari and Richardson studied the effects of spark timing on low-BTU engines [j]. Advancing spark timing decreases brake specific fuel consumption and extends the lean flammability limit of low-BTU fuels. Advancing spark timing earlier than $37^{\circ}$ BTDC does not improve brake specific fuel consumption.

Yamasaki, et al used simulated pyrolysis gas with $\mathrm{CO}_{2}$ and $\mathrm{N}_{2}$ as the inert gas components in an SI engine [s]. Pyrolysis gas with $\mathrm{CO}_{2}$ results in lower indicated thermal efficiency than pyrolysis gas with $\mathrm{N}_{2}$. For both $\mathrm{CO}_{2}$ and $\mathrm{N}_{2}$, increasing the inert gas composition decreases the indicated thermal efficiency. Increasing the engine load increases the indicated thermal efficiency.

\section{Dual Fuel CI Engine Performance}

Kawasaki and Yamane studied the use of low-BTU pyrolysis gas from wood biomass in a biodiesel dual fuel CI engine [n]. As the heat input from the pyrolysis gas increases, the brake thermal efficiency decreases. The $\mathrm{HC}$ and $\mathrm{CO}$ emissions increase with increasing heat input, but the $\mathrm{NO}_{\mathrm{x}}$ emissions decrease. Retarding injection timing increases $\mathrm{CO}$ emissions, decreases $\mathrm{NOx}$ emissions, and has little to no effect on $\mathrm{HC}$ and $\mathrm{H}_{2}$ emissions and brake thermal efficiency. The two pyrolysis gas compositions have similar brake thermal efficiency and $\mathrm{HC}$ and $\mathrm{CO}$ emissions. The pyrolysis gas with greater $\mathrm{H}_{2}$ and $\mathrm{CH}_{4}$ composition has increased $\mathrm{NO}_{\mathrm{x}}$ over the pyrolysis gas with lower $\mathrm{H}_{2}$ and $\mathrm{CH}_{4}$ composition.

Modarres Razavi and Karim found that using gaseous low-BTU fuels in a dual fuel engine increases the ignition delay compared to dual fuel engines using natural gas [q]. Using pilot diesel fuels with cetane numbers greater than standard diesel fuel can decrease the ignition delay, offsetting the increase caused by using low-BTU fuels. Using diesel fuels with better physical properties (greater heating value and lower density) also decreases the ignition delay.

Mahammadi, et al researched low-BTU fuel that consists of $\mathrm{H}_{2}$ and $\mathrm{N}_{2}$ in a dual fuel CI engine [r]. Increasing the low-BTU fuel as a percentage of intake air decreases the brake thermal efficiency. Tippayawong, et al used low-BTU fuel from the anaerobic decomposition of animal manure in a dual fuel CI engine [1]. The low-BTU fuel replaced about $90 \%$ of the diesel fuel. The dual fuel operation had power output about $5 \%$ to $10 \%$ greater than for pure diesel operation. Dual fuel operation also resulted in increased thermal efficiency and specific fuel consumption. Long term, the biogas fuel did not cause any significant wear in the engine components. However, it did result in a coating of soft, wet carbon residue on some of the components, which was easily cleaned.

Ando, et al tested hydrogen based fuel $\left(12 \% \mathrm{H}_{2}, 0 \% \mathrm{CH}_{4}\right)$ and methane based fuel $\left(5.7 \% \mathrm{H}_{2}\right.$, $7.2 \% \mathrm{CH}_{4}$ ) with approximately the same heating value in a dual fuel $\mathrm{CI}$ engine [o]. At wide open throttle (WOT), the hydrogen based fuel had slightly lower brake thermal efficiency than natural gas at all engine speeds. The methane based fuel had significantly lower brake thermal efficiency at low to medium speeds. The methane based fuel could not provide stable combustion at high engine speeds. Both the hydrogen based fuel and the methane based fuel had significantly lower brake power output for all speeds. At partial load and $2800 \mathrm{rpm}$, the hydrogen based fuel and the natural gas had similar brake thermal efficiency and brake power output when the data is normalized for energy input. The methane based fuel had poor brake thermal efficiency and brake power output compared to both hydrogen based fuel and natural gas. At partial load and 2000 rpm, the hydrogen based fuel and methane based fuel had similar brake thermal efficiency and brake power output. The engine can operate using hydrogen based fuel with good stability over a wide range of equivalence ratios, which is important because the fuel composition can fluctuate causing the equivalence ratio to fluctuate. The methane based fuel has a very narrow range of equivalence ratios for which the engine performance is stable. 


\section{Emissions}

Advancing the spark timing increases $\mathrm{NO}_{\mathrm{x}}$ and $\mathrm{HC}$ emissions, but has no effect on $\mathrm{CO}$ emissions. Equivalence ratios below 0.5 (very lean combustion) result in COV of indicated mean effective pressure above $5 \%$, which is too unstable for reliable engine performance $[j][s]$. As the equivalence ratio is increased to stoichiometric, maximum in-cylinder pressure and maximum heat release rate increase [s].

Lalk and Blacksmith studied simulated lignite coal gas with heating values about $10 \%-15 \%$ of the heating value of standard natural gas in a dual fuel CI engine [i]. The lignite gas was simulated as $15.7 \% \mathrm{H} 2,2.6 \% \mathrm{CH} 4,0.2 \% \mathrm{C} 2 \mathrm{H} 6,20.9 \% \mathrm{CO}$ and the remainder is composed $\mathrm{CO}_{2}$ and $\mathrm{N}_{2}$. The use of low-BTU fuel results in 5\%-10\% decrease in brake thermal efficiency compared to pure diesel operation. Advanced injection timing at high speeds results in an increase in power output and an increase in diesel fuel consumption. Advanced injection timing results in increased knocking caused by autoignition of the low-BTU fuel. At lower speeds, the low-BTU fuel combustion is more complete and brake thermal efficiency and power output increase as a result. Full load low-BTU dual fuel operation can be achieved with up to $70 \%$ energy contribution from low-BTU fuel.

In a dual fuel $\mathrm{CI}$ engine, the emissions of $\mathrm{CO}, \mathrm{HC}$, and PM increase with increased low-BTU fuel addition [r]. As the $\mathrm{H}_{2}$ is increased to $30 \%$ of the low BTU fuel, these effects are decreased. For most low BTU fuel addition, the CO, HC, and PM emissions are greater than for pure diesel operation. The $\mathrm{NO}_{\mathrm{x}}$ emissions increase with increased low BTU fuel addition. Increasing the $\mathrm{H}_{2}$ as a percentage of the low BTU fuel further increases the $\mathrm{NO}_{\mathrm{x}}$ emissions. However, the $\mathrm{NO}_{\mathrm{x}}$ emissions are lower for all low-BTU fuel addition than for pure diesel operation.

Ando, et al tested hydrogen based fuel $\left(12 \% \mathrm{H}_{2}, 0 \% \mathrm{CH}_{4}\right)$ and methane based fuel $\left(5.7 \% \mathrm{H}_{2}\right.$, $7.2 \% \mathrm{CH}_{4}$ ) with approximately the same heating value in a dual fuel $\mathrm{CI}$ engine [o]. Both hydrogen based fuel and methane based fuel have near zero $\mathrm{NO}_{\mathrm{x}}$ emissions for all equivalence ratios tested in the dual fuel $\mathrm{CI}$ engine [o]. Hydrogen based fuel has greater $\mathrm{CO}$ emissions than natural gas for all equivalence ratios. Methane based fuel has greater CO emissions than hydrogen based fuel for all equivalence ratios. All three fuels have very low CO emissions when equivalence ratio is slightly leaner than stoichiometric. Hydrogen based fuel has near zero HC emissions for all equivalence ratios, but $\mathrm{H}_{2}$ emissions were not included the total $\mathrm{HC}$ emissions. Methane based fuel has greater HC emissions than both natural gas and hydrogen base fuel. Both $\mathrm{HC}$ and $\mathrm{CO}$ emissions were very high outside of the stable combustion region for all fuels.

\section{Improvements}

Yamasaki, et al found that combustion can be made more stable by increasing $\mathrm{H}_{2}$ concentration in the fuel [s]. Bade Shrestha and Naryanan discovered that adding $\mathrm{H}_{2}$ to landfill gas increases peak pressure and decreases ignition delay, combustion duration, and COV of peak pressure, which corresponds to faster, more stable combustion [e]. Porpatham, et al studied the use of methane based low-BTU fuel in an SI engine with $\mathrm{H}_{2}$ added up to $15 \%$ [g]. Adding $\mathrm{H}_{2}$ to the fuel extends the lean flammability limit of the mixture. At equivalence ratios greater than 0.73 , the addition of $\mathrm{H}_{2}$ decreases the brake power and brake thermal efficiency because of retarded spark timing. The brake thermal efficiency is greatest around stoichiometric combustion. For all equivalence ratios, increasing $\mathrm{H}_{2}$ addition decreases $\mathrm{HC}$ emissions. The $\mathrm{HC}$ emissions are lowest around stoichiometric combustion. The $\mathrm{NO}_{\mathrm{x}}$ emissions are greatest around stoichiometric combustion. For combustion richer than stoichiometric, the $\mathrm{CO}$ emissions increase for all $\mathrm{H}_{2}$ addition. For leaner combustion, the $\mathrm{CO}$ emissions are very low for all $\mathrm{H}_{2}$ addition. At equivalence ratios less than 0.7 , the COV of indicated mean effective pressure is greater than $5 \%$. At equivalence ratios greater than 0.7, the COV of indicated mean effective pressure is less than 5\%. Addition of $\mathrm{H}_{2}$ requires more retarded spark timing. Increased $\mathrm{H}_{2}$ addition results in decreased ignition delay and combustion duration. The ignition delay and combustion duration decrease with richer mixture. 
Research by Porpatham, et al focuses on using a lime water scrubber to reduce the $\mathrm{CO}_{2}$ content of methane based low-BTU fuel before burning it in an SI engine [f]. The fuel used in the experiment is $41 \% \mathrm{CO}_{2}$ (the rest is methane) and is reduced to $30 \%$ and $20 \% \mathrm{CO}_{2}$ for experiments. For all $\mathrm{CO}_{2}$ percentages, the brake power is highest at near stoichiometric combustion. Reducing the $\mathrm{CO}_{2}$ content increases the brake power at both full and part throttle. The maximum brake thermal efficiency is increased from $25 \%$ to $30 \%$ for full throttle and from $18 \%$ to $23 \%$ at part throttle with $\mathrm{CO}_{2}$ reduction. The $\mathrm{HC}$ emissions are reduced slightly for both full and part throttle. However, the $\mathrm{NO}_{\mathrm{x}}$ emissions increase significantly for full and part throttle. The $\mathrm{CO}$ emissions increase with decreased $\mathrm{CO}_{2}$ in the biogas, but at equivalence ratios below 0.95 the $\mathrm{CO}$ emissions are near zero. The cylinder pressure increases for both stoichiometric and lean combustion. Decreasing the $\mathrm{CO}_{2}$ decreases the combustion duration and allows for less advanced spark timing. The COV of indicated mean effective pressure is below $5 \%$ for combustion richer than 0.75 equivalence ratio.

\section{References for 4.1}

[a] Packham, K., "The case for waste to energy: utilizing low-BTU reciprocating gas engine generators,” Technical information from Cummins Power Generation, Power topic \#6015 (2007).

[b] Goldstein, R., "2006 update: the state of U.S. landfill gas utilization projects.”

[c] Pierpaoli, P. and Diotallevi, A., "Generating electrical energy from landfill gas: an Italian experience,” International Energy Journal, 8 (2007) 45-50.

[d] Iacoboni, M., Chow, J., and Wheless, E., "Calabasas Landfill microturbine power generation project: lessons learned after one-year of operation."

[e] Bade Shrestha, S.O., and Naryanan, G., "Landfill gas with hydrogen addition - a fuel for SI engines,” Fuel, 87 (2008) 3616-3626.

[f] Porpatham, E., Ramesh, A., and Nagalingam, B., "Investigation on the effect of concentration of methane in biogas when used as a fuel for a spark ignition engine,” Fuel, 87 (2008) 1651-1659.

[g] Porpatham, E., Ramesh, A., and Nagalingam, B., "Effect of hydrogen addition on the performance of a biogas fuelled spark ignition engine," Internation Journal of Hydrogen Energy, 32 (2007) 2057-2065.

[h] He, C., Herman, D.J., Minet, R.G., and Tsotsis, T.T., “A catalytic/sorption process for landfill gas cleanup,” Industrial and Engineering Chemistry Research, 36 (1997) 4100-4107.

[i] Lalk, T.R., and Blacksmith, J.R., "Dual-fueling of a single cylinder diesel engine with simulated low-BTU lignite gas as the primary fuel," SAE 820316.

[j] Macari, N.C., and Richardson, R.D., "Operation of a Caterpillar 3516 spark-ignited engine on low-BTU fuel,” Journal of Engineering for Gas Turbines and Power, 109 (1987) 443447.

[k] Kawai, K., Yoshikawa, K., Kobayashi, H., Tsai, J.S., Matsuo, M., and Katsushima, H., "High temperature air combustion boiler for low BTU gas," Energy Conversion and Management, 43 (2002) 1563-1570.

[1] Tippayawong, N., Promwungkwa, and Rerkkriangkrai, P., "Long-term operation of a small biogas/diesel dual-fuel engine for on-farm electricity generation,” Biosystems Engineering, 98 (2007) 26-32.

[m] Serio, M., Kroo, E., Florczak, E., Wojtowicz, M., Wignarajah, K., and Fisher, J., “A prototype pyrolysis / oxidation system for solid waste processing," SAE 2005-01-3083.

[n]Kawasaki, K., and Yamane, K., "Experimental study of a dual-fuel diesel engine with biodiesel and low-calorie gas fuels,” SAE 2007-01-2026. 
[o] Ando, Y., Yoshikawa, K., Beck, M., and Endo, H., "Research and development of a low-BTU gas-driven engine for waste gasification and power generation,” Energy, 30 (2005) 22062218.

[p] Wheless, E., and Pierce, J., "Siloxanes in landfill and digester gas update.”

[q] Modarres Razavi, M.R., and Karim, G.A., "Examination of the dual-fuel engine performance using low BTU gaseous fuels.”

[r] Mahammadi, A., Shioji, M., Ishiyama, T., and Kitazaki, M., "Utilization of low-calorific gaseous fuel in a direct-injection diesel engine,” Journal of Engineering for Gas Turbines and Power, 128 (2006) 915-920.

[s] Yamasaki, Y., Tomatsu, G., Nagata, Y., and Kaneko, S., "Development of high thermal efficiency and small size gas engine system using biomass gas fuel,” SAE 2007-01-2042.

\section{2 - Investigation of Impact of Diluents and Intake Pressure on Combustion Process of SI NG Engine Operated with Stoichiometric Mixture (Subtasks 4.2- 4.6)}

The objective of this research was to investigate the effect of the addition of diluents including nitrogen $\left(\mathrm{N}_{2}\right)$ and carbon dioxide $\left(\mathrm{CO}_{2}\right)$, equivalence ratio, intake pressure, engine speed and spark timing on the engine performance, combustion process and exhaust emissions of a single cylinder spark ignition (SI) engine. The experimental data obtained in experimental research provide valuable technical data to better understand the combustion and emissions characteristics of low BTU fuels burned in turbocharged SI engine. The data will be used to support the development and validation of numerical simulation model capable of predicting the engine performance, combustion process, and exhaust emissions of SI engines operated on methane $\left(\mathrm{CH}_{4}\right)$ containing gases fuels with the presence of a relatively large amount of diluents such as $\mathrm{CO}_{2}$ and $\mathrm{N}_{2}$.

The presence of diluents in low BTU gas decreased engine power output due to the decrease in fuel $\left(\mathrm{CH}_{4}\right)$ available for power production, the slowing down in flame propagation rate as indicated by the elongation in combustion duration, and retarding in combustion phasing due to the elongated ignition delay. However, the presence of diluents in low BTU fuels helps to suppress the onset of knock, which allow the operation of SI engines under advanced spark timing toward to optimal one and further boosted pressure for the improvement in thermal efficiency and recovery in power loss due to the presence of diluents. Also, the presence of diluents slightly deteriorates the combustion stability but still be able to achieve stable combustion when tested at equivalence ratio over 0.85 . However, the presence of diluents was expected to affect the combustion stability when operated around the lean operational limit.

The boosting of intake pressure was found to significantly increase the cylinder pressure and heat release rate. The increase heat release rate was mainly due to the increase fuel flow rate and slightly improved flame propagation rate as indicated by the slight increase in the maximum normalized peak heat release rate. The presence of diluents was found to slow down the flame propagation rate, reduce the emissions of NOx benefiting from the reduction in combustion temperature, and slightly increase the emissions of $\mathrm{CO}$ and $\mathrm{HC}$.

The effect of engine speed on the engine performance, combustion process and exhaust emissions was also investigated under naturally aspirated condition. Based on the experimental data obtained in this research, the effect of engine speed on engine power, combustion process 
(ignition delay and combustion duration) is relatively weak. In comparison, advancing the spark timing was shown to dramatically increase the cylinder pressure, improve the brake thermal efficiency, increase the exhaust emissions of $\mathrm{NO}_{\mathrm{x}}$ especially at lean operation and emissions of HC especially at stoichiometric mixture. However, the effect of spark timing on the emissions of CO was relatively weak.

Based on the experimental data obtained in this research, the application of low BTU gaseous fuel in SI engines requested the further optimization to the operating parameters. Among all possible parameters, the spark timing, intake pressure and possible application of EGR or adjustment if already applied will be the key parameters to be optimized. The presence of diluents in low BTU gas provides the "natural cool EGR" for the reduction in $\mathrm{NO}_{\mathrm{x}}$ emissions and the suppression of the onset of knock while operating at sparking approaching the optimal timing.

\section{Measurement and Process of Experimental Data}

The engine operation data measured includes engine speed, torque, intake temperature, intake pressure, exhaust temperature, exhaust pressure, flow rate of intake air, fuel (natural gas) and diluents including $\mathrm{N}_{2}$ and $\mathrm{CO}_{2}$ as shown in Table 31. The engine operation data was further processed to obtain the brake thermal efficiency, engine power (kW), and brake mean effective pressure (BMEP), brake thermal efficiency as shown in Table 32. .

The engine emissions data measured includes, NOx, $\mathrm{CO}, \mathrm{THC}, \mathrm{CH}_{4}$, non-methane $\mathrm{HC}$ (NMHC) and $\mathrm{CO}_{2}$. The engine power and emissions data were further processed to obtain the specific emissions data in $\mathrm{g} / \mathrm{kW}$-hr as shown in Table 33. In processing emissions data, the $\mathrm{CO}_{2}$ added to intake fuel was not included in the exhaust emissions. The emissions of THC, CO and $\mathrm{CO}_{2}$ were further processed to obtain the combustion efficiency of natural gas.

Table 31 Example of Engine Operation Data

\begin{tabular}{|c|c|c|}
\hline Engine Speed & rpm & 1500 \\
\hline Engine Torque & Lbf-ft & \\
\hline Intake Pressure & bar & 1.5 \\
\hline Exhaust Pressure & bar & \\
\hline Spark Timing & ${ }^{\circ}$ CA DTDC & \\
\hline Flow Rate of Air & & \\
\hline Flow of Natural Gas & & \\
\hline Equivalence Ratio & & \\
\hline Concentration of $\mathrm{N}_{2}$ Added to NG & & \\
\hline Concentration of $\mathrm{CO}_{2}$ Added to NG & & \\
\hline Flow Rate of $\mathrm{N}_{2}$ (diluents) & & \\
\hline Flow Rate of $\mathrm{CO}_{2}$ (diluents) & & \\
\hline
\end{tabular}


Table 32 Example of Performance Data

\begin{tabular}{|c|c|c|}
\hline Speed & rpm & 1499.52 \\
\hline Torque & $\mathrm{ft}-\mathrm{lb}$ & 151.30 \\
\hline Brake Power & $\mathrm{kW}$ & 28.26 \\
\hline Air/fuel ratio & & \\
\hline Brake Mean Effective Pressure & $\mathrm{kPa}$ & \\
\hline Mass Flow rate of NG & $\begin{array}{l}\mathrm{kg} / \mathrm{ho} \\
\text { ur }\end{array}$ & \\
\hline Brake Thermal Efficiency & $\%$ & \\
\hline
\end{tabular}

Table 33 Example of Engine Emissions Data

\begin{tabular}{|c|l|c|}
\hline BSNOx & $\begin{array}{l}\mathrm{g} / \mathrm{kW} \\
\mathrm{hr}\end{array}$ & 29.09 \\
\hline BSCO & $\begin{array}{l}\mathrm{g} / \mathrm{kW} \\
\mathrm{hr}\end{array}$ & 1.67 \\
\hline BSHC & $\begin{array}{l}\mathrm{g} / \mathrm{kW} \\
\mathrm{hr}\end{array}$ & 1.56 \\
\hline $\mathrm{BSCH}_{4}$ & $\begin{array}{l}\mathrm{g} / \mathrm{kW} \\
\mathrm{hr}\end{array}$ & 1.37 \\
\hline BSNMHC (non-CH & \\
\hline BSCO & $\begin{array}{l}\mathrm{g} / \mathrm{kW} \\
\mathrm{hr}\end{array}$ & 0.19 \\
\hline Combustion Efficiency of NG & $\begin{array}{l}\mathrm{g} / \mathrm{kW} \\
\mathrm{hr}\end{array}$ & 432.12 \\
\hline
\end{tabular}

In each operation, the cylinder pressure of 100 consecutive cycles was measured. The raw cylinder pressure data measured was first filtered using a moving average data filter to remove the high frequency combustion noise and pressure fluctuation due to the ignition of spark (Figure 68 and Figure 69. 


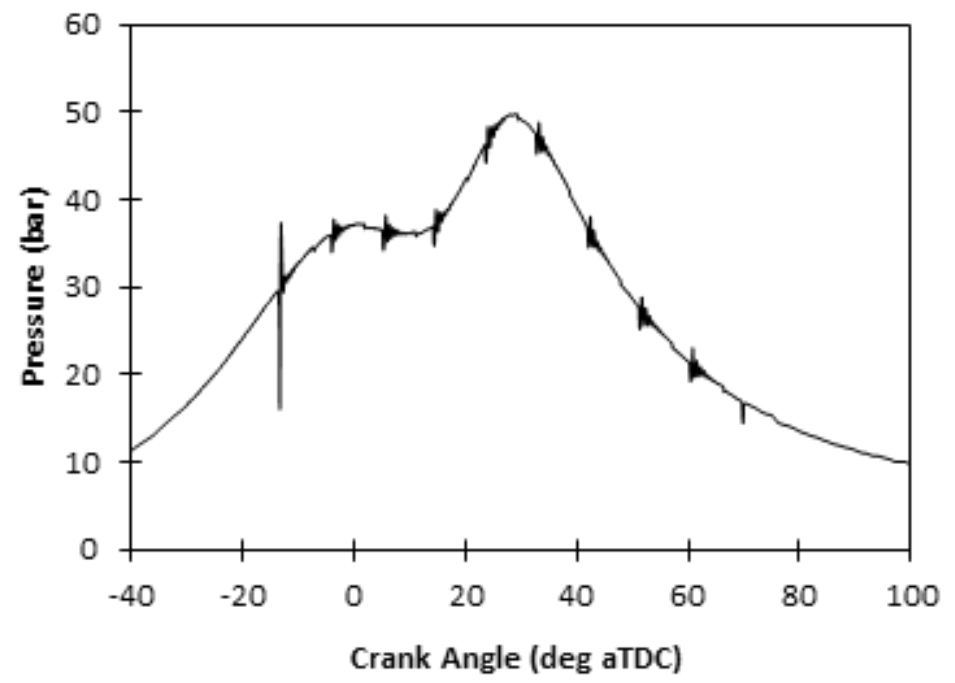

Figure 68 Raw Cylinder Pressure, Pin=1.5bar, N=1500rpm, ER=0.85, ST=13.4 CA BTDC, and diluent $=30 \% \mathrm{~N} 2$

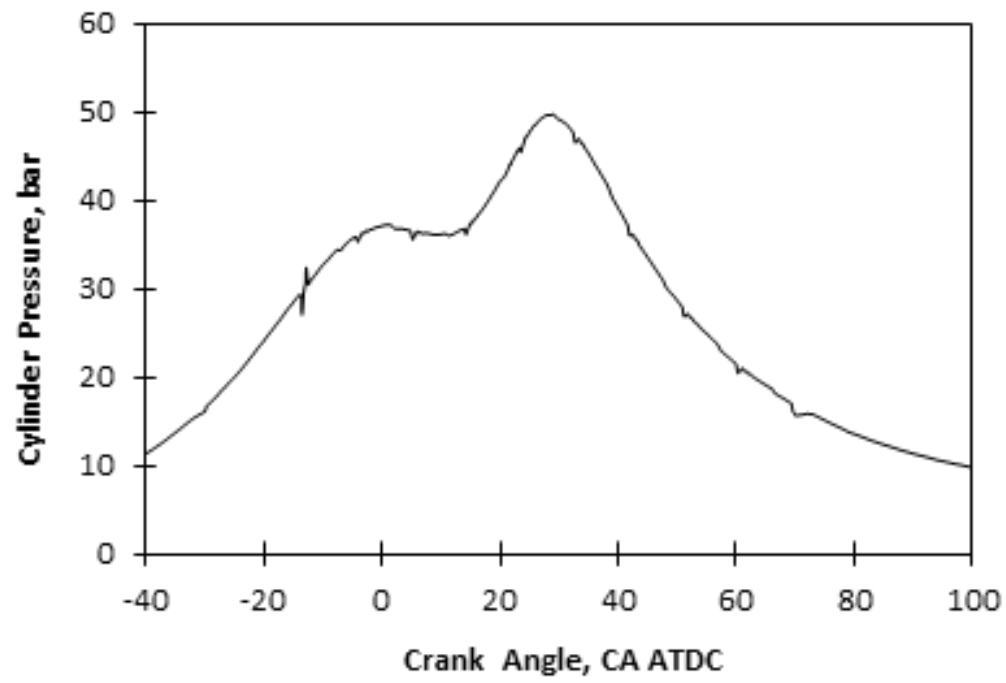

Figure 69 Cylinder Pressure Processed Using 15-point moving average data filter, Pin=1.5bar, $\mathrm{N}=1500 \mathrm{rpm}, \mathrm{ER}=0.85, \mathrm{ST}=13.4 \mathrm{CA}$ BTDC, and diluent=30\%N2

The filtered cylinder pressure of each cycle was processed to obtain a set of cylinder pressure data including the peak cylinder pressure, peak cylinder pressure rise rate and their phasing, indicated work, indicated mean effective pressure (IMEP), heat release rate (Figure 70). The heat release rate obtained was further filtered to get the smooth heat release data (Figure 71), and a set of heat release process data including the peak heat release rate and its phasing, phasing of combustion such as CA 5, CA10, CA50, CA90, and CA 95 defined as the crank angle location when $5 \%, 10 \%, 50 \%, 90 \%$, and $95 \%$ of energy released through combustion, ignition delay and combustion duration. 
In this research, the cylinder press of 100 consecutive working cycles was recorded. The filtered cylinder pressure of 100 cycles was averaged to obtain the average cylinder pressure, which was further processed to obtain a set of combustion parameters including start of combustion, phasing of combustion such as CA 5, CA10, CA50, CA90, and CA 95 defined as the crank angle location when 5\%, 10\%, 50\%, 90\%, and 95\% of energy released through combustion. A statistic analysis to the experimental data was conducted to obtain the coefficient of variation $(\mathrm{COV})$ in peak cylinder pressure $\left(\mathrm{COV}_{\mathrm{Pmax}}\right)$, IMEP $\left(\mathrm{COV}_{\mathrm{IMEP}}\right)$ and combustion parameters such as ignition timing.

Table 34 shows a list of engine combustion process parameters obtained for each set of data.

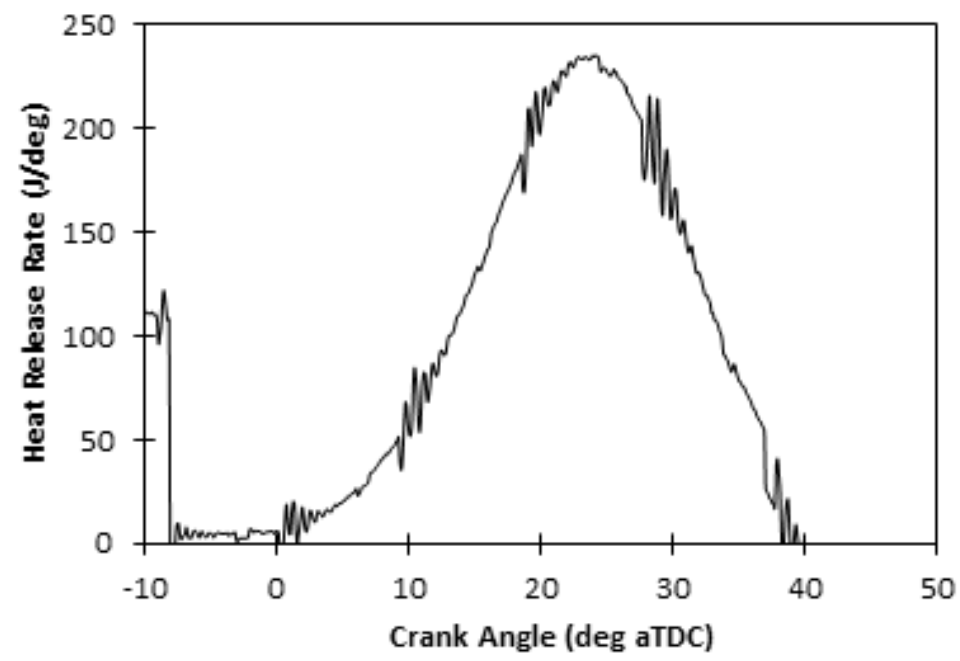

Figure 70 Raw Heat Release Data Obtained by Processing the Filtered Cylinder Pressure Data, $\mathrm{Pin}=1.5 \mathrm{bar}, \mathrm{N}=1500 \mathrm{rpm}, \mathrm{ER}=0.85, \mathrm{ST}=13.4 \mathrm{CA}$ BTDC, and diluent $=30 \% \mathrm{~N} 2$

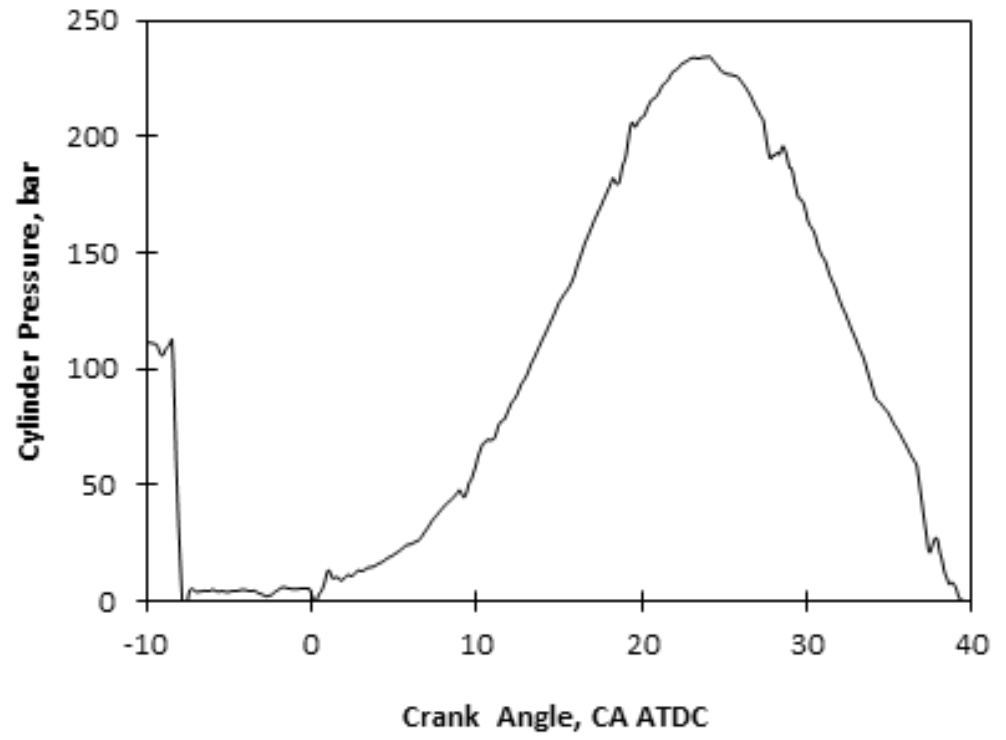

Figure 71 Filtered Heat Release Data, Pin=1.5bar, N=1500rpm, ER=0.85, ST=13.4 CA BTDC, and diluent $=30 \% \mathrm{~N} 2$ 
Table 34 Example of Cylinder Pressure and Engine Combustion Process Parameters

\begin{tabular}{|c|c|c|}
\hline Indicated work & J/cycle & \\
\hline Indicated thermal efficiency & $\%$ & 43.83 \\
\hline Peak Cylinder Pressure (Pmax) & & \\
\hline Phasing of Pmax & & \\
\hline Peak Pressure Rise Rate (PPRR) & & \\
\hline Phasing of PPRR & & \\
\hline Peak Heat Release Rate (PHRR) & & \\
\hline Phasing of PHRR & & \\
\hline CA5 & & \\
\hline CA10 & & \\
\hline CA50 & & \\
\hline CA90 & & \\
\hline CA95 & & \\
\hline Ignition Delay & & \\
\hline COVIMEP & & \\
\hline Combustion Duration (CA10-CA90) & deg & \\
\hline
\end{tabular}

\section{Experimental Results and Discussion}

\section{Effect of the addition of $\mathrm{CO}_{2}$ and $\mathrm{N}_{2}$ on knock limited spark timing}

In this research, the effect of the addition of $\mathrm{CO}_{2}$ and $\mathrm{N}_{2}$ on the knock limited spark timing was experimentally determined. The onset of knock was detected by the unique knocking noise observed. Figure72 shows the effect of the equivalence ratio and the onset of knock limited spark timing. As expected, lean operation suppress the onset of knock as indicated by the advancement of knock limited spark timing. The mixing of $30 \% \mathrm{CO}_{2}$ with natural gas also suppressed the onset of knock as indicated by the advancement in knock limited spark timing. This was due to the significant effect of the addition of $\mathrm{CO}_{2}$ in reducing the flame propagation speed and inhibited oxidation reaction. Both tend to suppress the onset of knock. This makes it possible to run the spark ignition engine with a spark timing optimized to obtain maximum thermal efficiency.

Figure 73 shows the effect of addition of $\mathrm{CO}_{2}$ on knock limited spark timing observed at 2 bar. Similar to knock limit observed at intake pressure of $1.5 \mathrm{bar}$, the addition of $\mathrm{CO}_{2}$ at 2 bar also significantly suppress the onset of knock especially at lean operation. 


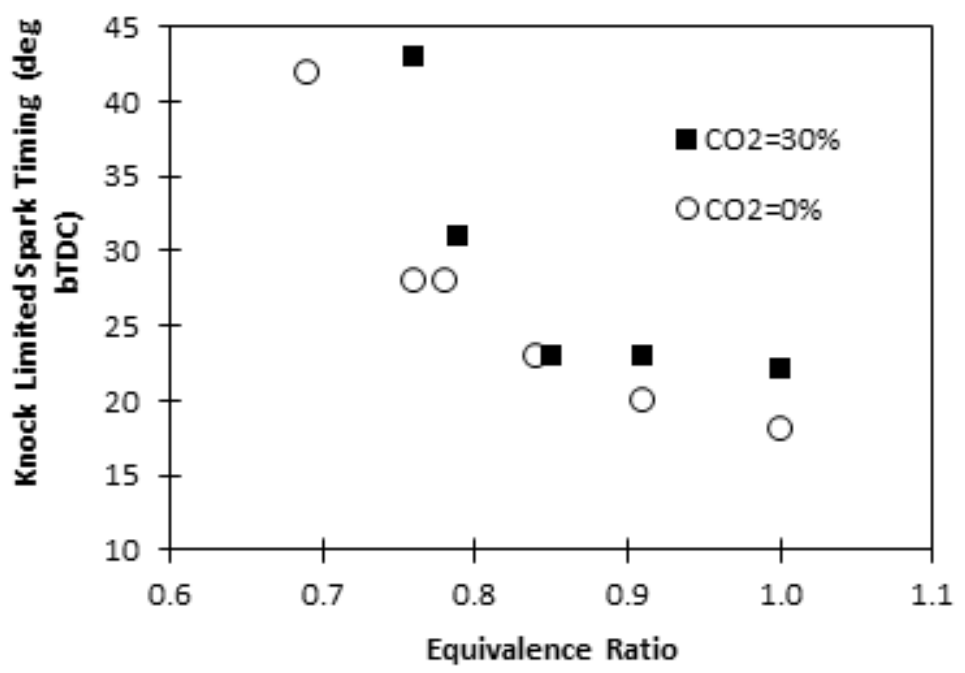

Figure 72 Effect of $\mathrm{CO} 2$ Addition on Knock Limited Spark Timing, N=1500 rpm, Pin=1.5 Bar, no knock observed with $60 \% \mathrm{CO} 2$

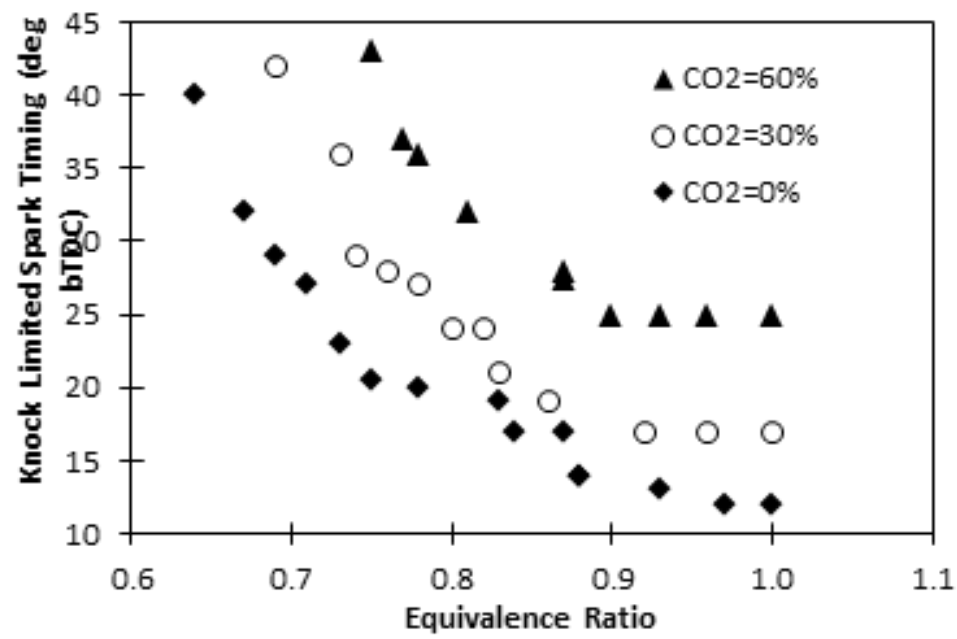

Figure 73 Effect of CO2 Addition on Knock Limited Spark Timing, N=1500 rpm, Pin=2.0 Bar

Figure 74 shows the effect of cylinder pressure and equivalence ratio on knock limited spark timing. As expected, the operation at a highly boosted pressure enhanced the onset of knock and limited the operation of SI engine with retarded spark timing so that the onset of knock can be suppressed.

As the addition of diluents suppresses the onset of knock as shown in Figure 72 and 73, the presence of diluents in low BTU gas will make it possible to advance the spark timing of SI engine towards the optimal one, which has the potential to improve the thermal efficiency of SI engines. 
Figure 74 Effect of Intake Pressure on Knock Limited Spark Timing, N=1500 rpm, no EGR, no diluents, no EGR

\section{Effect of the Presence of Diluents on Combustion and Emissions}

The test matrix for evaluating the effect of the addition of $\mathrm{N}_{2}$ and $\mathrm{CO}_{2}$ on the engine performance (thermal efficiency), combustion process and exhaust emissions is included in Table 35

Table 35 Test Matrix for Diluents Test, $N=1500 \mathrm{rpm}, \mathrm{ER}=1.0, \mathrm{P}_{\text {in }}=1.5$ bar, Spark timing $=15^{\circ} \mathrm{CA}$ BTDC

\begin{tabular}{|l|c|c|c|c|}
\hline & ER & $\mathrm{P}_{\text {in }}$ & $\mathrm{N}_{2} /\left(\mathrm{N}_{2}+\mathrm{NG}\right)$, vol. $\%$ & $\begin{array}{c}\mathrm{CO}_{2} /\left(\mathrm{CO}_{2}+\mathrm{NG}\right), \text { vol. } \\
\%\end{array}$ \\
\hline $\begin{array}{l}\text { Test } \\
1\end{array}$ & 1.0 & 1.5 & $0,20,40$, and 60 & 0 \\
\hline $\begin{array}{l}\text { Test } \\
2\end{array}$ & 1.0 & 1.5 & 0 & $0,20,40$, and 60 \\
\hline $\begin{array}{l}\text { Test } \\
3\end{array}$ & 0.85 & 1.5 & 0,30 & 0 \\
\hline $\begin{array}{l}\text { Test } \\
4\end{array}$ & 0.85 & 1.5 & 0 & $0,30,60$ \\
\hline
\end{tabular}

Figure 75 shows the effect of the addition of $\mathrm{N}_{2}$ to natural gas on the cylinder pressure, heat release process, normalized heat release rate, and mass fraction burned. As shown on Figure 75, the addition of $\mathrm{N}_{2}$ reduced the cylinder pressure after the initiation of combustion. The addition of $60 \% \mathrm{~N}_{2}$ to natural gas reduced the peak cylinder pressure from 92.20 to 80.25 bar. As shown in Figure 76, the addition of $\mathrm{CO}_{2}$ is more effective than $\mathrm{N}_{2}$ in reducing the peak cylinder pressure. The peak cylinder pressure observed with the addition of $60 \% \mathrm{CO}_{2}$ in intake fuel was $74.16 \mathrm{bar}$, which was much lower than the peak pressure of 80.25 bar observed with the addition of $60 \% \mathrm{~N}_{2}$. 


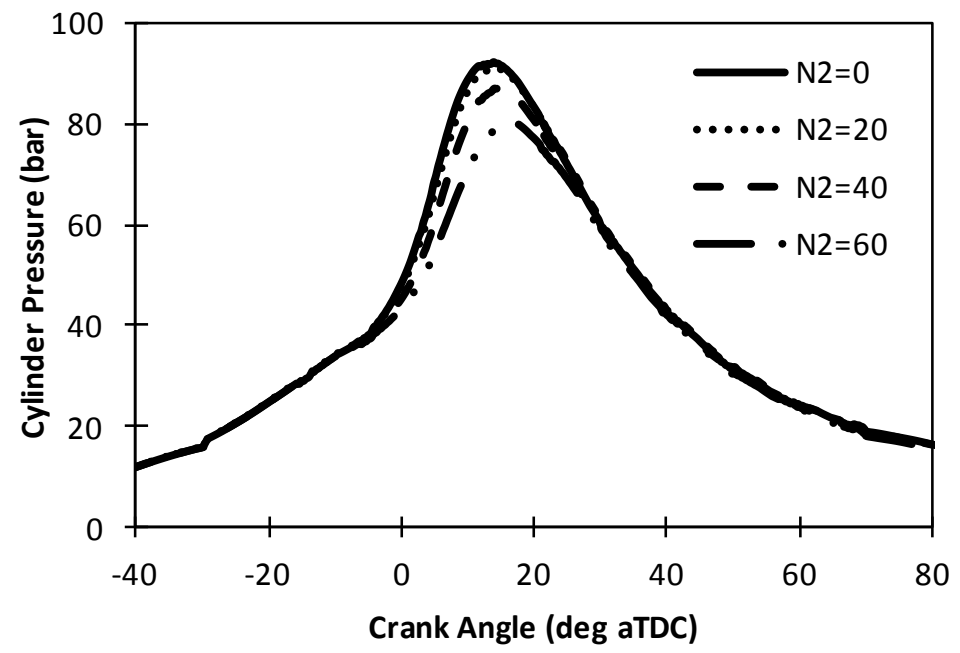

Figure 75 Effect of Intake N2 on In-Cylinder Pressure, N=1500 rpm, Pin=1.5 bar, Pout=1.65 bar, ST=15, ER=1.0

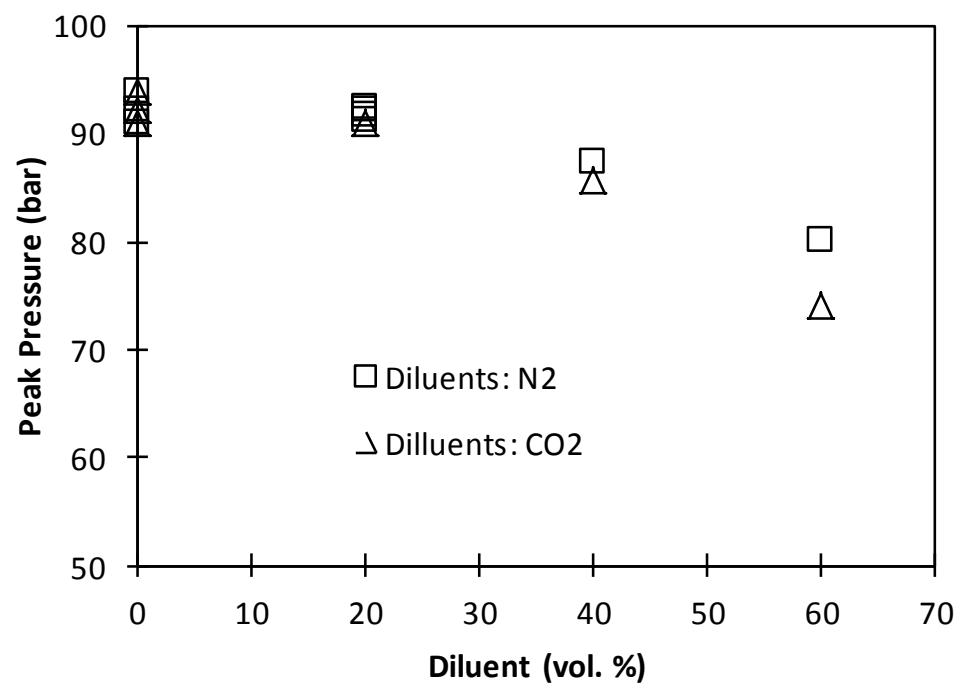

Figure 76 Effect of Diluents on Peak Pressure, N=1500 rpm, ER=1.0, Pin=1.5 bar, Pout=1.65 bar, ST=15 bTDC

Figure 77 and 78 shows the effect of the addition of diluents on engine load represented by indicated mean effective pressure (IMEP) and brake mean effective pressure (BMEP). As expected, the addition of diluents to fuel reduced the both IMEP and BMEP under constant intake pressure operation. Although $\mathrm{CO}_{2}$ is more effective in reducing the peak cylinder pressure (Figure76, the effect of $\mathrm{N}_{2}$ and $\mathrm{CO}_{2}$ in affecting the engine power was comparable (Figure 77 and Figure 78. 


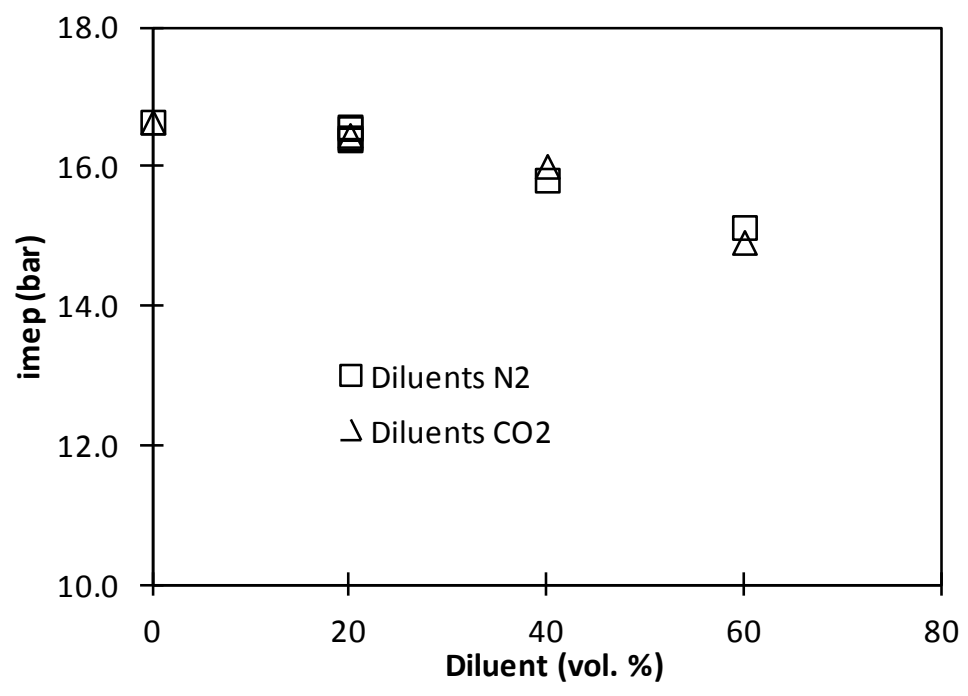

Figure 77 Effect of Diluents on IMEP, N=1500 rpm, ER=1.0, Pin=1.5 bar, Pout=1.65 bar, ST=15 bTDC

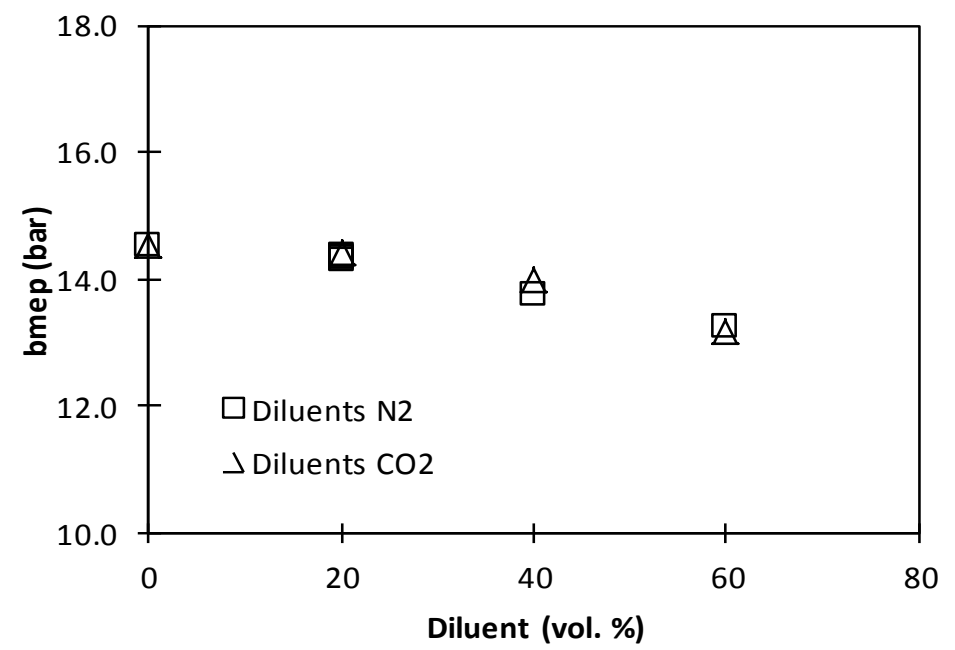

Figure 78 Effect of Diluents on BMEP, N=1500 rpm, ER=1.0, Pin=1.5 bar, Pout=1.65 bar, ST=15 bTDC

The reduced cylinder pressure was usually due to combined effect of the reduced heat release rate, elongated combustion duration or retarded combustion phasing. As shown in Figure 79, the addition of $\mathrm{N}_{2}$ reduced the peak heat release rate and retarded the phasing of peak heat release rate especially with the addition of a relatively large amount of diluents. The addition of $60 \% \mathrm{~N}_{2}$ was found to reduce the peak heat release rate from 470.12 to $355.27 \mathrm{~J} /{ }^{\circ} \mathrm{CA}$ and retarded the phasing of peak heat release from 5.24 to $10.53^{\circ} \mathrm{CA}$ ATDC. The reduced heat release rate was to some extent due to the reduced fuel flow rate as diluents dispel the amount of air and combustible fuel entering the cylinder. The addition of diluents also slow down the flame propagation rate and elongate the combustion process, as indicated by the normalized heat release rate shown in Figure 80. The elongated heat release process was also supported by the mass fraction burned shown in Figure 81. 


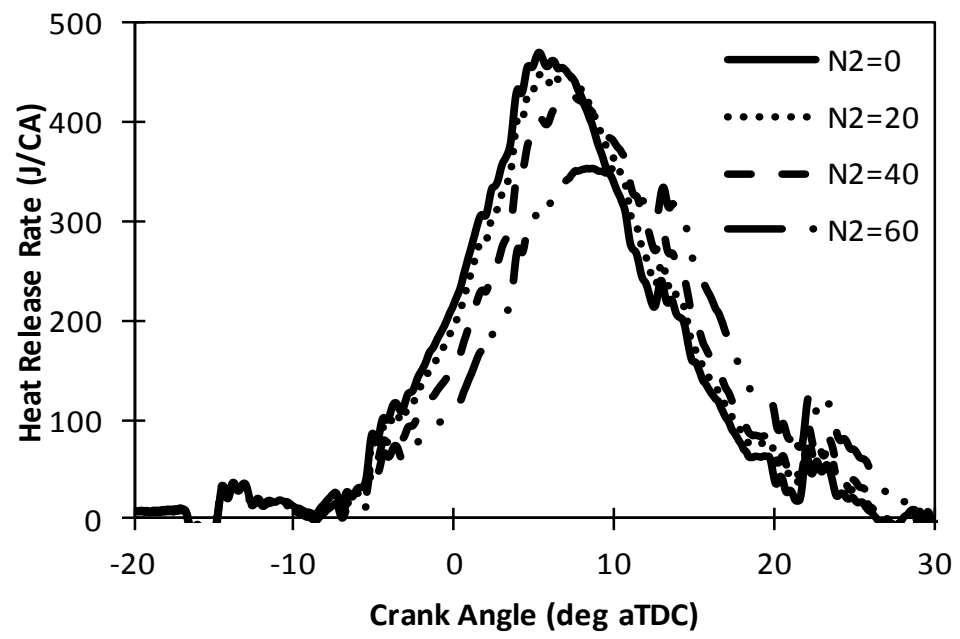

Figure 79 Effect of Intake N2 on Heat Release Rate, N=1500 rpm, Pin=1.5 bar, Pout=1.65 bar, $\mathrm{ST}=15, \mathrm{ER}=1.0$

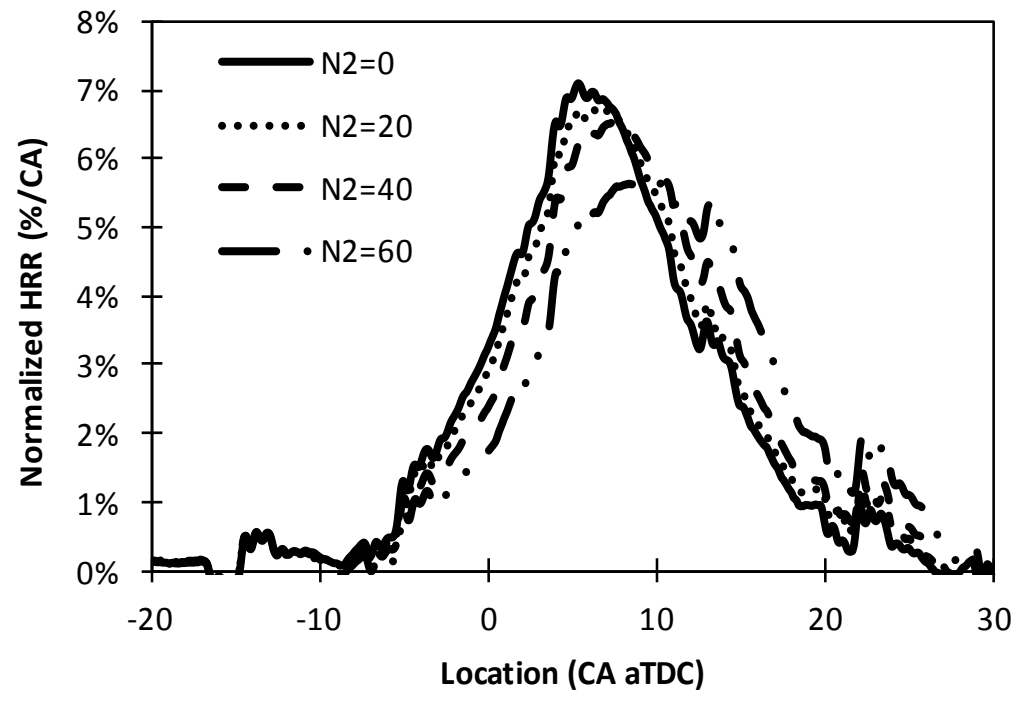

Figure 80 Effect of Intake $\mathrm{N}_{2}$ on Normalized Heat Release Rate, $\mathrm{N}=1500 \mathrm{rpm}, \mathrm{P}_{\text {in }}=1.5$ bar, $P_{\text {out }}=1.65$ bar, ST=15, ER=1.0 


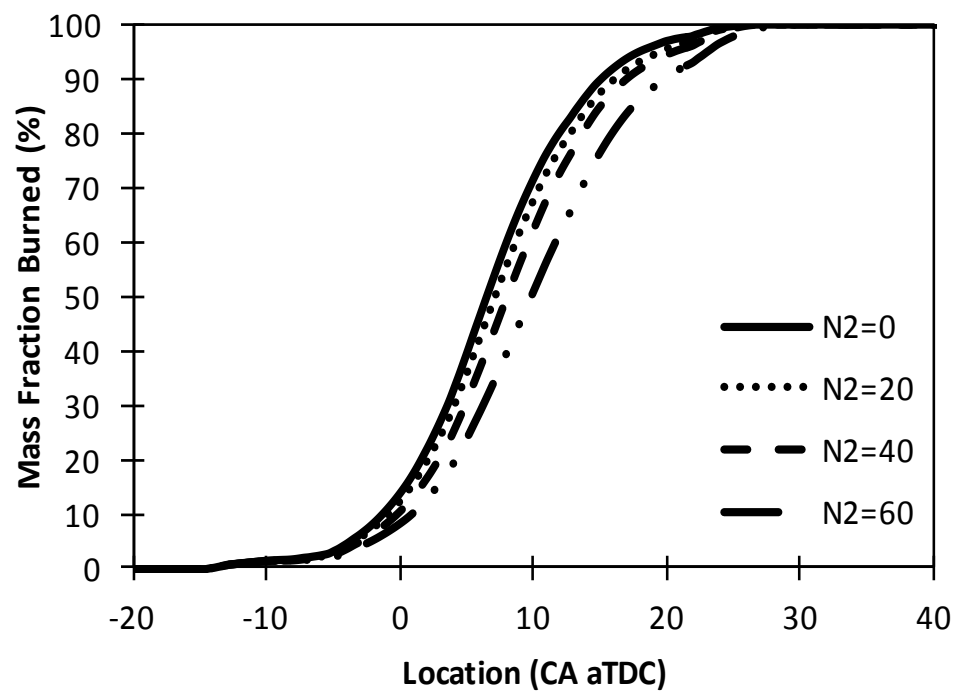

Figure 81 Effect of Intake N2 on Mass Fraction Burned, N=1500 rpm, Pin=1.5 bar, Pout=1.65 bar, ST=15, ER=1.0

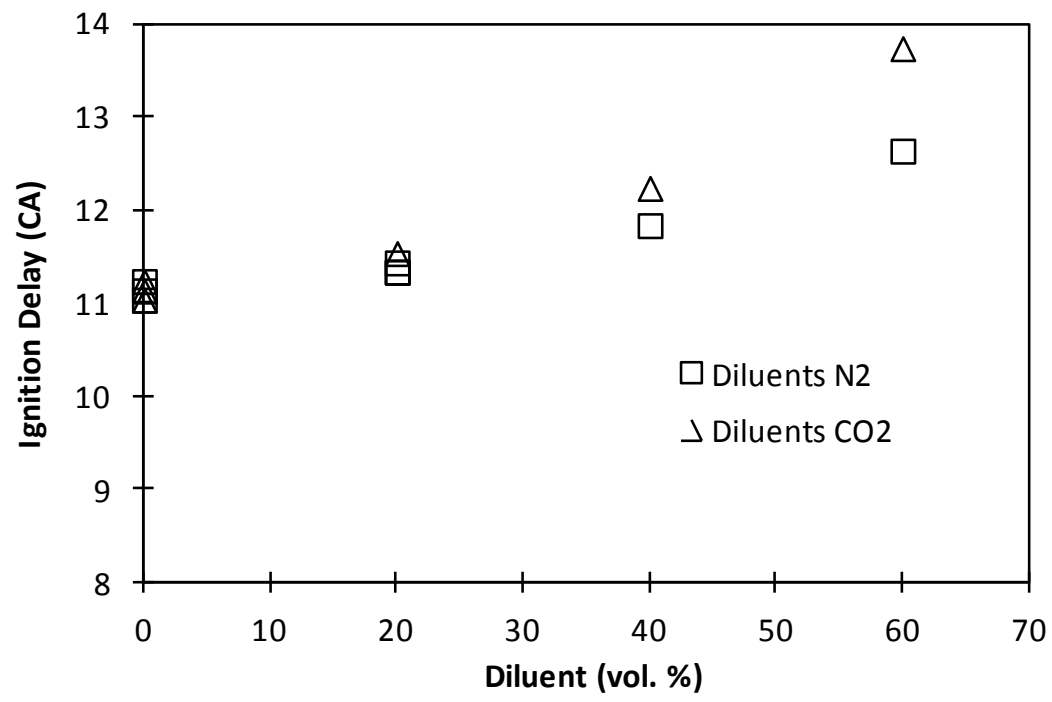

Figure 82 Effect of Diluents on Ignition Delay, N=1500 rpm, ER=1.0, Pin=1.5 bar, Pout=1.65 bar, ST=15 bTDC

Figure 82 compares the effect of $\mathrm{N}_{2}$ and $\mathrm{CO}_{2}$ on the ignition delay, defined as the crank angle period from ignition timing to CA5 defined as the crank angle when $5 \%$ of total heat was released. As expected, the addition of diluents into intake fuel elongated the ignition delay especially when a large amount of diluents were added. The addition of $60 \% \mathrm{~N}_{2}$ or $\mathrm{CO}_{2}$ elongated the ignition delay from 11.14 to 12.64 or $13.74{ }^{\circ} \mathrm{CA}$, respectively. As shown in Figure 83, the addition of $\mathrm{N} 2$ or $\mathrm{CO} 2$ also elongated the combustion duration. For example, the addition of $60 \% \mathrm{~N}_{2}$ or $\mathrm{CO}_{2}$ elongated the combustion duration from 21.5 to 25.3 or $27.7{ }^{\circ} \mathrm{CA}$, respectively. The elongated ignition delay and combustion duration contributed to the reduced peak cylinder pressure observed with the addition of diluents to intake fuel. 


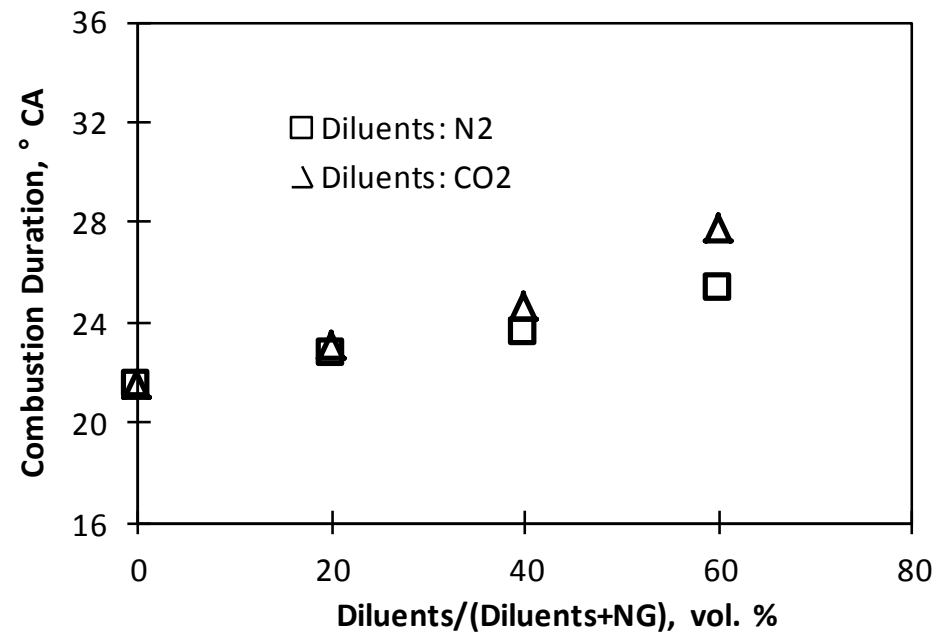

Figure 83 Effect of Diluents on Combustion Duration, N=1500 rpm, ER=1.0, Pin=1.5 bar, Pout=1.65 bar, ST=15 bTDC

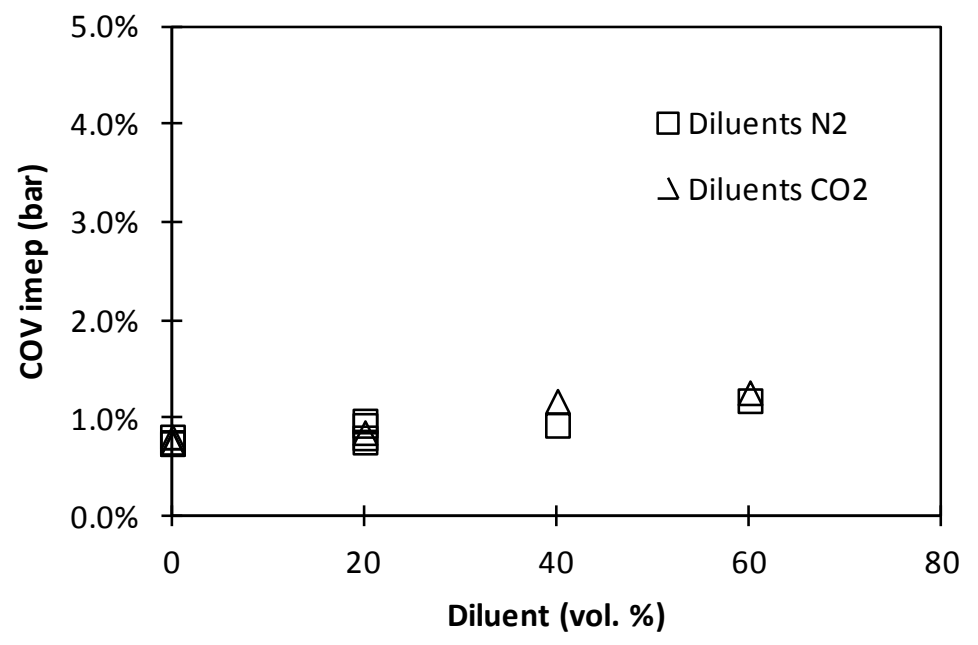

Figure 84 Effect of Diluents on COV IMEP, N=1500 rpm, ER=1.0, Pin=1.5 bar, Pout=1.65 bar, ST=15 bTDC

Figure 84 shows the effect of diluents on combustion stability. Although elongating both ignition delay and combustion duration, the effect of the addition of diluents on COV in IMEP is very mild. The maximum COV in IMEP of $1.18 \%\left(60 \% \mathrm{~N}_{2}\right)$ and $1.26 \%\left(60 \% \mathrm{CO}_{2}\right)$ indicated the very stable combustion of stoichiometric mixture of highly diluted low BTU fuels. As shown in Figure 85, the addition of diluents slightly reduced the emissions of $\mathrm{CO}_{2}$, indicating the slightly improved thermal efficiency. The improvement to thermal efficiency was due to the shifting of the combustion phasing toward the optimized one when diluents were added. It should be noted that the engine was operated under arbitrary spark timing. The optimization of spark timing may further improve the engine thermal efficiency under stoichiometric operation with highly diluted low BTU gases fuels. 


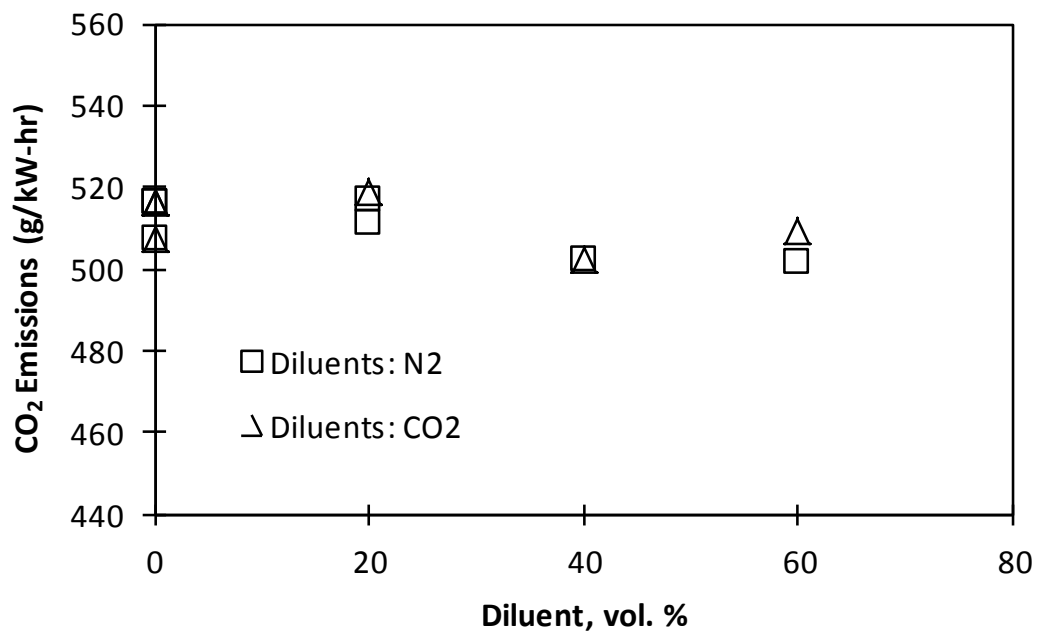

Figure 85 Effect of Diluents on $\mathrm{CO} 2$ Emissions (CO2 from the combustion of natural gas only), N=1500 rpm, ER=1.0, Pin=1.5 bar, Pout=1.65 bar, ST=15 bTDC

Figure 86 compares the effect of the addition of $40 \% \mathrm{~N}_{2}$ and $\mathrm{CO}_{2}$ on the cylinder pressure and heat release process. As shown in Figure 86, the addition of $\mathrm{CO}_{2}$ is more effective in reducing the cylinder pressure and slowing down the heat release process. This was also supported by the data shown in Figure 87. The addition of $60 \% \mathrm{~N}_{2}$ or $\mathrm{CO}_{2}$ under stoichiometric combustion was found to reduce the peak cylinder pressure from 92.20 to 80.25 and 74.16 bar, respectively. As shown in Figure 88, the reduced cylinder pressure was due to the reduced heat release rate, elongated heat release process and elongated ignition delay.

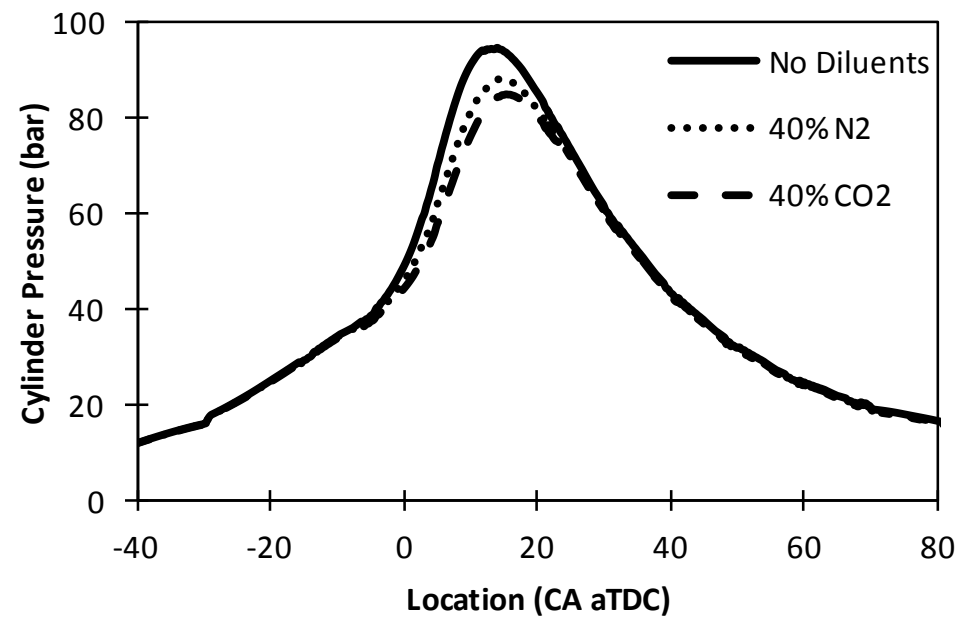

Figure 86 Effect of Diluents on In-Cylinder Pressure, N=1500 rpm, Pin=1.5 bar, Pout=1.65 bar, ST=15, ER=1.0 


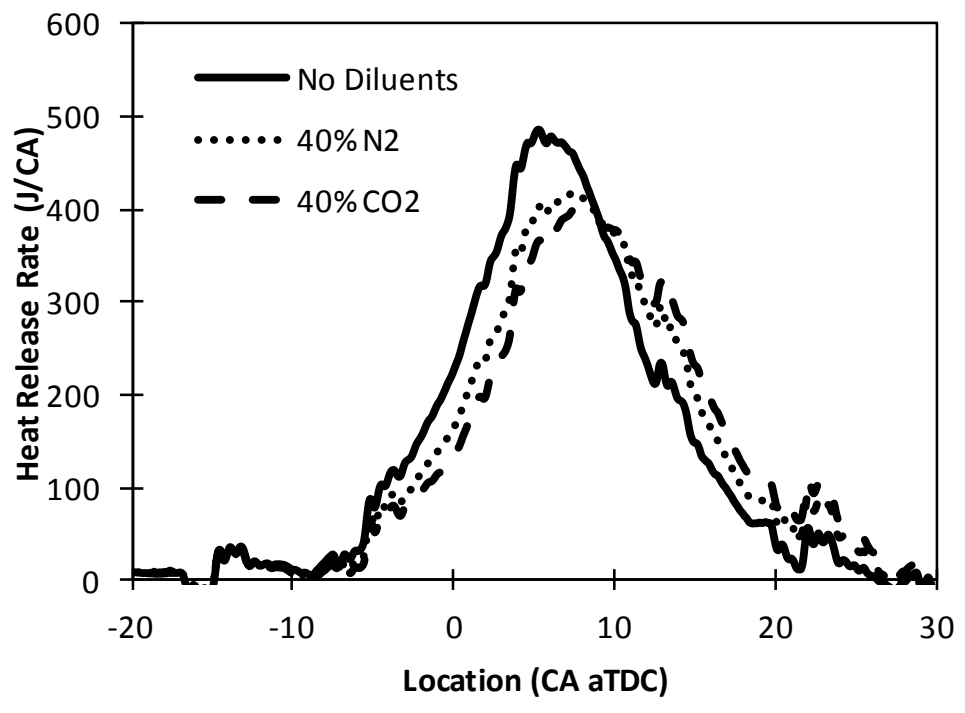

Figure 87 Effect of Diluents on Heat Release Rate, N=1500 rpm, Pin=1.5 bar, Pout=1.65 bar, $\mathrm{ST}=15, \mathrm{ER}=1.0$

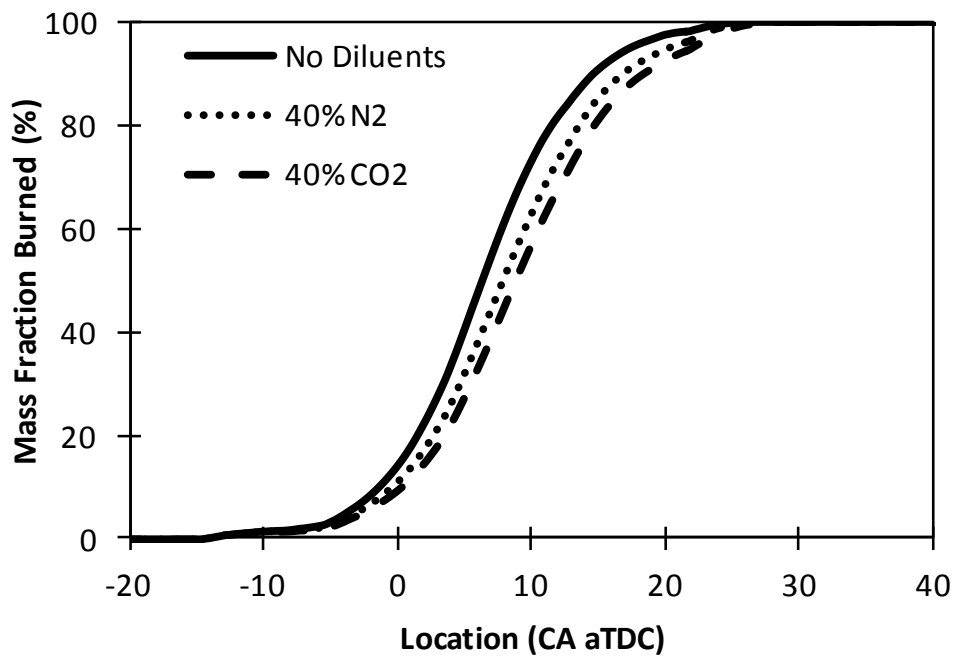

Figure 88 Effect of Diluents on Mass Fraction Burned, N=1500 rpm, Pin=1.5 bar, Pout=1.65 bar, ST=15, ER=1.0

Effect of the Intake Pressure on the Engine Performance, Combustion and Exhaust Emissions

The effect of intake pressure on the engine performance, combustion and exhaust emissions was investigated. The detailed test matrix can be found in Table 36. 
Table 36 Test Matrix for Diluents Test, $N=1500 \mathrm{rpm}, \mathrm{ER}=1.0, \mathrm{P}_{\mathrm{in}}=1.5$ bar, Spark timing $=15^{\circ} \mathrm{CA}$ BTDC

\begin{tabular}{|c|c|c|c|c|}
\hline & $\begin{array}{l}\mathrm{E} \\
\mathrm{R}\end{array}$ & $\mathrm{P}_{\text {in }}$ & $\begin{array}{c}\mathrm{N}_{2} /\left(\mathrm{N}_{2}+\mathrm{NG}\right) \text {, vol. } \\
\%\end{array}$ & $\begin{array}{l}\mathrm{CO}_{2} /\left(\mathrm{CO}_{2}+\mathrm{NG}\right), \\
\quad \text { vol. \% }\end{array}$ \\
\hline $\begin{array}{l}\text { Tes } \\
\mathrm{t} 1\end{array}$ & $0^{1 .}$ & 1.0. $1.43,1.50$ and 1.80 & 0 & 0 \\
\hline $\begin{array}{l}\text { Tes } \\
\mathrm{t} 2\end{array}$ & 0 & $\begin{array}{c}1.0,1.43,1.50,1.8,2.0, \\
2.2\end{array}$ & 40 & 0 \\
\hline $\begin{array}{l}\text { Tes } \\
\mathrm{t} 3\end{array}$ & 0 & $\begin{array}{c}\text { 1.0, 1.43, } 1.50,1.8,2.0, \\
2.2\end{array}$ & 0 & 40 \\
\hline $\begin{array}{l}\text { Tes } \\
\mathrm{t} 4 \\
\end{array}$ & $\begin{array}{l}0 . \\
87\end{array}$ & $1.0,1.5,1.8$ & 0 & 0 \\
\hline $\begin{array}{l}\text { Tes } \\
\text { t } 5\end{array}$ & $\begin{array}{l}0 . \\
87\end{array}$ & $1.0,1.5,1.8$ & 40 & 0 \\
\hline $\begin{array}{l}\text { Tes } \\
\text { t } 6\end{array}$ & $\begin{array}{l}0 . \\
87\end{array}$ & $1.0,1.5$ & 0 & 40 \\
\hline
\end{tabular}

Figure 89 shows the effect of intake pressure on the cylinder pressure, heat release process and mass fraction burned observed at stochiometric operation. As shown in Figure 89, the boosting of the intake pressure significantly increased the cylinder pressure. Increasing the cylinder pressure from 1.0 bar to 1.8 bar increased the cylinder pressure from 60.7 bar to 119.9 bar. The increased cylinder pressure was due to the increased heat release rate due to the burning of more fuel. As shown in Figure 90, increasing the cylinder pressure from 1.0 bar to 1.8 bar was found to increase the peak heat release rate from 299.0 to $592.74 \mathrm{~J} /{ }^{\circ} \mathrm{CA}$, which was 2.04 times that observed at intake pressure of 1.0 bar. The burning of more fuels with the boosting of intake pressure contributed to the increase in heat release rate. However, the changes in flame propagation rate may also affect the heat release rate.

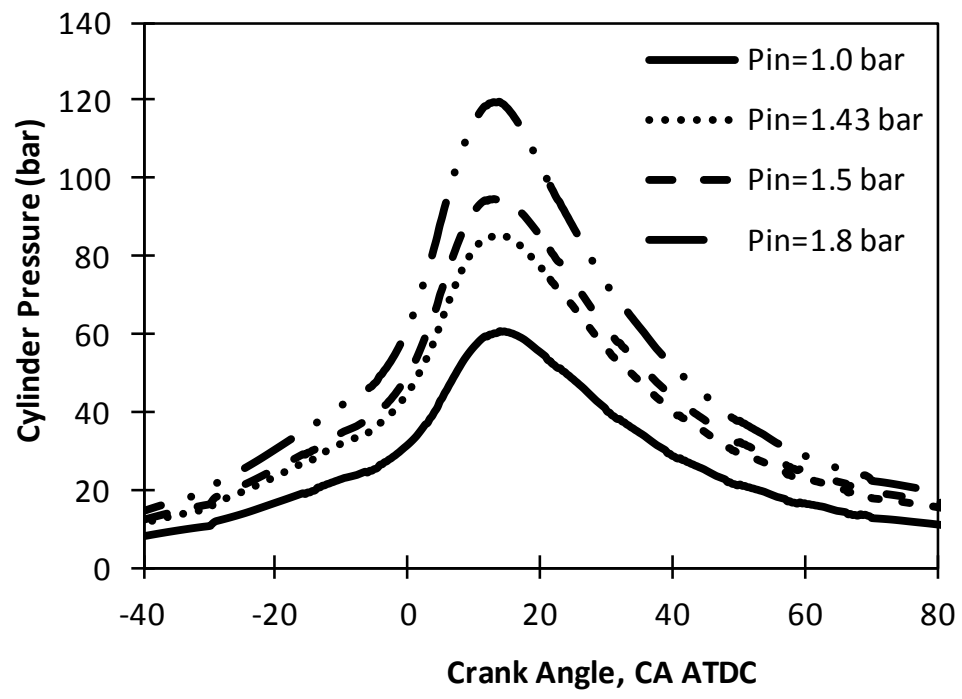

Figure 89 Effect of Intake Pressure on In-Cylinder Pressure, N=1500 rpm, Pout=Pin+1.15 bar, $\mathrm{ST}=15, \mathrm{ER}=1.0$, No Diluents 


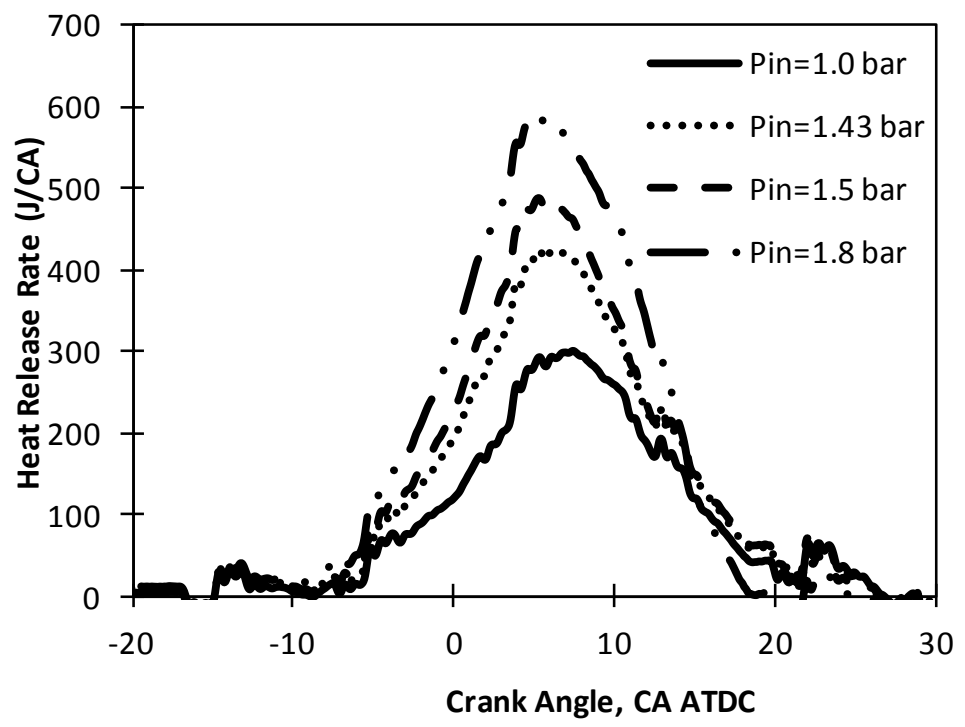

Figure 90 Effect of Intake Pressure on Heat Release Rate, N=1500 rpm, Pout=Pin+1.15 bar, $\mathrm{ST}=15, \mathrm{ER}=1.0$, No Diluents

In this research, the heat release rate was further processed to obtain the normalized heat research rate relative the total heat released by combustion. As shown in Figure 91, increasing the intake pressure from 1.0 to $1.8 \mathrm{bar}$ increased the normalized peak heat release rate from $6.71 \%$ to $7.37 \%(+9.8 \%)$ and slightly advanced the phasing of peak heat release rate from 7.35 to $5.15^{\circ} \mathrm{CA}$ ATDC, indicating the relatively faster flame propagation speed. The latter was also supported by the mass fraction burned shown in Figure 92.

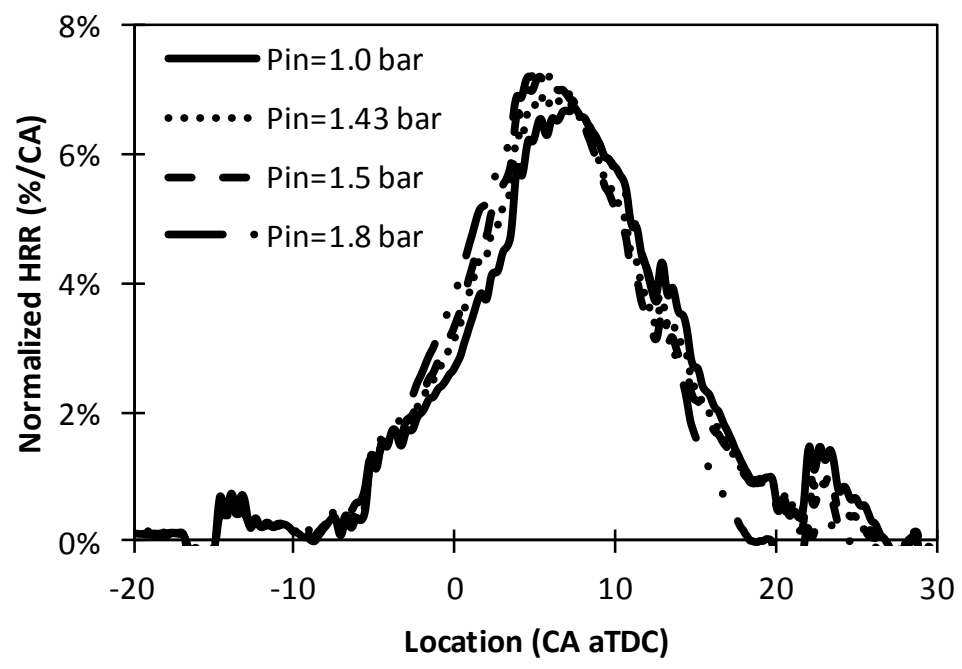

Figure 91 Effect of Intake Pressure on Normalized Heat Release Rate, N=1500 rpm, Pout=Pin+1.15 bar, ST=15, ER=1.0, No Diluents 


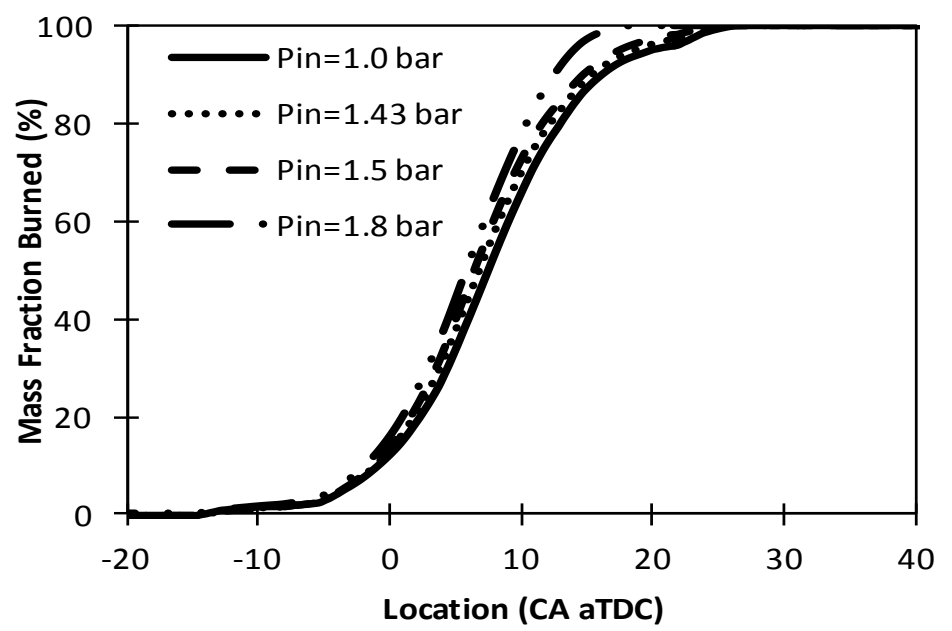

Figure 92 Effect of Intake Pressure on Mass Fraction Burned, N=1500 rpm, Pout=Pin+1.15 bar, ST=15, ER=1.0, No Diluents

It was evident that the increased cylinder pressure was due to mainly the burning of more fuel. The slightly accelerated flame propagation speed and advanced phasing of the peak heat release rate contributed to the increased cylinder pressure. Figure 93 shows the effect of intake pressure on the cylinder pressure and heat release process at stoichiometric mixture with the presence of $40 \% \mathrm{CO}_{2}$ in intake fuel. As expected, the boosting of the intake mixture heat release rate as shown in Figure 93, which was due to the burning of increased amount of fuel. However, with the addition of $40 \% \mathrm{CO}_{2}$, the effect of intake pressure on the mass fraction burned was relatively very mild as shown in Figure 94 when compared pure natural gas operation as shown in Figure 71 (d). As shown in Figure 95, the maximum normalized cylinder pressure observed at 1.8 bar was $6.12 \%$, which was $6.2 \%$ higher than that observed at intake pressure of 1 bar. The presence of diluents in intake fuel suppressed the effect of intake pressure on the flame propagation rate.

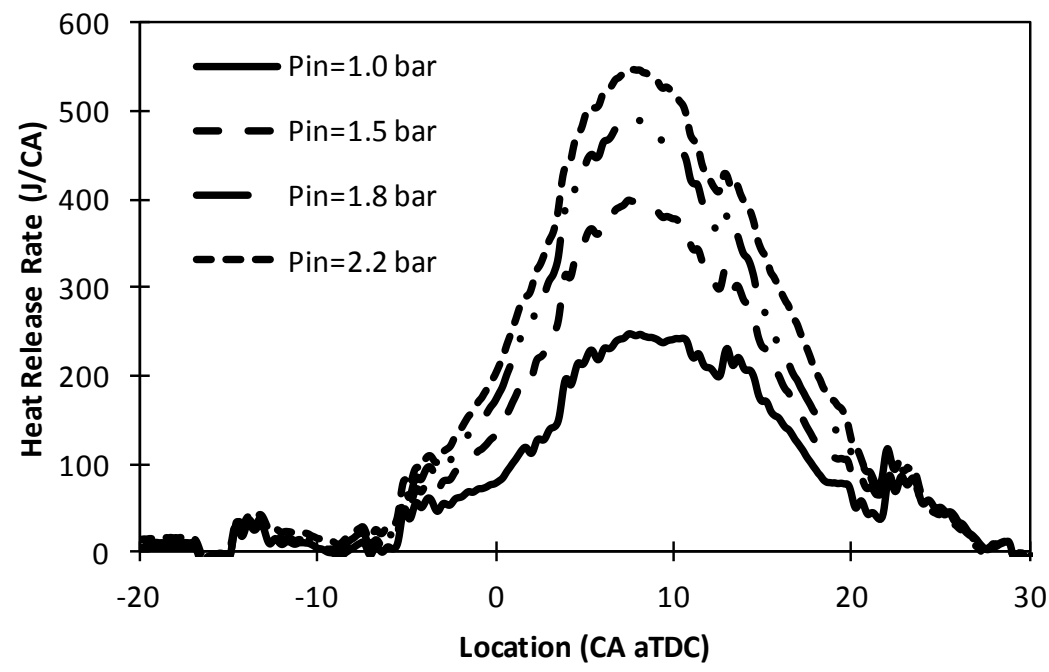

Figure 93 Effect of Intake Pressure on Heat Release Rate, N=1500 rpm, Pout=Pin+1.15 bar, $\mathrm{ST}=15, \mathrm{ER}=1.0, \mathrm{CO} 2=40 \%$ 


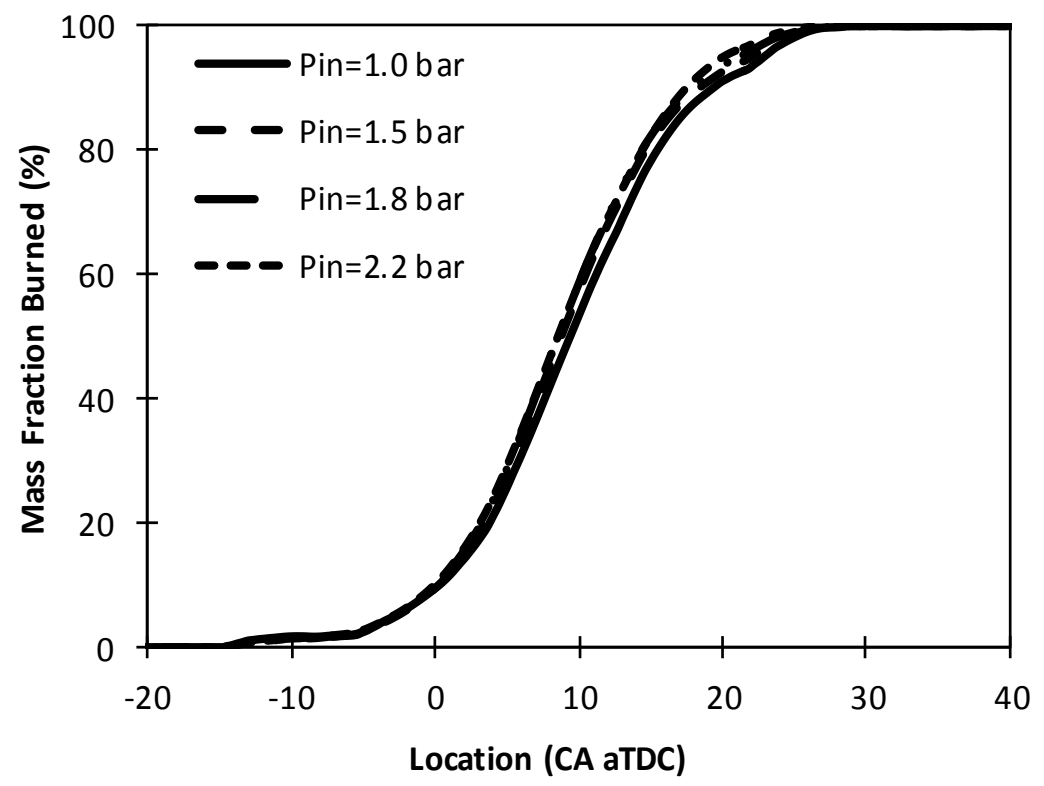

Figure 94 Effect of Intake Pressure on Mass Fraction Burned, $\mathrm{N}=1500 \mathrm{rpm}$, Pout=Pin+1.15 bar, ST=15, ER=1.0, CO2=40\%

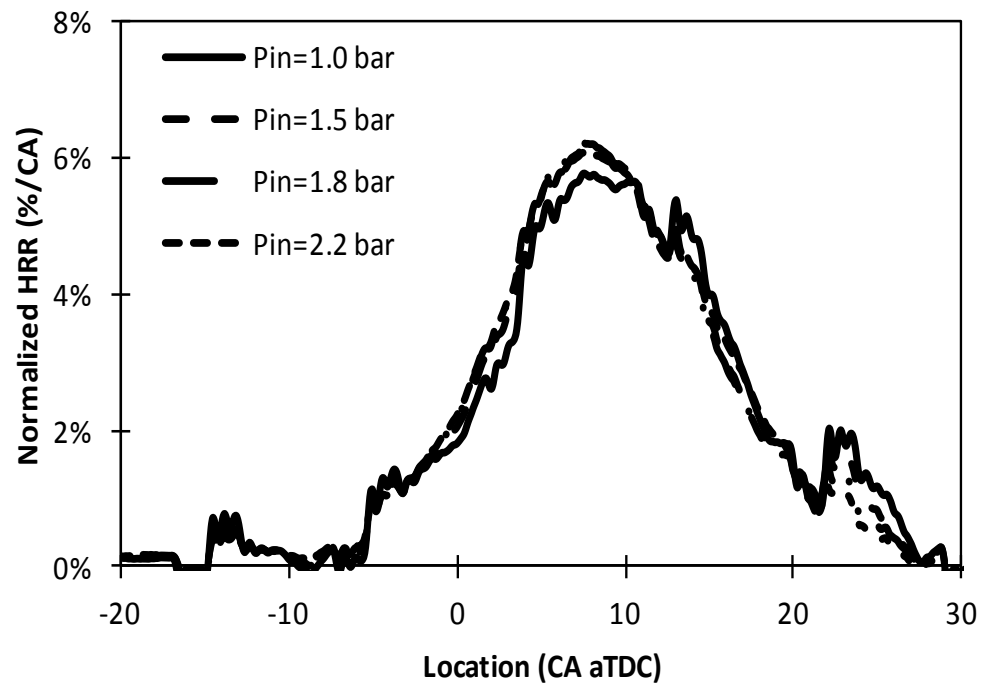

Figure 95 Effect of Intake Pressure on Normalized Heat Release Rate, N=1500 rpm, Pout=Pin+1.15 bar, ST=15, ER=1.0, CO2=40\%

Figure 96 shows the effect of the addition of $40 \% \mathrm{~N}_{2}, 40 \% \mathrm{CO}_{2}$ and intake pressure on the peak cylinder pressure and peak heat release rate. As expected, the boosting of the intake pressure increased the cylinder pressure, which was due to the burning of more fuel, the enhancement in the flame propagation speed, and the advancement of the phasing of the peak heat release rate. As shown in Figure 96, the addition of $40 \% \mathrm{~N}_{2}$ and $40 \% \mathrm{CO}_{2}$ reduced the peak cylinder pressure. As shown in Figure 96, the peak heat release rate observed at 2.2 bar intake pressure with the addition of $40 \% \mathrm{CO}_{2}$ and $\mathrm{N}_{2}$ was lower than the operation of diluents free operation at $1.8 \mathrm{bar}$ 
intake pressure.. This will allows the further boosting of the intake pressure while maintaining the peak cylinder pressure within safety limits. As shown in Figure 96, the addition of $\mathrm{CO}_{2}$ was more effective in reducing the peak cylinder pressure than the addition of $\mathrm{N}_{2}$ especially when a large amount of diluents were added.

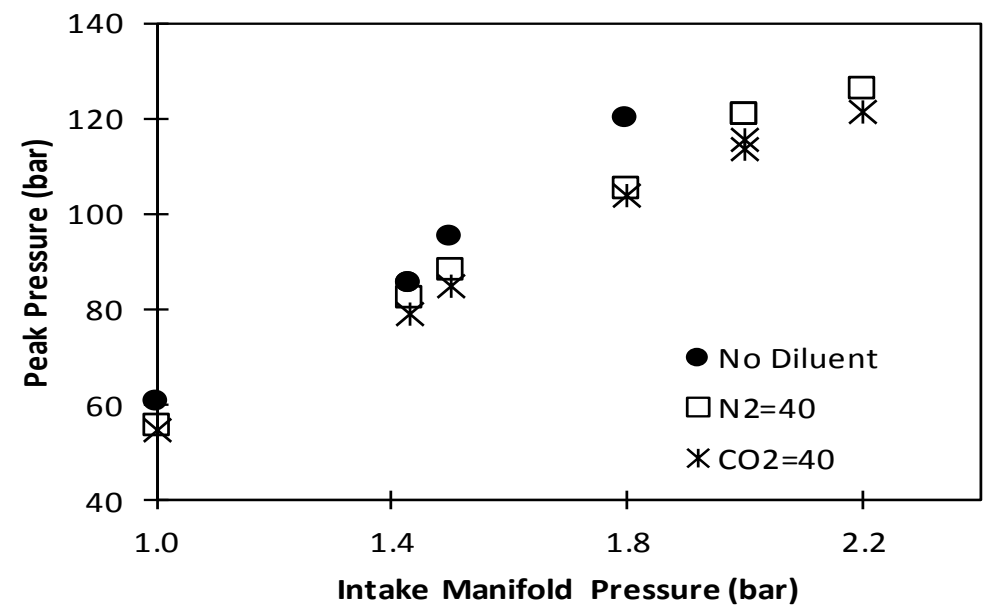

Figure 96 Effect of Diluents on Peak Pressure, N=1500 rpm, ER=1.0, ST=15 bTDC

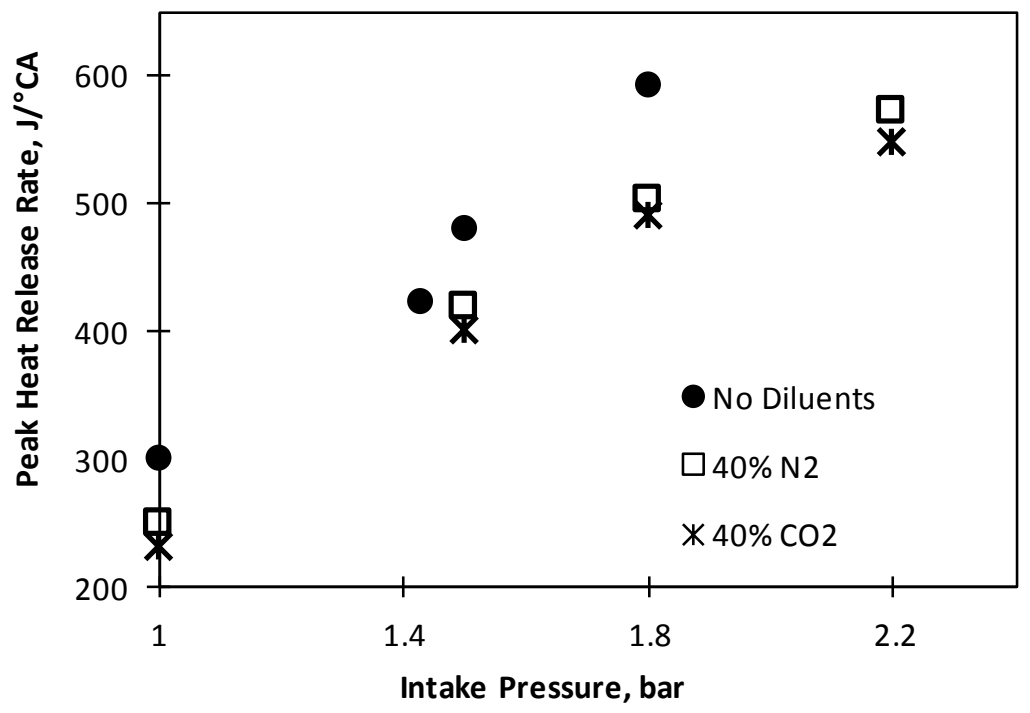

Figure 97 Effect of Diluents on Peak Heat Release Rate, N=1500 rpm, ER=1.0, Pin=1.5 bar, Pout=1.65 bar, ST=15 bTDC

The reduced peak cylinder pressure observed with the addition of diluents was due to the decrease in heat release rate. As shown in Figure 97, the addition of $40 \% \mathrm{~N}_{2}$ and $40 \% \mathrm{CO}_{2}$ at 1.8 bar intake pressure reduced the peak heat release rate from 592.74 to 502.22 and $490.80 \mathrm{~J} /{ }^{\circ} \mathrm{CA}$, respectively. As shown in Figure 98, the boosting the intake pressure at natural gas operation increased the normalized peak heat release rate, indicating the enhanced flame propagation speed. However, the addition of $40 \% \mathrm{~N}_{2}$ or $\mathrm{CO}_{2}$ suppressed the increase in normalized heat release rate resulted from the boosting of the intake pressure. As shown in Figure 98, with the addition of 
$40 \% \mathrm{~N}_{2}$ or $\mathrm{CO}_{2}$, the effect of intake pressure on the normalized peak heat release rate became mild. The relatively slower flame propagation rate observed with the addition of diluents could be beneficial to the operation of turbo-charged SI engine.

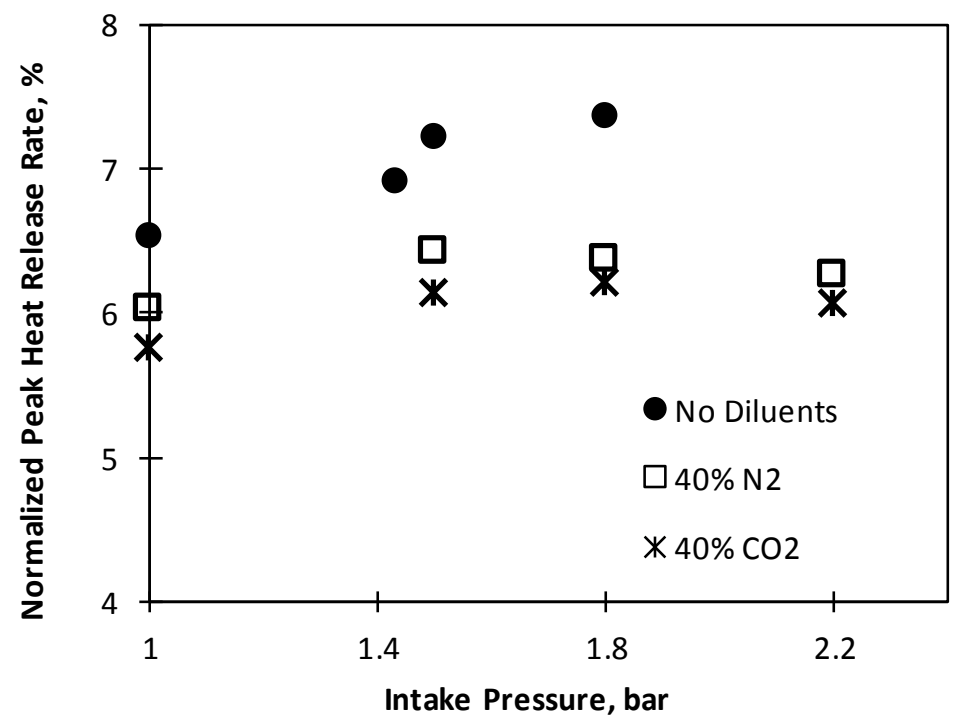

Figure 98 Effect of Diluents on Normalized Peak Heat Release Rate, N=1500 rpm, $\mathrm{ER}=1.0, \mathrm{ST}=15^{\circ} \mathrm{bTDC}$

Figure 99 and Figure 100 shows the effect of intake pressure and the addition of $\mathrm{CO}_{2}$ and $\mathrm{N}_{2}$ on the brake mean effective pressure (BMEP) and indicated mean effective pressure (IMEP), the addition of $\mathrm{CO}_{2}$ and $\mathrm{N}_{2}$ slightly reduced the BMEP and IMEP observed. This was due to the reduction in the flow rate of NG, and also the reduced flame propagation rate resulted from the addition of diluents.

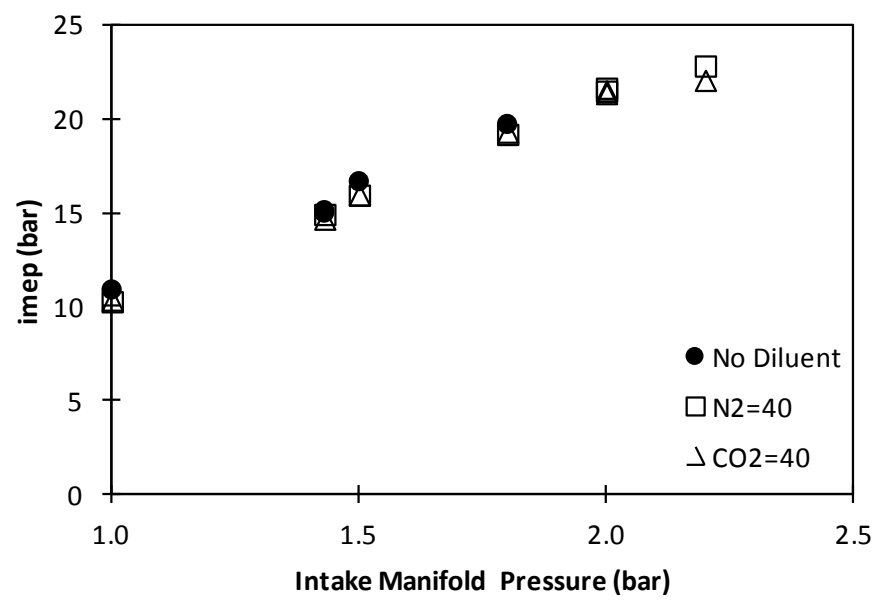

Figure 99 Effect of Intake Pressure on IMEP, N=1500 rpm, ER=1.0, Pout=Pin+0.15, ST=15 bTDC 


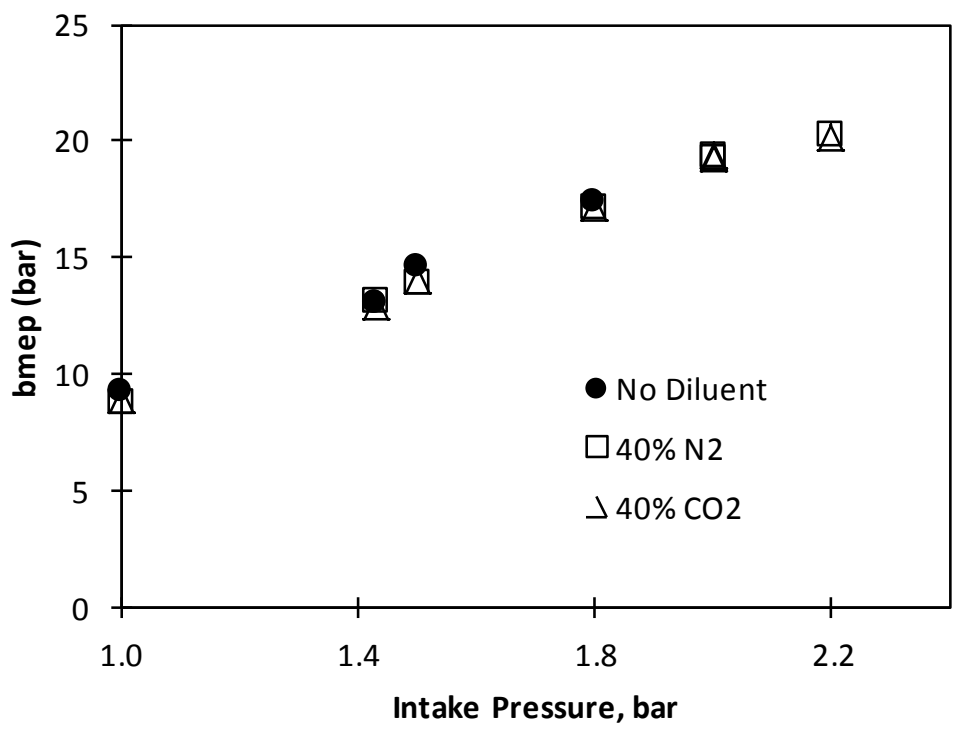

Figure 100 Effect of Intake Pressure and the Addition of Diluents on BMEP, N=1500 rpm, ER=1.0, Pout=Pin+0.15, ST=15 bTDC

Figure 101 shows the effect of intake pressure and the addition of $\mathrm{CO}_{2}$ and $\mathrm{H}_{2}$ on combustion stability as indicated by the coefficient of variation (COV) in IMEP (COVIMEP). The addition of diluents at stoichiometric mixture did deteriorate the stability of combustion.

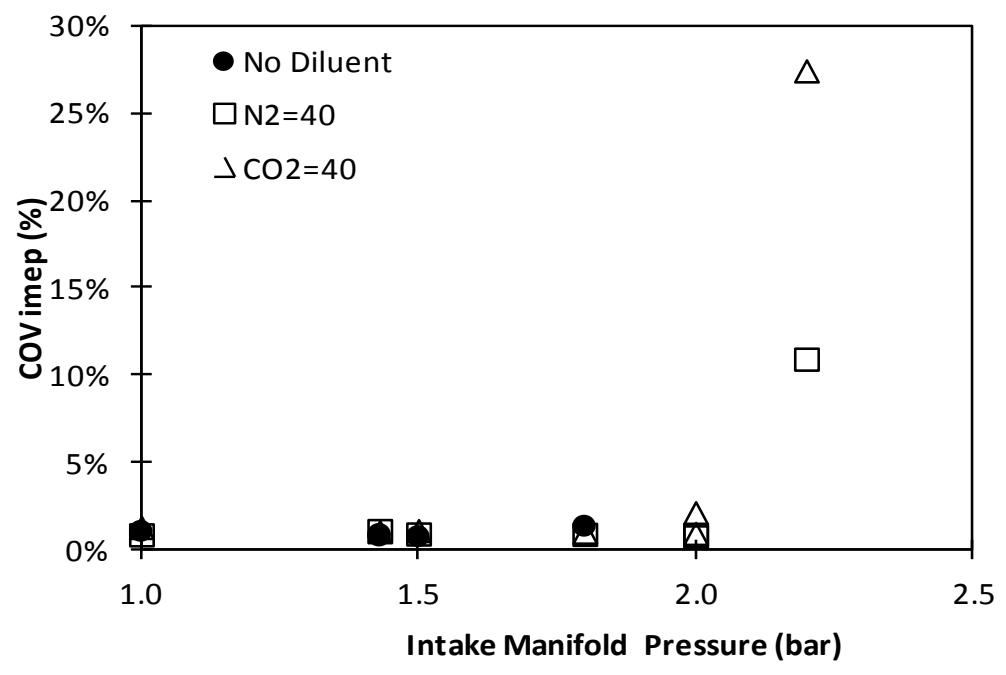

Figure 101 Effect of Intake Pressure on COV IMEP, N=1500 rpm, ER=1.0, Pout=Pin+0.15, ST=15 bTDC 


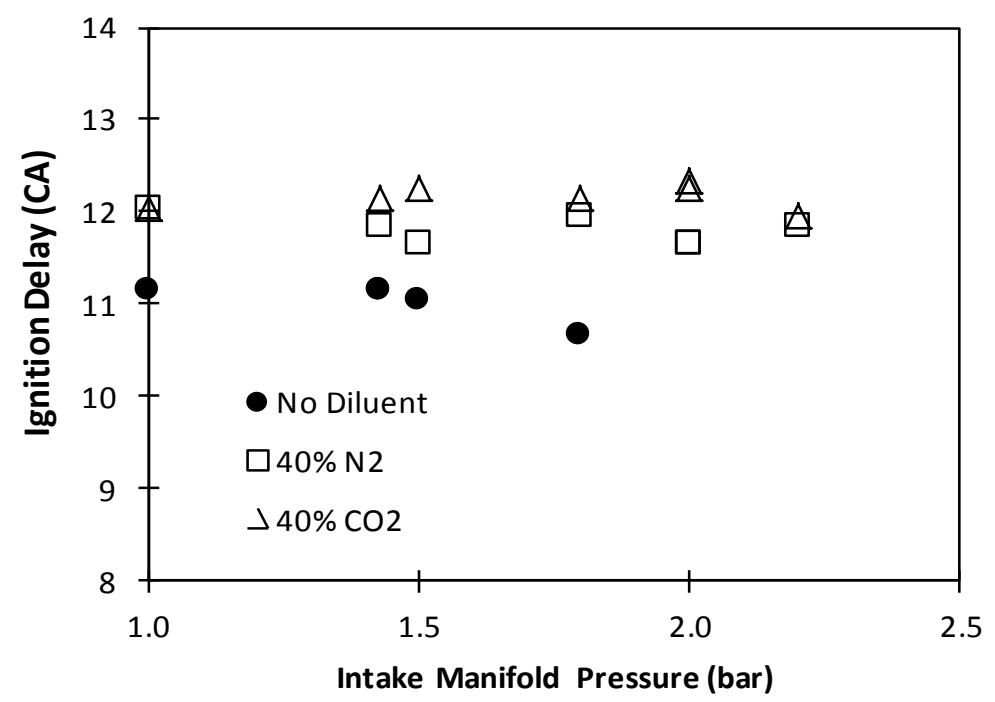

Figure 102 Effect of Intake Pressure and the Addition of Diluents on Ignition Delay, $\mathrm{N}=1500 \mathrm{rpm}, \mathrm{ER}=1.0$, Pout=Pin+0.15, ST=15 bTDC

Figure 102 shows the effect of intake pressure and the addition of diluents on ignition delay. The addition of $40 \% \mathrm{~N}_{2}$ or $\mathrm{CO}_{2}$ was shown to elongate the ignition delay by about $1{ }^{\circ} \mathrm{CA}$. In comparison, the effect of intake pressure on ignition delay was relatively small especially when diluents were added. As shown in Figure 103, the boosting of intake pressure reduced the combustion duration, indicating the improvement of the flame propagation rate. However, the addition of diluents suppressed the effect of boosting intake pressure in accelerating flame propagation rate. As shown in Figure 103, the effect of intake pressure on combustion duration observed with the addition of $40 \% \mathrm{~N}_{2}$ or $\mathrm{CO}_{2}$ was much weaker compared with the diluents free operation.

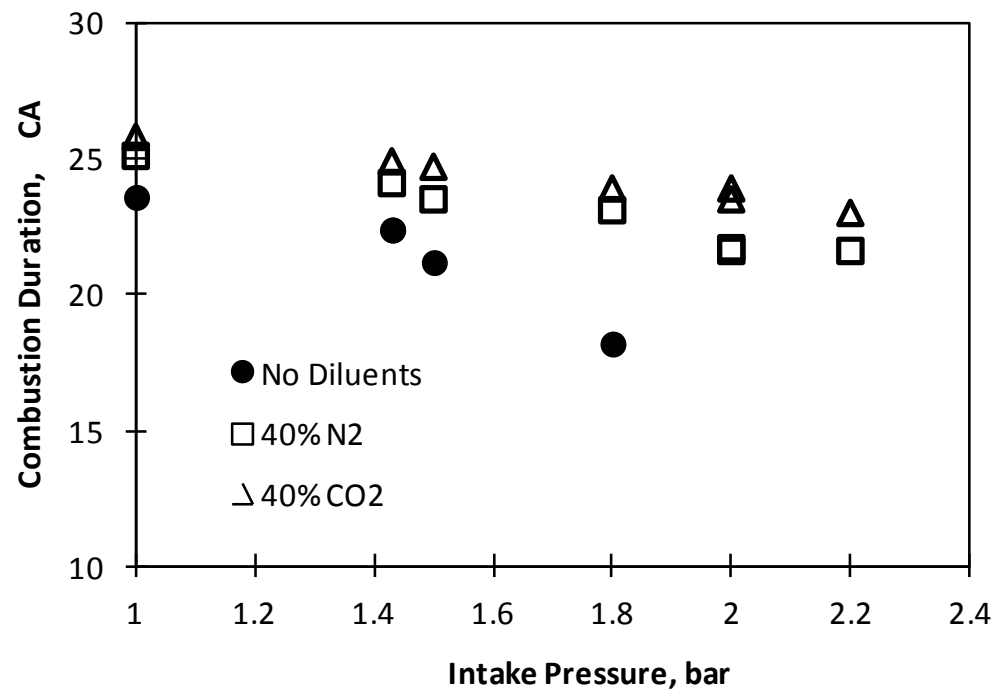

Figure 103 Effect of Intake Pressure and the Addition of Diluents on Ignition Delay, $\mathrm{N}=1500 \mathrm{rpm}, \mathrm{ER}=1.0$, Pout=Pin+0.15, ST=15 bTDC 
Figures 104 to 107 show the effect of intake pressure and the addition of $\mathrm{CO}_{2}$ and $\mathrm{N}_{2}$ on the emissions of $\mathrm{NO}_{\mathrm{x}}, \mathrm{CO}, \mathrm{HC}$, and $\mathrm{CO}_{2}$, respectively.

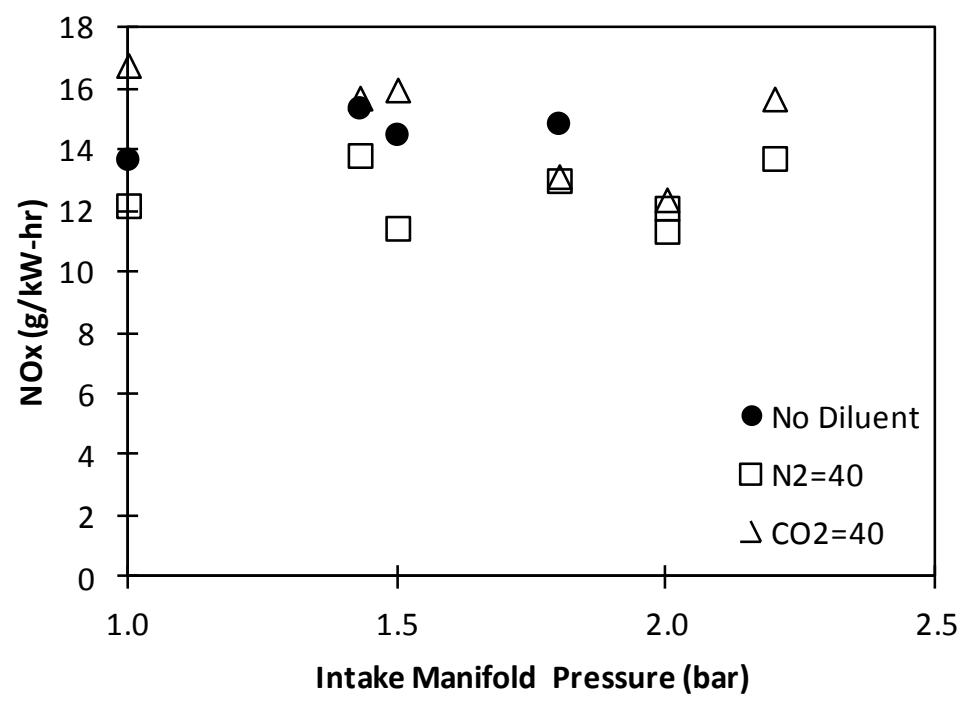

Figure 104 Effect of Intake Pressure on NOx Emissions, N=1500 rpm, ER=1.0, Pout=Pin+0.15, ST=15 bTDC

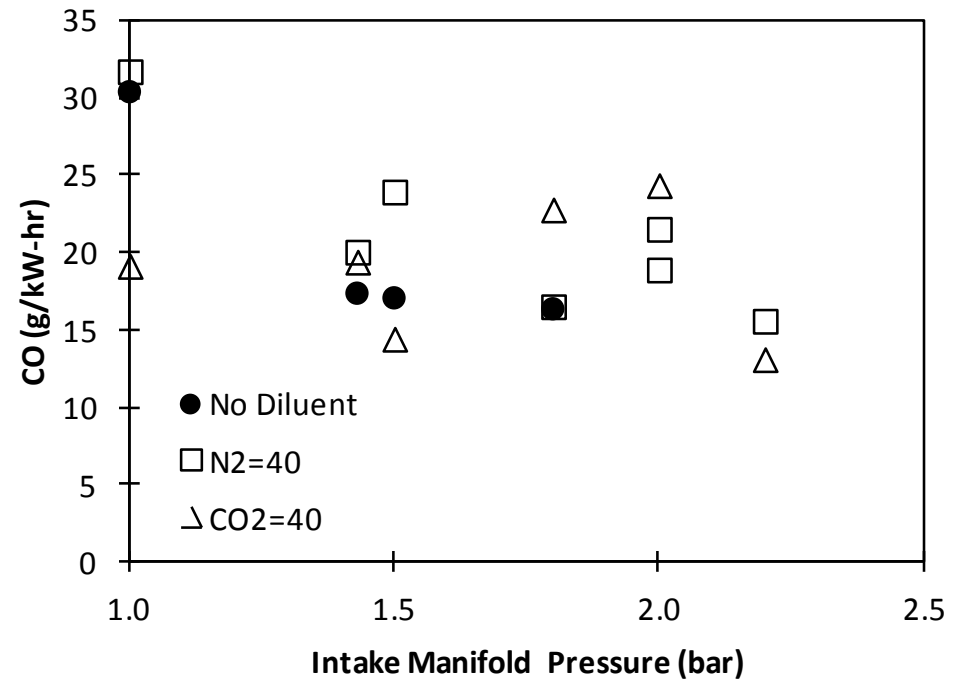

Figure 105 Effect of Intake Pressure on CO Emissions, N=1500 rpm, ER=1.0, Pout=Pin+0.15, ST=15 bTDC 


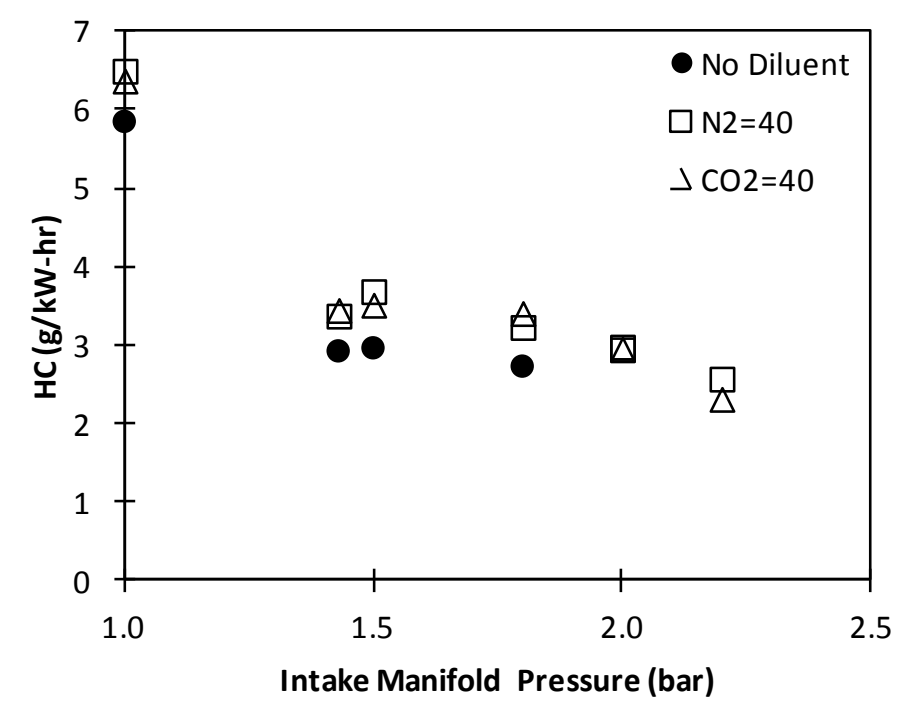

Figure 106 Effect of Intake Pressure on HC Emissions, N=1500 rpm, ER=1.0, Pout=Pin+0.15, ST=15 bTDC

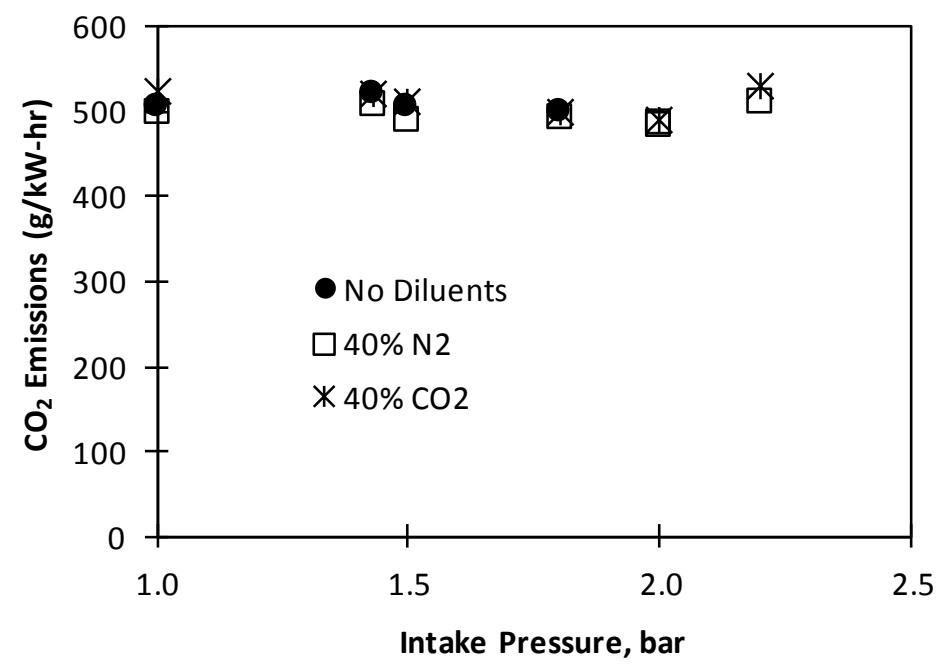

Figure 107 Effect of Intake Pressure on CO2 Emissions, N=1500 rpm, ER=1.0, Pout=Pin+0.15, ST=15 bTDC

Figures 108 to 112 show the effect of intake pressure and the addition of diluents on engine performance, combustion and exhaust emissions observed at lean mixture at ER of 0.87. As expected, increasing the intake pressure was found to increase the engine load as indicated by the increasing IMEP. The addition of $40 \% \mathrm{~N}_{2}$ and $\mathrm{CO}_{2}$ reduced the engine load especially when operated at highly boosted pressure. 


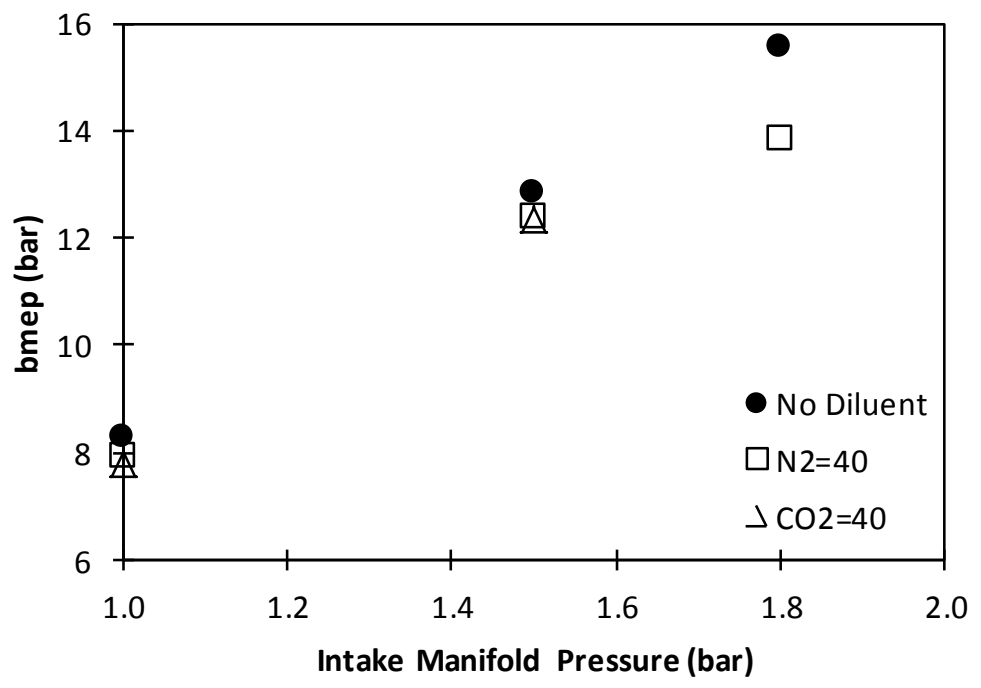

Figure 108 Effect of Intake Pressure on BMEP, N=1500 rpm, ER=0.87, Pout=Pin+0.15, ST=15 bTDC

Figure 109 shows the effect of intake pressure and diluents on peak pressure. Increasing intake pressure causes an increase in peak pressure as expected. Undiluted natural gas has the highest peak pressure, while $40 \% \mathrm{CO}_{2}$ has the lowest peak pressure. The decreased peak cylinder pressure observed with the addition of diluents make it possible to recover the power loss through the further boosting of the intake pressure.

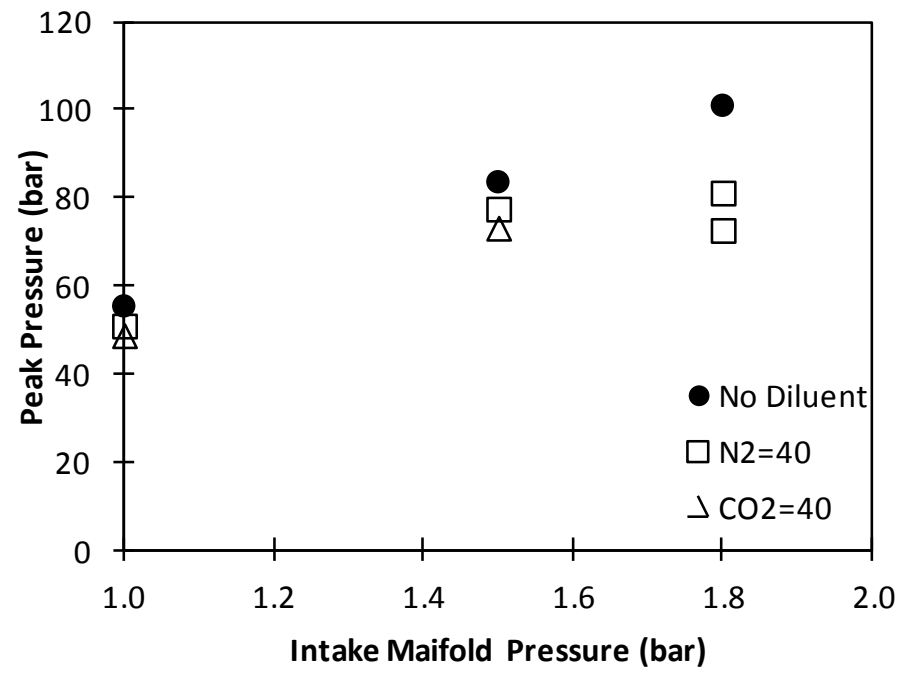

Figure 109 Effect of Intake Pressure on Peak Pressure, $\mathrm{N}=1500 \mathrm{rpm}$, ER=0.87, Pout=Pin+0.15, ST=15 bTDC 


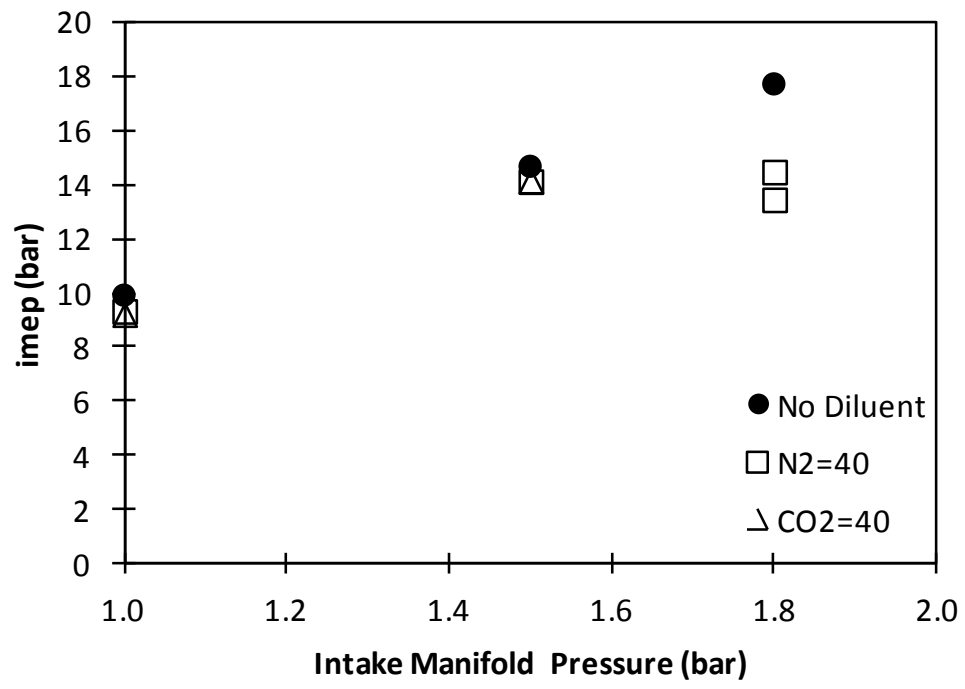

Figure 110 Effect of Intake Pressure on IMEP, N=1500 rpm, ER=0.87, Pout=Pin+0.15, ST=15 bTDC

Figure 111 shows the effect of intake pressure and diluents on ignition delay. Intake pressure has negligible effect on ignition delay. The presence of diluents leads to an increase in ignition delay with $40 \% \mathrm{CO}_{2}$ having a larger ignition delay than $40 \% \mathrm{~N}_{2}$.

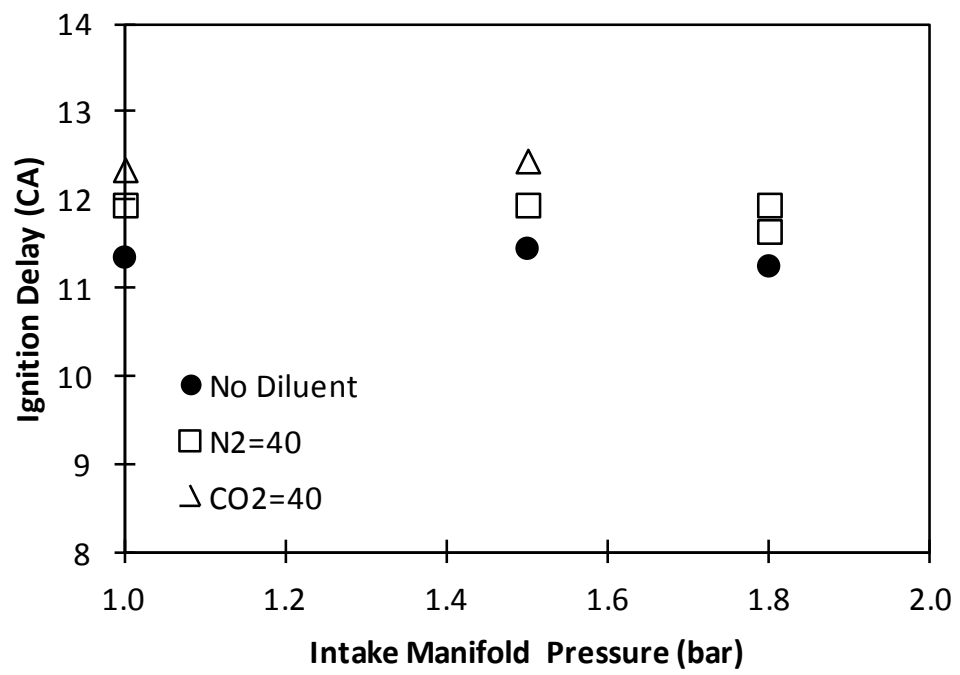

Figure 111 Effect of Intake Pressure on Ignition Delay, N=1500 rpm, ER=0.87, Pout=Pin+0.15, ST=15 bTDC 


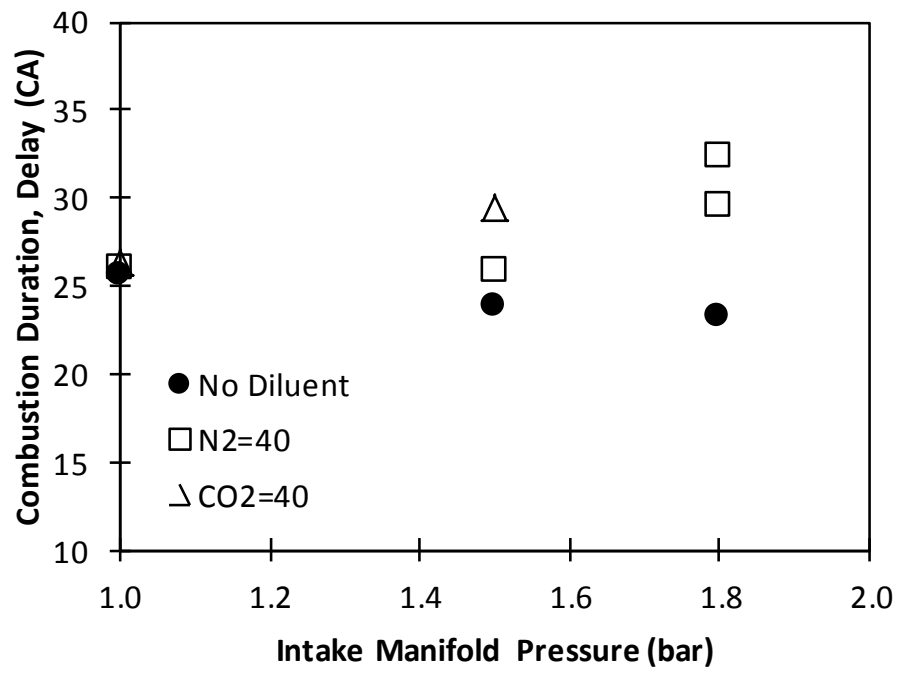

Figure 112 Effect of Intake Pressure on Combustion Duration, N=1500 rpm, ER=0.87, Pout=Pin+0.15, ST=15 bTDC

Figure 112 shows the effect of intake pressure and diluents on combustion duration delay. Intake pressure has negligible effect on ignition delay observed with diluents free operation. The presence of diluents leads to an increase in ignition delay with $40 \% \mathrm{CO}_{2}$ having a larger ignition delay than $40 \% \mathrm{~N}_{2}$. With the addition of diluents, increasing intake pressure was shown to elongate the combustion duration. As an example, with the addition of $40 \% \mathrm{CO}_{2}$, the combustion duration observed at intake pressure of 1.8 bar was $32.4{ }^{\circ} \mathrm{CA}$, which was much longer than the combustion duration of 26.4 observed at intake pressure of 1.0 bar.

Figures 113-118 show the effect of intake pressure and diluents on various emissions. As shown in Figure 113, increasing intake pressure from 1.0 bar to 1.5 bar slightly increased the $\mathrm{NO}_{\mathrm{x}}$ emissions, but increasing intake pressure beyond 1.5 bar has no effect on $\mathrm{NO}_{\mathrm{x}}$ emissions. For example, without the addition of diluents, the NOx emissions observed at 1.5 bar was 39.13 $\mathrm{g} / \mathrm{kw}$-hr, which was $8.6 \%$ higher than the NOx emissions of $36.64 \mathrm{~g} / \mathrm{kW}$-hr observed at $1.5 \mathrm{bar}$. At all intake pressures, the presence of diluents decreased the $\mathrm{NO}_{\mathrm{x}}$ emissions, with $\mathrm{CO}_{2}$ decreasing $\mathrm{NO}_{\mathrm{x}}$ emissions slightly more than $\mathrm{N}_{2}$, which was due to the decreased combustion temperature resulted from the elongated combustion duration, reduced fuel flow rate, and diluents effect in reducing the temperature rise resulted from the release of combustion heat. 


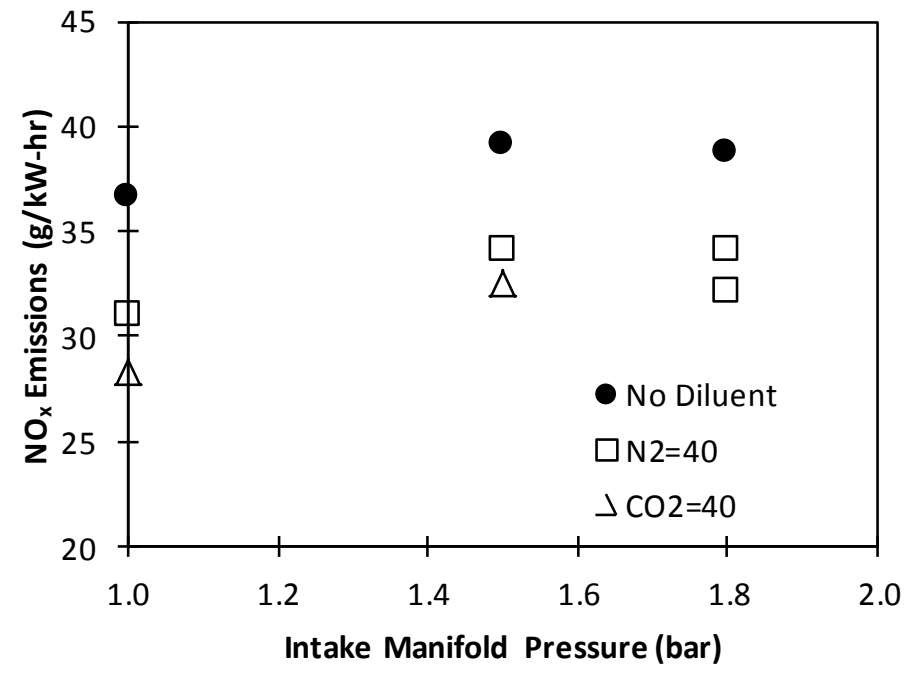

Figure 113 Effect of Intake Pressure on NOx Emissions, N=1500 rpm, ER=0.87, Pout=Pin+0.15, ST=15 bTDC

Figure 114 shows the effect of intake pressure and diluents on CO emissions. The CO emissions were found to increase with the increasing intake pressure. The presence of diluents (both $\mathrm{CO}_{2}$ and $\mathrm{N}_{2}$ ) also increases $\mathrm{CO}$ emissions.

Figure 115 shows the effect of intake pressure and diluents on the emissions of the unburned hydrocarbon. Increasing intake pressure significantly decreases the emissions of unburned hydrocarbon emissions. The presence of diluents causes an increase in unburned hydrocarbon emissions. However, as intake pressure increases, the effect of diluents on unburned hydrocarbon emissions decreases. When operated at intake pressure of $1.8 \mathrm{bar}$, the effect of diluents becomes negligible.

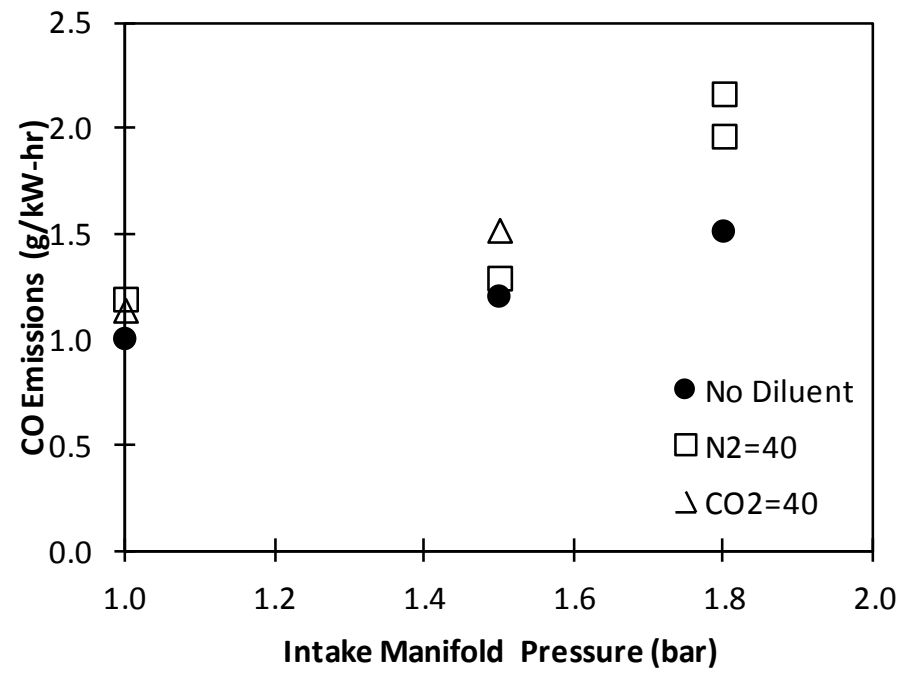

Figure 114 Effect of Intake Pressure on CO Emissions, N=1500 rpm, ER=0.87, Pout=Pin+0.15, ST=15 bTDC 


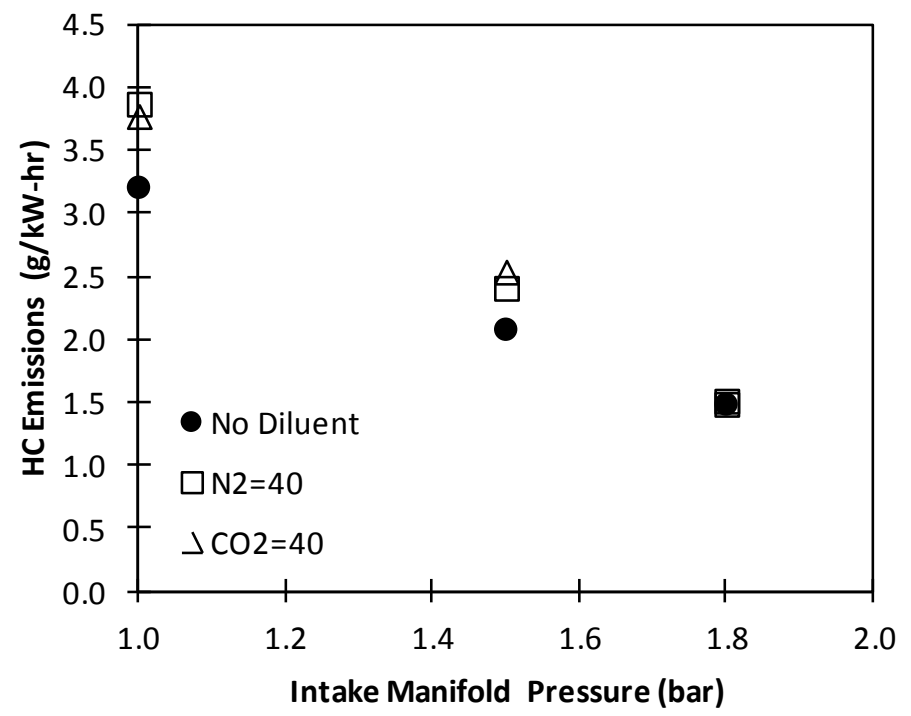

Figure 115 Effect of Intake Pressure on HC Emissions, N=1500 rpm, ER=0.87, Pout=Pin+0.15, ST=15 bTDC

Figure 116 shows the effect of intake pressure and diluents on $\mathrm{CO}_{2}$ emissions. The case with intake $\mathrm{CO}_{2}$ has been corrected to remove the emissions caused by intake $\mathrm{CO}_{2}$. Both intake pressure and diluents have very little effect on $\mathrm{CO}_{2}$ emissions.

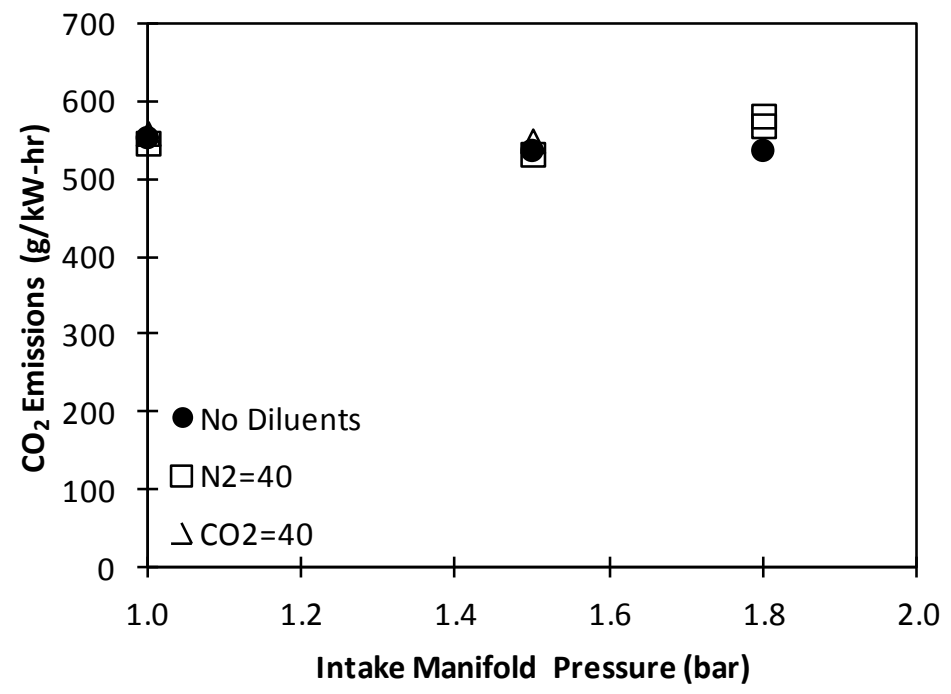

Figure 116 Effect of Intake Pressure on CO2 Emissions, N=1500 rpm, ER=0.87, Pout=Pin+0.15, ST=15 bTDC

Figure 117 shows the effect of intake pressure and the presence of diluents on combustion efficiency of NG. The boosting of intake pressure slightly increased the combustion efficiency. However, the addition of diluents has negligible effect on the combustion efficiency of NG. 


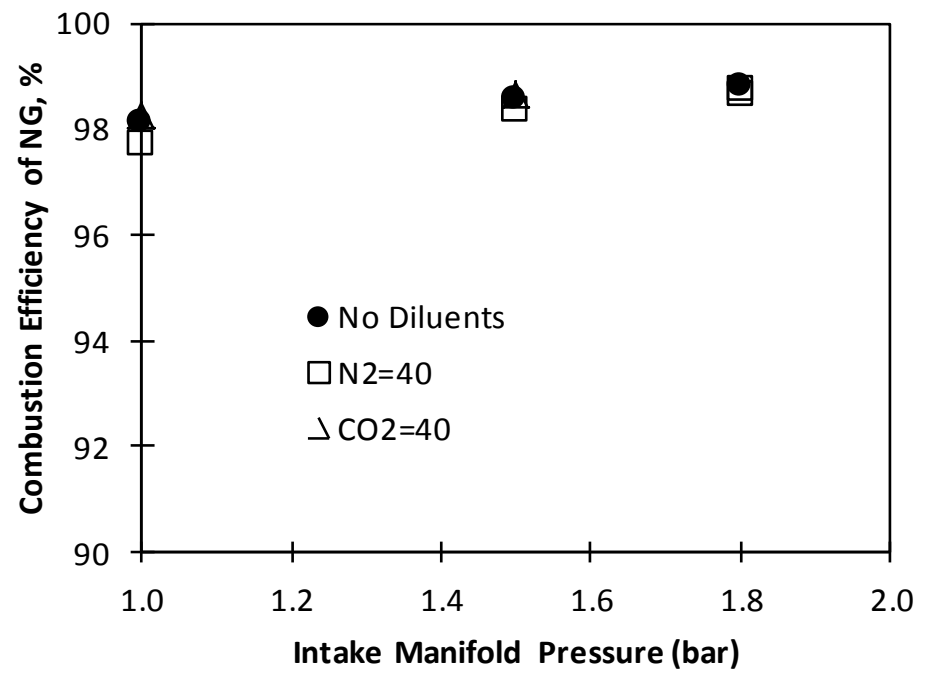

Figure 117 Effect of Intake Pressure on CO2 Emissions, N=1500 rpm, ER=0.87, Pout=Pin+0.15, ST=15 bTDC

Figure 118 shows the effect of intake pressure and diluents on COV of IMEP. Increasing intake pressure increases COV of IMEP for all three cases. At 1.0 bar intake pressure, diluents have no effect on COV of IMEP. At 1.5 bar intake pressure, $40 \% \mathrm{CO}_{2}$ has a higher COV of IMEP than both $40 \% \mathrm{~N}_{2}$ and undiluted $\mathrm{N}_{2}$. At 1.8 bar intake pressure, the presence of $\mathrm{N}_{2}$ causes a significant increase in COV of IMEP compared to undiluted natural gas.

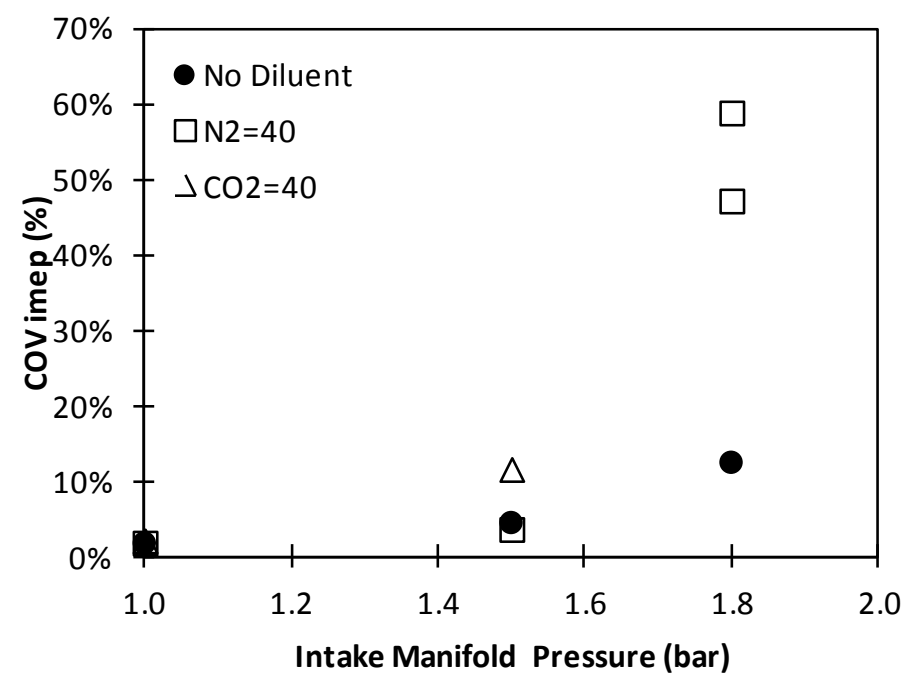

Figure 118 Effect of Intake Pressure on COV IMEP, N=1500 rpm, ER=0.87, Pout=Pin+0.15, ST=15 bTDC

\section{Effect of Engine Speed on Engine Performance, Combustion and Emissions}

In this research the effect of the engine speed on the combustion and exhaust emissions was experimentally examined with and without the addition of diluents. The detailed test matrix can be found in Table 37 and Table 38, respectively. 
Table 37 Changing Speed, ER=0.8, No Dilution, $\mathrm{P}_{\text {in }}=1$ bar, $\mathrm{ST}=15 \mathrm{deg}$ bTDC

\begin{tabular}{|c|c|c|c|c|}
\hline Speed & ER & $\begin{array}{c}\text { diluent } \\
\%\end{array}$ & Pin & ST \\
\hline 1200 & $0.8,1.0$ & 0 & 1 & 15 \\
\hline 1400 & $0.8,1.0$ & 0 & 1 & 15 \\
\hline 1500 & $0.8,1.0$ & 0 & 1 & 15 \\
\hline 1600 & $0.8,1.0$ & 0 & 1 & 15 \\
\hline 1800 & $0.8,1.0$ & 0 & 1 & 15 \\
\hline
\end{tabular}

Table 38 Changing Speed, ER=0.8, $\mathrm{CO}_{2}=40 \%, \mathrm{P}_{\mathrm{in}}=1 \mathrm{bar}, \mathrm{ST}=15 \mathrm{deg} \mathrm{bTDC}$

\begin{tabular}{|c|c|c|c|c|c|}
\hline Speed & ER & $\begin{array}{c}\text { dilue } \\
\text { nt }\end{array}$ & $\begin{array}{c}\text { diluent } \\
\%\end{array}$ & Pin & ST \\
\hline 1200 & $0.8,1.0$ & $\mathrm{CO} 2$ & 40 & 1 & 15 \\
\hline 1400 & $0.8,1.0$ & $\mathrm{CO} 2$ & 40 & 1 & 15 \\
\hline 1500 & $0.8,1.0$ & $\mathrm{CO} 2$ & 40 & 1 & 15 \\
\hline 1600 & $0.8,1.0$ & $\mathrm{CO} 2$ & 40 & 1 & 15 \\
\hline 1800 & $0.8,1.0$ & $\mathrm{CO} 2$ & 40 & 1 & 15 \\
\hline
\end{tabular}

Figure 119 shows the effect of engine speed on the cylinder pressure, heat release process and mass fraction burned. As shown in Figure 120, increasing engine speed slightly reduced the heat release rate and elongated the combustion process. As shown in Figure 121, increasing the engine speed was shown to elongate the heat release process.

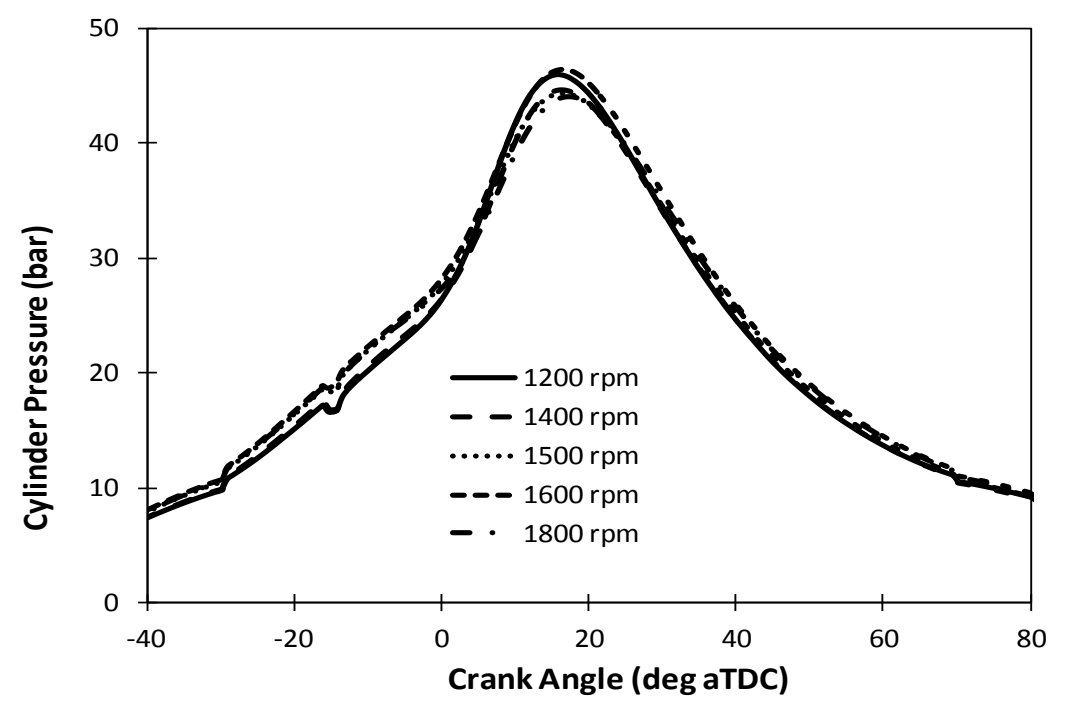

Figure 119 Effect of Engine Speed on In-Cylinder Pressure, Pin=1.0 bar, Pout=1.11 bar, $\mathrm{ST}=15, \mathrm{ER}=0.8$, No Dilution 


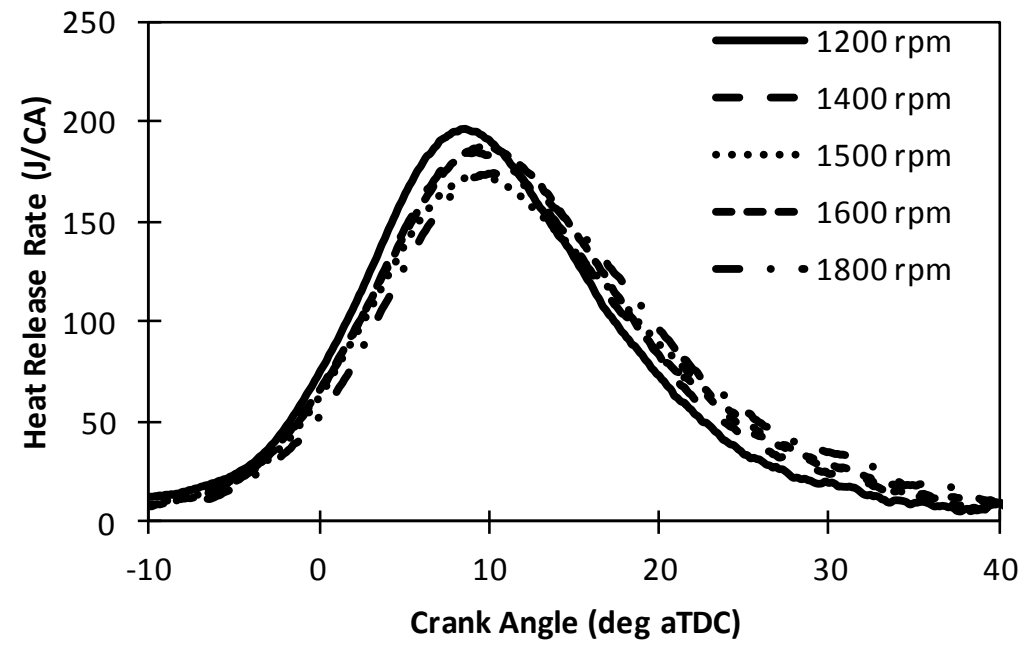

Figure 120 Effect of Engine Speed on Heat Release Rate, Pin=1.0 bar, Pout=1.11 bar, $\mathrm{ST}=15, \mathrm{ER}=0.8$, No Dilution

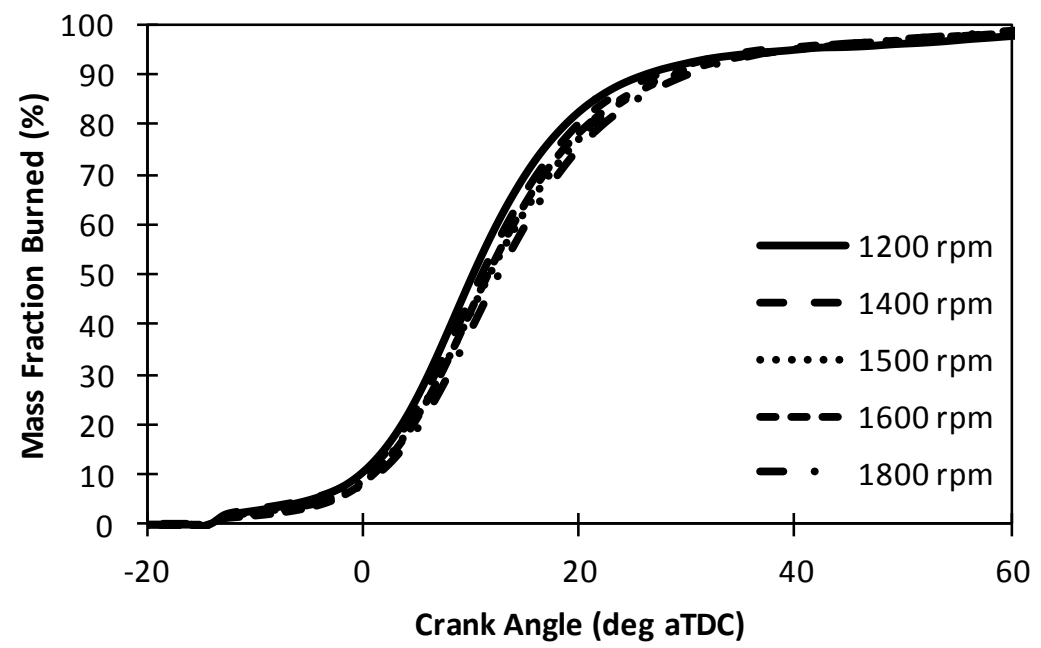

Figure 121 Effect of Engine Speed on Mass Fraction Burned, Pin=1.0 bar, Pout=1.11 bar, $\mathrm{ST}=15$, ER=0.8, No Dilution

Figures 122-133 show the effect of engine speed and equivalence ratio on the engine performance, combustion process parameters and exhaust emissions. As expected, the lean operation reduced the engine load as indicated by the reduced BMEP and IMEP. As shown in Figure 122 and 123, increasing the engine speed slightly increased the engine load with the exception of $1800 \mathrm{rpm}$.

Figure 124 shows the effect of engine speed on the peak cylinder pressure. Increasing engine speed slightly increased the peak cylinder pressure observed at stoichiometric operation. As an example, the peak cylinder pressure observed with ER of 1.0 at $1600 \mathrm{rpm}$ was $53.72 \mathrm{bar}$, which was $4.2 \%$ higher than that the peak cylinder pressure of 51.06 bar observed at $1200 \mathrm{rpm}$. However, the effect of engine speed on the peak cylinder pressure observed at lean operation was 
mild. For example, he peak cylinder pressure observed with ER of 0.8 at 1600 rpm was 46.37 bar, which was about $1 \%$ higher than the peak cylinder pressure of 45.92 bar observed at $1200 \mathrm{rpm}$.

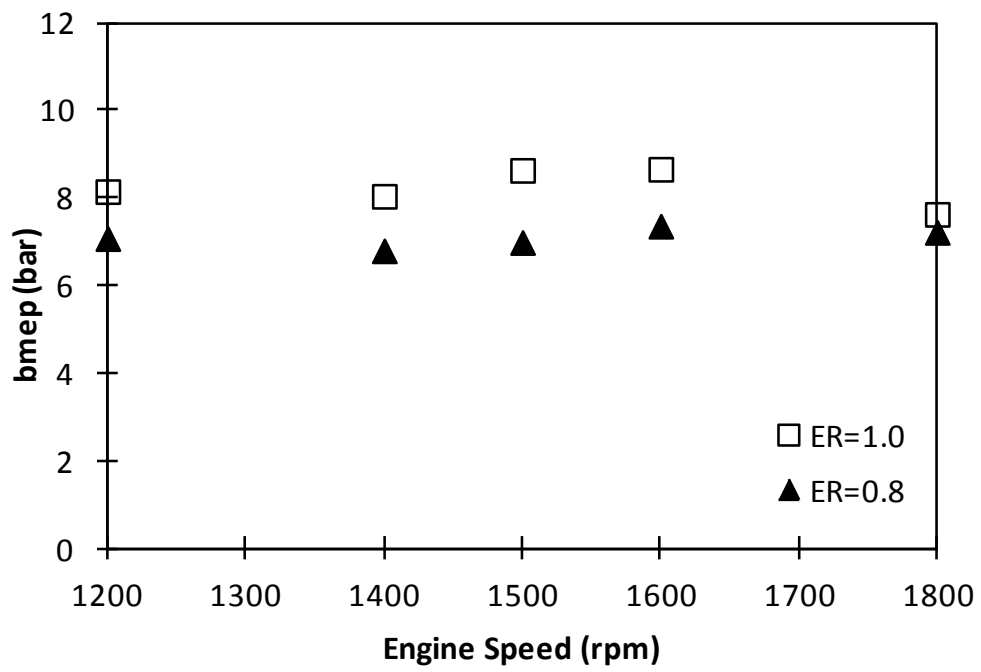

Figure 122 Effect of Engine Speed on BMEP, Pin=1.0, Pout=1.11, ST=15 bTDC, No dilution

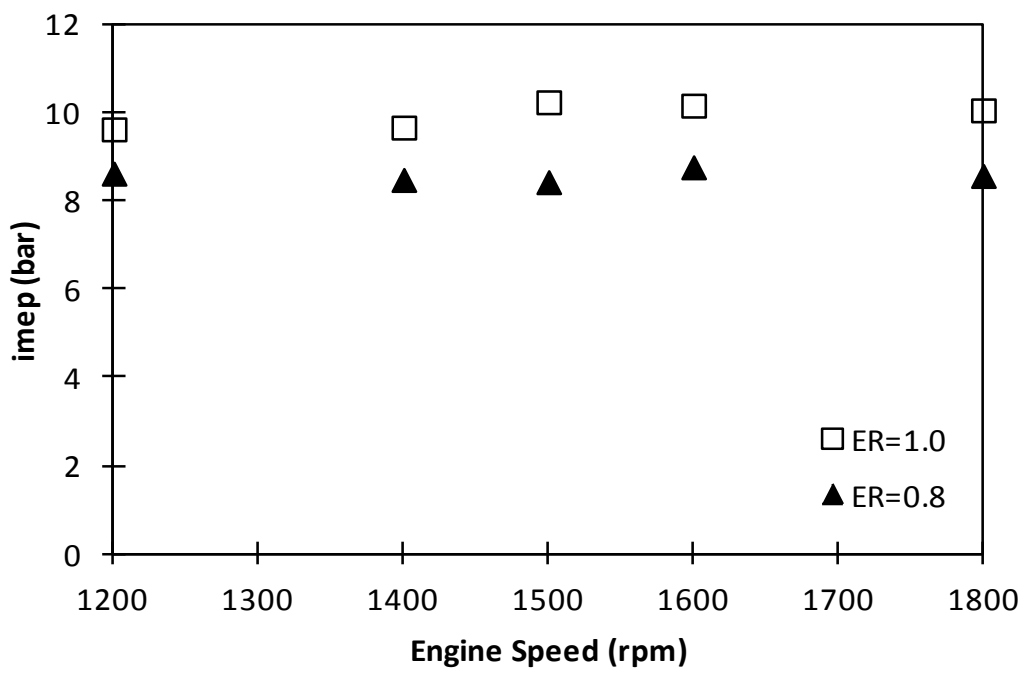

Figure 123 Effect of Engine Speed on IMEP, Pin=1.0, Pout=1.11, ST=15 bTDC, No dilution 


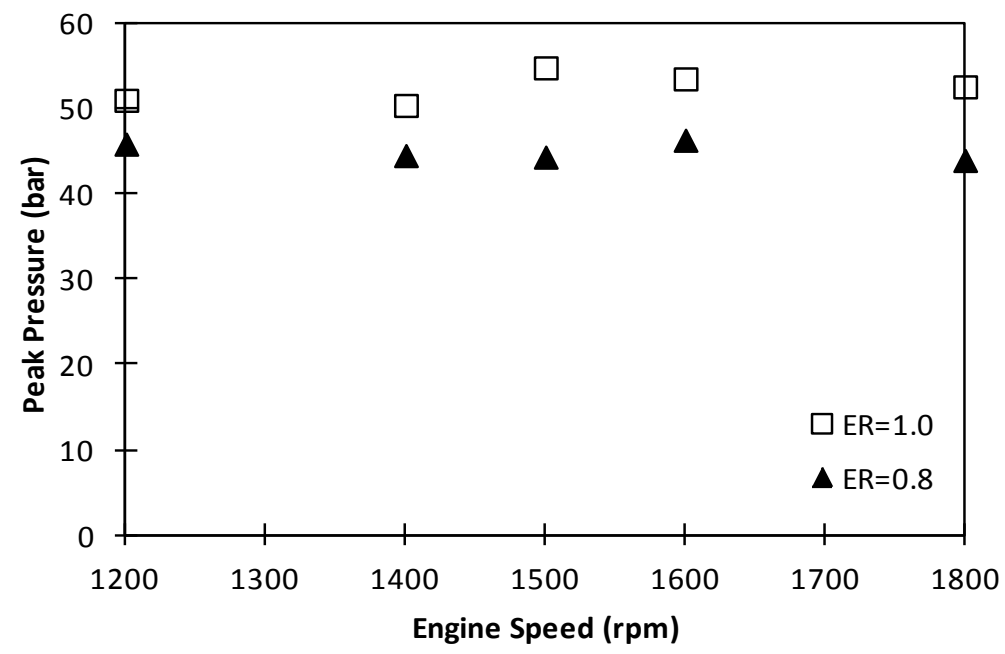

Figure 124 Effect of Engine Speed on Peak Pressure, Pin=1.0, Pout=1.11, ST=15 bTDC, No dilution

As shown in Figure 125, increasing engine speed was shown to slightly increase ignition delay. Increasing the engine speed from $1200 \mathrm{rpm} 1600$ was found to elongate the ignition delay from 10.0 CA to 12.0CA (+2.0 CA) when operated at ER of 0.8. When operated at stoichiometric mixture, the increase in engine speed elongated the ignition delay by $1.4 \mathrm{CA}$. As shown in Figure 126, the effect of engine speed on combustion duration was relatively small.

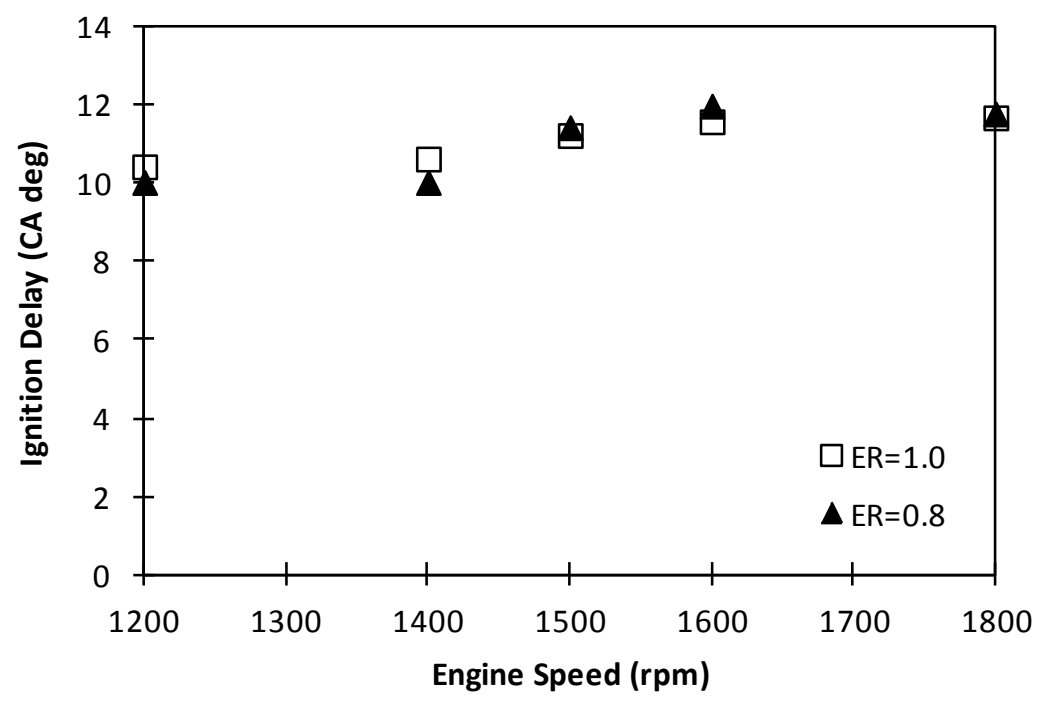

Figure 125 Effect of Engine Speed on Ignition Delay, Pin=1.0, Pout=1.11, ST=15 bTDC, No dilution 


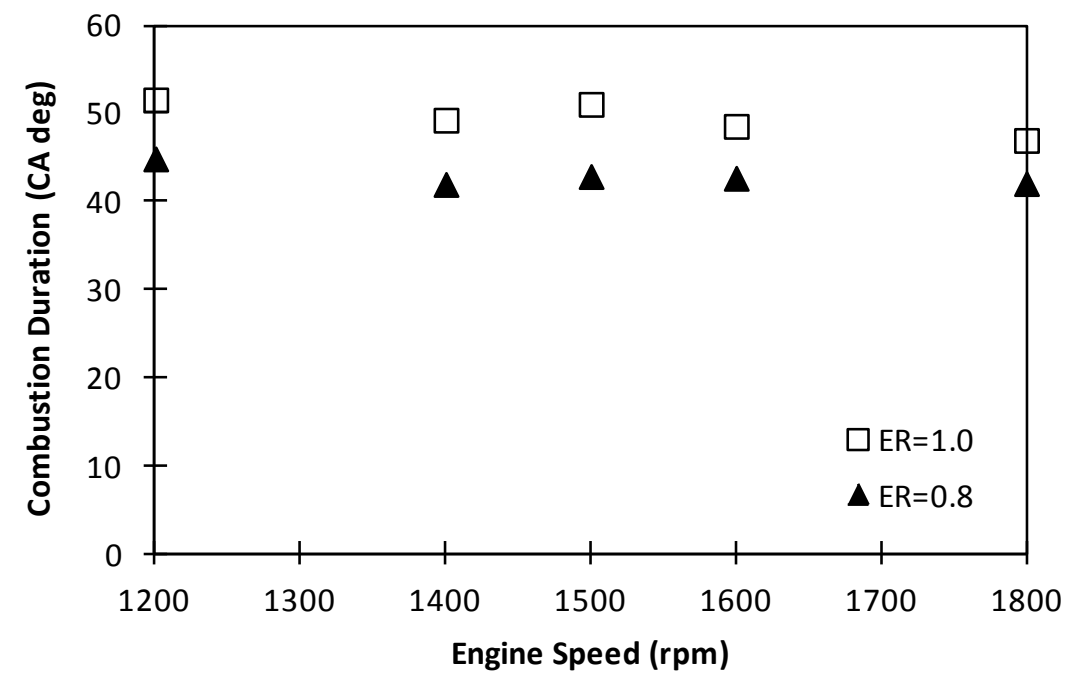

Figure 126: Effect of Engine Speed on Ignition Delay, Pin=1.0, Pout=1.11, ST=15 bTDC, No dilution

As shown in Figure 127, the effect of engine speed on the thermal efficiency was mild with the exception of $1400 \mathrm{rpm}$ under which the reduced thermal efficiency was observed.

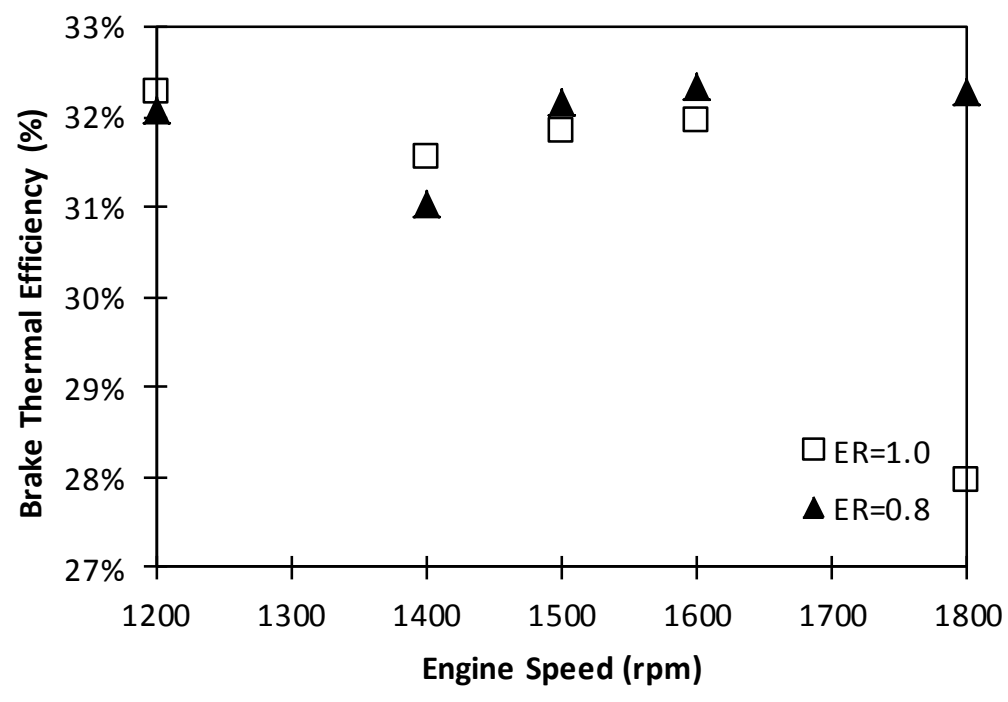

Figure 127: Effect of Engine Speed on Thermal Efficiency, Pin=1.0, Pout=1.11, ST=15 bTDC, No dilution

Figure 128 shows the effect of engine speed on $\mathrm{CO}$ emissions. The $\mathrm{CO}$ emissions observed at lean burn were extremely small. However, increasing engine speed was found to dramatically increase the emissions of $\mathrm{CO}$ observed at stoichiometric mixture. As an example, the CO emissions observed at $1800 \mathrm{rpm}$ were $35.93 \mathrm{~g} / \mathrm{kW}$-hr, which was 4.1 times the CO emissions observed at $1200 \mathrm{rpm}$. As shown in Figure 76 (g), the CO emissions observed at stoichiometric mixture were much higher than lean operation. 
Figure 129 shows the very mild effect of engine speed on HC emissions. The HC emissions observed at stoichiometric mixture was much higher than lean operation at ER of 0.87.

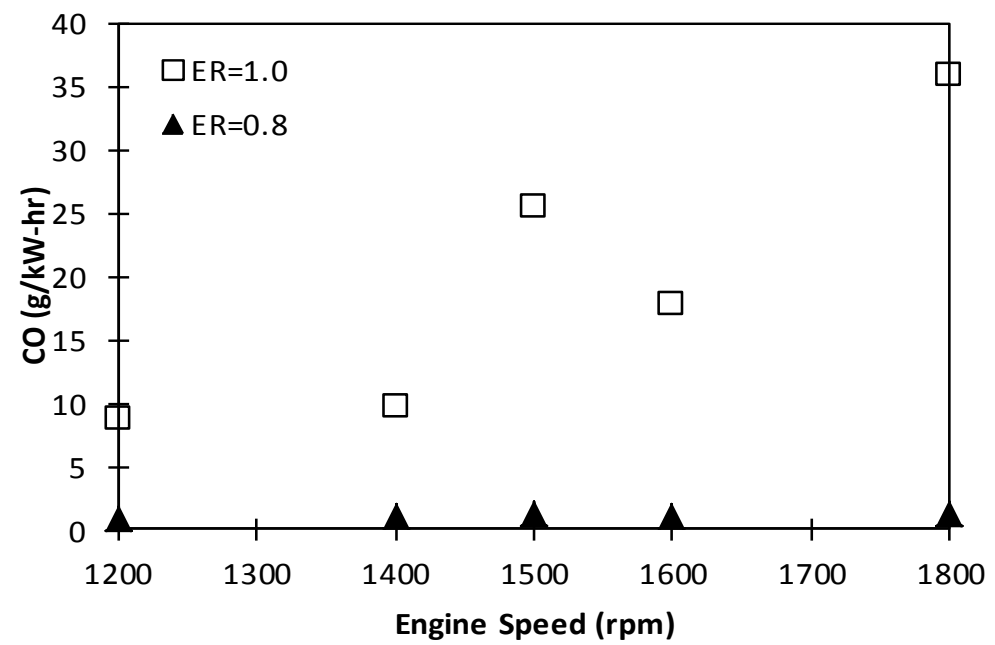

Figure 128 Effect of Engine Speed on CO Emissions, Pin=1.0, Pout=1.11, ST=15 bTDC, No dilution

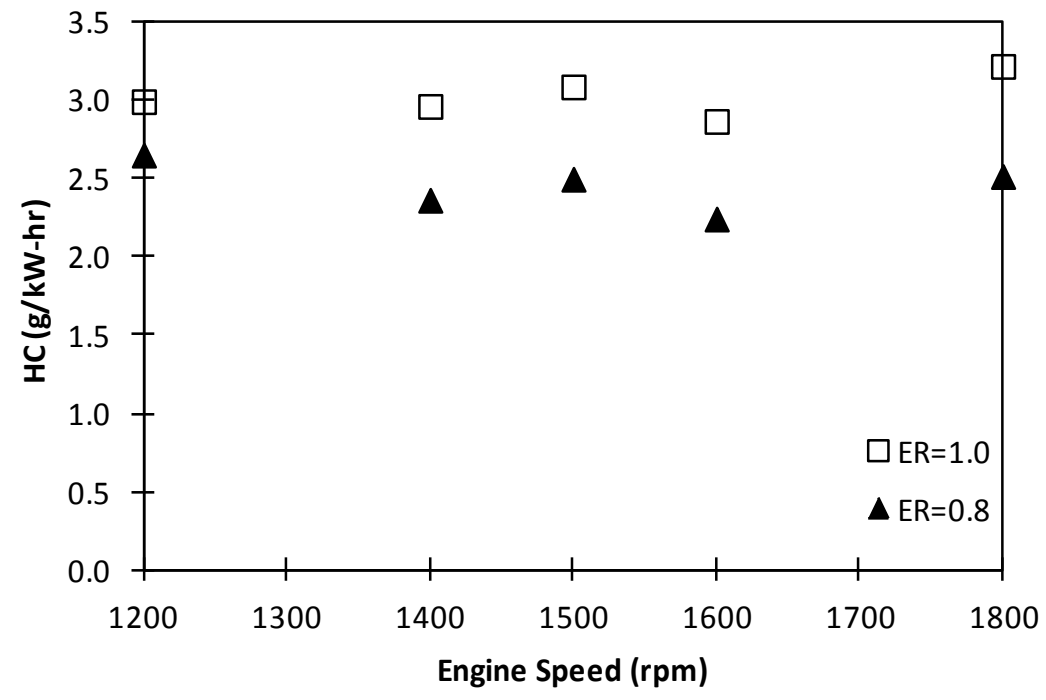

Figure 129 Effect of Engine Speed on HC Emissions, Pin=1.0, Pout=1.11, ST=15 bTDC, No dilution

Figure 130 shows the effect of engine speed and $\mathrm{ER}$ on $\mathrm{CO}_{2}$ emissions. The increase in engine speed has negligible effect on the emissions of $\mathrm{CO}_{2}$ with the exception of $\mathrm{CO} 2$ emissions observed at $1800 \mathrm{rpm}$ and ER of 1.0 . 


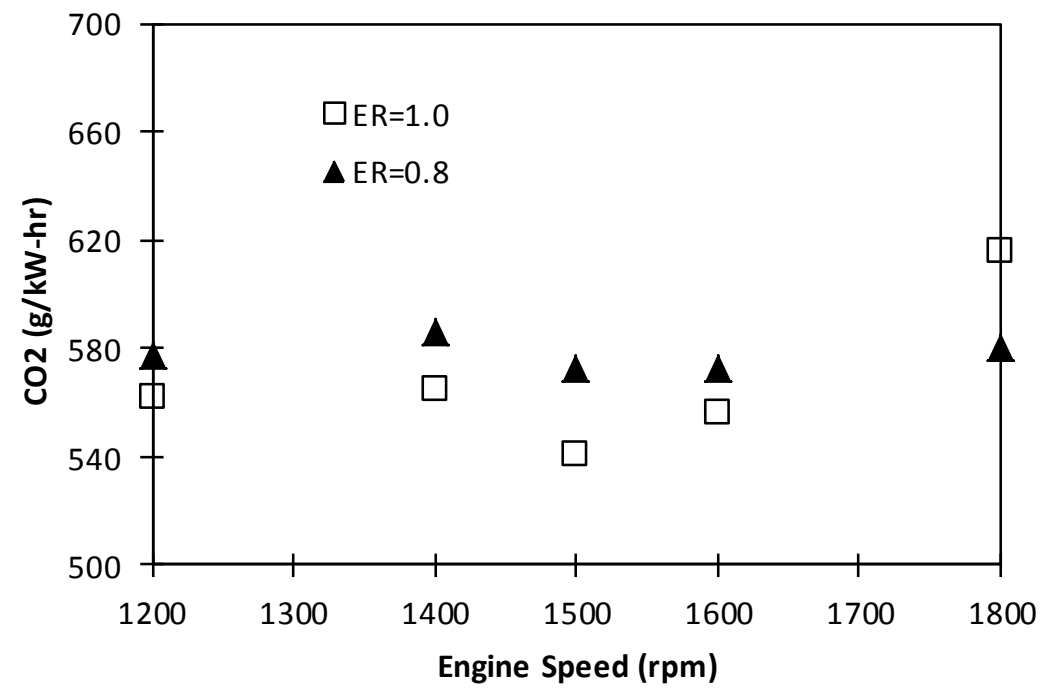

Figure 130 Effect of Engine Speed on CO2 Emissions, Pin=1.0, Pout=1.11, ST=15 bTDC, No dilution

Figure 131 shows the effect of engine speed on combustion efficiency calculated from the emissions data to be reported. Increasing engine speed at stoichiometric mixture was shown to decrease the combustion efficiency. For example, increasing the engine speed from $1200 \mathrm{rpm}$ to $1800 \mathrm{rpm}$ reduced the combustion efficiency from $98.0 \%$ to $94.0 \%$. The reduction in combustion efficiency was due to the increased emissions of $\mathrm{CO}$ as shown in Figure 128. In comparison, the effect of engine speed at lean operation $(\mathrm{ER}=0.8)$ on the emissions of $\mathrm{CO}$ and $\mathrm{HC}$ was mild as shown in Figure 128, and 129, respectively.

As shown in Figure 131, the operation of SI engine improved the combustion efficiency due to the notable reduction in the emissions of both CO and HC. As shown in Figure 128, the effect of engine speed on $\mathrm{CO}_{2}$ emissions was relatively weak.

Figure 132 shows the effect of engine speed and $\mathrm{ER}$ on $\mathrm{NO}_{\mathrm{x}}$ emissions. Increasing engine speed slightly decreased the emissions of $\mathrm{NO}_{\mathrm{x}}$. The NOx emissions observed at lean mixture $(E R=0.87)$ was much higher than the NOx emissions observed at stoichiometric mixture. 


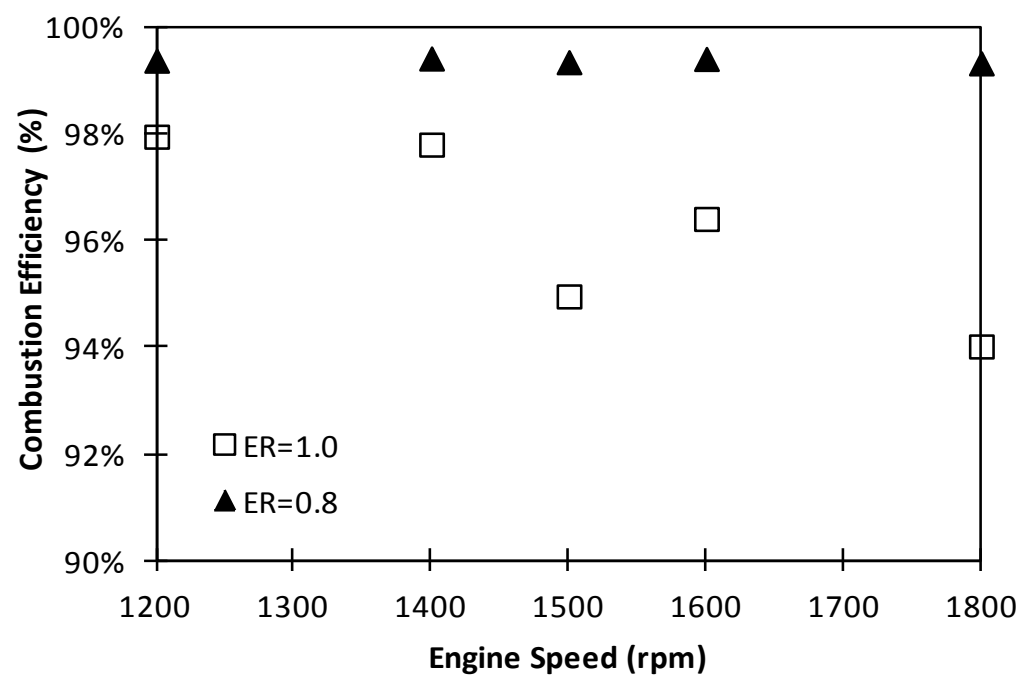

Figure 131 Effect of Engine Speed on Combustion Efficiency, Pin=1.0, Pout=1.11, ST=15 bTDC, No dilution

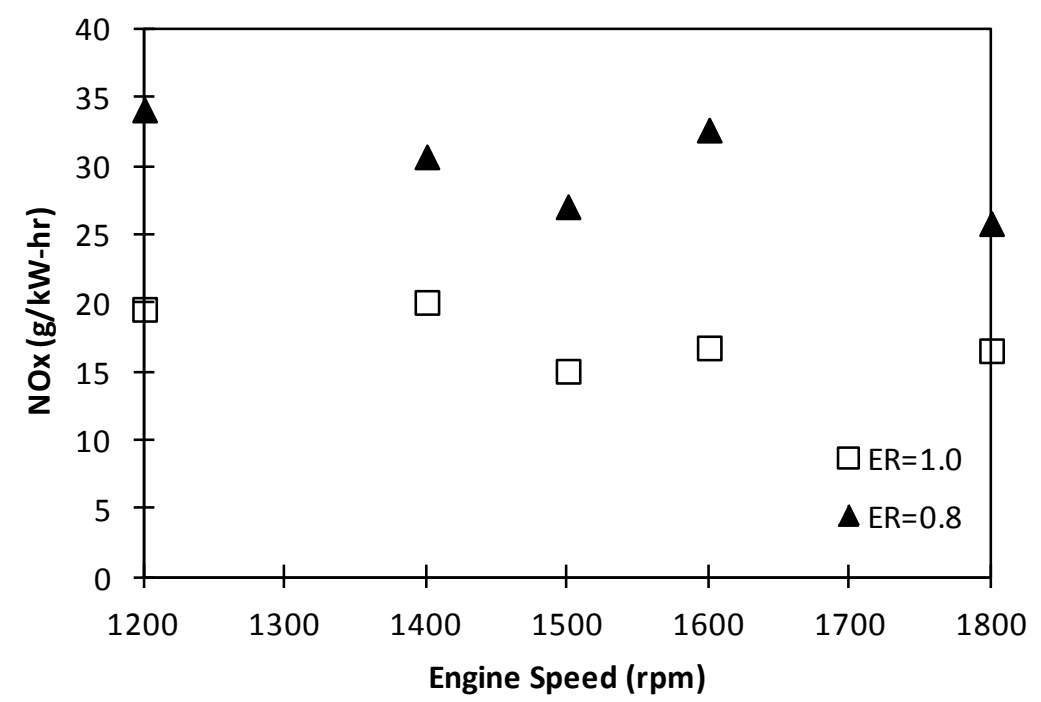

Figure 132 Effect of Engine Speed on NOx Emissions, Pin=1.0, Pout=1.11, ST=15 bTDC, No dilution

Figure 133 shows the effect of engine speed on combustion stability. Increasing engine speed improved the combustion stability as indicated by the decrease in COVIMEP. For example, increasing the engine speed from 1200 to $1800 \mathrm{rpm}$ at ER of 0.8 decreased the COVIMEP from 3.0 to 2.4 . 


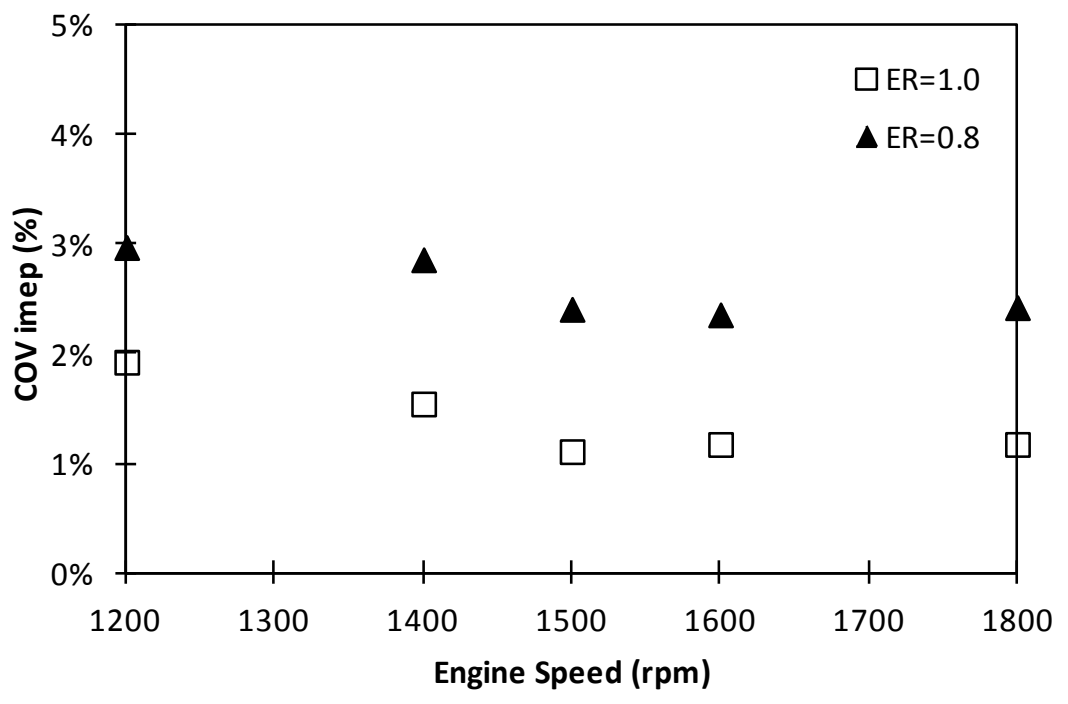

Figure 133 Effect of Engine Speed on COV IMEP, Pin=1.0, Pout=1.11, ST=15 bTDC, No dilution

Figures 134 to 145 show the effect of engine speed and the addition of $40 \%$ CO2 to natural gas on the engine performance, combustion process parameters and exhaust emissions when operated at stoichiometric mixture. As shown in Figure 134, when operated at stoichiometric mixture, increasing the engine speed slightly increased the engine load with the exception of 1800 rpm.

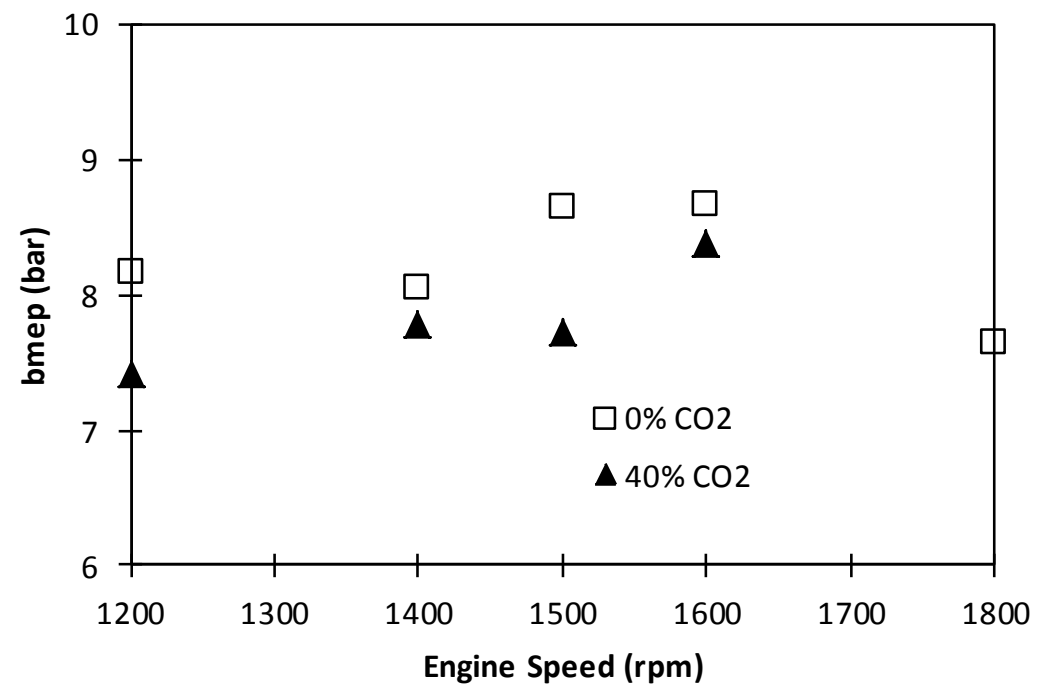

Figure 134 Effect of Engine Speed on BMEP, Pin=1.0, Pout=1.11, ST=15 bTDC, ER=1.0

Figure 135 shows the effect of engine speed and the addition of $40 \% \mathrm{CO}_{2}$ to natural gas on brake thermal efficiency. The increase in engine speed had negligible effect on the brake thermal efficiency of stoichiometric operation of natural gas without the addition of $\mathrm{CO}_{2}$ with the exception of $1800 \mathrm{rpm}$. However, the increase in engine speed improved the thermal efficiency observed with the addition of $40 \% \mathrm{CO}_{2}$ into natural gas. 


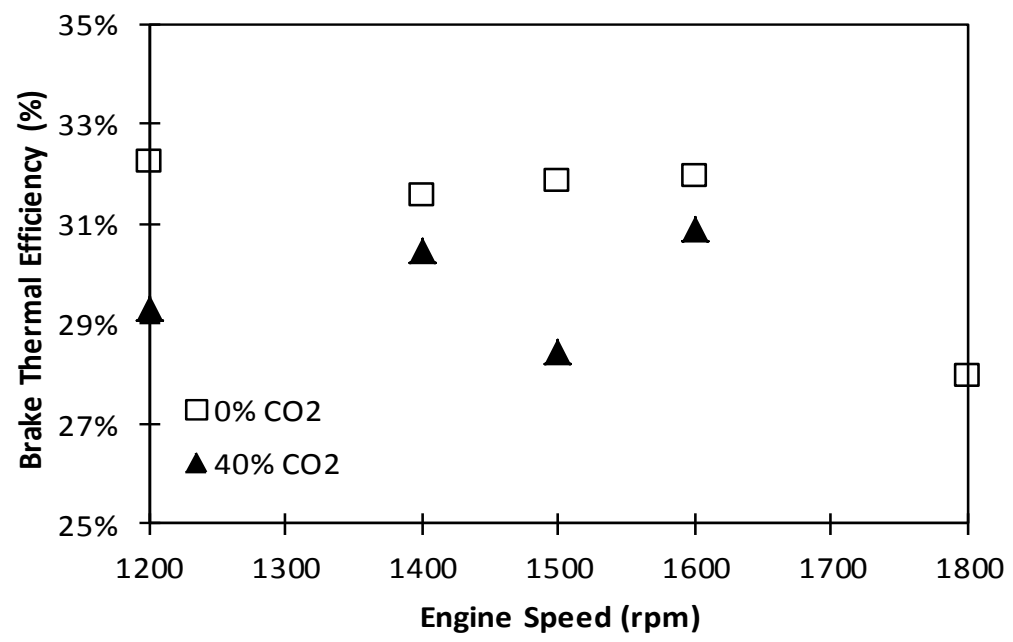

Figure 135 Effect of Engine Speed on Thermal Efficiency, Pin=1.0, Pout=1.11, ST=15 bTDC, ER=1.0

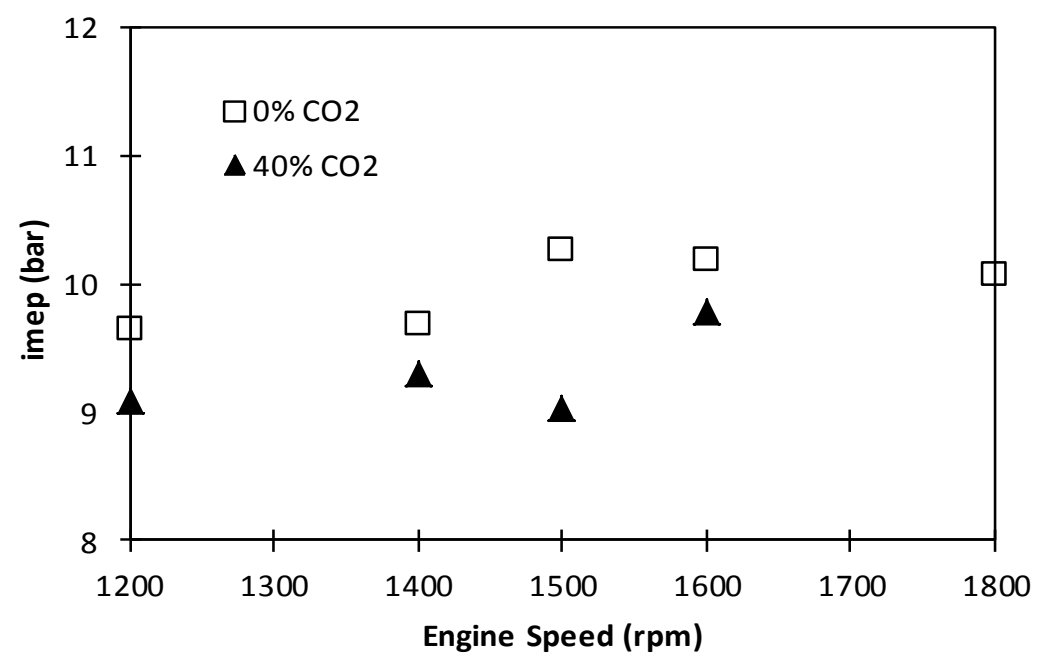

Figure 136 Effect of Engine Speed on IMEP, Pin=1.0, Pout=1.11, ST=15 bTDC, ER=1.0

Figure 136 shows the effect of engine speed on IMEP. The increase in engine speed increased the IMEP observed, which was consistent with the variation of BMEP data shown in 134. The addition of $40 \% \mathrm{CO}_{2}$ to natural gas reduced the IMEP observed due to the burning of less fuel. Figure 137 shows the effect of engine speed on the peak cylinder pressure. The increase in engine speed increased the peak cylinder pressure observed. The addition of $40 \% \mathrm{CO}_{2}$ to natural gas reduced the IMEP observed due to the burning of less fuel. 


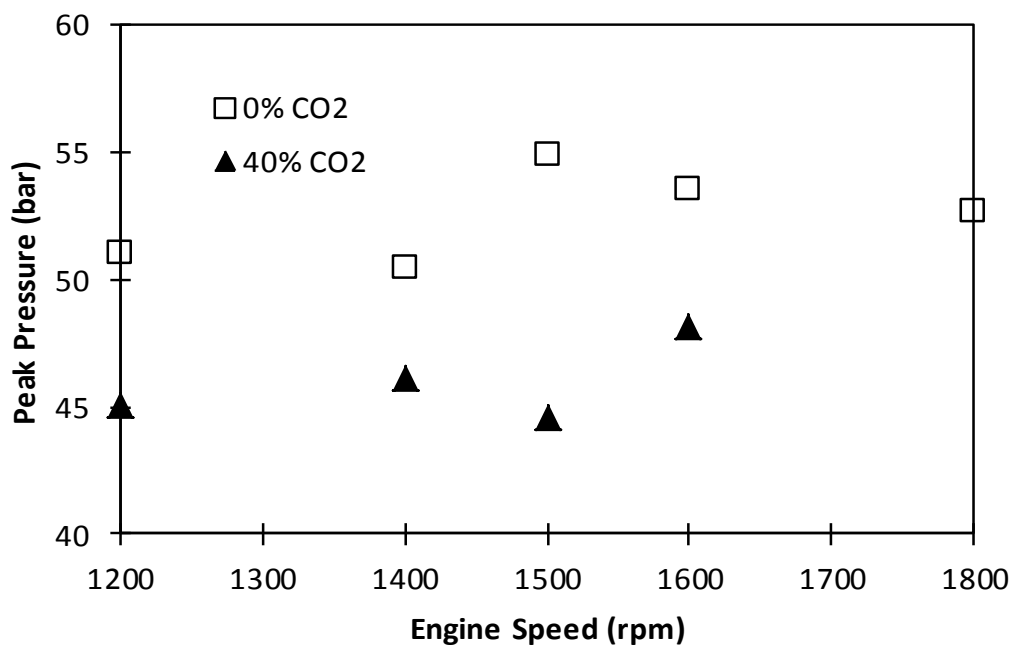

Figure 137 Effect of Engine Speed on Peak Pressure, Pin=1.0, Pout=1.11, ST=15 bTDC, $\mathrm{ER}=1.0$

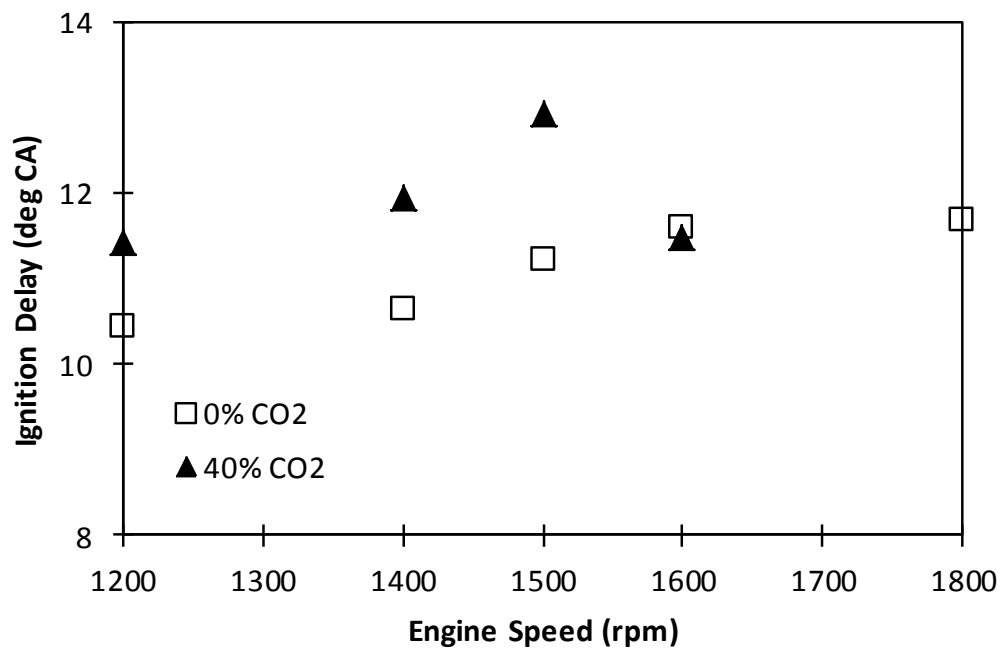

Figure 138 Effect of Engine Speed on Ignition Delay, Pin=1.0, Pout=1.11, ST=15 bTDC, ER=1.0

Figure 138 and 139 shows the effect of engine speed on ignition delay and combustion duration. As shown in Figure 138, the increase in engine speed elongated the ignition delay rated on basis of crank angle. The addition of $40 \% \mathrm{CO}_{2}$ to natural gas elongated the ignition delay, which was due to the longer time. The presence of $\mathrm{CO}_{2}$ elongated the initiation time period needed for flame kernel to develop. As shown in Figure 139, the effect of engine speed on the combustion duration was very weak. 


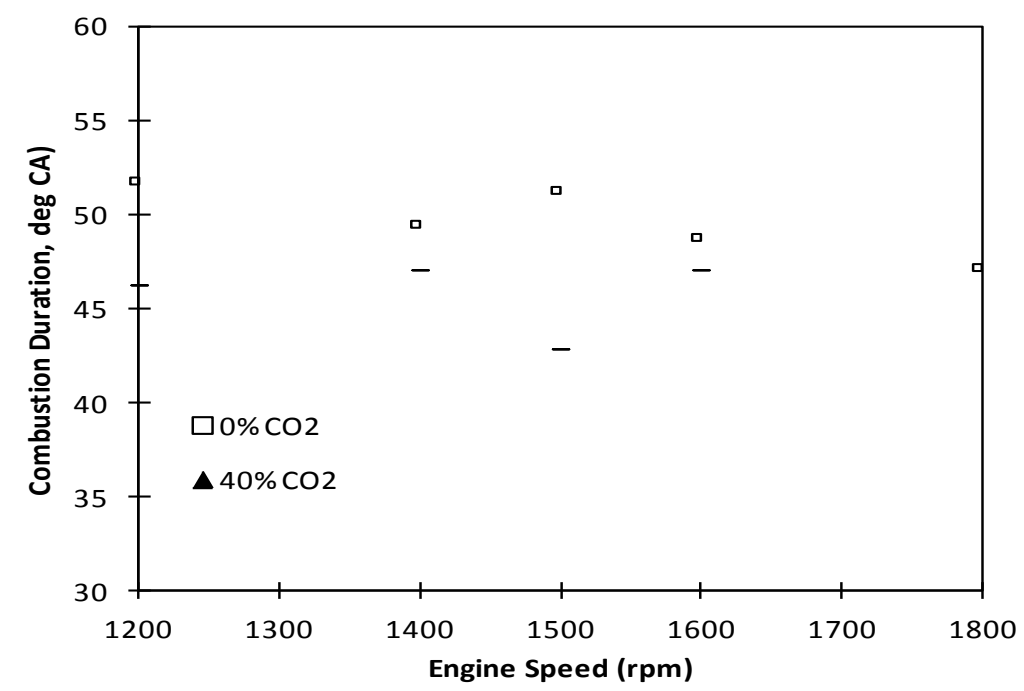

Figure 139 Effect of Engine Speed on Combustion Duration, Pin=1.0, Pout=1.11, ST=15 bTDC, ER=1.0

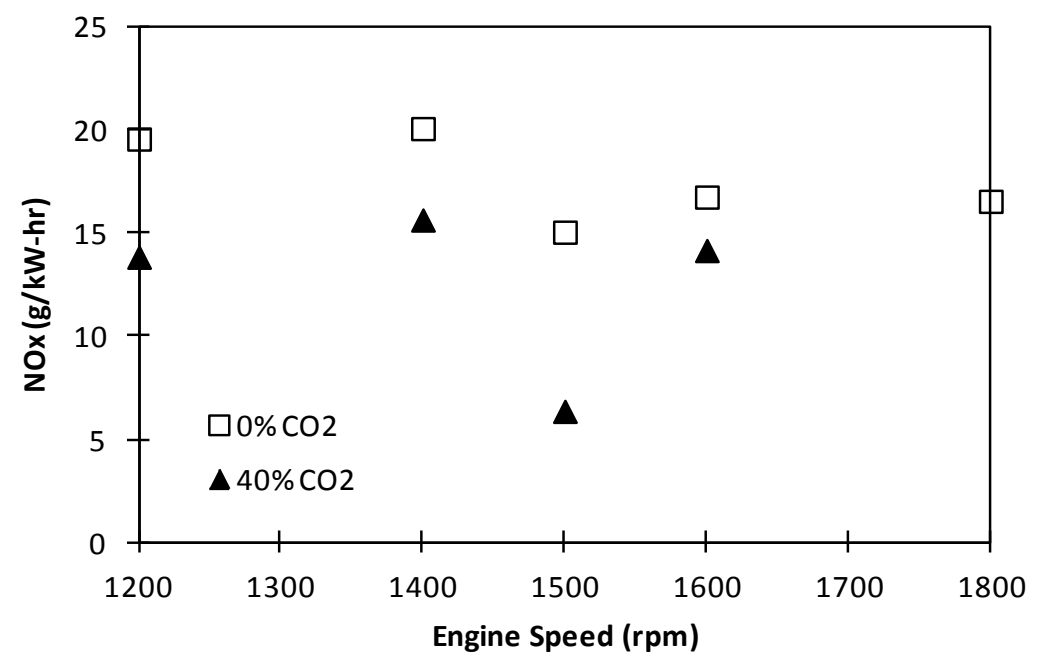

Figure 140 Effect of Engine Speed on NOx Emissions, Pin=1.0, Pout=1.11, ST=15 bTDC, ER=1.0

Figure 140 shows the effect of engine speed on the emissions of $\mathrm{NO}_{\mathrm{x}}$. The increase in engine speed slightly reduced the emissions of $\mathrm{NO}_{\mathrm{x}}$ observed at stoichiometric mixture when no $\mathrm{CO}_{2}$ was added. The addition of $40 \% \mathrm{CO}_{2}$ to natural gas reduced the emissions of $\mathrm{NO}_{\mathrm{x}}$. Figures 141 and 142 show the effect of engine speed on the emissions of CO and HC. As shown in Figure 141, increasing engine speed was found to gradually increase the emissions of CO observed without toe addition of $\mathrm{CO}_{2}$. However, the $\mathrm{CO}$ emissions observed at different engine speed are comparable with the exception of $1500 \mathrm{rpm}$. As shown in Figure 141 and142, the addition of $40 \%$ $\mathrm{CO}_{2}$ to natural gas significantly increased the emissions of $\mathrm{CO}$ and $\mathrm{HC}$ at stoichiometric operation. 


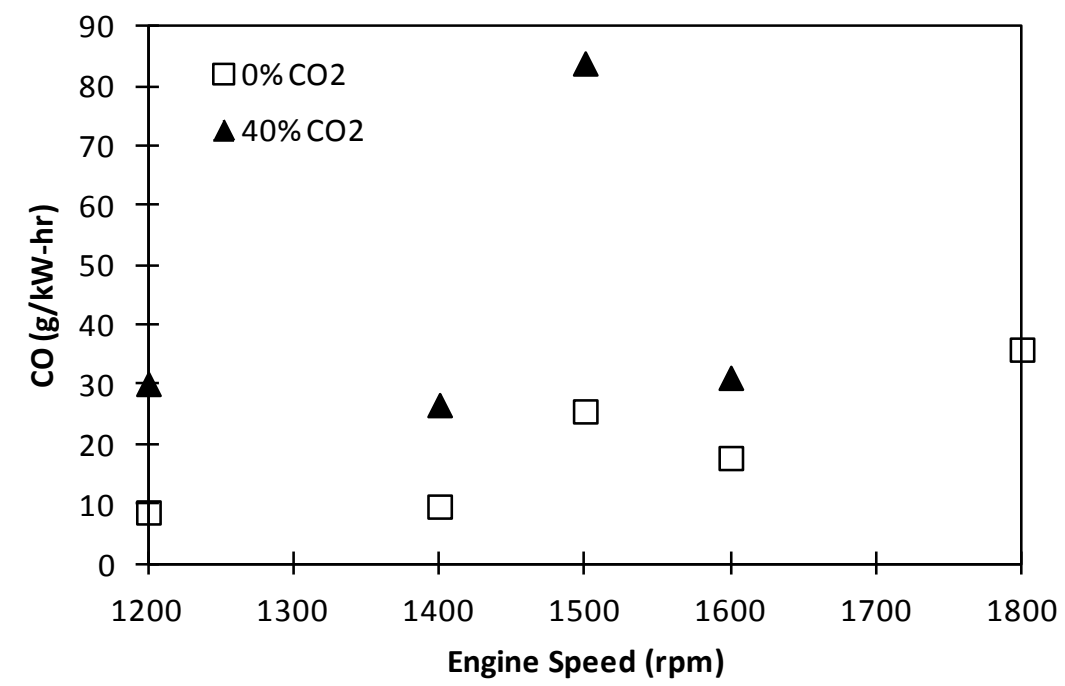

Figure 141 Effect of Engine Speed on CO Emissions, Pin=1.0, Pout=1.11, ST=15 bTDC, ER=1.0 (CO data for $1500 \mathrm{rpm}$ with $40 \%$ CO2 was not correct)

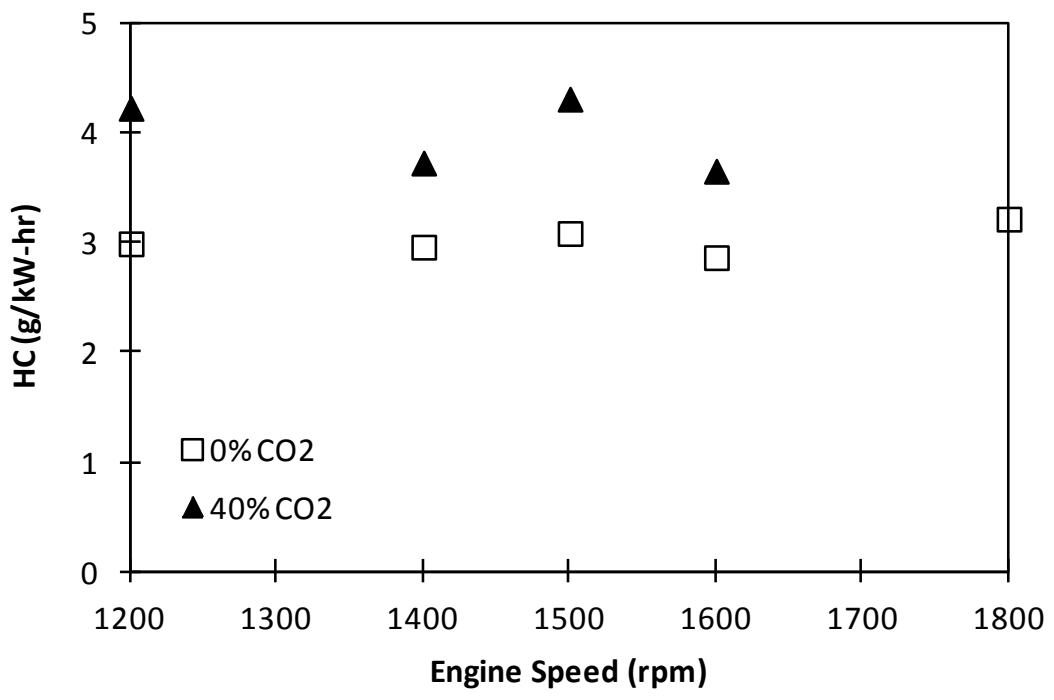

Figure 142 Effect of Engine Speed on HC Emissions, Pin=1.0, Pout=1.11, ST=15 bTDC, ER=1.0

Figure 143 shows the effect of engine speed on the emissions of $\mathrm{CO}_{2}$. The effect of engine speed and the addition of $40 \% \mathrm{CO}_{2}$ to natural gas on the emissions of $\mathrm{CO}_{2}$ at stoichiometric operation were very mild. 


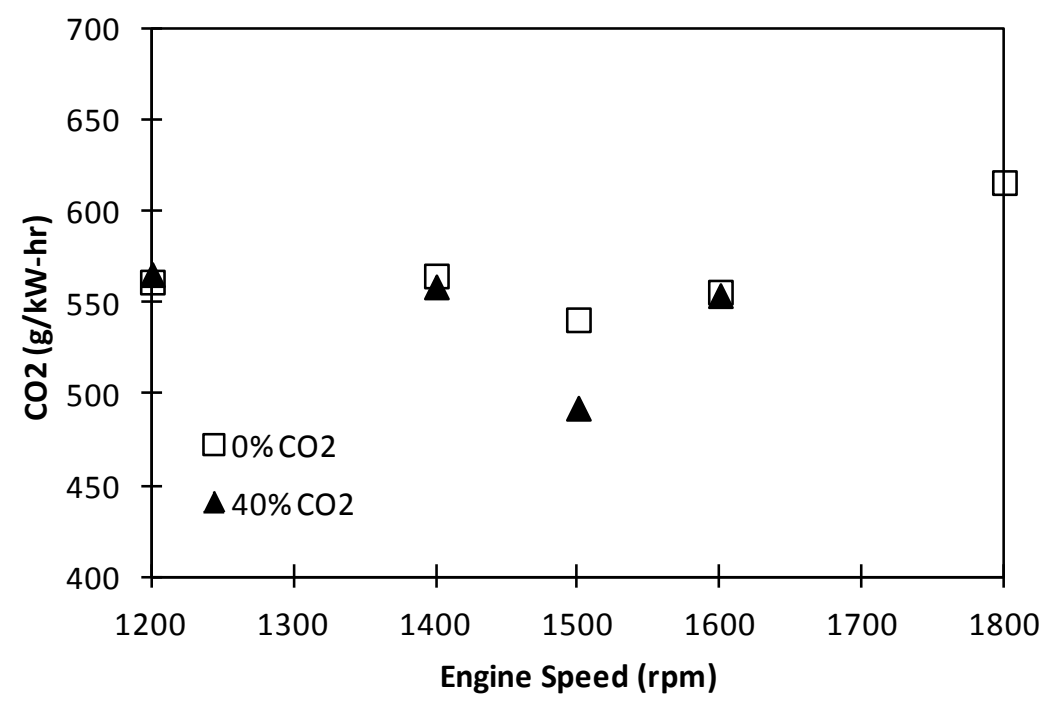

Figure 143 Effect of Engine Speed on CO2 Emissions, Pin=1.0, Pout=1.11, ST=15 bTDC, $\mathrm{ER}=1.0$

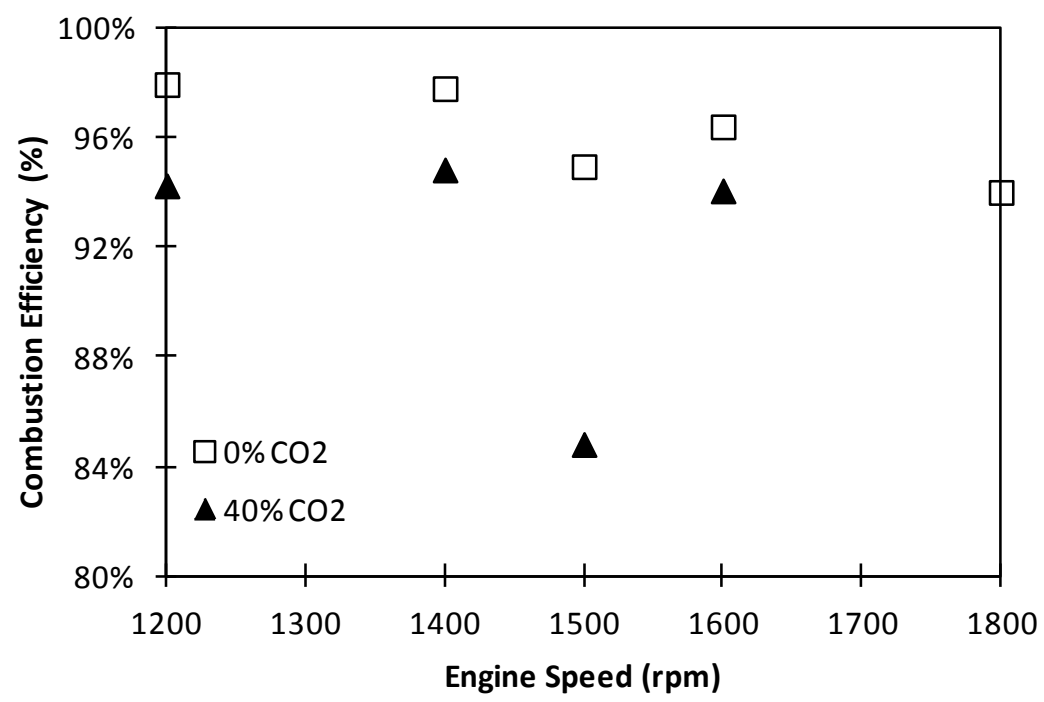

Figure 144 Effect of Engine Speed on Combustion Efficiency, Pin=1.0, Pout=1.11, ST=15 bTDC, ER=1.0

Figure 144 shows the effect of engine speed on combustion efficiency of natural gas. Increasing engine speed was shown to lightly decrease the combustion efficiency of natural gas observed when no $\mathrm{CO}_{2}$ was added, which was due to the increased emissions of $\mathrm{CO}$ shown in Figure 141. However, the effect of engine speed on combustion efficiency observed with the addition of $40 \% \mathrm{CO}_{2}$ was mild. As shown in Figure 144, the addition of $40 \% \mathrm{CO}_{2}$ to natural gas decreased the combustion efficiency of natural gas due to the increased emissions of $\mathrm{CO}$ and $\mathrm{HC}$ shown in Figure 141 and 142.

Figure 145 shows the effect of engine speed on combustion stability. Increasing engine speed was shown to slightly improve the combustion stability when operated without the addition of 
$\mathrm{CO}_{2}$. Without the addition of $\mathrm{CO}_{2}$, increasing engine speed from 1200 to $1800 \mathrm{rpm}$ decreased the COVIMEP from 1.74 to $1.18 \%$. As shown in Figure 145, with the addition of $40 \% \mathrm{CO}_{2}$, the effect of engine speed on COVIMEP was negligible.

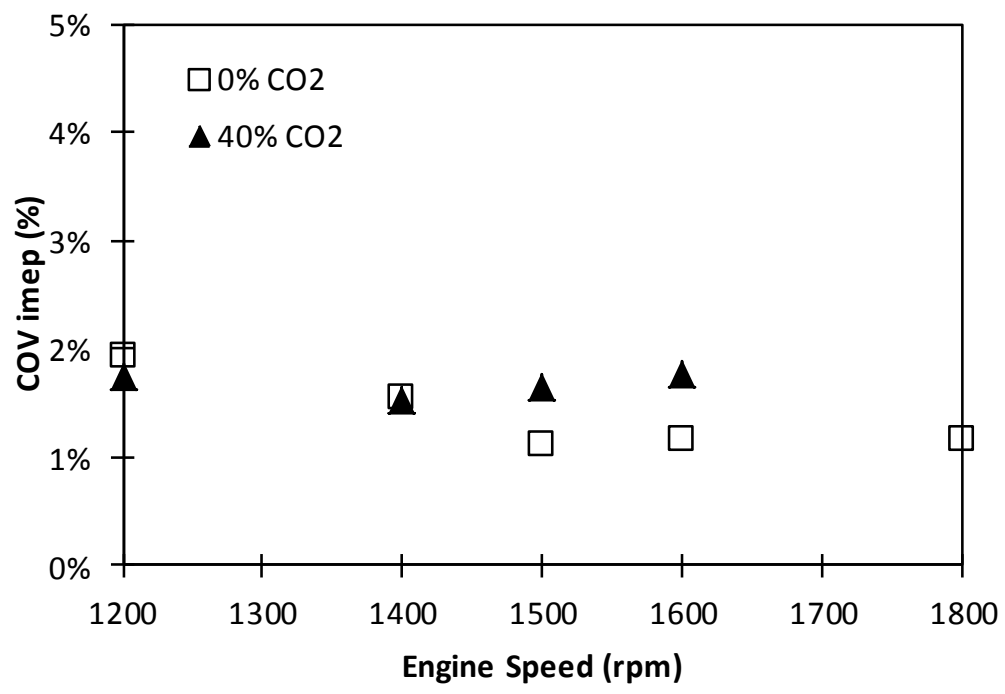

Figure 145 Effect of Engine Speed on COV IMEP, Pin=1.0, Pout=1.11, ST=15 bTDC, $E R=1.0$

\section{Effect of Spark Timing on Combustion and Emissions}

In this research, the effect of spark timing (from 27 to $9{ }^{\circ} \mathrm{CA}$ BTDC) on the engine performance, combustion process and exhaust emissions was investigated under both lean and stoichiometric operation with and without the addition of $\mathrm{CO}_{2}$. The detailed test matrix was shown in Table 39and Table 40, respectively.

Table 39 Changing Spark Timing, Speed $=1500 \mathrm{rpm}$, ER=0.8, No Dilution, $P_{\text {in }}=1$ bar

\begin{tabular}{|c|c|c|c|c|c|}
\hline Speed & ER & $\begin{array}{c}\text { dilue } \\
\text { nt }\end{array}$ & $\begin{array}{c}\text { diluent } \\
\%\end{array}$ & Pin & ST ( ${ }^{\circ}$ BTDC) \\
\hline 1500 & $0.8,1.0$ & -- & 0 & 1 & 27 \\
\hline 1500 & $0.8,1.0$ & -- & 0 & 1 & 24 \\
\hline 1500 & $0.8,1.0$ & -- & 0 & 1 & 21 \\
\hline 1500 & $0.8,1.0$ & -- & 0 & 1 & 18 \\
\hline 1500 & $0.8,1.0$ & -- & 0 & 1 & 15 \\
\hline 1500 & $0.8,1.0$ & -- & 0 & 1 & 12 \\
\hline 1500 & $0.8,1.0$ & -- & 0 & 1 & 9 \\
\hline
\end{tabular}


Table 40 Changing Spark Timing, Speed $=1500 \mathrm{rpm}$, ER=0.8, CO2=40\%, Pin=1 bar

\begin{tabular}{|c|c|c|c|c|c|}
\hline Speed & ER & $\begin{array}{c}\text { diluen } \\
\mathrm{t}\end{array}$ & $\begin{array}{c}\text { diluen } \\
\mathrm{t} \%\end{array}$ & $\begin{array}{c}\text { Pin } \\
\text { (bar) }\end{array}$ & ST ( $\left.{ }^{\circ} \mathrm{BTDC}\right)$ \\
\hline 1500 & $0.8,1.0$ & $\mathrm{CO}_{2}$ & 40 & 1 & -27 \\
\hline 1500 & $0.8,1.0$ & $\mathrm{CO}_{2}$ & 40 & 1 & -24 \\
\hline 1500 & $0.8,1.0$ & $\mathrm{CO}_{2}$ & 40 & 1 & -21 \\
\hline 1500 & $0.8,1.0$ & $\mathrm{CO}_{2}$ & 40 & 1 & -18 \\
\hline 1500 & $0.8,1.0$ & $\mathrm{CO}_{2}$ & 40 & 1 & -15 \\
\hline 1500 & $0.8,1.0$ & $\mathrm{CO}_{2}$ & 40 & 1 & -12 \\
\hline 1500 & $0.8,1.0$ & $\mathrm{CO}_{2}$ & 40 & 1 & -9 \\
\hline
\end{tabular}

Figure 146 shows the effect of spark timing on cylinder pressure, heat release rate and mass fraction burned. As expected, the retarding of spark timing reduced the peak cylinder pressure and retarded the phasing where peak cylinder pressure was observed. As an example, the retarding of the spark timing from $27{ }^{\circ} \mathrm{CA}$ BTDC to $9{ }^{\circ} \mathrm{CA}$ BTDC reduced the peak cylinder pressure from 61.56 bar to 33.78 bar (Figure 147), and retarded the phasing of the peak cylinder pressure from $8.5^{\circ} \mathrm{CA}$ ATDC to $22.84{ }^{\circ} \mathrm{CA}$ ATDC. The reduction in peak cylinder pressure was due to the retarding the heat release process as shown in Figure 148. The retarding of the spark timing also decreased the peak heat release rate observed. The retarding in heat release process was also supported by the mass fraction burned as shown in Figure 149.

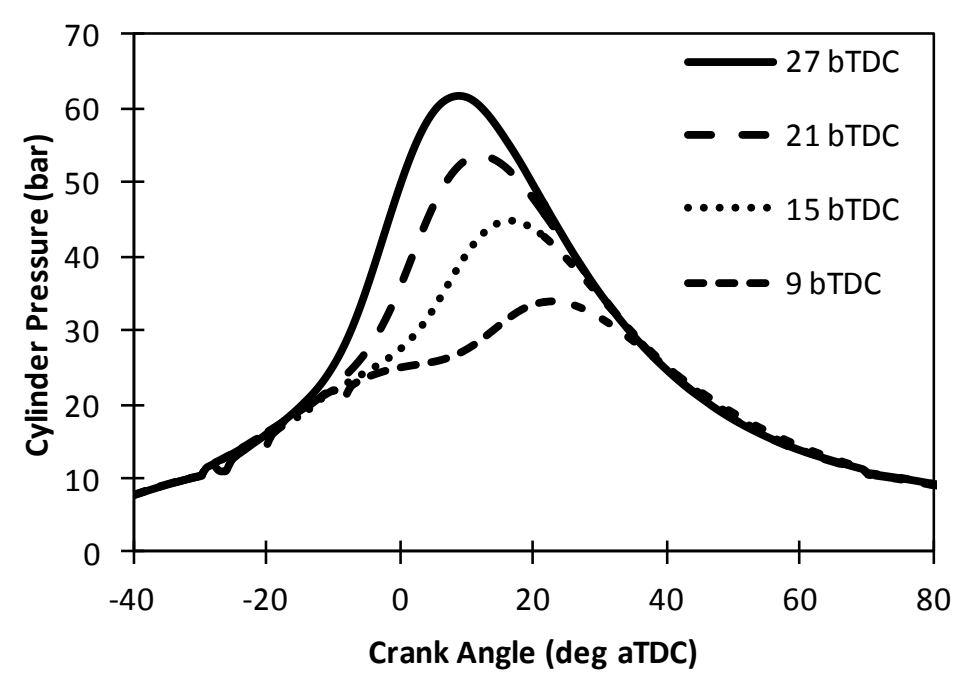

Figure 146 Effect of Spark Timing on In-Cylinder Pressure, Pin=1.0 bar, Pout=1.11 bar, $\mathrm{N}=1500 \mathrm{rpm}, \mathrm{ER}=\mathbf{0 . 8}$, No Dilution 


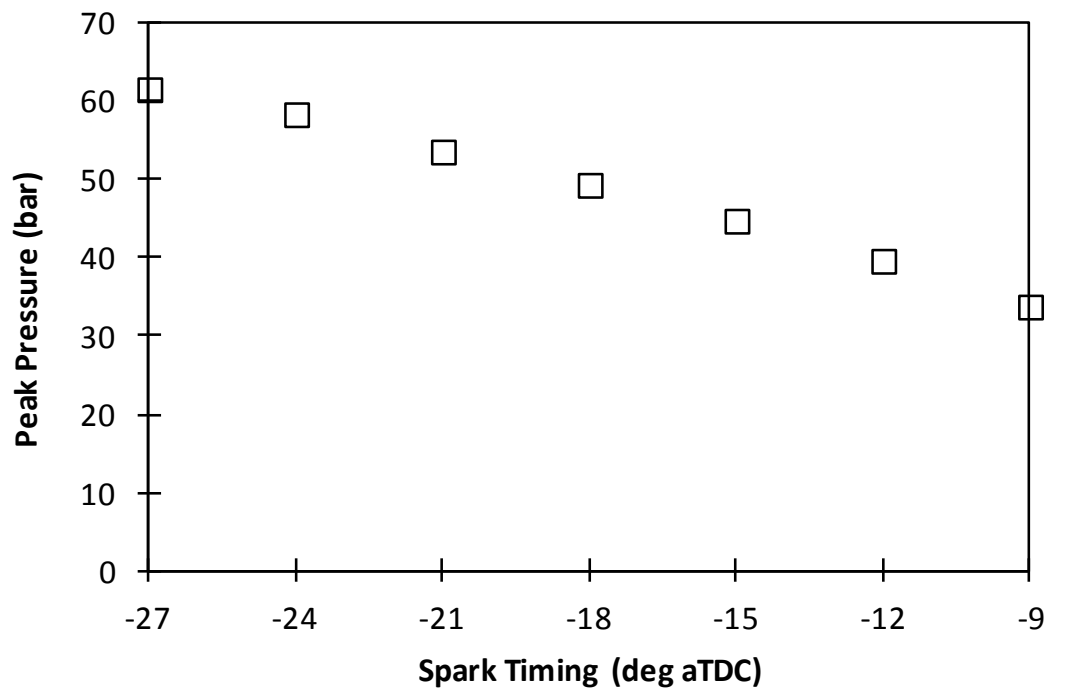

Figure 147 Effect of Spark Timing on Peak Pressure, Pin=1.0, Pout=1.11, ER=0.8

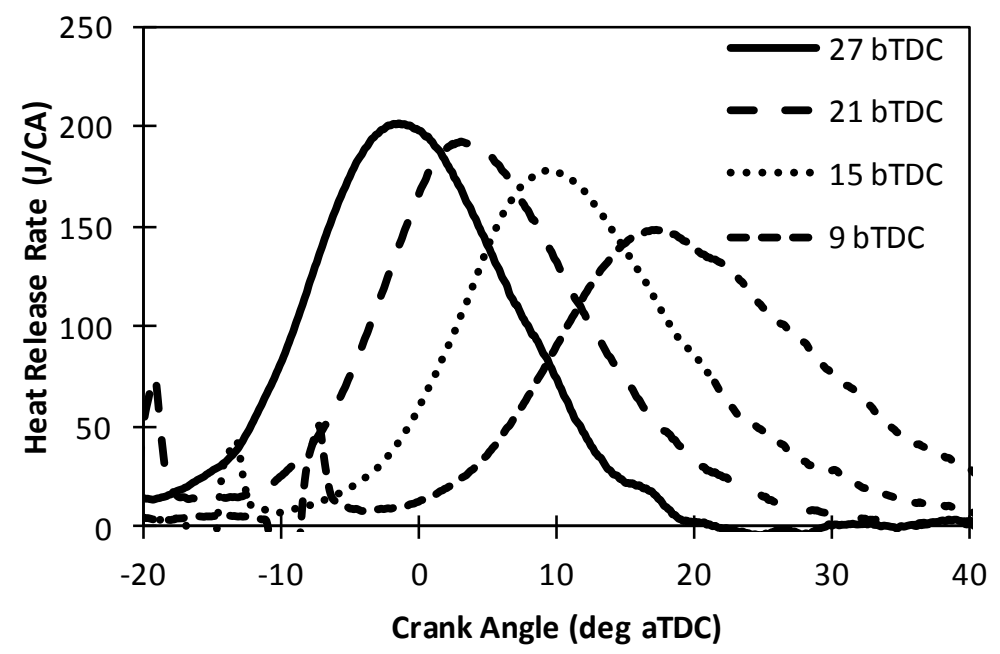

Figure 148 Effect of Spark Timing on Heat Release Rate, Pin=1.0 bar, Pout=1.11 bar, $\mathrm{N}=1500 \mathrm{rpm}, \mathrm{ER}=\mathbf{0 . 8}$, No Dilution 


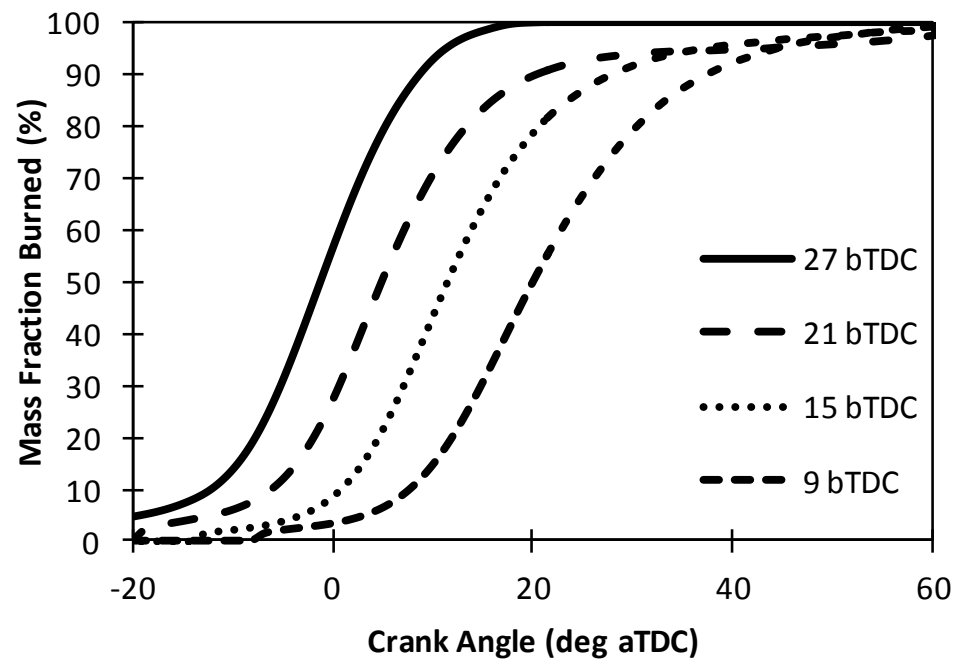

Figure 149 Effect of Spark Timing on Mass Fraction Burned, Pin=1.0 bar, Pout=1.11 bar, $\mathrm{N}=1500 \mathrm{rpm}, \mathrm{ER}=\mathbf{0 . 8}$, No Dilution

Figure 150 shows the effect of spark timing and the addition of $40 \% \mathrm{CO}_{2}$ on the engine performance, combustion process parameter and exhaust emissions. As shown in Figure 150, the advancing of the ignition timing from 9 to $21^{\circ} \mathrm{CA}$ BTDC gradually improve the engine power output as indicated by the gradually increased BMEP.

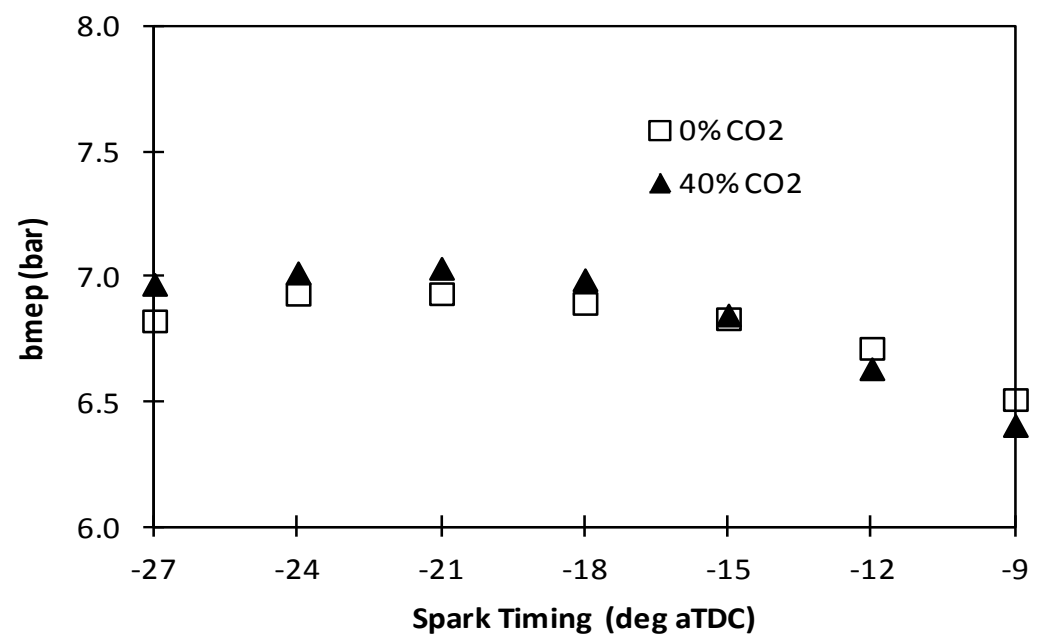

Figure 150 Effect of Spark Timing on BMEP, Pin=1.0, Pout=1.11, ER=0.8 


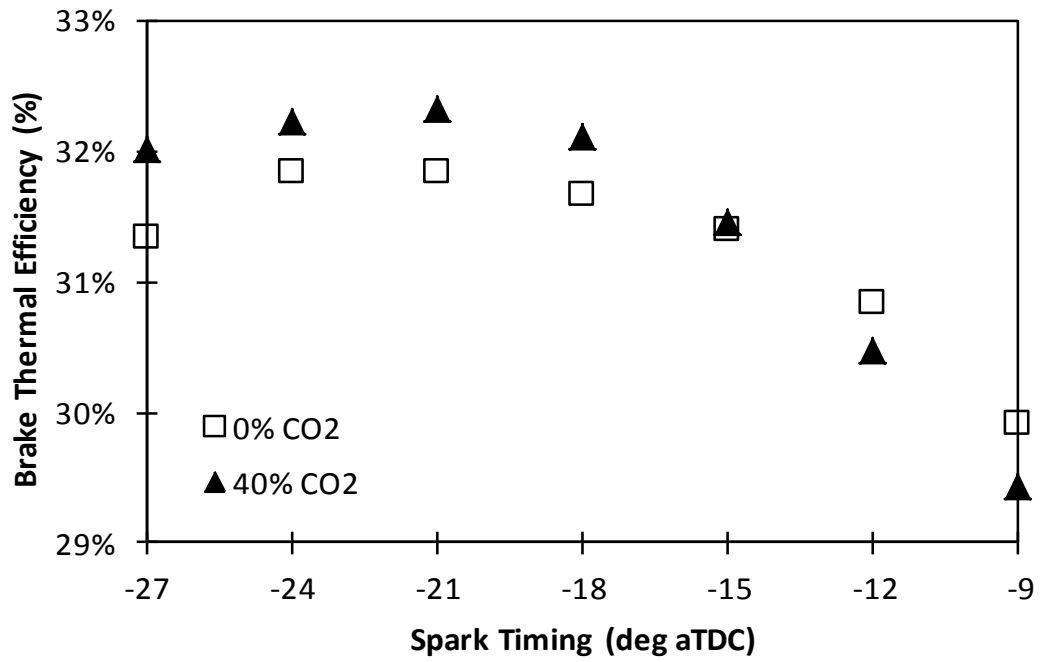

Figure 151 Effect of Spark Timing on Thermal Efficiency, Pin=1.0, Pout=1.11, ER=0.8

The improvement to engine power was due to the improvement in thermal efficiency as shown in Figure 151. For example, when operated without the addition of $\mathrm{CO}_{2}$, the advancing of the spark timing from 9 to $21{ }^{\circ} \mathrm{CA}$ BTDC improved the thermal efficiency from $29.90 \%$ to $31.85 \%$ (+6.52\%). When operated with the addition of $40 \% \mathrm{CO}_{2}$ in natural gas, the advancing of the spark timing from 9 to $21{ }^{\circ} \mathrm{CA}$ BTDC improved the thermal efficiency from $29.43 \%$ to $32.32 \%$ $(+9.82 \%)$. It was also found that the addition of $40 \% \mathrm{CO}_{2}$ into natural gas improved the maximum thermal efficiency when operated at advanced spark timing ( $>15^{\circ} \mathrm{CA}$ BTDC). As an example, the addition of $40 \% \mathrm{CO}_{2}$ to natural gas increased the maximum thermal efficiency from $31.85 \%$ and $32.32 \%$, which was improved by $1.5 \%$.

Figure 152 shows the effect of spark timing on the IMEP calculated using the cylinder pressure. Advancing the spark timing gradually increased the IMEP due to the advancement of combustion phasing toward the optimal one. As expected, the addition of $40 \% \mathrm{CO}_{2}$ reduced the IMEP (Figure 152 and peak cylinder pressure (Figure 153). As shown in Figure 154, the advancing of spark timing was found to decrease the ignition delay, which would further advance the phasing of combustion. The effect of spark timing on combustion duration can be found in Figure 155. 


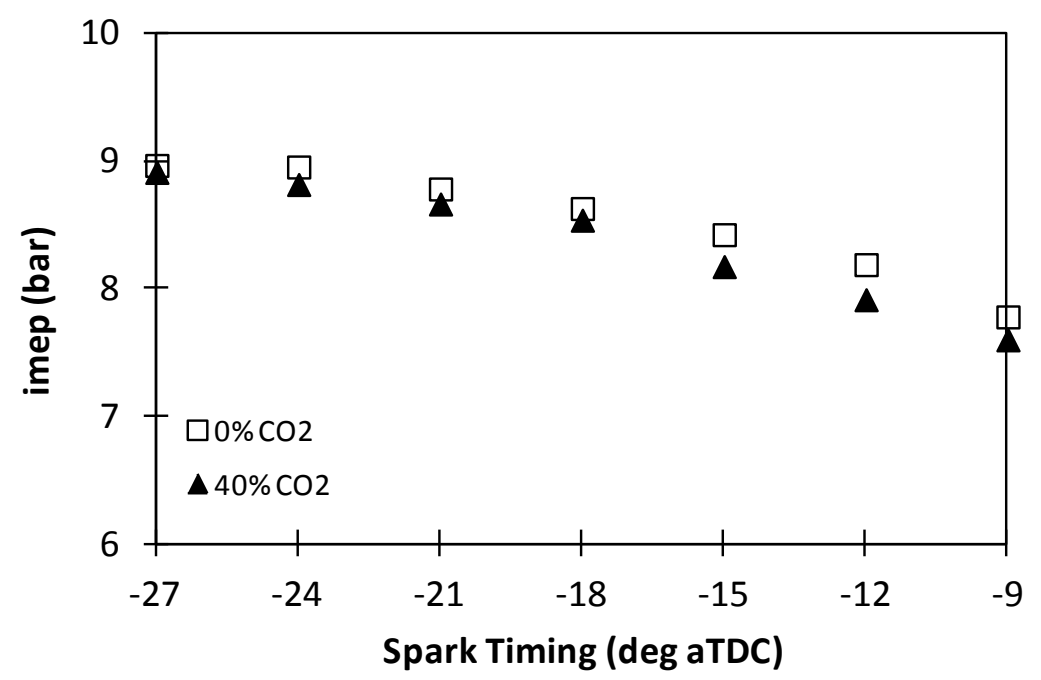

Figure 152 Effect of Spark Timing on IMEP, Pin=1.0, Pout=1.11, ER=0.8

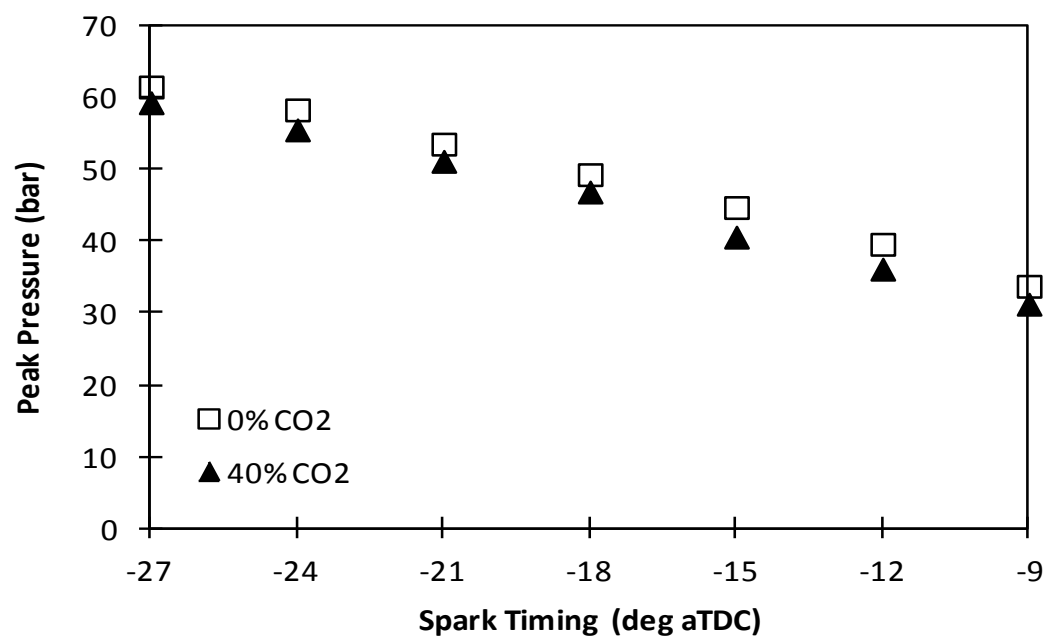

Figure 153 Effect of Spark Timing on Peak Pressure, Pin=1.0, Pout=1.11, ER=0.8 


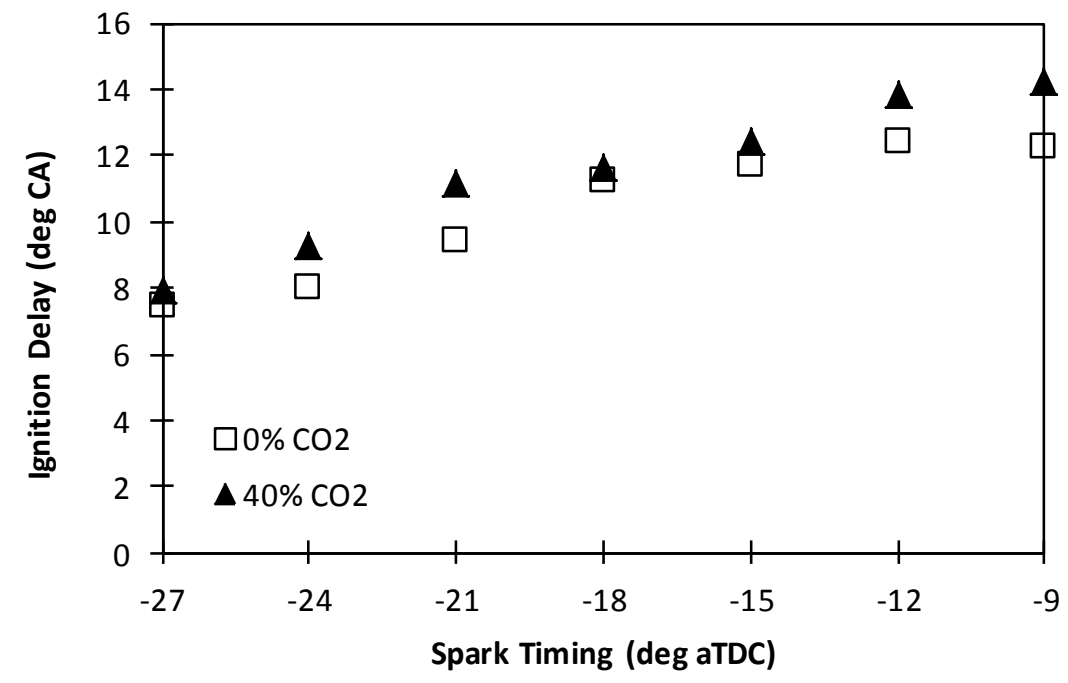

Figure 154 Effect of Spark Timing on Ignition Delay, Pin=1.0, Pout=1.11, ER=0.8

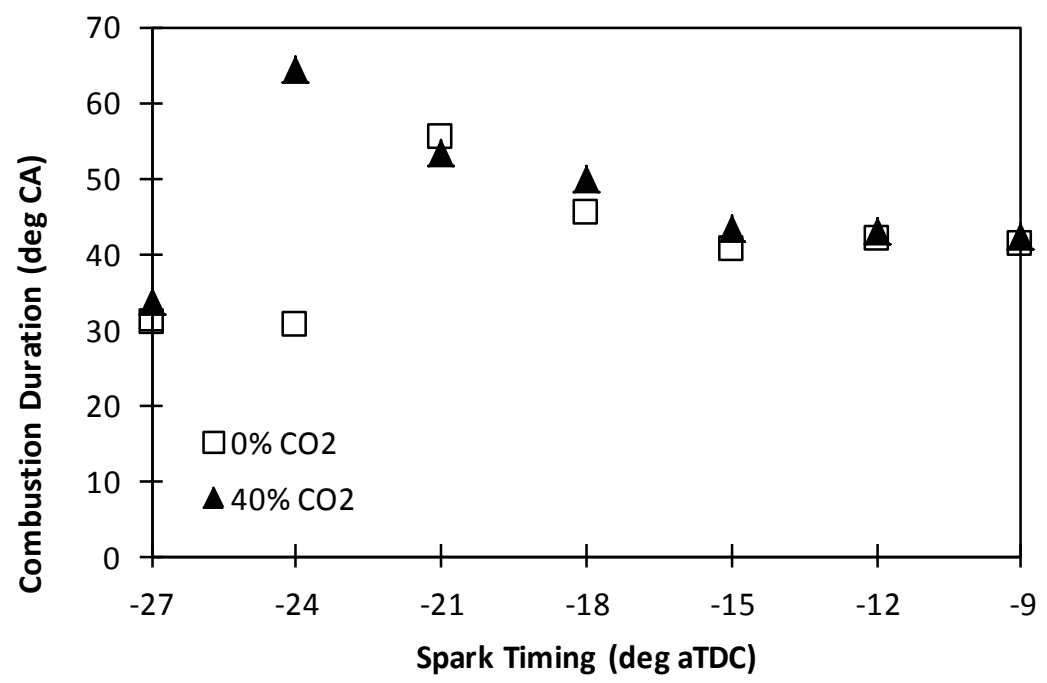

Figure 155 Effect of Spark Timing on Ignition Delay, Pin=1.0, Pout=1.11, ER=0.8

Figure 156 shows the effect of spark timing on $\mathrm{NO}_{\mathrm{x}}$ emissions. As expected Advancing the spark timing was found to increase the emissions of NOx due to the increased temperature of combustion products resulted from the advancing of phasing of combustion process as shown earlier. As $\mathrm{NO}_{\mathrm{x}}$ emissions was one of the main pollutants regulated by emissions regulations, the reduction of NOx emissions through either EGR or SCR technology usually results in decrease in thermal efficiency. Accordingly, the spark timing of spark ignition engine needs optimized to obtain the best compromise between the thermal efficiency and $\mathrm{NO}_{\mathrm{x}}$ emissions. 


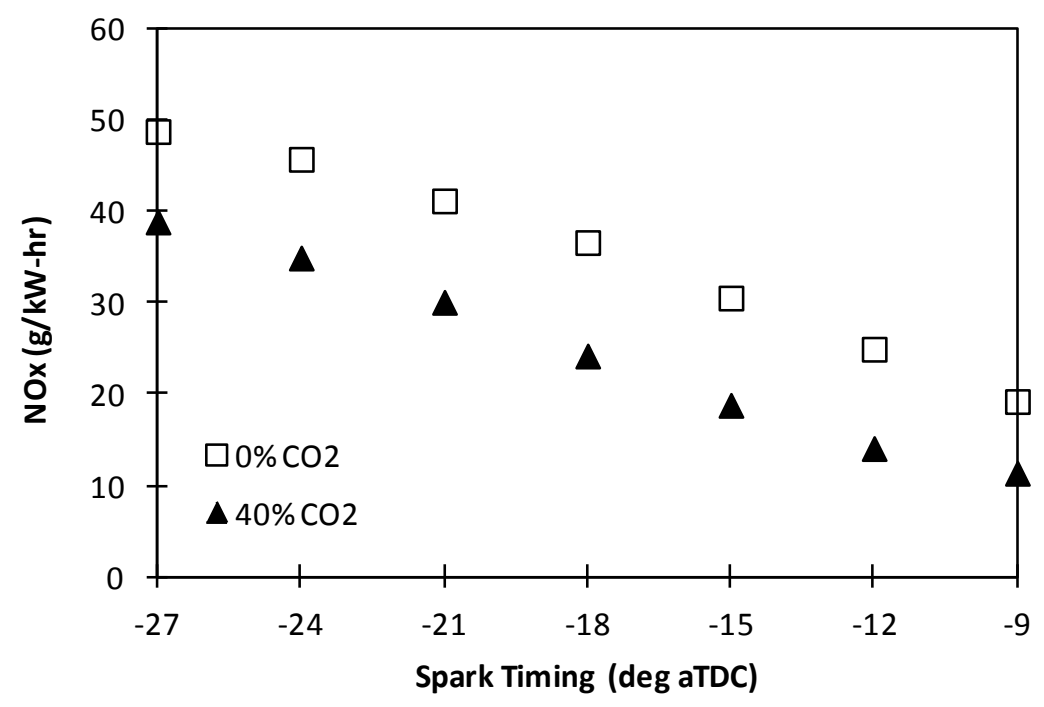

Figure 156 Effect of Spark Timing on NOx Emissions, Pin=1.0, Pout=1.11, ER=0.8

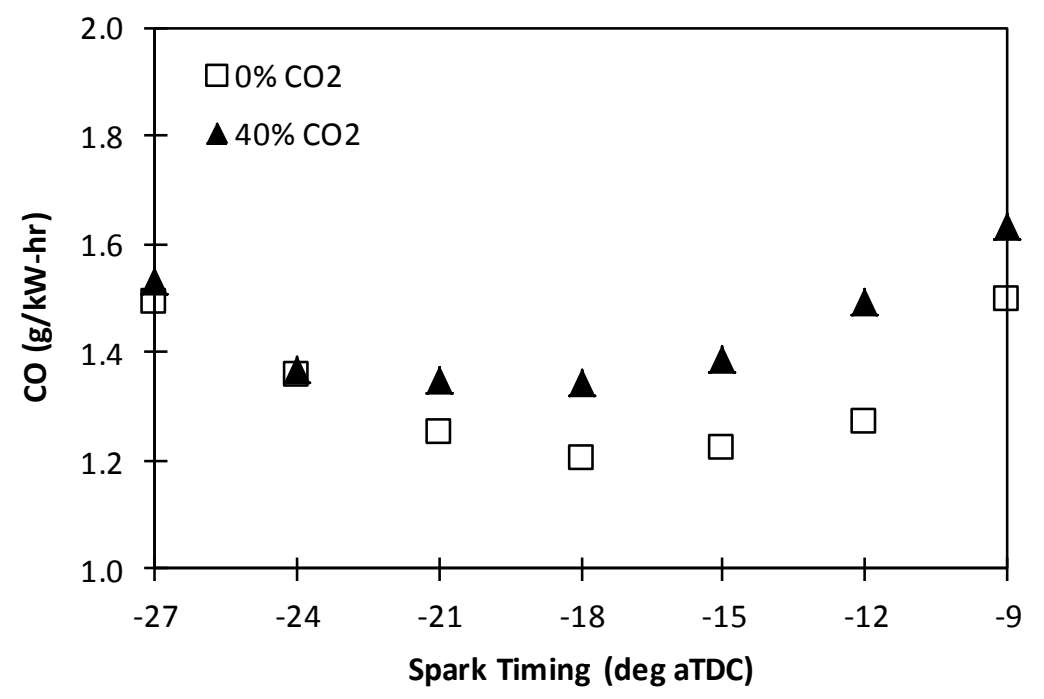

Figure 157 Effect of Spark Timing on CO Emissions, Pin=1.0, Pout=1.11, ER=0.8

Figure 157 shows the effect of spark timing on the emissions of CO. Advancing the spark timing was found to reduce $\mathrm{CO}$ emissions until the observation of minimum $\mathrm{CO}$ emission at spark timing of $18{ }^{\circ} \mathrm{CA}$ BTDC. Further advancing the spark timing increased the emissions of CO.

Figure 158 shows the effect of spark timing on HC emissions. Advanced spark timing was shown to increase the emissions of HC. This was due to the increase in cylinder pressure, which compressed more unburned air/fuel mixture to the crevice of the combustion chamber, one major source of HC emissions. 


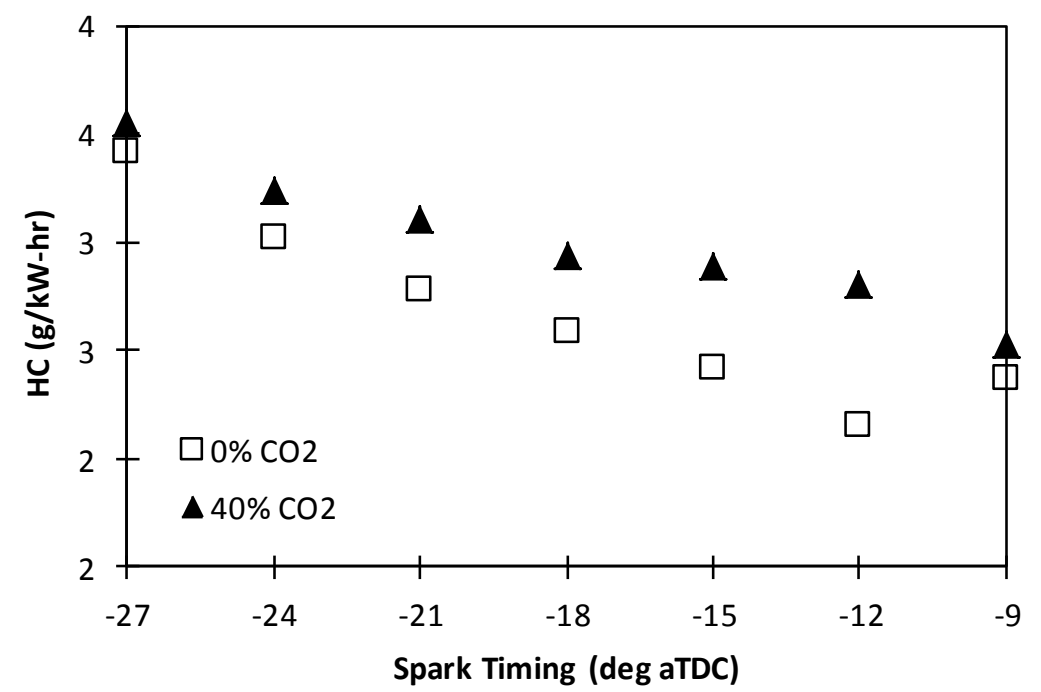

Figure 158 Effect of Spark Timing on HC Emissions, Pin=1.0, Pout=1.1, ER=0.8

Figure 159 shows the effect of spark timing on the emission of $\mathrm{CO}_{2}$. In this research, the $\mathrm{CO}_{2}$ added to intake mixture as diluents has been deducted when calculating $\mathrm{CO}_{2}$ emissions. As shown in Figure 159, advancing the spark timing was shown to dramatically reduce the emissions of $\mathrm{CO}_{2}$ due to the improvement in the brake thermal efficiency shown earlier. The minimum $\mathrm{CO}_{2}$ emissions were observed at 21 and $24{ }^{\circ} \mathrm{CA}$ ATDC operated with and without the addition of $\mathrm{CO}_{2}$ into natural gas. Further advancing the spark timing would increase the emissions of $\mathrm{CO}_{2}$. As shown in 159, the addition of $40 \% \mathrm{CO}_{2}$ to natural gas increased the emissions of $\mathrm{CO}_{2}$ when operated at retarded spark timing but reduced the $\mathrm{CO}_{2}$ emissions when operated at advanced spark timing.

The emissions of $\mathrm{HC}, \mathrm{CO}$ and $\mathrm{CO}_{2}$ were further processed to calculate the combustion efficiency of natural gas. As shown in Figure 160, the effect of spark timing on combustion efficiency of natural gas was mild. The addition of $40 \% \mathrm{CO}_{2}$ to natural gas slightly reduced the combustion efficiency of natural gas. 


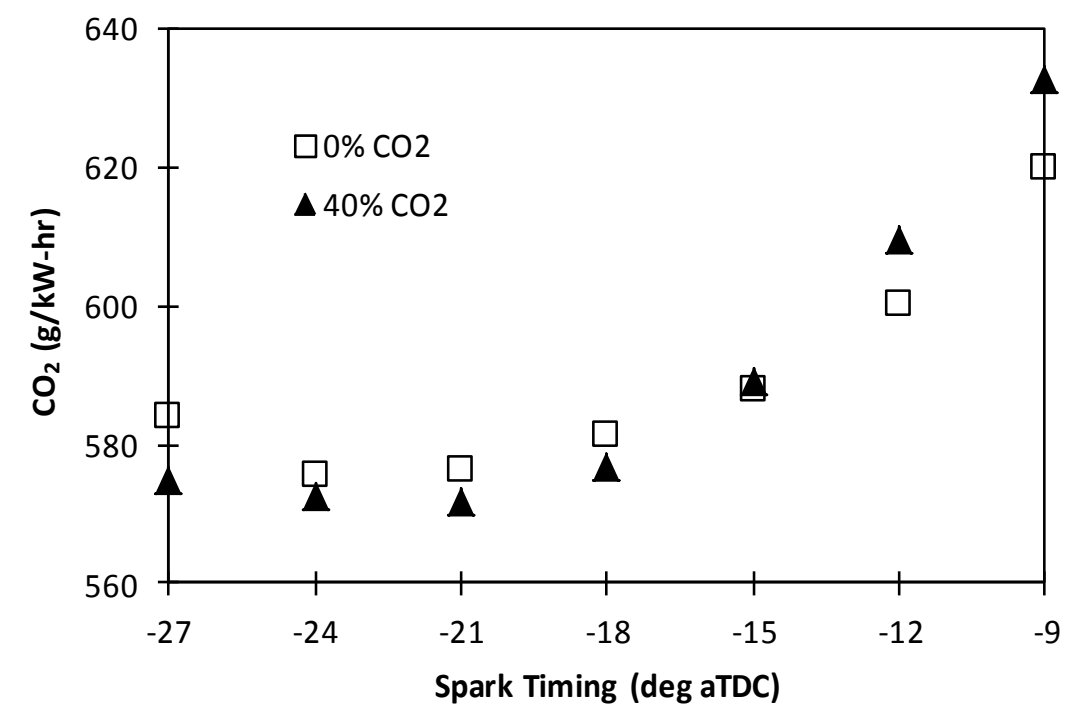

Figure 159 Effect of Spark Timing on CO2 Emissions, Pin=1.0, Pout=1.1, ER=0.8

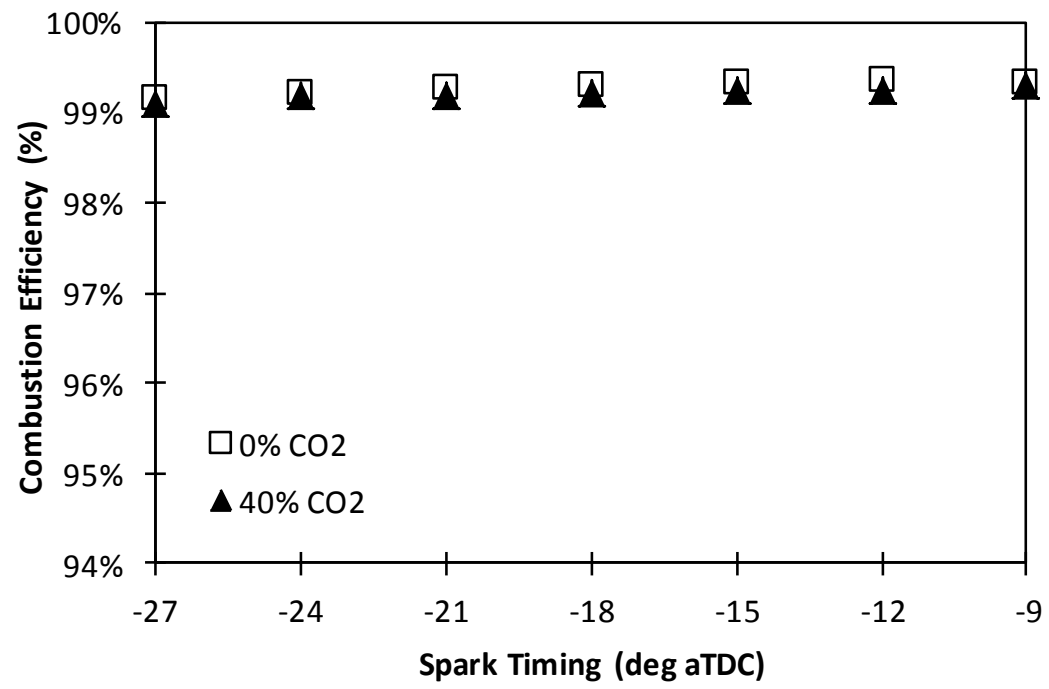

Figure 160 Effect of Spark Timing on Combustion Efficiency, Pin=1.0, Pout=1.11, $\mathrm{ER}=0.8$

Figure 161 shows the effect of spark timing on the combustion stability. Advancing the spark timing slightly decreased the COV of IMEP indicating the minor improvement to combustion stability. As shown in Figure 161, the effect of the addition of $40 \% \mathrm{CO}_{2}$ to natural has had mild effect on combustion stability. 


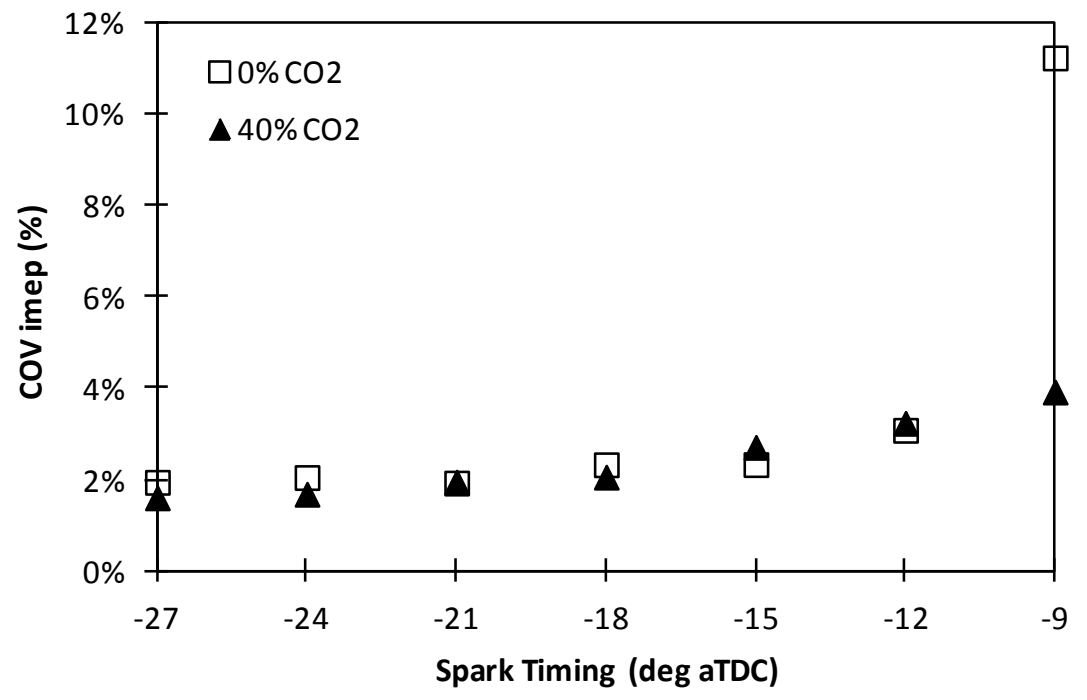

Figure 161 Effect of Spark Timing on COV IMEP, Pin=1.0, Pout=1.11, ER=0.8

Figures 162 to 173 show the effect of spark timing on engine performance, combustion process, exhaust emissions and combustion stability at stoichiometric operation. As shown in Figure 162, advancing spark timing was shown to increase the power output (BMEP) when operated with and without the addition of $40 \% \mathrm{CO}_{2}$. The maximum engine load was found at spark timing of $21^{\circ} \mathrm{CA}$ ATDC. The improved power was due to the improvement to the brake thermal efficiency as shown in Figure 163.

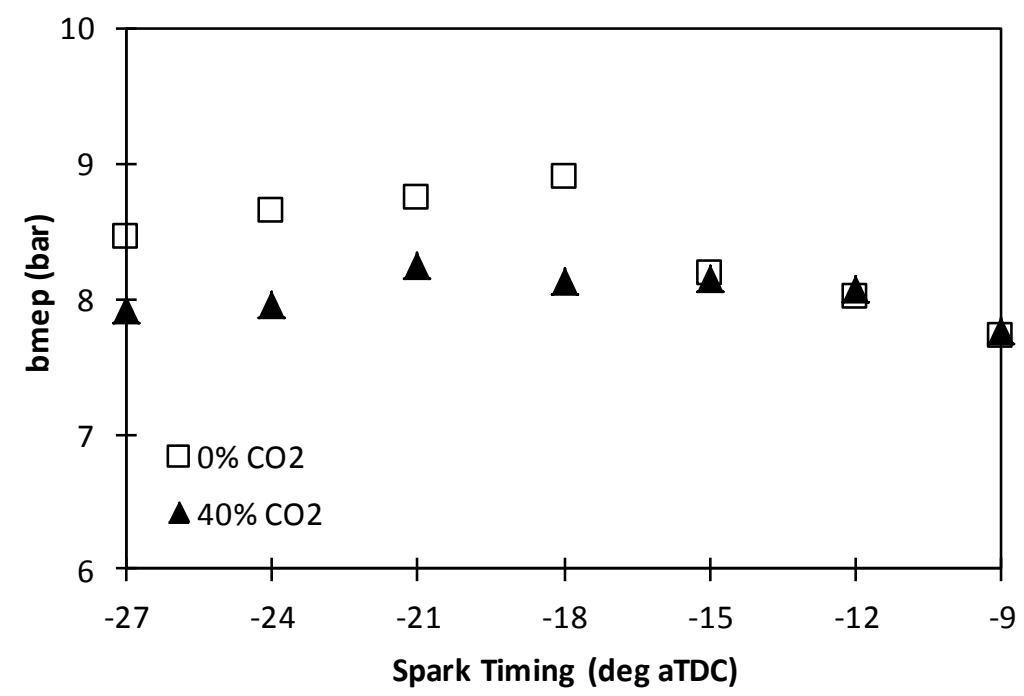

Figure 162 Effect of Spark Timing on BMEP, Pin=1.0, Pout=1.11, ER=1.0 


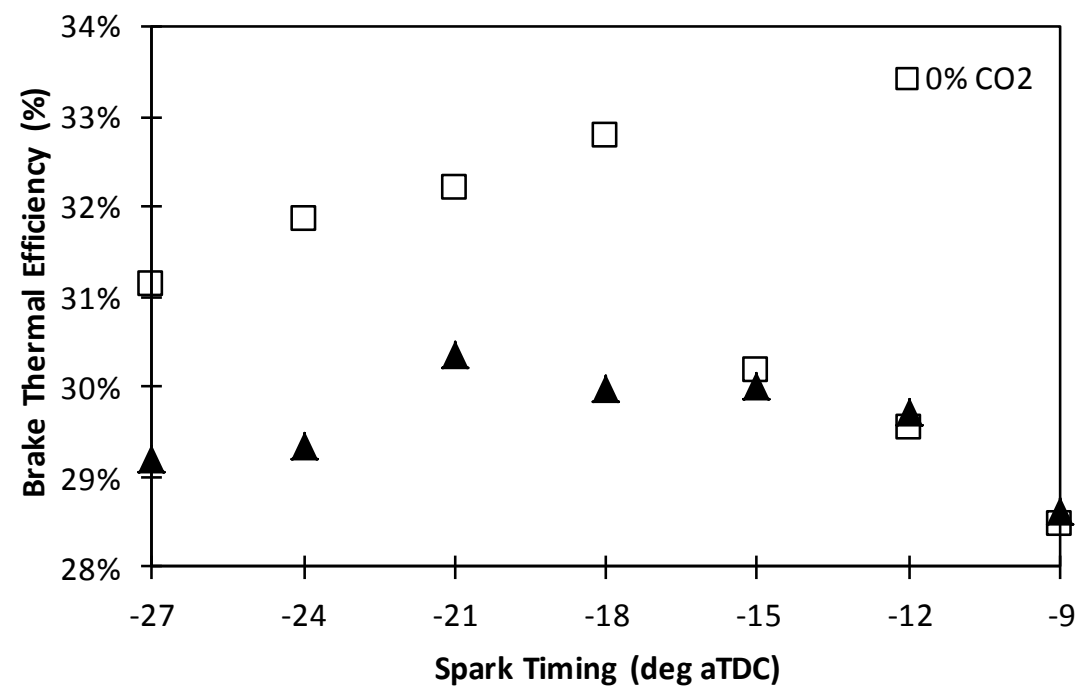

Figure 163 Effect of Spark Timing on Thermal Efficiency, Pin=1.0, Pout=1.11, ER=1.0

Figure 164 shows the effect of spark timing on the IMEP calculated using the cylinder pressure. Advancing the spark timing gradually increased the IMEP due to the advancement of combustion phasing toward the optimal one. As expected, the addition of $40 \% \mathrm{CO}_{2}$ reduced the IMEP (Figure 164) and peak cylinder pressure (Figure 165). The advancing of spark timing from $9^{\circ}$ to $27^{\circ} \mathrm{CA}$ BTDC increased the peak cylinder pressure from 40.40 bar to 72.66 bar.

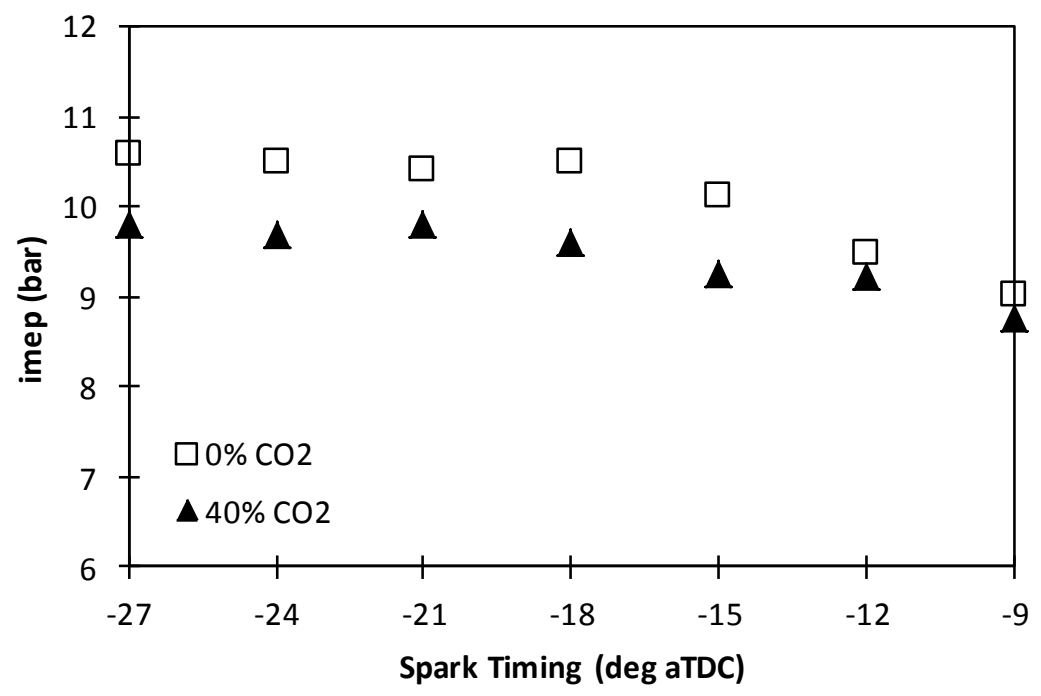

Figure 164 Effect of Spark Timing on IMEP, Pin=1.0, Pout=1.11, ER=1.0 


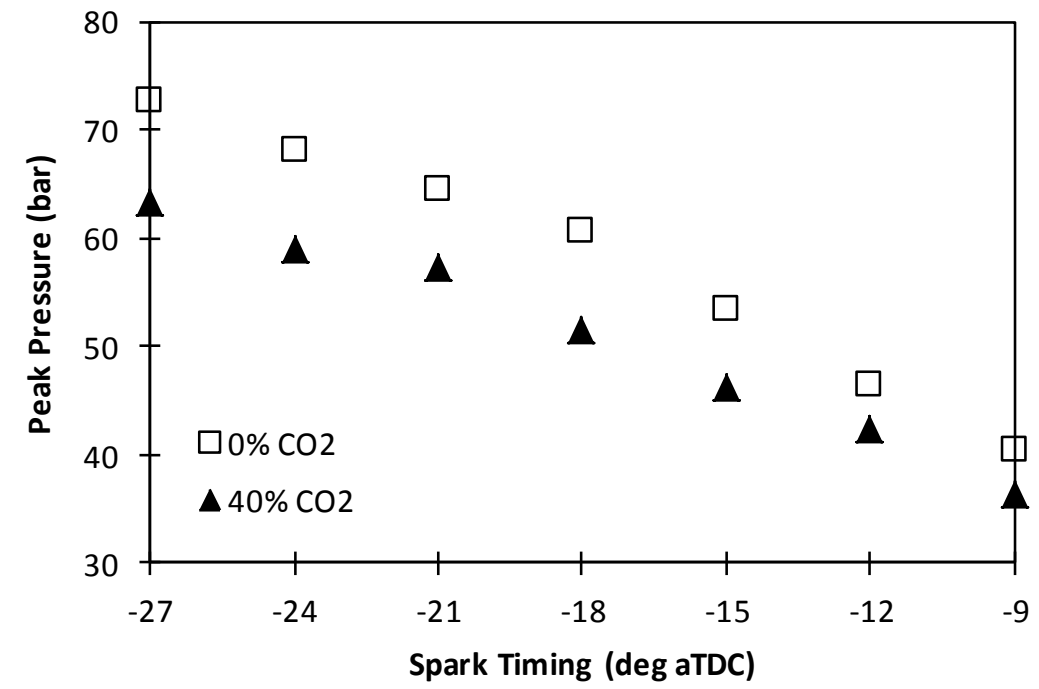

Figure 165 Effect of Spark Timing on Peak Pressure, Pin=1.0, Pout=1.11, ST=15 bTDC, $E R=1.0$

As shown in Figure 166, the advancing of spark timing was found to decrease the ignition delay, which would further advance the phasing of combustion. The effect of spark timing on combustion duration can be found in Figure 167.

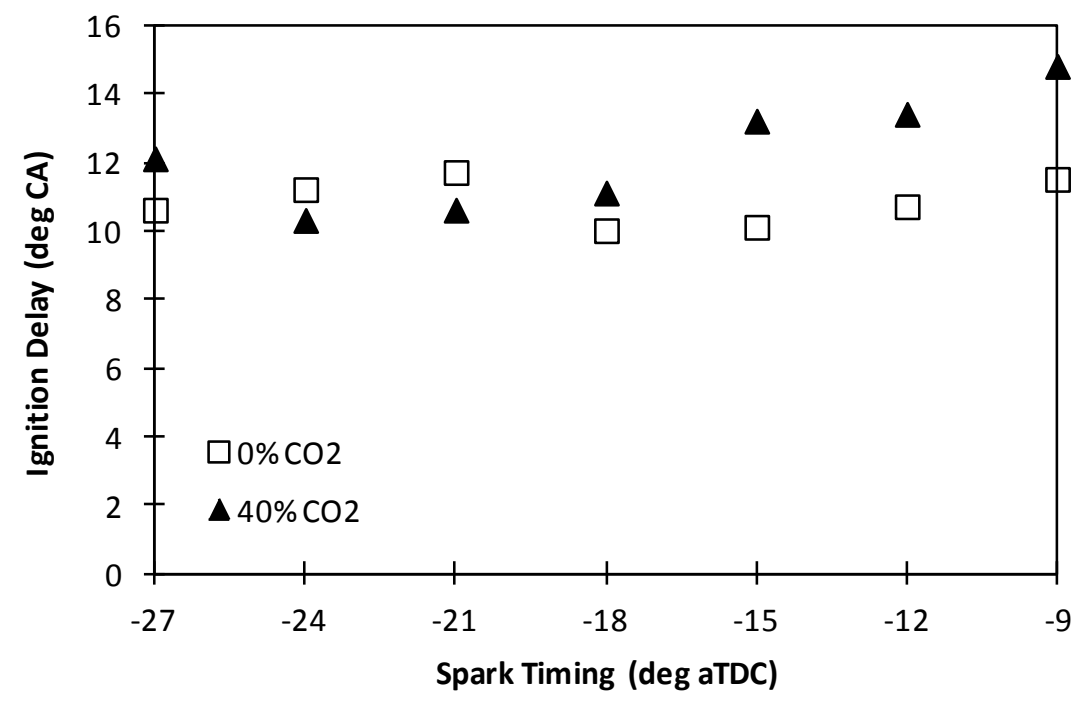

Figure 166 Effect of Spark Timing on Ignition Delay, Pin=1.0, Pout=1.11, ER=1.0 


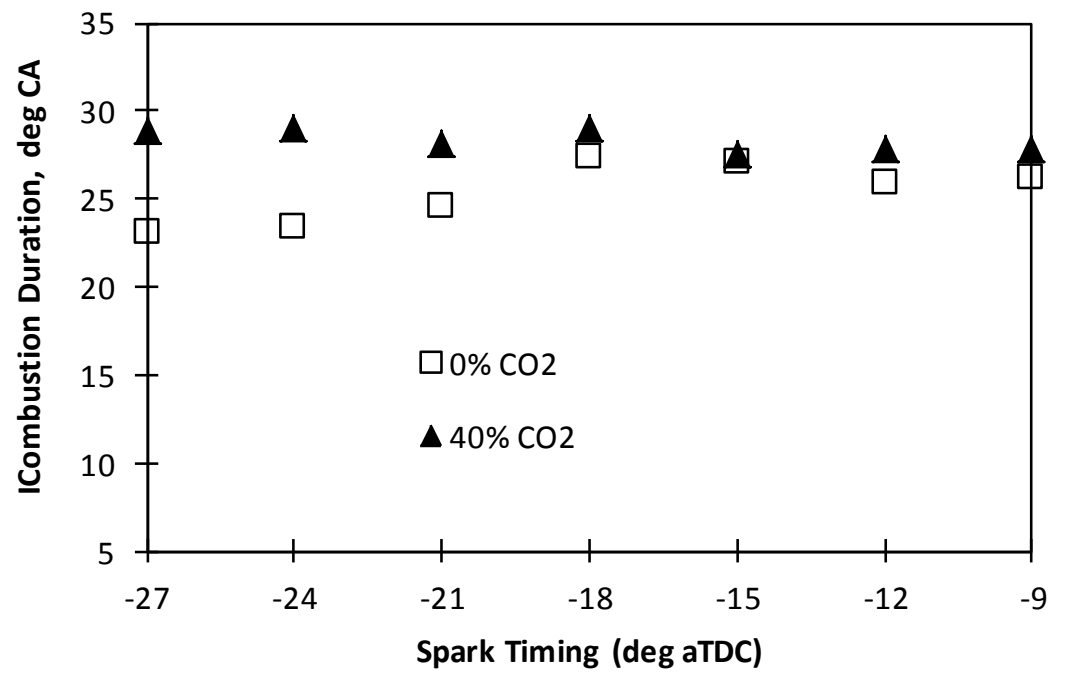

Figure 167 Effect of Spark Timing on Combustion Duration, Pin=1.0, Pout=1.11, ER=1.0

Figure 168 shows the effect of spark timing on $\mathrm{NO}_{\mathrm{x}}$ emissions. As expected, advancing the spark timing was found to significantly increase the emissions of $\mathrm{NO}_{2}$ at stoichiometric operation without the addition of $\mathrm{CO}_{2}$. However, with the addition of $\mathrm{CO}_{2}$, the effect of spark timing on $\mathrm{NO}_{\mathrm{x}}$ emissions at stoichiometric operation was mild.

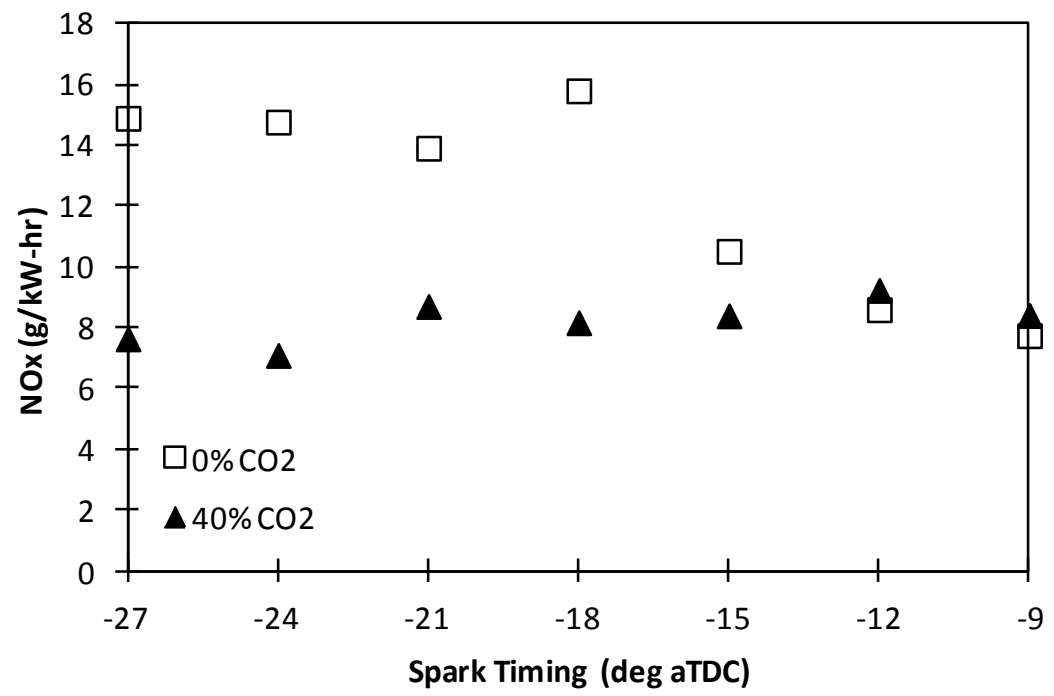

Figure 168 Effect of Spark Timing on NOx Emissions, Pin=1.0, Pout=1.1, ER=1.0

Figure 169 shows the effect of spark timing on the emissions of CO. Advancing the spark timing was found to gradually reduce $\mathrm{CO}$ emissions at stoichiometric operation without the addition of $\mathrm{CO}_{2}$. With the addition of $40 \% \mathrm{CO}_{2}$ to natural gas, the advancing of spark timing was shown to increase the emissions of CO.

Figure 170 shows the effect of spark timing on HC emissions. Advanced spark timing was shown to increase the emissions of HC. This was due to the increase in cylinder pressure, which compressed more unburned air/fuel mixture to the crevice of the combustion chamber, one major source of $\mathrm{HC}$ emissions. As shown in Figure 170, the addition of $40 \% \mathrm{CO}_{2}$ increased the emissions of HC, 


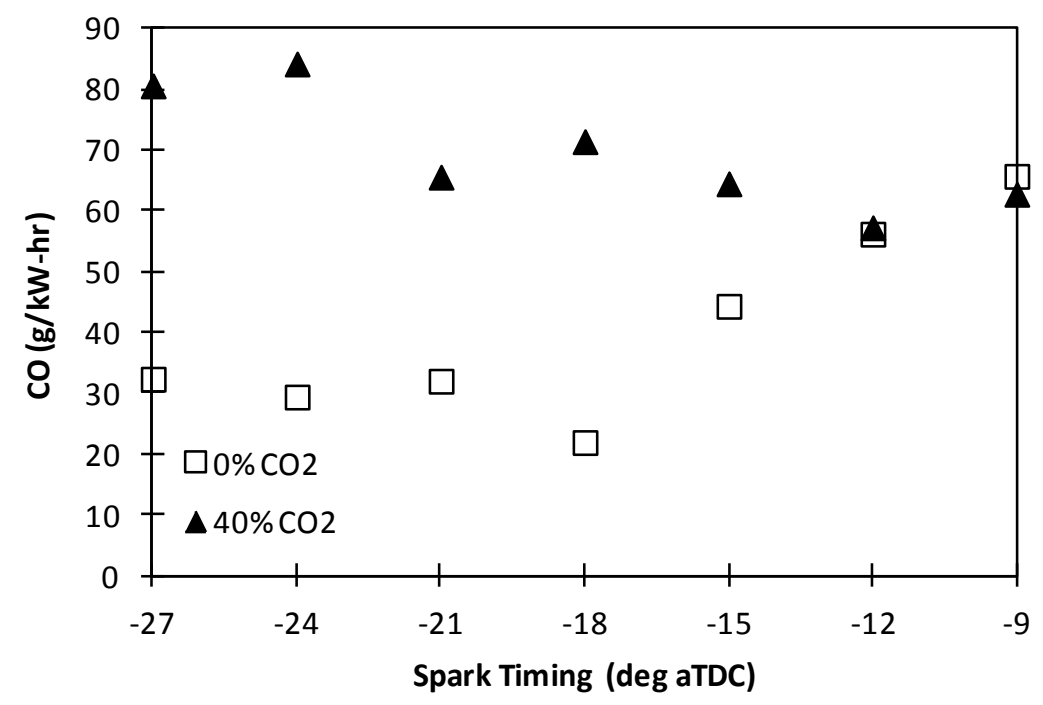

Figure 169 Effect of Spark Timing on CO Emissions, Pin=1.0, Pout=1.11, ER=1.0

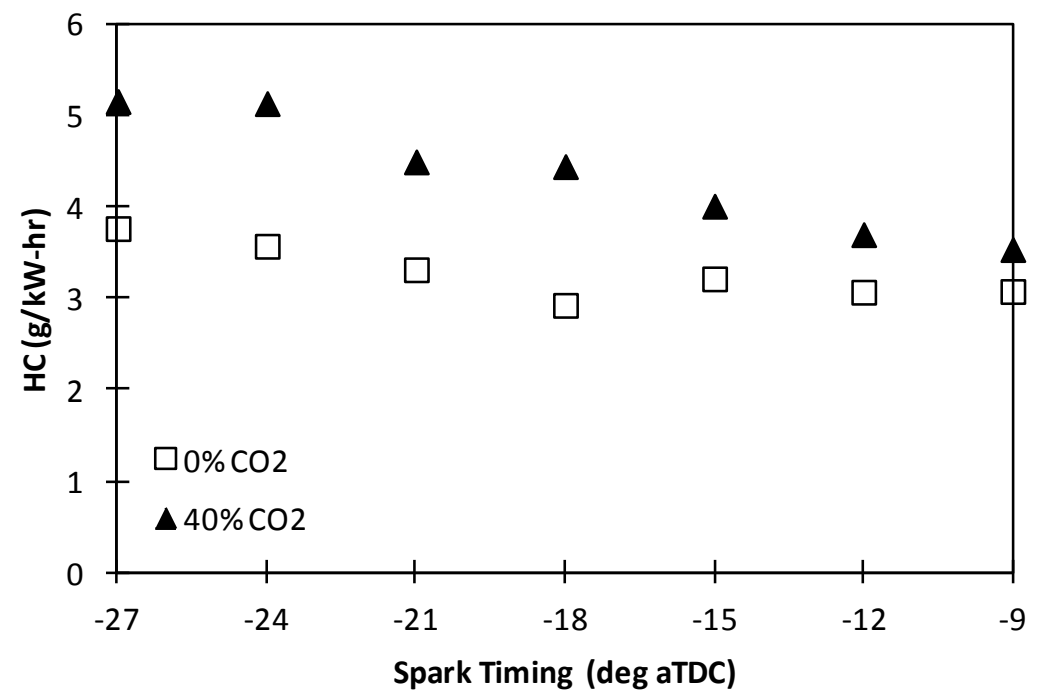

Figure 170 Effect of Spark Timing on HC Emissions, Pin=1.0, Pout=1.11, ER=1.0 


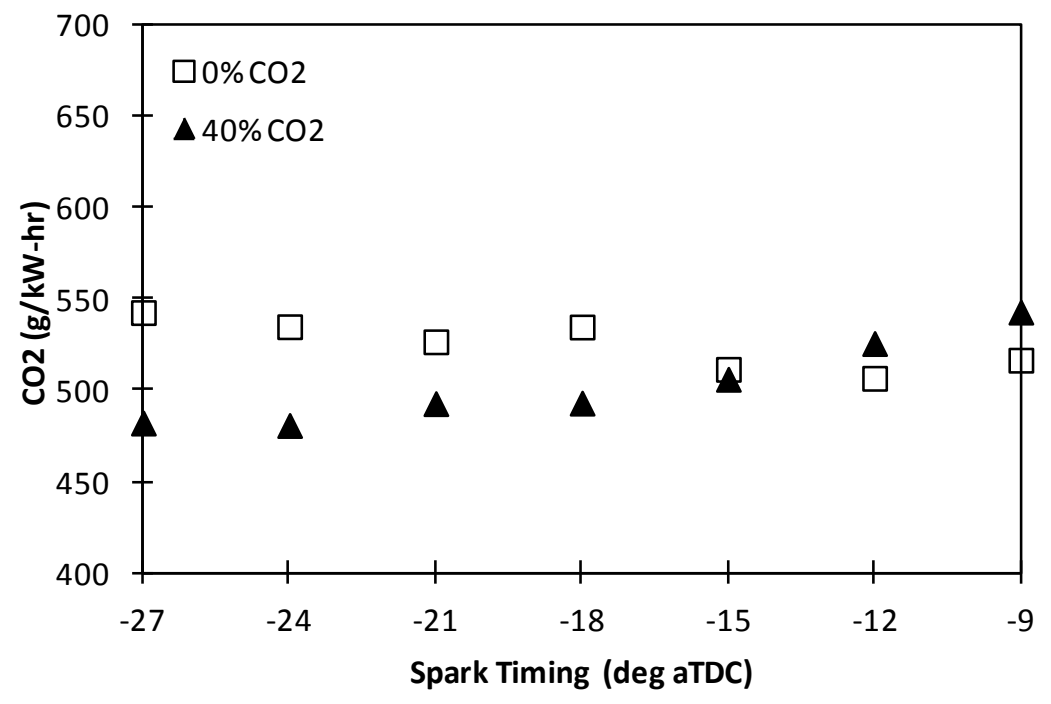

Figure 171 Effect of Spark Timing on CO2 Emissions, Pin=1.0, Pout=1.11, ER=1.0

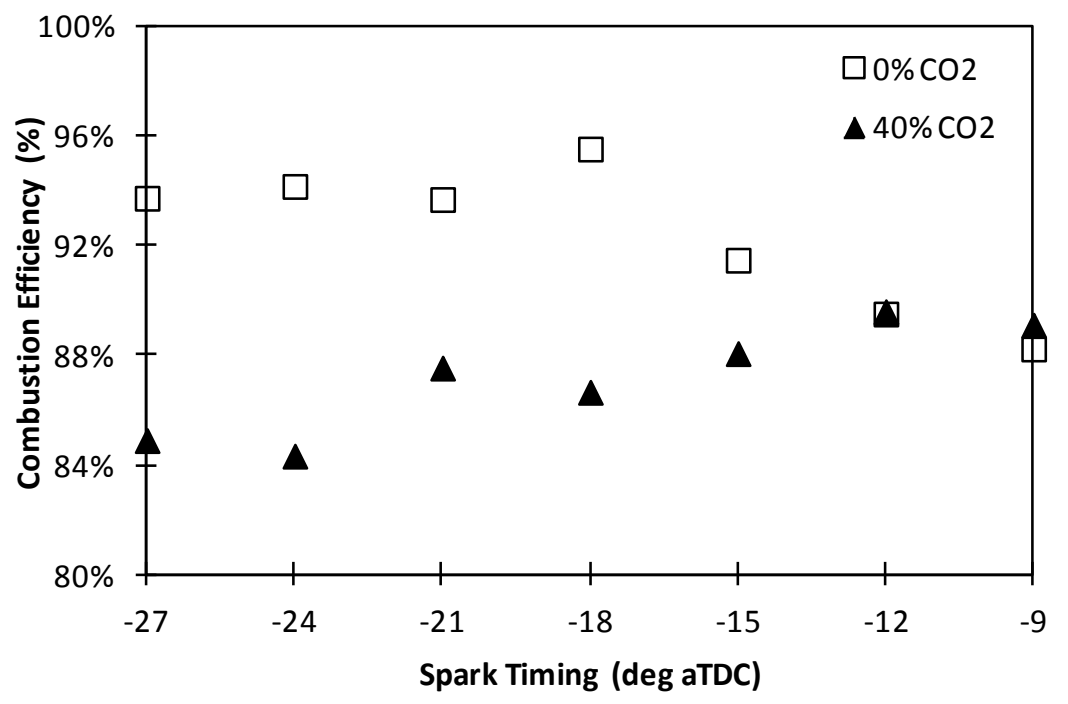

Figure 172 Effect of Spark Timing on Combustion Efficiency, Pin=1.0, Pout=1.11, $E R=1.0$

Figure 173 shows the effect of spark timing on the combustion stability. Advancing the spark timing slightly decreased the COVIMEP indicating the minor improvement to combustion stability. As shown in Figure 173, the addition of $40 \% \mathrm{CO}_{2}$ to natural slightly increased the observed COV of IMEP. 


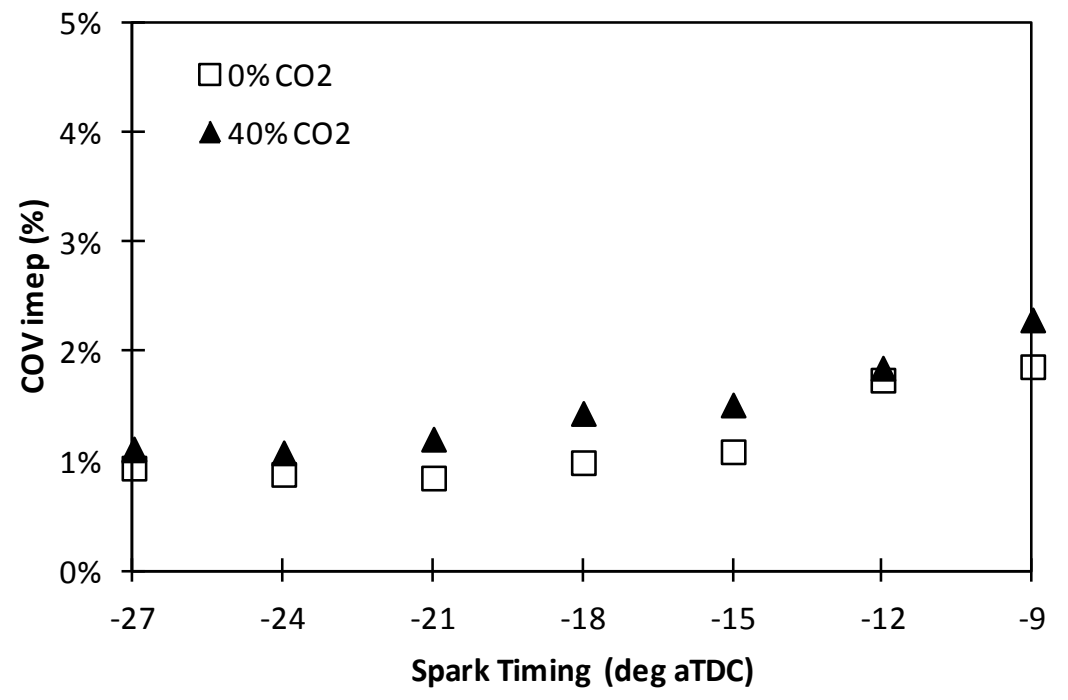

Figure 173 Effect of Spark Timing on COV ${ }_{\text {IMEP }}, P_{\text {in }}=1.0, P_{\text {out }}=1.11, E R=1.0$ 


\subsection{Prototype Commercial Gas Quality Sensor for Opportunity Fueled Engines}

GTI has licensed its patents and know-how for the GQS for opportunity fueled internal combustion reciprocating engines to CMR Group. GTI and CMR also executed an agreement for joint development of the commercial GQS for this field of use. Efforts to begin the joint development have been delayed due to unforeseen issues. This development effort is now expected to begin in early 2014.

\subsection{Field Evaluation of Integrated fuel gas cleanup with heat recovery on $\sim 1 \mathrm{MWe}$ engine with cooled EGR and Advanced Engine Monitoring and Control System for Opportunity Fuel}

Budget that was originally allocated for this task was shifted to the development of the gas quality sensor for both biogas and producer gas opportunity fuels. 


\section{Supporting Information and Photographs}

The experimental setup utilized during the testing at Continental Controls Corp facility in Sept 2009 is shown in Figure 1. The sampling system was added to enable air/fuel mixture sampling from the engine's manifold operating under vacuum.

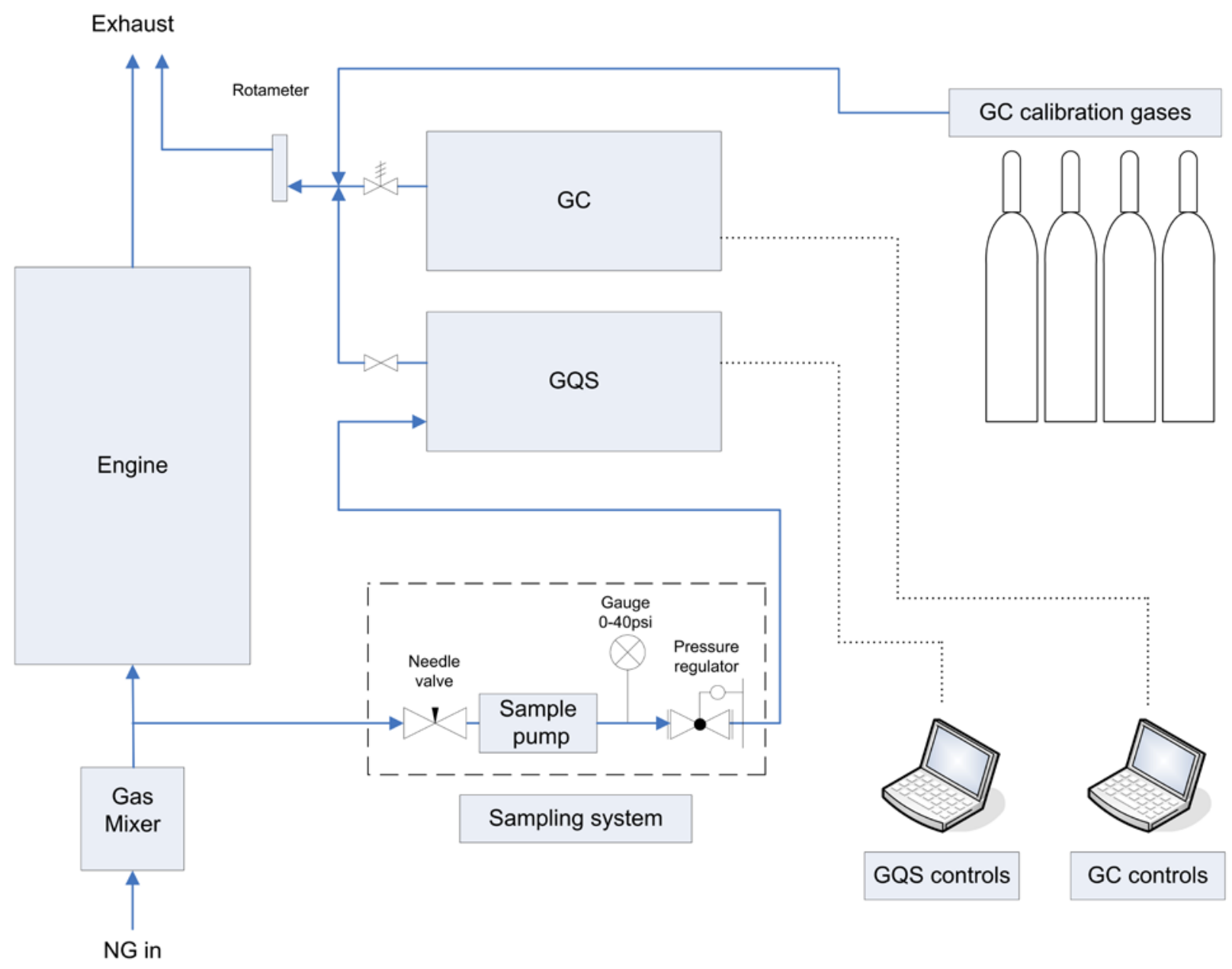

Figure 174 Experimental setup schematic

Continuous monitoring of the air/natural gas mixture composition and heating value was conducted over the entire duration of testing. The results of the monitoring are shown in Figure 2 and Figure 3. 


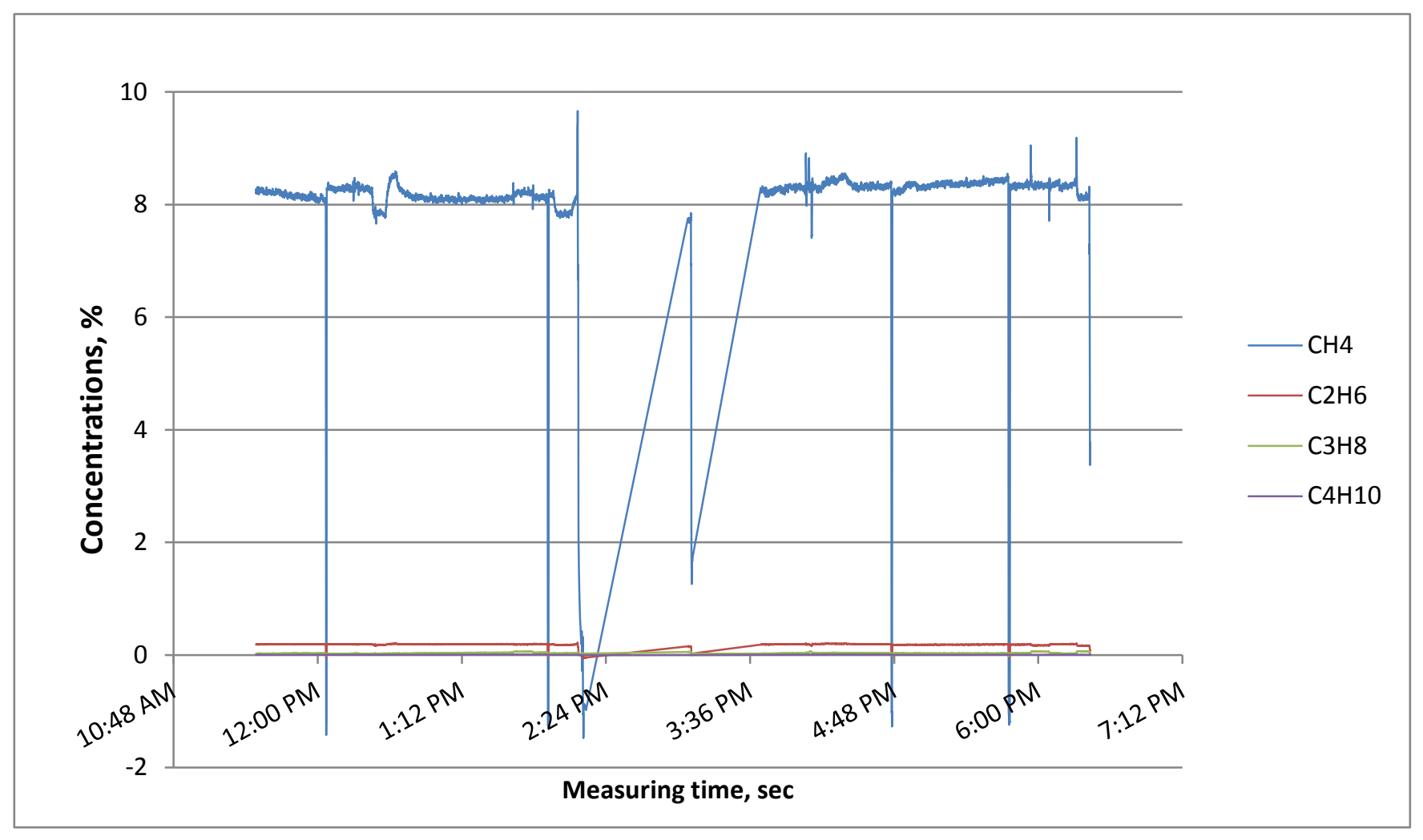

Figure 175 Hydrocarbon speciation in the air/fuel mixture 


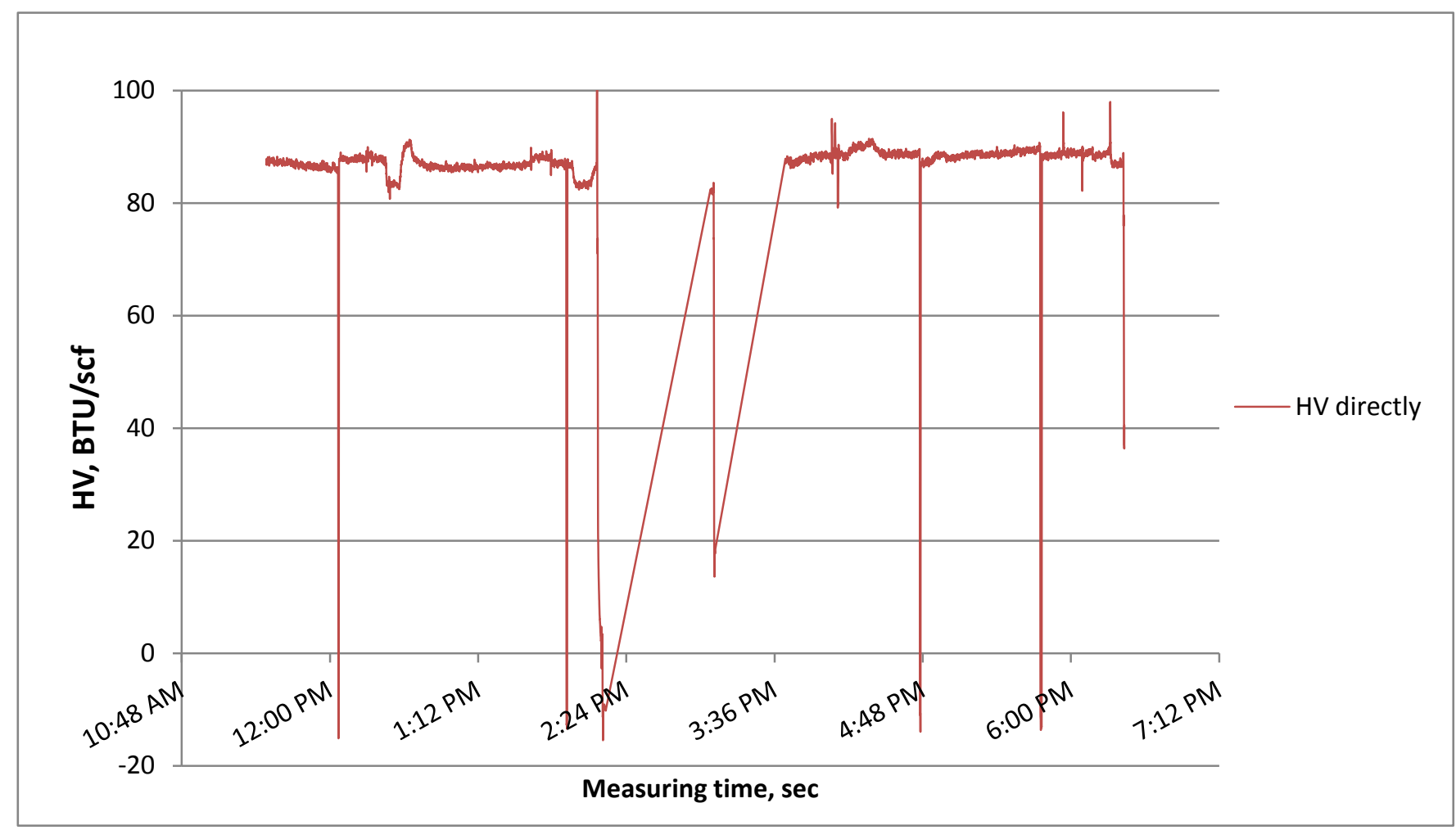

Figure 176 Airlfuel heating value

The test results showed that the GQS is capable of monitoring air/fuel mixture's HV accurately for the duration of the test and could be effectively interfaced with the engine's data. The sudden drops and spikes in the values shown in the graphs represent transitional regimes during the engine shut downs and starts as well as operation instabilities caused by load changes.

Periodic gas chromatograph sampling was conducted concurrently with the GQS monitoring during the test. The comparison of the data obtained with GC and GQS showed an excellent agreement, particularly

- Deviation of the methane concentration from the values measured with GC did exceed $0.25 \%$

- Heating values measured with GC and GQS agreed within 2 Btu range 


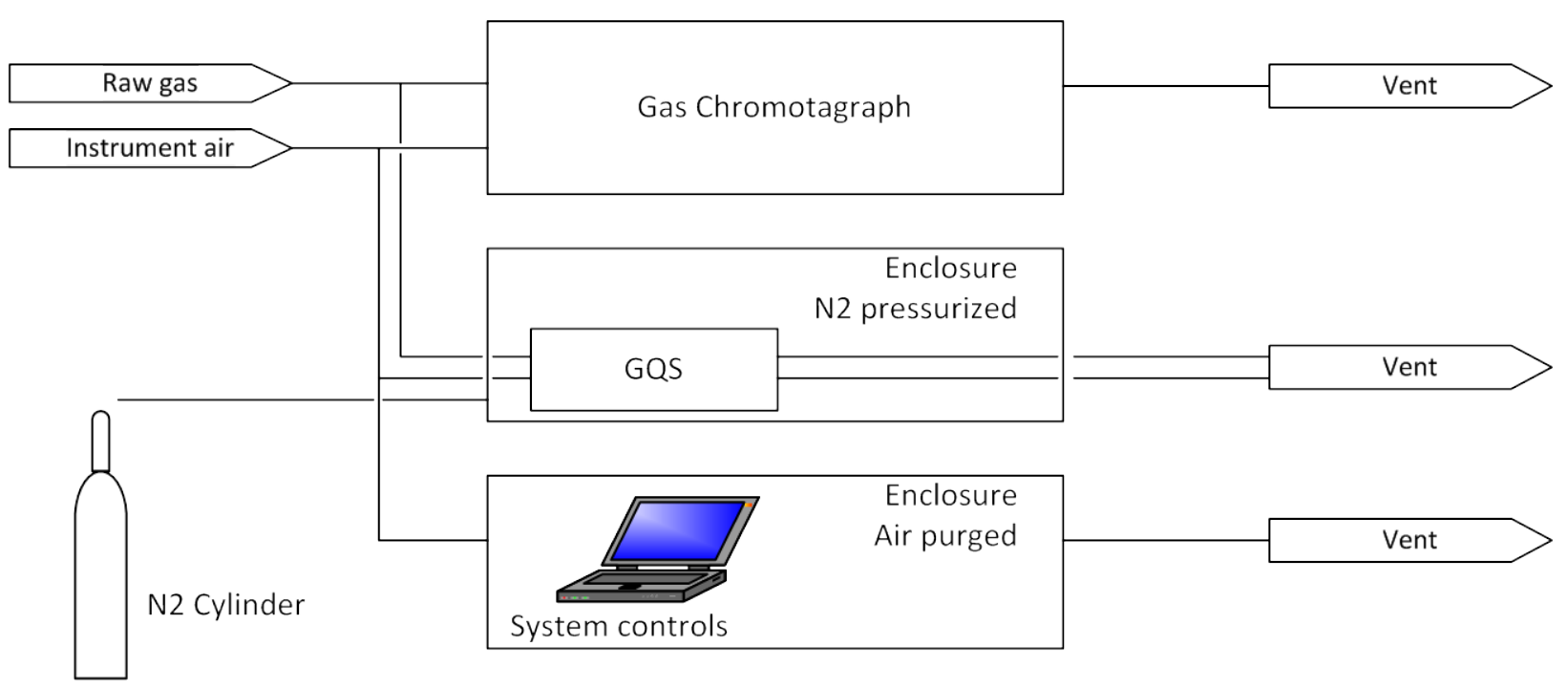

Figure 4 Schematic of GQS installation at Escondido WWTF

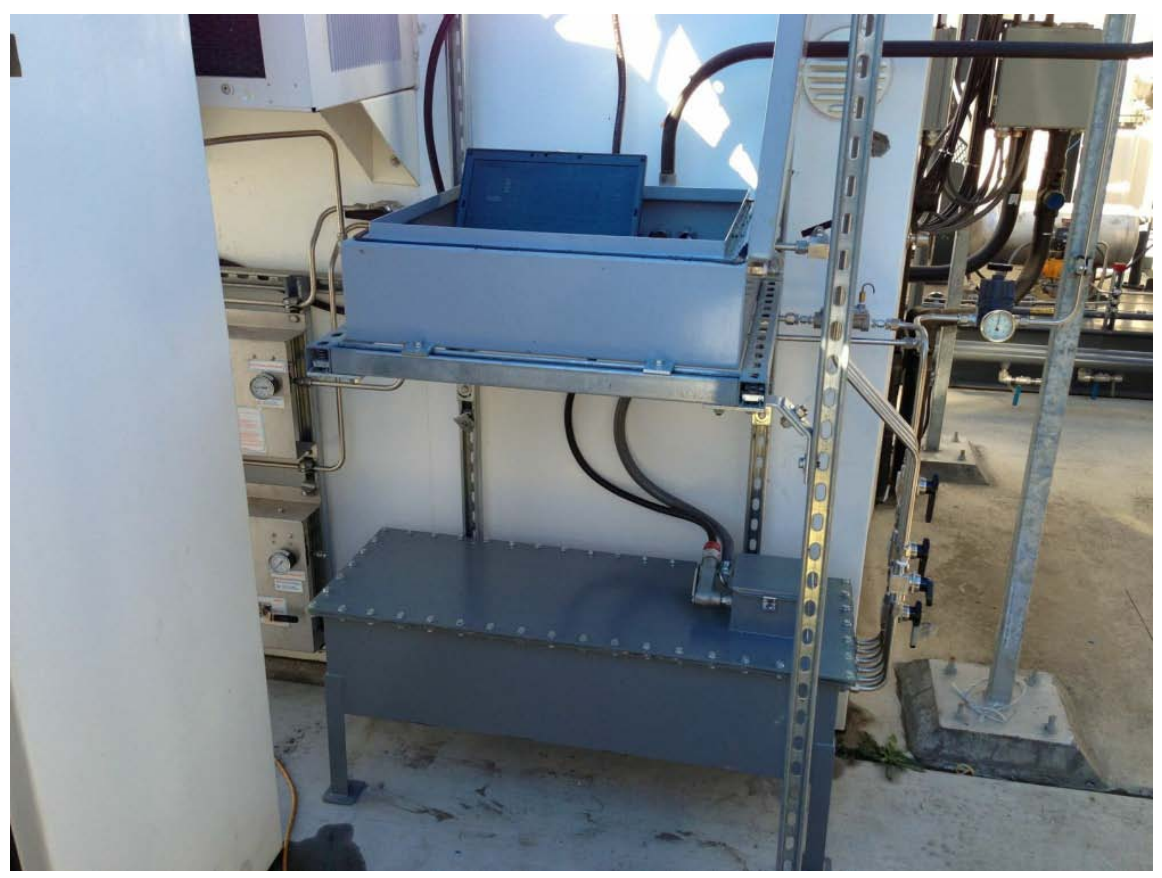

Figure 5 Photograph of GQS Setup at Escondido WWTF 